\title{
STUDIES OF THE JANUARY 31, 1986 NORTHEASTERN OHIO EARTHQUAKE
}

\author{
A Report to the \\ U.S. Nuclear Regulatory Commission
}

Prepared by the

U.S. Geological Survey

\author{
R.L. Wesson AND C. NICholson \\ EDITORS
}

OPEN-FILE REPORT $86-331$

This report is preliminary and has not been edited or reviewed for conformity with U.S. Geological Survey publication standards and stratigraphic nomenclature. Any use of trade names and trademarks in this publication is for descriptive purposes only and does not constitute endorsement by the U.S. Geological Survey.

Reston, Virginia 


\section{TABLE OF CONTENTS}

I. EXECUTIVE SUMMARY

R.L. Wesson

II. INTRODUCTION

R.L. Wesson, C. Nicholson 2

ACKNOWLEDGMENTS

III. HISTORICAL SEISMICITY

C.W. Stover, G. Reagor, S.T. Algermissen $\quad 5$

IV. MAINSHOCK

$\begin{array}{ll}\text { J.W. Dewey, C. Nicholson, M. Hopper } & 6\end{array}$

$\begin{array}{lr}\text { V. AFTERSHOCKS } & \mathbf{8}\end{array}$

Aftershock Locations

C. Nicholson, C. Langer, C. Valdes 10

Focal Mechanism Solutions

C. Nicholson, C. Langer, C. Valdes $\quad 11$

VI. POSSIBLE ROLE OF FLUID INJECTION

Motivation and Background

R.L. Wesson

12

Estimation of the State of Stress

E. Roeloffs, C. Nicholson, R.L. Wesson, J.D. Bredehoeft

Fluid Pressure Changes in Epicentral Area and Conclusions

E. Roeloffs, J.D. Bredehoeft

Solution Mining

R.L. Wesson

VII. HIGH FREQUENCY GROUND MOTION

Overview and Introduction

R.D. Borcherdt

Recording Instrumentation

R.D. Borcherdt

Station and Aftershock Locations

C. Valdes, G. Glassmoyer, R.D. Borcherdt

Characteristics of High Frequency Ground Motions

R.D. Borcherdt, G.M. Glassmoyer

VIII. CONCLUSIONS AND RECOMMENDATIONS 
FIGURE CAPTIONS

FIGURES $\quad 56$

$\begin{array}{ll}\text { APPENDIX A-HISTORICAL SEISMICITY } & 109\end{array}$

$\begin{array}{ll}\text { APPENDIX B-PHASE DATA FOR AFTERSHOCKS } & 117\end{array}$ 


\section{EXECUTIVE SUMMARY}

This report describes the results of investigations of the northeastern Ohio earthquake of January 31, 1986 undertaken by the U.S. Geological Survey at the request of the Nuclear Regulatory Commission. These investigations include a study of the mainshock, its aftershocks, and previous seismicity; an assessment of the degree to which the deep fluid injection wells in the area may have influenced the recent earthquake activity; and an investigation of the high frequency nature of the seismograms recorded from both the mainshock and its aftershocks.

Analysis of the mainshock and aftershocks indicates no obvious structure or fault with which the January 31 earthquake can be associated. Locations of aftershocks obtained to date are permissive of the interpretation of a fault striking somewhat east of north, but as most of the aftershocks are tightly clustered in space, they provide only very weak evidence for the orientation of such a structure.

Estimates of stress inferred from commercial hydrofracturing measurements suggest that the state of stress in northeastern Ohio is close to the theoretical threshold for small earthquakes as predicted by the Mohr-Coulomb failure criterion. Given this state of stress, triggering of small earthquakes by fluid injection would not be surprising. However, the distance of the January 31 earthquake and its aftershocks from the wells (with the exception of the very small earthquake on March 12), the lack of any small earthquakes detected near the bottom of the wells, the history of small to moderate earthquakes in the region prior to the initation of injection, and the attenuation of the pressure field with distance from the injection wells, all argue for a "natural" origin for the earthquake. Therefore, although triggering remains a possibility, the probability that the injection played a significant role in triggering the earthquake, based on the information currently available, must be regarded as low. The analysis of the possible relation between the injection wells and the January 31 earthquake has indicated nothing to suggest the occurrence of an earthquake larger than that expected for the broad region, or the activation of a major structure closer to the wells or near the power plant.

High-resolution (up to $96 \mathrm{~dB}$ ), broadband ( $<200 \mathrm{~Hz}$ ) recordings of the aftershock sequence show that seismic signals as high as $130 \mathrm{~Hz}$ were resolvable above noise levels 
for the larger aftershocks $\left(m_{b} 2.2 ; 2.5\right)$ at hypocentral distances up to $18 \mathrm{~km}$. Signals relatively rich in high frequencies were also observed on the strong-motion records of the mainshock for frequencies up to the upper bandwidth limit of the recorders $(30 \mathrm{~Hz})$. Based on the aftershock data, spectral ratios computed to estimate the amplitude response of local site conditions at a site near the Perry Nuclear Plant (site GS01) show exaggerated vertical ground shaking near 4-7 $\mathrm{Hz}$ and near $20 \mathrm{~Hz}$. The peaks in spectral ratios near these frequencies appear to be attributable, at least in part, to resonances in the nearsurface soil layers. Smaller, but apparently significant, resonances are also indicated in the spectral ratios for horizontal motions.

Investigations to date have suggested the value of additional studies in several areas. Continued earthquake monitoring in the vicinity of the epicenter of the January 31 earthquake would be of considerable value both for the generic problem of trying to understand earthquakes in the eastern United States and from the point of view of continued investigation into the question of a possible relationship between the January earthquake and fluid injection. Additional geophysical investigations, particularly using the seismic reflection technique and research-quality measurements of stress in boreholes, would also be useful in attempting to understand the structural and tectonic conditions that led to the earthquake. Generic studies of site resonances, including field and numerical studies, would help in assessing the potential levels of exaggerated ground shaking and their significance for engineering purposes.

\section{INTRODUCTION}

On January 31, 1986, at 11:46 EST an earthquake of magnitude 4.9-5.0 [NEIS] occurred about $40 \mathrm{~km}$ east of Cleveland, Ohio, and about 17-18 km south of the Perry Nuclear Power Plant. The earthquake was felt over a broad area including 11 states, the District of Columbia, and parts of Ontario, Canada, caused intensity VI-VII at distances of $15 \mathrm{~km}$, and generated relatively high accelerations $(0.18 \mathrm{~g})$ of short duration at the plant. Because of the nature of this event and its proximity to a critical facility, a rapid response by the seismological community was triggered. The result was some 47 stations occupying 64 sites were deployed by 7 agencies or institutions. These included Lamont- 
Doherty Geological Observatory, the Tennessee Earthquake Information Center, St. Louis Univeristy, the University of Wisconsin, the U.S. Geological Survey, Weston Geophysical Corporation and Woodward-Clyde Consultants. Analog portable seismographs were operating within $10 \mathrm{hrs}$ of the mainshock, and broadband wide-dynamic range digital GEOS instruments were recording within 27. Thirteen aftershocks were detected as of April $15^{\text {th }}$, with six occurring within the first 8 days. The latest was on March $24^{\text {th }}$. Two of the aftershocks were felt. Coda magnitudes for the aftershocks ranged from -0.5 to 2.5. Focal depths for all the earthquakes range from 2 to $7 \mathrm{~km}$.

Of concern was whether the mainshock indicated a level of seismic hazard in excess of that previously believed to exist in the region. The January $31^{\text {st }}$ earthquake was the largest to occur in the northeast Ohio region since records of earthquake activity began, however, approximately $\mathbf{3 0}$ earthquakes of smaller magnitude were previously recorded in this area. The largest of these prior earthquakes was of comparable magnitude $\left(m_{b}=\right.$ 4.5-4.7) and occurred in 1943.

Another aspect of this sequence was the possibility that the recent earthquakes were induced by deep injection well activities. Three wells that penetrate the basement are currently operating within $15 \mathrm{~km}$ of the earthquakes and there was concern expressed that the wells may have played a significant role in triggering the earthquake activity.

Although the attenuation of seismic waves is less severe in the eastern as opposed to the western United States, unusually high frequencies were recorded at considerable distances for both the mainshock and its aftershocks. A question arose as to whether these high frequencies were a result of regional path effects, unusual source characteristics, or specific site resonances.

This report discusses the results of three lines of investigation carried out by the U.S. Geological Survey and includes compilations of data from a number of different sources. The first is a basic study of the mainshock and its aftershocks, and includes locations, focal mechansims and information on previous historical seismicity. The second involves an investigation of the deep fluid injection wells, and an assessment on the degree to which the wells may have influenced the recent earthquake activity. The third study concerns the character of the earthquake seismograms, principally from the aftershocks, 
and the nature of the high frequency content of the recorded ground motion, particularly at the Perry Nuclear Power Plant.

\section{ACKNOWLEDGMENTS}

This study was conducted on behalf of, and with financial support from, the Office of Nuclear Reactor Regulation, U. S. Nuclear Regulatory Commission.

The authors acknowledge and appreciate the cooperation, exchange of data, and discussions with the following agencies and individuals:

Calhio Chemical Company

William Toth

Cleveland Electric Illuminating Company

Eilleen Buzzelli, Frank Stead, Mike Hayner

Electric Power Research Institute

Carl Stepp

Lamont-Doherty Geological Observatory

Nano Seeber, John Armbruster, Keith Evans, David Simpson

Geauga County Disaster Services Agency

Dale Wedge, Pat Linn

Geoscience Services

Joseph Fischer

John Carroll University

William Ott, S.J.

Nuclear Regulatory Commission

Leon Reiter, Phyllis Sobel

Ohio Geological Survey

Horace Collins, Mike Hansen

Ohio Division of Oil and Gas

Dennis Crist

Ohio Environmental Protection Agency

Gerry Myers 
Petro Evaluation Services Company

Jay Henthorn

Resouce Services, Inc.

Warren Latimer

St. Louis University

Steve Nyers, Robert Herrmann

Tennessee Earthquake Information Center

Jer-Ming Chiu

University of Wisconsin

Doug Christensen

Weston Geophysical Corporation

Richard Holt, Gabriel LeBlanc, Preston Turner

Woodward-Clyde Consultants

Tom Statton, Richard Quittmeyer, Kathy Mroteck

\section{HISTORICAL SEISMICITY}

Compilations of historical earthquakes in northeastern Ohio based on felt reports extend back to at least the mid-1850's. Instrumental recordings of local and regional earthquakes began in northeastern Ohio when John Carroll University, located in the outskirts of eastern Cleveland, started operation of its observatory in 1904. A seismicity map for Ohio (Figure 1, Stover et al., 1979) indicates about 30 earlier earthquakes in the northeastern region of the state. Since 1850 , the repeat time for felt earthquakes is about 9 years, although earthquakes large enough to cause damage (intensity VI) are rare. The largest event known prior to 1986 was a magnitude 4.5-4.7 earthquake that occurred in 1943. This 1943 earthquake was recently relocated using the same velocity model as was used to locate the 1986 mainshock (J. Dewey, written communication, 1986). Its revised location $\left(41.628^{\circ} \mathrm{N} \pm 14 \mathrm{~km}, 81.309^{\circ} \mathrm{W} \pm 10 \mathrm{~km}\right)$ is just slightly west of the 1986 event. Thus, the earthquake of 1986 should not be considered unusual.

Appendix A contains an expanded, updated version of the seismicity catalog for the state of Ohio. Only those earthquakes with epicenters within the boundary of the state 
are listed, even though additional earthquakes in bordering states or in Canada may have been felt or have caused damage in Ohio. Most notable of these are the Attica, New York earthquake of 1929 ( $m_{b}=5.2$ ), and the northern Kentucky (Sharpsburg) earthquake of $1980\left(m_{b}=5.2\right)$. The largest event in Ohio was part of an earthquake swarm near Anna in 1937, and had a magnitude between 5 and 5.5. Another earthquake of particular interest is the 1983 event $\left(m_{b L g}=2.7\right)$ near Perry, the location of which is unfortuately rather uncertain (Appendix A). In November of 1983, an earthquake of about magnitude 2.5 was observed by stations operated by the University of Western Ontario (G. LeBlanc, personal communication). Its position is unknown, however, its seismogram is similar in many respects to the January, 1983 event. Its absence from the U.S. earthquake catalogs implies a detection threshold for this part of Ohio at or above magnitude 2.5.

\section{MAINSHOCK}

The earthquake of January 31, 1986 occurred at 11:46 EST. There was no immediate foreshock sufficiently large to record on the instruments at John Carroll University, although there is a suggestion of two earlier events, one on January $23^{\text {rd }}$ and the other on January $30^{\text {th }}$, based on comparison of the daily seismograms with that of the largest aftershock (J. Armbruster, personal communication, 1986). The mainshock was felt over a wide area and as far away as northern Virginia. The magnitude of the event was $m_{b}=$ 4.9 (NEIS) based mostly on data from Europe, or $m_{b L g}=5.0$ (SLU) from surface waves.

By holding the focal depth fixed at $10 \mathrm{~km}$, the mainshock epicenter was located at $41.650^{\circ} \mathrm{N}$ latitude and $81.162^{\circ} \mathrm{W}$ longitude, using $\mathrm{P}$-wave arrivals from 41 stations. All of the stations utilized in the location procedure were within $10^{\circ}$ of the earthquake, the closest station being CLE (John Carroll University) at $0.32^{\circ}$, and the farthest was POW (Powhatan, Arkansas, SLU) at $9.55^{\circ}$. The velocity model developed by Nuttli et al.[1969] from earthquake travel-times in the central United States was used in the location process and resulted in a maximum horizontal standard error in location of $\pm 4.6 \mathrm{~km}$, based on a $90 \%$ confidence ellipsoid.

Within the resolution of the data, moment of the mainshock is estimated to be about $3 \times 10^{23}$ dyne-cms, based on inversion of surface waves, with a focal depth of $8 \mathrm{~km}$ and a 
focal mechanism that is either right-slip $\left(\mathrm{N} 20^{\circ} \mathrm{E}\right)$ or left-slip $\left(\mathrm{N} 290^{\circ} \mathrm{W}\right)$ on nearly vertical nodal planes (A. Dziewonski, R. Herrmann, personal communication, 1986). A bodywave moment tensor inversion was attempted, but amplitudes were too small for sufficient resolution (J. Nabelek, personal communication).

Both the U.S. Geological Survey and Weston Geophysical Corporation conducted intensity studies immediately following the mainshock (Figures 2 and 3). Most notable of the earthquake effects were: the fairly widespread region of panic in Painesville and Mentor (including the temporary evacuation of several public buildings); the collapse of a ceiling, a broken water main, significant damage sustained by the city sewer lagoon, and a large number of chimneys thrown down in Chardon; a large area of disturbed wells and a damaged trailer near Hambden; cracks that developed in the Thompson High School (causing a temporary evacuation); damage to the foundations of the Amish School and City Hall in Huntsburg; and a broken gas line as far away as South Russell (Geauga County Disaster Services Agency, 1986). Fifteen people were reported to have suffered minor injuries. Isolated intensities approached VII (Figure 3) although in general the maximum intensity was VI (Figure 2). The intensity at the Perry Nuclear Power Plant was V.

Preliminary intensities reported by the USGS (Figure 2) were determined during a canvas of the epicentral area on February 4-11, 1986. The highest intensities found (Modified Mercalli intensity VI) occurred up to $15 \mathrm{~km}$ away from the instrumental epicenter. Two areas defined by the intensity VI isoseismal are identified. One, which includes the earthquake epicenter, is somewhat elongated in a northeast-southwest direction with an additional lobe to the northwest. Such elevated levels of intensity toward the lake are not unexpected, as site resonances within lake sediments often amplify strong ground motion (c.f., Section VII). The other area of intensity VI is off to the southeast. Damage within intensity VI isoseismals consisted primarily of wall cracks, cracked or fallen plaster, fallen ceiling tiles, damaged chimneys, disturbed wells, items fallen off shelves, broken pipe seals and cracked windows. Fallen plaster generally occurred in older buildings. Disturbed ceiling tiles, usually along the juncture of the ceiling with an outside wall, occurred where the intensity based on other indicators was V to VI. 
The isoseismals shown in Figure 2 are dashed because additional data will soon be available from a more systematic survey involving USGS intensity questionnaires. When the new data are included, configurations of present isoseismals may change although major modifications are not expected. At present, however, an area that encompasses most of the intensity $\mathrm{V}$ isoseismal may be defined by an ellipse with semi-major and semi-minor axes of 100 and $60 \mathrm{~km}$, respectively, and oriented in a northeast direction. The "valley" of low intensities (primarily III-IV) found within this area of intensity V's has no apparent correlation with regional bedrock geology, although the southwest section of the intensity low does correspond to an area of kames and eskers. Futher work is needed, however, to establish more definitive relationships, once the more complete data are available.

\section{AFTERSHOCKS}

This discussion covers aftershocks recorded during the period 31 January to 15 April, 1986, and describes analysis of data collected by field teams from the U.S. Geological Survey, as well as the analysis of arrival time and first motion data obtained from the other cooperating groups listed above. Most instrumentation consisted of single-component highfrequency analog recorders. However, the U.S. Geological Survey deployed 10 broad-band, high-dynamic range digital GEOS instruments with internal clocks synchronized to radio time code (WWV). These stations started operation on February $1^{\text {st }}$, and several were still

in operation as of April $3^{\text {rd }}$. Station locations, time histories, Fourier amplitude spectra, preliminary aftershock locations as well as discussions of the deployment and instrument capabilities of the GEOS stations are given in Borcherdt [1986]. Including both analog and digital recording by all of the groups and agencies, some 47 stations operating at 64 sites were deployed. Table 1 lists station names, affiliations and locations for the sites occupied during the aftershock study.

As of 15 April, some 13 aftershocks were located. Most of these events occurred within the first 8 days; two were felt. Coda magnitudes ranged from -0.5 to 2.5 based on a formula developed for earthquakes in the northeastern United States [Chaplin et al., 1980]. Figure 4 presents seismograms of some of the earthquakes recorded on the analog instruments. It is obvious that in many cases the events are very small. Because of the 
dense network of stations (Figure 5), however, even the smallest event was reported by at least 6 stations.

In addition to the aftershocks, several events believed to be quarry blasts were also recorded (Figure 6). These events all occurred on weekdays during working hours, generated nearly the same signals at the recorders, had lower frequency content content, and exhibited an air wave. Two of these events were located as a matter of course (Figure 9) and were found to occur near a sand and gravel pit south of Thompson and east of Rt.528.

Three preliminary velocity models were used to locate the earthquakes and are given in Table 2. The first is a simple two-layer model to accommodate the Paleozoic section over the granitic basement. It is essentially the same model used by Weston Geophysical to initially locate earthquakes in their aftershock survey. The second is somewhat more complex and is based on a surface-wave inversion across the Cincinnati Arch by Herrmann [1969]. The third is a composite from several different sources and consists of 5 sedimentary layers over crystalline basement at a depth of $2.1 \mathrm{~km}$. The interfaces are based on an extensive compilation of information from wells drilled at least as far as the top of the PreCambrian basement (Cleveland Electric Illuminating Company, 1982). An average of down-hole and cross-hole velocity logs were used to determine the $P$ and $S$ wave velocities in the upper $0.5 \mathrm{~km}$. Velocities in the basement, lower crust and mantle are based on regional earthquake travel-time studies [Nuttli et al., 1969]. Velocities in the Paleozoic section are inferred from refraction studies in adjacent areas [Press, 1966]. All three models should be considered preliminary. With the exception of the near-surface $P$ and $S$ velocities in the third model, the velocities used in the models are not based on actual in situ measurements in the epicentral region, and several are only estimates from a limited set of available data. Furthermore, none of the models takes into consideration the slight dip of the top of the PreCambrian interface, which near the shore of Lake Erie is about 1830 meters $(6,000$ feet) deep but near the epicentral region, it is about 2130 meters $(7,000$ feet $)$.

The earthquakes were located using HYPOELLIPSE [Lahr, 1985] and as many of the available arrival-times as were internally consistant. Arrivals based on the digitally recorded GEOS intruments were given preferential weight because of the higher precision 
of timing, the greater resolution in picking the arrivals and the greater confidence in identifying the shear-wave arrival on the three-component instruments. A serious complication in the earthquake locations was that many of the single-component stations reported secondary arrivals that were often a converted phase ( $S$ to $P$ ). Figure 7 shows a composite Wadati diagram for vertical stations operated by the USGS. The slope is 1.68 indicating that many of the secondary arrivals plotted as $S$ traveled part of their ray paths as $P$ waves. Preliminary studies of these phases [R. Borcherdt, L. Seeber] indicates that the arrival times are consistent with conversion taking place at either the base of the Paleozoic section ( $P$ to $S$ ) or the base of the unconsolidated surface sediments ( $S$ to $P$ ). Thus, in order not to mix both converted and direct shear arrivals, two sets of locations are given. The first set utilizes only the data from the USGS instruments (Figure 8) and is shown in Figure 9. $S$ arrivals from the GEOS three-component stations are used and the earthquakes are located using the simplest velocity model (model \#1). These locations give the results from a fairly homogeneous data set for which a high degree of confidence is associated with each arrival. For comparative purposes, a second set is given that utilizes all the available data. In this second set (e.g., Figure 13), there is better station coverage and therefore greater precision, however, accuracy is somewhat degraded because of slight variations in internal timing within each of the networks included and because some of the additional stations had poorer resolution in identifying arrival times off analog records. The second set also gives preferential weight to the GEOS instrument readings and employs the prefered 7-layer velocity model (model \#3). It is apparent, however, that even with different velocity models or different procedures used in the location process, the earthquake epicenters do not vary by much (Table 3). Only the focal depths are significantly affected, with systematic biases of up to a kilometer when separate models are used.

\section{Aftershock Locations}

One of the more notable features of the aftershock sequence was that it contained so few events. No aftershocks were detected in the first $26 \mathrm{hrs}$ and only thirteen were reported by April 15th. Whereas, with the Sharpsburg, Kentucky, earthquake of 1980, 60 
aftershocks were located within the first 16 days; and in the case of the Goodnow, New York, earthquake $\left(M_{L}=5.2\right)$ of 1983 , almost 100 aftershocks were recorded in the month following the mainshock. In addition, most of the early aftershocks of the 1986 event occurred within a very small source volume. Figures 9 through 11 show the locations of the first 6 aftershocks using only the USGS stations. These earthquakes describe a very small source region that could be considered an ellipse with semi-major and minor axes of 1.2 and $1.0 \mathrm{kms}$. The vertical extent of the activity is confined to a narrow seismogenic zone between 4 and $7 \mathrm{kms}$ deep. If only this initial seismicity is used, there is not sufficient resolution or spatial extent in activity to define any preferred fault structure, and indeed, activity originating from a single point source can not be precluded. Vertical cross sections shown in Figure 11 demonstrate that independent of the observation point, no particular planar feature is evident.

Using all the available data, however, some evidence of a fault structure emerges. Figure 12 shows all the available aftershock locations as well as station coverage within the immediate vicinity. Although the initial aftershock activity remains in a very small cluster, there was an event on March 24th that is located about a kilometer outside the immediate source region of the mainshock (Figure 13). Its location to the SSW, coupled with a poorly resolved trend in the earthquake epicenters, suggests a short fault segment oriented $15^{\circ}$ to $20^{\circ}$ east of north, consistent with one of the nodal planes observed in the preliminary focal mechanism of the mainshock. Vertical cross sections taken perpendicular and parallel to a strike of $\mathrm{N} 20^{\circ} \mathrm{E}$ (Figure $13, \mathrm{~B}$ and $\mathrm{C}$ ), suggest that rupture may have occurred at depth on a nearly vertical fault with a NNE orientation.

In addition to the tight cluster of aftershocks, one small earthquake was detected near station GS02 (Figure 12) on March $12^{\text {th }}$. Its relative proximity to the Calhio injection wells, suggests that at least this single event may be a candidate for having been induced. This event is discussed further in Section VI.

\section{Focal Mechanism Solutions}

Single-event focal mechanism solutions (lower hemisphere equal-area projections) were constructed using polarity data from nearly all the temporary stations deployed. Readings 
from both sets of USGS instruments, Lamont, TEIC, Weston Geophysical and WoodwardClyde were combined to produce the results shown in Figures 14-17. For those few events that were too small to yield a sufficient number of first motions to determine a single-event solution, a composite of the first motions of these smaller events is given along with the focal mechanism solution of the largest aftershock (Figure 18). As expected, the largest events give the most consistent results. These earthquakes exhibit focal mechanism solutions with NNE and WNW striking nodal planes (Figure 14). If the NNE-striking nodal plane is taken as the fault orientation, then motion during the earthquake is oblique right-slip. Other focal mechanisms (Figures 15-17) exhibit significantly different nodal plane orientations. Although it is certainly true that for some of these smaller events, the actual first-motion may have been lost in the background noise, the consistent change in large numbers of first-motions observed at various stations (while preserving the specific radiation pattern of a double-couple source) lends credence to the interpretation that the focal mechanism for all the aftershocks is not the same. For some, a large component of normal faulting is observed in the fault plane solution (e.g., 860210), while others exhibit nodal planes with significantly different orientations (e.g., 860207). In general, however, most of the focal mechanisms are consistent with a maximum horizontal stress field striking ENE. The observation that different focal mechanisms are found throughout the aftershock sequence suggests that more than one favorably oriented fracture is being reactivated. Furthermore, because the orientations in slip vary from predominantly strike-slip to oblique slip with a large component of normal faulting, this implies ratios of the principal stresses such that the vertical stress is intermediate, but very close to the maximum horizontal stress.

\section{POSSIBLE ROLE OF FLUID INJECTION}

\section{Motivation and Background}

It has been conclusively demonstrated that under some conditions, the increase in fluid pressure in the earth's crust as the result of the injection of fluid or the impoundment of a reservoir, can trigger earthquakes [c.f., Raleigh et al., 1976]. In view of the deep waste disposal wells in operation near the epicenter of the January 31 Northeastern Ohio 
earthquake, a study was undertaken to determine, to the extent possible, whether the waste injection wells may have played some role in triggering the earthquake. In addition, the possible role of solution mining for salt, previously active in the area, was also considered.

Well-documented examples of earthquake activity induced by fluid injection include earthquakes triggered by waste injection near Denver [Healy et al., 1968; Hsieh and Bredehoeft, 1981], by secondary recovery of oil near Rangely, Colorado [Raleigh et al., 1976] and in West Texas [Davis, 1985], and by solution mining for salt in western New York State [Fletcher and Sykes, 1977]. Other cases of induced seismicity, owing to either fluid injection or reservoir impoundment were recently reviewed and discussed by Simpson [1986]. In each of these cases it is possible to show two characteristics of the induced earthquakes. First, there is a very close geographic association between the bottom of the injection wells and the locations of the earthquakes in the resulting sequence. Second, it is possible to perform calculations based on the measured or inferred state of stress in the earth's crust and the measured injection pressure to determine whether the theoretical threshold for the occurrence of an earthquake is met. These calculations are referred to as the determination of the state of "effective stress" and its relation to the "Mohr-Coulomb failure criteria," [see, for example, Jaeger and Cook, 1976].

Two deep injection wells near Perry, Ohio, are the most likely candidates for possible earthquake triggering in view of their depth, injection pressure and length of operation. The first of these wells, Calhio \#1, was completed in 1971 [Natural Resources Management Corp., 1971]. Full-scale injection of waste into the well began in 1975. A second well, Calhio \#2, was completed in 1981, and has been used as a backup to the first well since that time [Resource Services Inc., 1980]. The two wells are located somewhat less than $1 \mathrm{~km}$ apart, therefore at distances more than a few kilometers away, the wells can be considered as a single point source of fluid. More than 1.19 billion liters (315 million gallons) of fluid have been injected into the two wells, principally into Calhio \#1 (Figure 19)[Ohio EPA, written communication, 1986]. Both wells are about 1800-m deep, extending a short distance into the PreCambrian crystalline basement. The basement in this region is overlain by a section of essentially flat-lying sedimentary rocks of Paleozoic age. The formations of principal interest in this study are the basal sandstone (Mt. Simon formation) and the overlying 
Rome and Maynardsville formations. The Mt. Simon formation was the targeted injection zone, but initial drill stem and injection tests indicated a lower than expected permeability. Consequently, both wells are open to both the Mt. Simon and Maynardsville formation [Natural Resources Management Corp., 1971]. Typical injection pressure at an injection rate of 320 liters $/ \mathrm{min}$ ( $85 \mathrm{gals} / \mathrm{min}$ ) have reached a maximum of $110 \mathrm{bars}(1620 \mathrm{psi})$ at the wellhead. The corresponding pressure at the bottom of the well is the sum of the wellhead pressure plus the hydrostatic pressure caused by the weight of the fluid in the well itself. This amounts to an additional 181 bars (2658 psi) or a total pressure of 291 bars (4278 psi), taking 1.025 as the average density of the injected fluid.

As described in the previous section, the mainshock of the January 31 earthquake, and all its immediate aftershocks are rather tightly clustered about $5 \mathrm{~km}$ north-northwest of Hambden, Ohio. As shown in Figure 20, the deep injection wells near Perry, Ohio, are about $12 \mathrm{~km}$ farther to the north. There was, however, one small (coda magnitude -0.2) earthquake located close to the wells on March $12^{\text {th }}$. Figure 21 shows the seismogram of this event as recorded by station GS02. Subsequent examination of all the available records proved that this earthquake was recorded by at least 5 other stations. The location of this earthquake is about $1 \mathrm{~km}$ west of station GSO2 and about $3 \mathrm{~km} \mathrm{SSW}$ of the Calhio wells (Figure 20). Furthermore, its focal depth was determined to be $2 \mathrm{~km}$. This corresponds to the base of the Paleozoic section and is the same depth at which fluid is injected from the Calhio wells. Although this one earthquake could be a random event, its depth and position relative to the injection wells is suggestive. Whether additional earthquakes, triggered by well injection, have occurred is uncertain. Although no known earthquake is located immediately adjacent to the wells, the detection threshold for earthquakes near the well prior to the installation of portable equipment following the January 31 earthquake (relying on the seismograph at John Carroll University in Cleveland) is estimated to be somewhat greater than magnitude 2.5. Consequently, it is conceivable that additional small earthquakes could have occured nearer to the wells between the initiation of injection operations and the January 31 earthquake.

In the best documented case of injection induced seismicity, at the Rocky Mountain Arsenal near Denver, small earthquakes began near the bottom of the injection wells, then 
migrated out along a northwesterly trend for a distance of about 6-7 km [Healy et al., 1968]. After the sequence had been in progress for 5 years (18 months after well operations ceased), the earthquakes continued to occur near the base of the wells but primarily in a linear zone 4-6 km away and at a depth of 4-6 km. The occurrence of the one small earthquake near the well, as shown in Figure 20, gives some support to the possibility that other earthquakes, including the 1986 mainshock, may also have been triggered by injection activities.

\section{Estimation of the State of Stress}

The principle sources of information about crustal stress in the epicentral area are: measurements of the instantaneous shut-in pressure (ISIP) made during commercial hydrofracture operations (these indicate the magnitude of the least compressive stress), breakdown pressures during well stimulation (these provide estimates on a combination of both the maximum compressive stress and the tensile strength of the rock being fractured), fracture re-opening pressures (which provide estimates of the maximum compressive stress alone), and focal mechanism orientations which provide some indication of the ratios between all three principal stresses. In the case of Lake County, Ohio, data from three wells (the two Calhio wells and the Diamond Alkalai brine disposal well near Painesville) can be used to set bounds on many of the critical values necessary to make a proper evaluation of the degree to which stress conditions may have been affected as a result of well operations.

In addition, K. Evans (written communication, 1986) has compiled a number of ISIP measurements into a map showing the ratio of overburden stress to the minimum compressive stress for the Appalachian Basin. Several of the measurements included in his data set were made expressly for the purpose of determining the state of stress in the rock and not simply for well stimulation. These data show that below the regional evaporite layer, this ratio is uniform throughout much of the northern Appalachian basin. These stress ratios vary from about 0.6 to 0.7 , with values tending to decrease slightly toward the south. Stress ratios smaller than unity suggest that the vertical direction is either the intermediate or greatest principal stress, and therefore that hydrofrac operations in this region open vertical fractures perpendicular to the horizontal least compressive stress. 
For those hydrofrac operations that were performed for the purpose of stress measurement, the direction of maximum compressive stress is NE to East. Although a shallow stress measurement was in fact made very near the disposal well site (at the Perry Nuclear Power Plant), the unusually high stress ratio found is probably attributable to decoupling above the evaporite layer and consequently not representative of the basement stress-field magnitude ratios (K. Evans, written communication).

The horizontal NE striking maximum compressive stress obtained by hydrofrac measurements is consistent with the preliminary focal mechanism for both the 1986 mainshock and many of its aftershocks. An important implication, however, of the focal mechanisms is that because the predominant style of faulting observed is nearly pure strikeslip, the maximum compressive stress is horizontal and greater than the overburden. The fact that some of the earthquakes exhibit large components of normal faulting, however, implies that the stress difference between the vertical and maximum horizontal compressive stress is not large.

\section{State of stress at bottom of injection wells}

Table 4 lists relevant values for principal stress available from both existing well data and regional variations. The calculations or extrapolations are done in bars $(1 \mathrm{bar}$ $=14.7 \mathrm{psi}$ ), and represent the best estimates presently available. It should be noted that there is a large uncertainty in many of these values (particularly the maximum horizontal compressive stress), mainly because commercial measurements are ill-suited for this analysis and because accurate detailed measurements within the epicentral region are not available. In nearly all cases, some assumptions and interpretations of the existing well records had to be made to determine the values calculated. Thus, the values presented in Table 4 should be considered very preliminary. The preferred values listed at the bottom of the table are not simple averages of all the available estimates for that particular value, but represent our considered opinion as to the most likely estimate.

The vertical stress can be calculated once the weight of the overburden is known. Density logs taken in the Calhio wells indicate an average density of $2.6 \mathrm{~g} / \mathrm{cm}^{3}$ (K. Evans, written communication). This implies a density gradient of .255 bar/meter or 459 bars at 
the bottom of the well. Nearly identical values of overburden stress were measured in a deep Michigan hole drilled through similar materials [Haimson, 1978].

Values for the least principal stress at the base of the Paleozoic section (bottom of the wells) can be estimated from the instantaneous shut-in pressure (ISIP) recorded while each of the wells was hydrofractured. The actual measurement of this pressure is made at the top of the hole, so it has to be corrected by adding to it the pressure of the weight of the fluid column in the drill string. Some uncertainty is introduced by this correction because although most of the wells were stimulated with fresh water (specific gravity $1.0 \mathrm{~g} / \mathrm{cm}^{3}$ ), the presence of other material in the injected fluid (acid, sand, waste, brine, etc.) will make the density of the fluid somewhat higher. To simplify matters, a standard value of 180 bars is assumed for the correction to the bottom of the wells (1800 meters), unless specific information was available to indicate a different value was more appropriate. In several cases, values for the ISIP are measured both early and late into the hydrofrac procedure. Table 4 lists both values. Since the value measured after extended pumping is often not a true indication of the least principal stress, initial values of ISIP are assumed to be more valid. Initial values, corrected to the bottom of the well, range from 262 to 302 bars. If regional values of the stress ratio are used (assuming 460 bars for the vertical stress), the minimum stress ranges from 275 to 321 bars. Thus, these two independent estimates yield similar values. Extrapolations from downhole measurements made at regional distances (Michigan and western New York) range as high as 370 bars [Haimson, 1978; Hickman et al., 1985]. The preferred value is taken to be 300 bars. This is on the conservative side, as small values of ISIP (and therefore the minimum horizontal compressive stress) imply a larger stress differential relative to the maximum horizontal compressive stress, and thus a greater likelihood for shear failure along preexisting favorably-oriented fractures.

Formation pore pressure is measured directly during drill stem tests. Table 5 lists values of pore pressure measured in both the Mt. Simon and Maynardville formations from the two Calhio wells. The two sets of measurements were made about 9 years apart. Those made in the Calhio \#2 well indicate a change in the formation pore pressure since extensive pumping began in the Calhio \#1 well four years earlier (1975). The apparent increase in pore pressure with time found in the Maynardsville is consistent with calculated effects of 
fluid injection in the adjacent well. The apparent decrease in pore pressure found in the Mt. Simon, however, is anomalous and may reflect the imprecision of the measurements. In any case, the values obtained are all close to hydrostatic if the density of the connate water is assumed to be $1.2 \mathrm{~g} / \mathrm{cm}^{3}$.

From the preliminary focal mechanism solutions, the maximum horizontal compressive stress is at or above the vertical stress (i.e., $\geq 460$ bars). Values extrapolated from regional downhole measurements are in excess of 500 bars [e.g., Hickman et al., 1985]. Estimates derived from formation breakdown pressures during well stimulation in the Calhio wells give lower values, but they need to be corrected for the effective tensile strength of the rock. This would revise these estimates upwards by anywhere from 40 to 100 bars, as tensile strength can vary over a considerable range. Measurements derived from well records made during the stimulation of the brine well near Painesville are suspect, since the hydrofrac procedure was done through perforated casing [Petro Evaluation Services Inc., 1985]. Of all the measurements, the value of the maximum compressive stress is the least well known. Accurate assessment of this value is critical to evaluations of the effects of the injection wells. Larger values imply a larger stress differential, and thus a greater potential for failure of the rock. It must be emphasized that because of the large uncertainties in the value of the maximum principal stress, no definitive statement regarding the potential for failure can be made at the present time, however, estimates based on the lower bound to the maximum horizontal compression (i.e., the vertical stress of 460 bars) are useful, as they would represent conservative estimates on how close to failure conditions are at the top of the basement.

Using the preferred values given in Table 4, it appears that without fluid injection, the conditions are near but do not exceed failure at the bottom of the wells. Figure 22a is a graphical representation of the Mohr-Coulomb failure criterion. Shear failure is likely to occur when the shear stress $(\tau)$ exceeds values defined by the linear relation $\tau=\tau_{0}+\mu \sigma_{n}$, where $\tau_{0}$ is the effective tensile strength, $\mu$ is the coefficient of friction, and $\sigma_{n}$ is the stress normal to the plane of slip. For a preexisting fracture with no cohesion, $\tau_{0}$ is zero. Shear stress along fractures of various orientations are linear combinations of the maximum and minimum compressive stresses, and are defined by the locus of points 
around the Mohr circle, whose center is the average between the maximum and minimum principal stresses (right circle, Figure 22a). Larger stress differences between the maximum and minimum, result in larger Mohr circles and larger available shear stresses for favorably oriented fractures. In the presence of a fluid, the effective stress levels are reduced by the amount of the formation pore pressure, which moves the Mohr circle to the left (middle circle, Figure 22a). This condition is close to but does not exceed the failure criterion for a fracture with no cohesion. At a nominal injection pressure of 110 bars, however, this would bring the zone immediately surrounding the well bottom to an effective stress state near critical for favorably oriented preexisting fractures having a cohesive strength of as much as 40 bars and friction coefficient near 0.6 (left circle, Figure 22a). Preliminary focal mechanisms and hydrofrac stress measurements suggest that vertical planes striking NNE and ESE would be most favorably oriented for failure. And since the overburden is only a lower bound for the estimate of the maximum compressive stress, the actual conditions for failure would be more critical than the situation shown.

Because fluid injection could have brought at least the region near the bottom of the well into a critical stress state, the absence of any known earthquakes in the immediate vicinity of the well suggests that there are no favorably oriented weak fractures near the well. Thus, either existing fractures have cohesion strengths greater than 40 bars, or if weaker fractures do exist, they are not favorably oriented for failure in the existing stress field. The predominant dip of fractures observed in a core taken from the injection zone in Calhio well \#2 is 20 degrees. Such fractures would not be favorably oriented for failure according to the forgoing analysis, as shear stress is maximum only for near vertical faults.

\section{State of stress in the hypocentral region}

Estimation of the preexisting state of stress at the hypocenter requires extrapolation of measurements to a depth of 5 to $8 \mathrm{~km}$, a procedure that is somewhat controversial. McGarr (1980) shows that although it is permissible to extrapolate individual stress components to depth in laterally homogeneous environments, the linear extrapolation of principal stresses is not theoretically justified.

In the epicentral region, the compilation by K. Evans indicates a stress ratio of about 
0.63 determined in hydrofrac operations in the Silurian Clinton-Medina sandstone. If the same ratio is applied at the hypocentral depth of $5 \mathrm{~km}$, then the overburden pressure of about 1300 bars corresponds to a minimum compressive stress of 820 bars. Hydrostatic fluid pressure at $5 \mathrm{~km}$ depth would be 590 bars, assuming a density of $1.2 \mathrm{~g} / \mathrm{cm}^{3}$ for the connate brines. This state of effective stress is plotted on the Mohr circle diagram in Figure 22b. This figure again indicates a near-critical stress state for favorably oriented pre-existing fractures.

\section{Fluid Pressure Changes in Epicentral Area Due to Fluid Injection}

Estimation of the fluid pressure change near the earthquake hypocenters is inconclusive because we lack detailed information about the nature of the reservoir into which the waste is being injected. The characteristics of the reservoir in the vicinity of the well are known from measurements made during well completion. Using these characteristics, three alternate reservoir models were evaluated in order to determine what the increase in fluid pressure at the hypocenter may have been. The first model is an infinite isotropic reservoir; the second two are reservoirs of rectangular cross section, extending to infinity in the third direction, which is assumed to be in the direction connecting the well and the hypocenters. These models are for the purpose of studying how fluid pressure propagated horizontally from the well and do not address the question of how the fluid migrated downward $3 \mathrm{~km}$ from the injection horizon to the approximate hypocentral depth of $5 \mathrm{~km}$.

\section{Reservoir properties}

The wastes are injected into both the Maynardville and Mt. Simon formations that lie just above the PreCambrian granitic basement. Table 6 lists properties of these formations obtained from the UIC permit application for well number 2. It is stated in the report from Resources Services [1980] that these two zones are very similar in wells numbers 1 and 2. A representative transmissivity for the entire injection zone is $4.2 \mathrm{E}-6 \mathrm{~m}^{2} / \mathrm{s}$. Although the storativity, which gives the amount of fluid released per unit column of aquifer for a unit decline in head, is unknown, a minimum value can be obtained by neglecting the compressibility of the reservoir. For a formation having the thickness of the Maynardville and Mt. Simon formations combined, and a porosity of 0.08 , the minimum 
storativity is $2.2 \mathrm{E}-5$. An assumption of minimum storativity results in a maximum value for the cone of impression surrounding a source. A more realistic value of $5.4 \mathrm{E}-5$ for the storativity is obtained by assuming a reservoir compressibility of $3.5 \mathrm{E}-6$ per bar. Although the storativity does not have a great effect on the infinite reservoir calculations, it does have a significant effect on the strip reservoir calculations.

For purposes of calculating pressure $12 \mathrm{~km}$ from the well, it suffices to use an average fluid injection rate. The total volume injected into both wells is 1.17 billion liters (310 million gallons) during the period from March 1975 through November, 1985. For purposes of the following analysis, this amount was assumed to be injected over the total lifetime of the well (i.e, 1972-1986, or about fourteen years), corresponding to an average injection rate of 6.7 million liters/month. This assumption slightly underestimates the pressure affect of the wells. Because the distance between the wells (about $0.5 \mathrm{~km}$ ) is small compared to the distance from the wells to the hypocenter, the two wells have been modeled as a single fluid source.

\section{Infinite reservoir model (radial flow)}

In order to maintain injection pressure of 110 bars or less for the assumed 14-year period of operation of the injection wells, a slight increase in transmissivity to $4.5 \mathrm{E}-6$ $\mathrm{m}^{2} / \mathrm{s}$ was assumed. Figure 23 shows pressure versus distance for different time periods after initiation of injection at 7 million liters/month into an infinite reservoir with a transmissivity as specified and a storage coefficient of 5.4E-5. Figure 24 is a plot of pressure versus time at the well bore for the same model. The infinite reservoir model

yields an estimate of slightly less than 2 bars for the increase in fluid pressure $12 \mathrm{~km}$ from the well, which is where the January $31^{\text {st }}$ earthquake occurred.

\section{Infinite strip reservoir model}

The pressure falloff with distance is greatest for the infinite reservoir because fluid is free to flow in all directions. However, if fluid flow is confined to a narrow reservoir trending from the wells to the hypocentral region, then the pressure at a given distance from the well will be higher. This type of model was used by Hsieh and Bredehoeft [1981] to calculate the pressure distribution around the Rocky Mountain Arsenal well implicated 
in the 1960's Denver earthquake sequence. In the case of the Cleveland earthquakes, there is no independent evidence that the injection zone has a long, narrow configuration. However, the calculations are useful in that they illustrate how large a pressure buildup at epicentral distances is possible, and because they show that the injection pressure history at the well bore may be diagnostic of the shape of the reservoir.

Figures 25 and 26 show pressure versus distance for several times after the beginning of injection for two strip reservoir models. The model used for Figure 25 has transmissivity equal to that assumed for the infinite reservoir model, and a width of $7.5 \mathrm{~km}$. The model used for Figure 26 has a higher transmissivity of $2.0 \mathrm{E}-5 \mathrm{~m}^{2} / \mathrm{s}$, and the reservoir is $1 \mathrm{~km}$ wide. For the wider strip, pressure at the epicentral distance is comparable to that for the infinite reservoir. However, for the narrow strip, pressure at the epicentral distance is about 38 bars 15 years after beginning injection.

\section{Injection pressure}

Figure 24 shows the injection pressure versus time record that would have been observed at the wellhead for the three different reservoir models. In each case, pressure at the well bore is always less than the maximum injection pressure of 110 bars for the first 14 years of injection, but the time history of the injection pressure is different in each case. A detailed analysis of the injection pressure history would be able to discriminate between the cases of an infinite reservoir and a narrow strip, and might thus place more constraints on the amount of pressure buildup at the hypocenter. Preliminary analysis of injection pressures with time at the Calhio \#1 and \#2 wells indicate that the pressure buildup (i.e., resistence to flow) at the wells is consistent with a radial flow model (Ohio EPA, written communication, 1986).

\section{The effect of ceasing injection}

Figure 27 shows pressure versus distance for the three reservoir models assuming that injection is stopped after 15 years. In each case, although the pressure near the well falls steadily, the fluid pressure at the epicentral distance, as well as at greater distances, continues to rise for at least 10 years after cessation of injection. The pressure at the wellhead would vary with time as shown in Figure 28 if injection were stopped; the rate of 
pressure decline would be diagnostic of the configuration of the reservoir, possibly within a year after cessation.

\section{Conclusions}

With our present information, it is not possible to confirm or reject the hypothesis that injection of waste into the Calhio wells triggered the earthquake activity near Painesville. If the state of stress in the hypocentral region is comparable to that at the bottom of the injection wells, then it appears that elevating the pressure by 110 bars would have resulted in a state of effective stress that would be judged critical on the basis of the Mohr-Coulomb failure criterion. The actual state of stress at the bottom of the well, however, is likely to be closer to failure than this estimate because the stress regime appears to be one in which the overburden underestimates the maximum compressive stress. Thus, because these stress estimates are uncertain, and also because they are not based on measurements made at the hypocenter, it is not possible to specify a level of pressure below which seismicity could not have been induced.

The actual pressure elevation in the hypocentral region due to the injection operation is certainly less than 110 bars, and probably less than about 40 bars. Whatever this pressure is, it will continue to rise whether or not injection continues, unless an extraction operation is undertaken.

However, in light of the fact that the mainshock and most of the aftershocks occurred at considerable distance from the active wells, the pressure fall-off with distance from the wells, the occurrence of small to moderate earthquakes in this region prior to initiation of injection, the lack of large numbers of small earthquakes (commonly observed in cases of induced seismicity) and the lack of earthquakes immediately below the wells all argue for a "natural" origin for the earthquake on January $31^{\text {st }}$. Thus, although triggering remains a possibility, the probability based on existing data that the injection wells played a significant role in causing the earthquake sequence is considered low. 


\section{Solution Mining and Earthquakes in Northeastern Ohio}

The association of solution mining with the occurrence of small earthquakes in western New York State [Fletcher and Sykes, 1977], and the extensive salt mining operations in northeastern Ohio [Clifford, 1973], motivated a study of possible correlations between recent historical earthquakes and solution salt mining in Ohio. Solution mining for salt began in northeastern Ohio in 1889 (Figure 29a) [Clifford, 1973] and continues to the present, although several previously active operations have been closed down. The location of solution mining operations and additional locations of deep fluid injection [Clifford, 1975] are compared with the location of felt earthquakes in Figure 29b. Based on the spatial proximity and temporal association with active solution mining activities, it could be argued that the 1906 and 1930 earthquakes, 15 and $35 \mathrm{~km}$ southeast of Cleveland, respectively, could be associated with solution mining operations. Other earthquakes east of Cleveland, might be associated with well activities, if the reported locations for these events are in substantial error, and their actual locations are much closer to the well operations. However, in view of the large number of earthquakes reported prior to the initiation of solution mining, and the apparent occurrence of at least some earthquakes in northeastern Ohio beyond the range of expected influence from mining operations, it seems reasonably clear that at least some of the earthquakes are natural and that solution mining is not a necessary condition for the occurrence of earthquakes.

\section{HIGH FREQUENCY GROUND MOTION}

\section{Overview}

A ten-station array of broad-band digital instrumentation (GEOS) was deployed by the U.S. Geological Survey to record the aftershock sequence of the moderate earthquake that occurred on January 31,1986 (16:46:43 UTC). The occurrence of the event has raised questions concerning the character of earthquake-induced high-frequency ground motions in the area. This report provides interpretation of some of the data collected by the digital GEOS recording systems. Observations of ground motions generated by aftershocks suggests that vertical ground shaking at frequencies near $20 \mathrm{~Hz}$ are significantly higher at 
a site near the Perry Nuclear Power Plant than are levels of shaking at $20 \mathrm{~Hz}$ for sites closer to the hypocenters. Spectra computed for the mainshock recorded at the power plant suggests similar exaggerated levels of vertical shaking near $20 \mathrm{~Hz}$. Levels of shaking observed on the annulus of the containment structure during the mainshock are larger than those of the base of the reactor building foundation. This observation suggests that both the containment vessel and the near-surface soil layer may have contributed to observed levels of exaggerated vertical shaking near $20 \mathrm{~Hz}$. Spectral amplifications computed from broad-band high-resolution recordings of the aftershock sequence near Painesville, Ohio, the aftershock sequence near Coalinga, California, and uphole-downhole recordings near Parkfield, California, suggest that local site conditions may significantly amplify highfrequency $(10-80 \mathrm{~Hz})$ ground motions. Such amplification effects are likely to be most significant in areas of low attenuation such as the eastern United States, and are important from an engineering point of view because of their potential influence on predicted peak acceleration values.

\section{Introduction}

Considerable scientific and engineering interest in the event resulted in a team of five seismologists being dispatched from Menlo Park, California on the evening of January 31 to install ten digital event recorders (GEOS) in the epicentral area [see Borcherdt et al., 1985 and Borcherdt, 1986 for a detailed description of the recording equipment and configuration used to record this data set]. The seismograms and computed Fourier amplitude spectra collected from this deployment are presented in detail by Glassmoyer et al.[1986].

Recent improvements in recording system technology have permitted the extension of both bandwidth and dynamic range for recorded seismic signals. In the case of the data set recorded near Painesville, Ohio the digital recording systems (GEOS) were operated at 400 samples-per-second (sps) per-channel at high gain $(42,48,54 \mathrm{~dB})$. These instrument settings imply a Nyquist frequency of $200 \mathrm{~Hz}$ and a capability to record small-amplitude seismic signals near background noise levels at high resolution. The Fourier amplitude spectra computed for the recording of the larger aftershocks [Glassmoyer et al., 1986] show that earthquake-generated ground motions in excess of $100 \mathrm{~Hz}$ were recorded for some of 
the larger aftershocks. Such signals are generally not recorded on conventional seismic data acquisition systems. As a result, the collected data set provides an excellent opportunity to examine the influence of local site conditions on high-frequency ground motions.

Pioneering quantitative studies of the effects of local site conditions on ground motion recorded in the United States [Gutenberg, 1957; Borcherdt, 1968, 1970] confirmed the existence of amplified ground motions on certain types of geologic deposits, results that had initially been observed in Japan and the USSR [for a comprehensive bibliography of early observations see Duke, 1958]. The studies of the effects of local site conditions in the San Francisco Bay region [Borcherdt, 1970; Borcherdt and Gibbs, 1976] and those in the Los Angeles region [Gutenberg, 1957; Rogers et al., 1984] established that it is possible to obtain estimates of the effects of local geological conditions from comparative ground motion measurements. They showed that simultaneous measurements of ground motion at appropriately selected recording sites can be utilized to isolate the effects of local geological conditions from those of the source, travel path and recording instruments. Although the measurements of the amplitude response of the local site conditions were shown to be an approximation, their work showed that the general characteristics of the response could be inferred and extrapolated over a wide range in amplitude to estimate the likely response of the local deposits during large earthquakes. These studies established the existence of predominant ground frequencies for certain types of deposits, however, other sites showed no single predominant ground frequency [Borcherdt, 1970; Borcherdt and Gibbs, 1976; Rogers et al., 1984]. Where data were available, it was also shown that exaggerated levels of ground motion observed from small levels of ground shaking correlated well with areas of high intensity during damaging earthquakes [Borcherdt and Gibbs, 1976; Rogers et al., 1984]. These observations on the amplitude response for local geologic deposits have been confined primarily for frequencies less than 5-10 Hz, because of the limited resolution characteristics of instrumentation (24-40 dB). Modern instrumentation with substantially improved signal resolution capabilities offers the opportunity to extend the bandwidth for observed responses to much higher frequencies.

Recent studies of the effects of local site conditions using modern recording capabilities suggests that the amplitude response characteristics of local deposits can be extended to 
frequencies perhaps as high as $100 \mathrm{~Hz}$ for sites near the source. Borcherdt et al.[1983] observed that exaggerated ground shaking in the frequency range 10-25 $\mathrm{Hz}$ was apparent for sites located on thick sections of alluvium in the vicinity of Coalinga, California. They observed that local site resonances were consistently observed for events with similar azimuths and locations, but that significant changes in azimuth and/or locations for the events seemed to give rise to significant changes in the high-frequency amplitude response characteristics inferred from spectral ratios. Cranswick et al. [1985] also have observed exaggerated ground shaking at some sites in New Brunswick, Canada and near Goodnow, New York. These observations obtained with modern instrumentation (GEOS) confirm that local geologic conditions can play a significant role in modifying observed highfrequency $(>10 \mathrm{~Hz}$ ) ground motions. In addition, these effects may also play a significant role in biasing estimates of small earthquake source parameters.

Recent studies of the response of near-surface deposits as observed on wide-dynamicrange instrumentation near Parkfield, California [Borcherdt et al., 1985] show that nearsurface deposits can consistently yield significant levels of amplified high-frequency ( $>10$ $\mathrm{Hz}$ ) ground motions.

In this section, we document the nature of the high-frequency ground motion observed at the GEOS recording sites near Painesville, Ohio. In particular, the three sites selected along a linear array between the epicenters and the shore of Lake Erie are examined in detail. The high-frequency amplitude response of the lake shore sedimentary deposits are estimated and compared with those observed on the main shock records.

\section{Recording Instrumentation}

The GEOS recording system (Figure 30), deployed to record the aftershock sequence, was developed by the U.S. Geological Survey for use in a wide variety of active and passive seismic experiments. The digital data acquisition system operates under control of a central microcomputer which permits simple adaptation of the system in the field to a variety of experiments including near-source high-frequency studies of strong motion aftershock sequences, crustal structure, teleseismic earth structure, earth tidal strains, and free oscillations [see Borcherdt et al., 1985, for detailed description]. 
The aftershock sequence was recorded on GEOS instruments configured as threechannel systems. The recorders were operated at 400 sps at gains of 42,48 , and $54 \mathrm{~dB}$ with no anti-aliasing filters [see Borcherdt, 1986, for variations on this configuration used at other sites]. This instrument configuration permitted broad-band high-resolution records to be obtained for the anticipated small magnitude events. Unit-impulse response for the recording system and two types of sensors (velocity transducer and force-balanced accelerometer) are shown in Figure 31.

\section{Station and Aftershock Locations}

Locations for the stations deployed in the 10-station array are shown in Figure 32 together with the location of the mainshock. Station locations, determined from 7.5minute series topographic maps, were independently checked by a second interpreter and are believed to be accurate to within 60 meters. Station coordinates are listed in Table 1.

Objectives in the choice of the station locations included event location, source parameter determination, attenuation of high-frequency ground motion along a linear north-south array, and effects of local site conditions at stations GS01 and GS02. Due to the suspected low seismicity and expected small magnitudes for aftershocks, attempts were made to locate the stations at sites with anticipated low seismic background noise levels in areas (with the exception of station GS01) where the effects of local soil conditions were expected to be minimized. To reduce the effect of the adverse environmental conditions $\left(-15^{\circ} \mathrm{C}\right.$; snow and ice) on the recording equipment, each unit was located in an unheated shelter (small tool sheds or abandoned animal shelters some distance from local sources of cultural noise).

Six aftershocks were detected and recorded by three or more GEOS stations during the time period 1 February 19:45 to 10 February 20:07 GMT. The occurrence times of the six aftershocks, locations, and the number of stations detecting each one are listed in Table 7. Comparison of the events recorded on GEOS with those apparent on visible recorders (C. Langer and N. Seeber, personal communication, 1986) confirms that all events identified on visible recorders were detected and recorded on at least the three stations closest to the epicenters. Expansion of the digital traces on a graphics terminal permitted 
picking of $P$ and $S$ arrival times to within 0.02 seconds by two independent observers. The automatic clock corrections provided every 12 hours and recorded on the GEOS tapes indicate the clock errors for the GEOS recordings are within $\pm 5 \mathrm{~ms}$.

Four of the aftershocks (2 February 03:22, 3 February 19:47, 5 February 06:34, and 6 February 18:36) triggered four or more GEOS recorders with an appropriate station distribution to permit location of the events based only on $P$ arrival times. The epicenters for these four events, located with the layered crustal model \#1 (Table 2) and $P$ arrival times only, are within $0.44 \mathrm{~km}$ of $41^{\circ} 38.85^{\prime} \mathrm{N}$ and $81^{\circ} 9.51^{\prime} \mathrm{W}$, and at depths between 4.0 $\mathrm{km}$ to $6.5 \mathrm{~km}$ (essentially the locations shown in Figure 10).

\section{Characteristics of High Frequency Ground Motions}

Previous studies of seismic attenuation have established that seismic wave fields in the eastern United States, in general, attenuate less rapidly than those in the western United States [Nuttli, 1973]. As a result, high-frequency energy is generally more prevalent in seismograms recorded in the eastern United States. In addition, improvements in recording capabilities (bandwidth and dynamic range) also contribute to improvements in resolution of high-frequency energy. Consequently, it is of some interest to investigate the high-frequency character of ground motions recorded during the aftershock sequence and compare the results with those recorded during the mainshock at the Perry Nuclear Plant. The time histories and corresponding Fourier spectra for the recordings of the aftershocks are presented by Glassmoyer et al.[1986]. The strong-motion records and corresponding spectra as processed by Kinemetrics/Systems [1986] are presented in a strong-motion data report by Cleveland Electric Illuminating Company.

\section{Strong-motion data}

Two sets of three-component strong-motion time histories were recorded at the Perry Nuclear Plant during the $m_{b} 4.9$ main shock. One set was obtained at the base of the reactor building foundation (elevation $175 \mathrm{~m}$ or $575 \mathrm{ft}$ ) and the other on the containment vessel annulus at an elevation of $208 \mathrm{~m}$ (or $682 \mathrm{ft}$ ). The recordings were made with Kinemetrics model SMA-3 accelerograph systems with a nominal dynamic range of $40 \mathrm{~dB}$, 
natural frequencies between $50.6-53.7 \mathrm{~Hz}$, and percent critical damping between 64 and 72 percent.

The acceleration, velocity, and displacement time histories obtained at the foundation of the reactor building are shown in Figure 33. The corresponding time histories obtained on the annulus of the containment vessel are shown in Figure 34. Relative velocity response and Fourier spectra corresponding to Figures 33 and 34 are shown in Figures 35 and 36, respectively. Maximum acceleration, velocity, and displacement values observed for each component and location are shown on the respective figures. A characteristic of special interest regarding the recorded strong ground motions is the preponderance of relatively high-frequency motions, especially apparent in the recordings made on the annulus of the containment structure (Figure 34). Inspection of the relative velocity response spectra and Fourier spectra computed for records from the annulus (Figure 36) shows well-defined peaks at about $4 \mathrm{~Hz}$ and $20 \mathrm{~Hz}$ for all three components of motions. The peak near $20 \mathrm{~Hz}$ is especially pronounced on the vertical and south-horizontal components. Comparison of the spectra computed on the annulus with that recorded at the foundation of the reactor structure shows that the peak relative response near $20 \mathrm{~Hz}$ on the annulus is $3-7$ times as large as that at the base of the reactor structure. Comparison of the spectra near $4 \mathrm{~Hz}$ for the two locations shows the peak relative velocity responses are comparable on the vertical components and 2-3 times larger on the annulus. These data, without further analysis, would suggest that in general, vibratory motions at/or near $20 \mathrm{~Hz}$ were significantly larger (3-7 times) than those observed at the base of the reactor building. Increases in motion of the annulus near $4 \mathrm{~Hz}$ are smaller than those near $20 \mathrm{~Hz}$ and reach a maximum of about 2-3 times on the horizontal components.

\section{Aftershock data}

The seismograms and corresponding Fourier amplitude spectra obtained for the aftershocks recorded at the GEOS stations are presented by Borcherdt [1986]. For purposes of comparing the aftershock data with that of the mainshock, we shall restrict the discussion to the data recorded for the two larger aftershocks (events 19:47, $M \sim 2.2 ; 18: 36, M \sim 2.5$ in Borcherdt, 1986). We shall also restrict the discussion to the data collected along the 
north-south lineation of stations (GS01, GS02, and GS03). Station GS01 is about $400 \mathrm{~m}$ northeast of the Perry Nuclear Plant, station GS02 is located about $8 \mathrm{~km}$ further south, and station GS03 an additional $5 \mathrm{~km}$ further south and about $2 \mathrm{~km} \mathrm{NNW}$ of the epicentral area.

Equiscaled plots of the time histories recorded at stations GS01 and GS02 are shown for the 19:47 event and the 18:36 event in Figures 37 and 38, respectively. The time histories have not been corrected for geometrical spreading. Comparison of the two plots shows that some of the amplitudes recorded at the station farthest from the epicenter (GS01) are larger than those recorded at station (GS02), which is about $8 \mathrm{~km}$ closer to the epicenter. The peak amplitudes for the 18:36 event slightly exceeded full-scale response at $54 \mathrm{~dB}$ gain at station GS02. As a result, comparison of peak amplitudes for the 18:36 event must be less conclusive than similar comparisons for the 19:47 event. Exceedence of full-scale response for the 18:36 event is expected to have only a minor influence on estimates of Fourier amplitude spectra.

Comparison of the vertical time histories at stations GS01 and GS02 for the 19:47 event (Figure 37) shows that the vertical peak amplitudes are as much as 4 times larger at station GS01 than at station GS02. The well-defined pulse of large vertical amplitude during the time interval for the arrival of the $P$ wave at station GSO1 is to be contrasted to the more gradual build-up in amplitude during the $S$ wave arrival interval. The exaggerated vertical motions, with a modulated appearance during the $S$ wave interval, might be interpreted as evidence for some type of resonance, either in the near-surface geologic layers or in some nearby man-made structure. It does not appear that the same phenomenon can account for the relatively large pulse near the onset of the initial $P$ energy. Comparison of the vertical time histories for the 18:36 event (Figure 38) again shows larger motions at station GS01 during the $S$ wave arrival interval with some suggestion of resonance. The peak amplitudes recorded during the arrival of the $P$ wave are not larger than those observed at station GSO2.

Comparing the horizontal amplitudes at station GS01 with those at station GS02 for the 19:47 event shows that only the initial $S$ arrival on the radial (north-south) component is significantly larger at station GS01. Comparison of peak amplitudes for the 18:36 event 
(Figure 38) is inconclusive as the peak amplitudes slightly exceeded full-scale response at $54 \mathrm{~dB}$ gain at station GS02.

A plot of peak acceleration amplitudes as observed for the 19:47 event at stations GS01, GS02, and GS03 is shown in Figure 39a. The plot shows that the maximum vertical amplitude at station GSO1 which occurred near the onset of the seismogram is about 4 times larger than that at either stations GS02 or GS03 which are closer to the hypocenter at distances of $10.3 \mathrm{~km}$ and $6.9 \mathrm{~km}$, respectively. Station GS01 is $18.7 \mathrm{~km}$ from the hypocenter. The plot (Figure 39) shows exaggerated peak amplitudes for the radial or north-south horizontal component at station GS01 but not for the east-west component.

A plot of peak amplitudes corrected for geometrical spreading is shown in Figure 39b. The amplitudes at stations GS01 and GS02 have been multiplied by the reciprocal of the ratio in hypocentral distance of the station to that of station GS03. (The geometrical attenuation factors are 2.8 and 1.7 for stations GS01 and GS02, respectively). The plot of peak amplitudes corrected for geometrical spreading (Figure 39b) provides strong evidence for exaggerated ground shaking at station GS01.

Fourier amplitude spectra for each of the recordings at the three stations have been computed [Glassmoyer et al., 1986; see Figures B-6, 7, 8 and B-17, 18, 19]. The spectra show that the events 19:47 and 18:36 generated signals resolvable with the GEOS above background noise up to frequencies exceeding $100 \mathrm{~Hz}$. The spectra show that the vertical motions detected at each of the sites show a rapid fall-off with increasing frequency only for frequencies exceeding about 70 or $80 \mathrm{~Hz}$. The spectra for horizontal motions indicate an increased fall-off rate with increasing frequency for frequencies exceeding 30-40 Hz. The increased fall-off rate for the horizontal motions is consistent with intrinsic material absorption for shear waves being greater than that for compressional waves.

Spectral ratios for the frequency band 0-130 $\mathrm{Hz}$ are shown in Figure 40. Spectral ratios for the band 0-50 Hz are shown in Figure 41. The spectral ratios shown in Figures 40 and 41a, b, c have been computed from the ratio of the Fourier amplitude spectra for station GS01 to that of the corresponding component of motion recorded at station GS02. The ratios in Figures 40 and $41 \mathrm{~d}$, e, f, have been computed from corresponding spectra of stations GS01 and GS03. The spectral ratios are computed for only those frequencies for 
which the spectral signal-to-noise ratios were greater than two. Spectral noise levels were determined from 1.25 seconds of noise prior to the onset of seismic energy. The spectra were computed from 10 seconds of time history sampled at $400 \mathrm{sps}$ commencing about 1 second prior to the onset of the $P$ wave. The spectra were smoothed with a 15-point triangular Hanning window which corresponds to a window width of $1.5 \mathrm{~Hz}$. The scale factor to permit the ratios to be corrected for geometrical spreading is indicated in each of the figures.

The computed ratios (Figure 40) show that seismic energy was resolvable above instrument noise levels at the gain levels specified for the GEOS up to frequencies as high as $130 \mathrm{~Hz}$. This upper limit represents a substantial extension in observable bandwidth over that previously observed from conventional strong-motion recorders with an upper limit of about 30-35 Hz. Interpretation of the significance of seismic signals in the 50-130 $\mathrm{Hz}$ band must await more detailed investigations.

Comparison of the spectral ratios shown for the $0-50 \mathrm{~Hz}$ band (Figure 41) for the 19:47 event with those for the 18:36 event show that the spectral ratios are similar in many respects with a few notable differences. The extent to which the ratios are similar argues that these spectral ratios provide an estimate of the amplitude response of station GS01 relative to that at station GS02 (Figures 41a, b, and c) and station GS03 (Figures $41 \mathrm{~d}$, e, and $\mathrm{f}$ ). One notable difference in comparing the ratios for the two events is the reduction in the ratios computed for the vertical component of motion recorded from the 18:36 event. In situ relative instrument calibration characteristics computed prior to the 19:47 event and about 48 hours later, just prior to the 18:46 event, show that the computed calibration curves agree to within a percent over the entire band for which there is a good signal-to-noise ratio in the input signal. Variations near $100 \mathrm{~Hz}$ are due to seismic noise at the site during the second calibration interval. As a result, the apparent reduction in ratios for the 18:36 event does not seem to be associated with changes in instrument response.

Dominant features of the spectral ratios are the predominant peaks which occur for the vertical motion near $20 \mathrm{~Hz}$. The occurrence of these peaks on each of the ratios computed from the vertical motions provides strong evidence for an exaggerated level of vertical shaking near $20 \mathrm{~Hz}$ at station GSO1. Evidence for exaggerated level of shaking 
near $20 \mathrm{~Hz}$ is also apparent in the spectra computed from the strong motion recordings (see Figures 35 and 36$)$. The distance $(\sim 400 \mathrm{~m})$ of station GS01 from the location of the strong-motion recorders would argue that the predominant peak in the aftershock ratios is associated with a resonance in the local soil layer. Consideration of the near-surface velocity $\log$ (Table 8 ) as compiled from cross-hole measurements shows an abrupt change in $P$ velocity at an interface between glacial till and shale at a depth of about 20 meters below the surface. If we assume a simple one-dimensional model with vertically incident $P$ waves, then the thickness corresponding to a $20 \mathrm{~Hz}$ resonance for an average $P$ wave velocity of $1525 \mathrm{~m} / \mathrm{sec}(5000 \mathrm{ft} / \mathrm{sec})$ would be

$$
H=\frac{V}{4 f} \approx \frac{1525 \mathrm{~m} / \mathrm{s}}{4(20 \mathrm{~Hz})}=19 \mathrm{~m}
$$

The extent to which this estimated thickness agrees with that shown in drill hole logs (see Table 8) for the till-shale interface, provides additional evidence that the exaggerated levels of shaking near $20 \mathrm{~Hz}$ are due to amplification by the surface layer of soil of thickness about 20 meters. The exaggerated level of shaking observed on the annulus of the containment vessel argues that a resonance near $20 \mathrm{~Hz}$ might also exist in the plant structure. If both resonances do indeed coincide, then ground motions near these frequencies could be expected to be significantly larger on the structure than if only one or no such resonances existed.

\section{CONCLUSIONS AND RECOMMENDATIONS}

\section{Absence of Obvious Structure}

Analysis of the mainshock and aftershocks indicate no obvious structure or fault with which the January 31 earthquake can be associated. The hypocenter of the earthquake was located in the PreCambrian basement rocks. Two kilometers of Paleozoic and younger age rocks cover basement in this region. Although there is no evidence of any surface expression of the fault responsible for the earthquake, gravity and aeromagnetic field data display some relief, suggesting the presence of a basement structure; but no structure 
has been currently defined which might be considered a capable fault in the sense used by the Nuclear Regulatory Commission. Locations of aftershocks obtained to date are permissive of the interpretation of a fault striking somewhat east of north, but as most of the aftershocks are tightly clustered in space, they provide only very weak evidence for the orientation of a fault.

\section{Stress Regime}

Analysis of available stress measurements as discussed above seems to indicate that the state of stress in northeastern Ohio is close to the theoretical threshold for small earthquakes as predicted by the Mohr-Coulomb failure criterion. This should not be surprising given the history of small to moderate earthquakes in the region.

\section{Possible Role of Injection Wells}

Although given the state of stress discussed above, triggering of small earthquakes by fluid injection would not be surprising, the distance of the January 31 earthquake and its aftershocks from the wells (with the exception of the very small earthquake on March 12), the lack of any small earthquakes detected near the bottom of the wells, the history of small to moderate earthquakes in the region prior to the initation of injection, and the attenuation of the pressure field with distance from the injection wells, all argue for a "natural" origin for the earthquake. Therefore, although triggering remains a possibility, the probability that the injection played a significant role in triggering the earthquake, based on the information currently available, must be regarded as low. The analysis of the possible relation between the injection wells and the January 31 earthquake has indicated nothing to suggest the occurrence of an earthquake larger than that expected for the broad region, or the activation of a major structure closer to the wells or near the power plant.

\section{Value of Continued Earthquake Monitoring}

Continued earthquake monitoring in the vicinity of the epicenter of the January 31 earthquake will be of considerable value for two reasons. First, as indicated above, the lack of many small earthquakes detected near the bottom of the injection wells is a very 
important factor in concluding that the probability of an injection being the triggering mechanism is low. Although the single, small earthquake on March $12^{\text {th }}$ may have been induced, no large numbers of small earthquakes, typical of induced earthquake sequences, have yet to be detected near the injection wells. Any more earthquakes closer to the bottom of the wells than the January 31 earthquake and its initial aftershocks could significantly alter the local seismic hazard assessment. Second, from the point of view of trying to understand the generic problem of eastern U.S. seismicity, the earthquake sequence near Hambden is invaluable and continued monitoring could prove of substantial importance in developing an understanding of the relationship between the January 31 earthquake and crustal structure, if any.

\section{High Frequency Ground Motions}

High-resolution (up to $96 \mathrm{~dB}$ ), broadband ( $<200 \mathrm{~Hz}$ ) recordings of the aftershock sequence show that seismic signals as high as $130 \mathrm{~Hz}$ were resolvable above noise levels for the larger aftershocks $\left(m_{b} 2.2 ; 2.5\right)$ at hypocentral distances up to $18 \mathrm{~km}$. Fourier amplitude spectra of velocity show that amplitude spectra decrease most rapidly with increasing frequency only for frequencies exceeding $70-80 \mathrm{~Hz}$ for vertical motion and 30$40 \mathrm{~Hz}$ for horizontal motion.

Signals relatively rich in high frequencies were also observed on the strong-motion records of the mainshock for frequencies up to the upper bandwidth limit of the recorders $(30 \mathrm{~Hz})$. Based on the aftershock data, spectral ratios computed to estimate the amplitude response of local site conditions at a site near the Perry Nuclear Plant (site GS01) show exaggerated vertical ground shaking near $4-7 \mathrm{~Hz}$ and near $20 \mathrm{~Hz}$. The peaks in the spectral ratios near these frequencies appear to be attributable to resonances in the near-surface soil layers. Smaller, but apparently significant, resonances are also indicated in the spectral ratios for horizontal motions.

Inspection of response spectra computed for strong-motion records of the mainshock on the annulus of the containment vessel and on the foundation of the reactor building also show amplified vibration of the containment structure near $20 \mathrm{~Hz}$. These strong-motion data suggest that a $20 \mathrm{~Hz}$ resonance may also be associated with the containment structure. 
At present insufficient data exists to conclusively determine if separate $20 \mathrm{~Hz}$ resonances exist in both the containment structure and the near-surface soil layers. If both resonances do exist then significantly exaggerated shaking near $20 \mathrm{~Hz}$ can be expected from future earthquakes.

Future studies to better describe the resonances suggested by the strong-motion data and the aftershock data would help in assessing the potential levels of exaggerated ground shaking and their significance for engineering purposes. Ambient vibration studies of pertinent structures, soil-structure interaction studies and comparative ground motion studies could contribute to an improved understanding of the significance of the observed motions. Additional investigations of local geologic and seismic site characteristics together with appropriate numerical models may also be warranted.

Evidence derived in this study and other recent studies using broadband instrumentation for levels of exaggerated ground shaking at high frequencies suggests that general studies pertinent to assessing the influence of possible high-frequency site resonances on peak accelerations in the band $10-40 \mathrm{~Hz}$ are warranted.

\section{Need to Understand Basement Structure}

Given the geologic setting and conditions in northeastern Ohio, the best chance to learn about the nature of the structure(s) responsible for the earthquakes will be through general geophysical investigations. Such studies might include seismic reflection, microgravity and/or detailed areomagnetic surveys. Seismic reflection profiles that penetrate to basement are likely to produce the highest resolution, and thus the greatest capability of identifying faults or other structures responsible for the seismicity, structures that may find little if any expression in the overlying rocks of Paleozoic age. Detailed gravity and magnetic surveys have already been commissioned, and hopefully they will also be revealing of significant local structure and/or basement topography.

\section{Research-quality Measurements in Boreholes}

As noted above, while the data from commercial hyrofractures has been valuable in estimating the regional state of stress, estimates could be made with considerably higher 
confidence if research-quality measurements in boreholes were carried out. The resulting estimates of stress would be valuable from several points of view. First, measurements could confirm the inferences drawn from the commercial hydrofactures with regard to the magnitude of the least and maximum horizontal compressive stresses. In researchquality measurements, care would be taken to assure that hydrofactures were created in a previously unfractured part of the hole, and thus insure that pre-existing fractures do not bias the result. In addition, research-quality hydrofractures utilize only small volumes of fluid to minimize any pressure difference between the tip of the extending crack and the borehole, an effect which is suspected to have biased some of the values obtained from the Calhio wells. Observations could also be made to determine the orientation of the created fractures and thus determine the suspected orientation of the maximum compressive stress. 


\section{REFERENCES}

Borcherdt, R. D. (1968), Spectral analysis of seismic measurements from nuclear explosions in Nevada recorded in the San Francisco Bay area, California, Geol. Soc. Amer. Spec. Paper 121, p. 486-487.

Borcherdt, R. D. (1970), Effects of local geology on ground motion near San Francisco Bay, Bull. Seismol. Soc. Am., v. 60, p. 29-61.

Borcherdt, R. D., and Gibbs, J. F. (1976), Effects of local geological conditions in the San

Francisco Bay region on ground motions and the intensities of the 1906 earthquake, Bull. Seismol. Soc. Am., v. 66, p. 467-500.

Borcherdt, R. D., Fletcher, J. B., Jensen, E. G., Maxwell, G. L., VanSchaack, J. R., Warrick, R. E., Cranswick, E., Johnston, M. J. S., and McClearn, R. (1985), A General Earthquake Observation System (GEOS), Bull. Seismol. Soc. Am., v. 75, p. $1783-1823$.

Borcherdt, R. D., editor (1986), Preliminary report on aftershock sequence for the earthquake of January 31, 1986, near Painesville, Ohio, U. S. Geol. Surv. Open-File Rep. 86-181, 11 pp. with figures and maps.

Chaplin, M. P., Taylor, S. R., and Tokoz, M. N. (1980), Coda-length magnitude scale for New England, Earthquake Notes, v. 51, p. 15-22.

Cleveland Electric Illuminating Company (1982), The Perry Nuclear Power Plant Units I and II: Final Safety Analysis Report, Cleveland, Ohio.

Clifford, M. J. (1973), Silurian rock salt of Ohio, Ohio Geol. Surv. Rep. of Investigations, v. 9, 42 pp., Columbus, Ohio.

Clifford, M. J. (1975), Subsurface liquid-waste injection in Ohio, Ohio Geol. Surv. Inform. Circular, v. 43, 27 pp., Columbus, Ohio.

Cranswick, E., Wetmiller, R., and Boatwright J. (1985), High-frequency observations and source parameters of microearthquakes recorded at hard-rock sites, Bull. Seismol. Soc. Am., v. 75, p. 1535-1568. 
Davis, S. (1985), Investigations of natural and induced seismicity in the Texas Panhandle, M. S. Thesis, University of Texas, Austin, $230 \mathrm{pp}$.

Duke, C. M., compiler (1958), Bibliography of effects of soil conditions on earthquake damage, Earthquake Eng. Inst., 47 pp.

Dunrud, C. R., and Nevins, B. B. (1981), Solution mining and subsidence in evaporite rocks in the United States, U. S. Geol. Surv. Map I-1298.

Fletcher, J. B., and Sykes, L. R. (1977), Earthquakes related to hyraulic mining and natural seismic activity in western New York State, J. Geophys. Res. , v. 82, p. 3767-3780.

Geauga County Disaster Service Agency (1986), Findings on damage associated with the January 31, 1986 earthquake, informal report, Chardon, Ohio.

Glassmoyer, G., Borcherdt, R., King, J., Dietal, C., Sembera, E., Roeloffs, E., Valdes, C., and Nicholson, C. (1986), Source and propagation characteristics for aftershock sequence near Painesville, Ohio (abstract), Eos (Trans. Amer. Geophys. Un. ), v. 67, p. 314 .

Gutenberg, H. B. (1957), Effects of ground on earthquake motion, Bull. Seismol. Soc. Am., v. 47 , p. 221-250.

Haimson, B. C. (1978), Crsutal stress in the Michigan basin, J. Geophys. Res. , v. 83, p. $5857-5863$.

Healy, J. H., Rubey, W. W., Griggs, D. T., and Raleigh, C. B. (1968), The Denver earthquakes, Science, v. 161, p. 1301-1309.

Herrmann, R. B. (1969), The structure of the Cincinnati Arch as determined by short period Rayleigh waves, Bull. Seismol. Soc. Am., v. 59, p. 399-407.

Hickman, S. H., Healy, J. H., and Zoback M. D. (1985), In situ stress, natural fracture distribution, and borehole elongation in the Auburn geothermal well, Auburn, New York, J. Geophys. Res. , v. 90, p. 5497-5512.

Hsieh, P. A., and Bredehoeft, J. D. (1981), A reservoir analysis of the Denver earthquakes: A case of induced seismicity, J. Geophys. Res. , v. 86, p. 903-920. 
Jaeger, J. C., and Cook, N. C. W. (1976), Fundamentals of Rock Mechanics, John Wiley and Sons, Inc., New York, 585 pp.

Kinemetrics/Systems (1986), $M_{L}=5.0$ earthquake, January $31^{\text {st }}, 1986$ : Strong-motion data from the Perry Nuclear Power Plant seismic instrumentation, Pasadena, Calif., $53 \mathrm{pp}$.

Lahr, J. C. (1985), HYPOELLIPSE/VAX: A computer program for determining local earthquake hypocentral paramters, magnitude and first-motion patterm, U. S. Geol. Surv. Open-File Rep. 84-519, 35 pp.

McGarr, A. (1980), Some constraints on levels of shear stress in the crust from observations and theory, J. Geophys. Res. , v. 85, p. 6231-6238.

Natural Resources Management Corp. (1971), Report on the drilling, testing and completion of the subsurface disposal well \#1, Calhio Chemicals, Inc., Perry, Ohio, 81 pp. with maps, figures and graphs.

Nuttli, O. W., Stauder, W., and Kisslinger, C. (1969), Travel time tables for earthquakes in the central United States, Earthquake Notes, v. 40, p. 19-28.

Ohio UIC Permit Application for Class I Injection well (1985), Calhio Chemicals, Inc., Perry, Ohio, Injection Well \#1, 22 pp.

Ohio UIC Permit Application for Class I Injection well (1985), Calhio Chemicals, Inc., Perry, Ohio, Injection Well \#2, 22 pp.

Petro Evaluation Services, Inc. (1985), Well completion record, saltwater injection well, Painesville, Lake County, Ohio, 5 pp.

Press, F. (1966), Seismic velocities, Handbook of Physical Constants, edited by S. D. Clark, Geol. Soc. Am. Memoir, v. 97, p. 195-218.

Raleigh, C. B., Healy, J. H., and Bredehoeft, J. D. (1976), An experiment in earthquake control at Rangely, Colorado, Science, v. 191, p. 1230-1237. 
Resources Services Inc. (1980), Report on the drilling, testing and completion of the subsurface disposal well, Injection Well \#2, Calhio Chemicals, Inc., Perry, Ohio, 84 pp. with maps, figures, and graphs.

Rogers, A. M., Borcherdt, R. D., Covington, P. A., and Perkins, D. M. (1984), A comparative ground response study near Los Angeles using recordings of Nevada nuclear tests and the 1971 San Fernando earthquake, Bull. Seismol. Soc. Am., v. 74, p. $1925-1950$.

Simpson, D. W. (1986), Triggerred earthquakes, Ann. Rev. Earth Planet. Sci., v. 14, p. 2142.

Stover, C. W., Reagor, B. G., and Algermissen, S. T. (1979), Seismicity map of the state of Ohio, U. S. Geol. Surv. Map MF-1142. 
TABLE 1. LOCATIONS OF STATIONS DEPLOYED TO MONITOR AFTERSHOCKS.

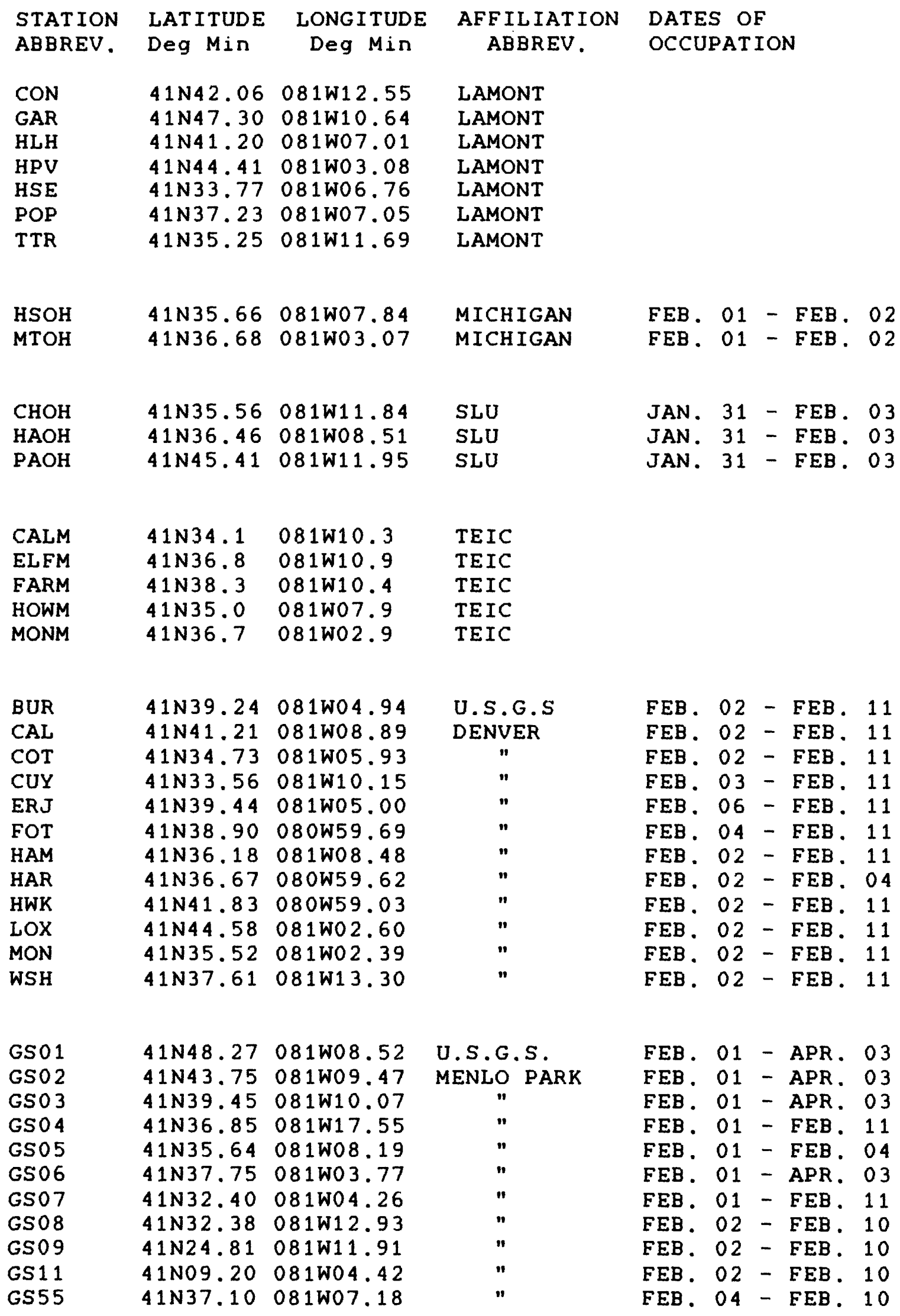




\begin{tabular}{|c|c|c|c|}
\hline $\begin{array}{l}\text { STATION } \\
\text { ABBREV. }\end{array}$ & $\begin{array}{l}\text { LATITUDE } \\
\text { Deg Min }\end{array}$ & $\begin{array}{l}\text { LONGITUDE } \\
\text { Deg Min }\end{array}$ & $\begin{array}{l}\text { AFF IL IATION } \\
\text { ABBREV. }\end{array}$ \\
\hline CFD & $41 N 40.45$ & $081 \mathrm{~W} 13.41$ & WESTON \\
\hline CLD & $41 N 31.44$ & $081 \mathrm{~W} 20.19$ & WESTON \\
\hline HTG & $41 N 37.17$ & 080 0พ57. 27 & WESTON \\
\hline KEL & $41 N 32.82$ & 081 W06. 12 & WESTON \\
\hline MFD & $41 \mathrm{~N} 27.77$ & 081 W0 4.41 & WESTON \\
\hline MIN & $41 N 33.56$ & $081 \mathrm{~W} 15.41$ & WESTON \\
\hline PAT & $41 N 33.63$ & $081 W 21.91$ & WESTON \\
\hline PER & $41 N 48.06$ & 081 W08. 61 & WESTON \\
\hline TOM & $41 N 41.29$ & 081 W0 3.09 & WESTON \\
\hline WEL & $41 N 45.00$ & 081 W09. 31 & WESTON \\
\hline WKR & $41 N 36.06$ & 081 W0 3.13 & WESTON \\
\hline WC0 1 & $41 N 36.90$ & $081 \mathrm{~W} 18.08$ & WOODWARD - CLYDE \\
\hline WCO 2 & $41 N 40.05$ & 081 W09. 53 & " \\
\hline WCO 3 & $41 N 43.87$ & 081 W0 4.46 & $"$ \\
\hline WCO 4 & $41 N 35.10$ & 081 พ09. 36 & $"$ \\
\hline WCO 6 & $41 N 32.40$ & 081 W01.75 & $"$ \\
\hline WCO 7 & $41 N 48.00$ & 081 W08. 58 & $"$ \\
\hline WC0 8 & $41 N 40.24$ & 081 W1 4.48 & $"$ \\
\hline WCO9 & $41 N 35.45$ & 081 พ09. 36 & $"$ \\
\hline
\end{tabular}


Table 2. Models used to locate events listed in Table 3

\begin{tabular}{|c|c|c|c|c|c|}
\hline $\begin{array}{l}\text { Depth } \\
(\mathrm{km})\end{array}$ & $\begin{array}{l}\text { Thickness } \\
\qquad(\mathrm{km})\end{array}$ & $\begin{array}{c}P \text { Velocity } \\
(\mathrm{km} / \mathrm{s})\end{array}$ & $\begin{array}{c}S \text { Velocity } \\
(\mathrm{km} / \mathrm{s})\end{array}$ & $V p / V s$ & Description ${ }^{*}$ \\
\hline 0.0 & 2.00 & 4.25 & 2.53 & 1.68 & Paleozoic section \\
\hline 2.00 & 99.00 & 6.50 & 3.87 & 1.68 & Granitic basement \\
\hline 0.0 & 1.00 & 3.70 & 2.06 & 1.80 & Upper Sedimentary \\
\hline 1.00 & 1.00 & 5.60 & 3.20 & 1.75 & Lower Sedimentary \\
\hline 2.00 & 35.00 & 6.33 & 3.66 & 1.73 & Granitic crust \\
\hline 37.00 & 99.00 & 8.10 & 4.68 & 1.73 & Mantle \\
\hline 0.0 & 0.05 & 1.80 & 0.60 & 3.00 & Glacial till \\
\hline 0.05 & 0.45 & 3.00 & 1.58 & 1.90 & Devonian shale \\
\hline 0.50 & 0.50 & 4.20 & 2.33 & 1.80 & Silurian dolomite \\
\hline 1.00 & 0.75 & 4.50 & 2.53 & 1.78 & $\begin{array}{l}\text { Ordovician limestone } \\
\text { and dolomite }\end{array}$ \\
\hline 1.75 & 0.35 & 4.75 & 2.70 & 1.76 & $\begin{array}{l}\text { Cambrian sandstone } \\
\text { and dolomite }\end{array}$ \\
\hline 2.10 & 17.90 & 6.15 & 3.54 & 1.74 & Precambrian granite \\
\hline 20.00 & 25.00 & 6.70 & 3.87 & 1.73 & Lower crust \\
\hline 40.00 & 99.00 & 8.15 & 4.63 & 1.75 & Mantle \\
\hline
\end{tabular}

*Weston Geophysical, Herrmann [1969], Cleveland Electric Illuminating Co. [1982] 
TABLE 3. LOCATIONS OF RECENT EARTHOUAKES AND BLASTS IN NORTHEASTERN OHIO.

$\begin{array}{cccccccccc}\text { DATE } & \text { ORIGIN } & \text { LATITUDE } & \text { LONGITUDE } & \text { DEPTH } & \text { MAG } & \text { NO. } & \text { RMS } & \text { ERH } & \text { ERZ AZI } \\ \text { YrMODY Hr:Mn SEC } & \text { Deg Min } & \text { Deg Min } & \mathrm{km} & & \text { PHA } & \text { sec } & \mathrm{km} & \mathrm{km} & \text { GAP }\end{array}$

MAINSHOCK AND PRIOR EVENTS

$\begin{array}{llllllll}430309 & 03: 25 & 25.00 & 41 N 37.80 & 81 w 18.60 & 8.00 & 4.7 & \text { (NEIS,Dewey, 1986) } \\ 830122 & 07: 46 & 59.30 & 41 N 48.00 & 81 w 10.00 & 6.00 & 2.7 & \\ 860131 & 16: 46 & 42.30 & 41 N 39.00 & 81 w 09.72 & 8.00 & 4.9 & \end{array}$

AFTERSHOCKS (MOOEL \#3)

$\begin{array}{rrrr}860201 & 18: 54 & 49.20 & 41 N 38.82 \\ 860202 & 3: 22 & 48.63 & 41 N 38.76 \\ 860203 & 19: 47 & 19.66 & 41 N 38.90 \\ 860206 & 6: 34 & 2.40 & 41 N 38.94 \\ 860206 & 18: 36 & 22.24 & 41 N 38.67 \\ 860207 & 15: 20 & 20.20 & 41 N 39.06 \\ 860210 & 20: 6 & 13.49 & 41 N 39.16 \\ 860223 & 3: 29 & 48.46 & 41 N 39.06 \\ 860224 & 16: 56 & 6.37 & 41 N 38.96 \\ 860228 & 1: 39 & 34.07 & 41 N 39.11 \\ 860308 & 20: 42 & 49.49 & 41 N 38.72 \\ 860312 & 8: 55 & 26.59 & 41 N 43.63 \\ 860324 & 13: 42 & 41.20 & 41 N 38.06\end{array}$

$81 w 9.42$
$81 w 9.63$
$81 w 9.61$
$81 w 9.64$
$81 w 9.64$
$81 w 9.25$
$81 w 9.27$
$81 w 9.44$
$81 w 9.81$
$81 w 9.69$
$81 w 9.36$
$81 w 10.24$
$81 w 9.97$

$4.97 \quad 1.4 \quad 21$

4.990 .8

6.931 .8

$2.07-.3$

6.89 2.4

4.641 .0

4.970 .9

$4.77-.3$

3.720 .1

4.310 .1

$4.42-.5$

$2.01-.2$

4.921 .3
0.13

0.06

0. 08

0.21

o. 12

0.07

0.09

0.08

0.09

o. 08

o. 10

0.06

0.06
0.45

0.26

0.26

0.83

0.28

0.29

0.29

0.47

0.56

0.49

0.66

1. 35

0.45
0.80100

0.2372

$0.36 \quad 74$

0.6649

0.4148

0.2242

0.4269

0.4396

0.71126

0.6992

0.61102

0.44216

0.4097

AFTERSHOCKS (MODEL \#2)

$\begin{array}{rrrr}860201 & 18: 54 & 49.35 & 41 N 38.77 \\ 860202 & 3.22 & 48.69 & 41 N 38.69 \\ 860203 & 19: 47 & 19.82 & 41 N 38.97 \\ 860205 & 6: 34 & 2.61 & 41 N 38.87 \\ 860206 & 18: 36 & 22.48 & 41 N 38.70 \\ 860207 & 16: 20 & 20.44 & 41 N 38.96 \\ 860210 & 20: 6 & 13.68 & 41 N 38.90 \\ 860223 & 3: 29 & 48.59 & 41 N 39.14 \\ 860224 & 16: 65 & 6.46 & 41 N 38.92 \\ 860228 & 1: 39 & 34.15 & 41 N 39.19 \\ 860308 & 20: 42 & 49.67 & 41 N 38.76 \\ 860324 & 13: 42 & 41.38 & 41 N 38.07\end{array}$

\begin{tabular}{|c|c|c|}
\hline $81 w$ & 9.38 & 5.16 \\
\hline $81 w$ & 9.41 & 5.37 \\
\hline $81 w$ & 9.57 & 5.89 \\
\hline $81 w$ & 9.47 & 1.62 \\
\hline $81 w$ & 9.66 & 5.46 \\
\hline $81 w$ & 9.26 & 3.63 \\
\hline $81 w$ & 9.44 & 4.39 \\
\hline $81 w$ & 9.39 & 4.76 \\
\hline $81 w$ & 9.61 & 4.62 \\
\hline $81 w$ & 9.38 & 4.73 \\
\hline $81 w$ & 9.42 & 3.99 \\
\hline $81 W$ & 0.06 & 4.47 \\
\hline
\end{tabular}

AFTERSHOCKS (MODEL \#1)

$\begin{array}{rrrrr}21 & 0.10 & 0.37 & 0.64 & 100 \\ 24 & 0.09 & 0.34 & 0.38 & 70 \\ 44 & 0.12 & 0.44 & 0.30 & 71 \\ 20 & 0.22 & 0.94 & 1.05 & 51 \\ 43 & 0.13 & 0.46 & 0.31 & 48 \\ 27 & 0.09 & 0.35 & 0.27 & 43 \\ 26 & 0.10 & 0.33 & 0.48 & 71 \\ 16 & 0.05 & 0.33 & 0.30 & 96 \\ 10 & 0.06 & 0.46 & 0.66 & 122 \\ 12 & 0.06 & 0.31 & 0.44 & 97 \\ 12 & 0.11 & 0.76 & 0.71 & 102 \\ 12 & 0.06 & 0.47 & 0.42 & 96\end{array}$

SEE TABLE 7

BLASTS

$860205 \quad 15.3906 .45 \quad 41 N 40.08$

$860206 \quad 17: 57 \quad 03.86$

$41 \mathrm{~N} 40.02$
$81 \mathrm{WO} .28$

81 wo2. 46
$0.90 \quad 0.6 \quad 13$

$\begin{array}{lll}0.01 & 0.4 \quad 12\end{array}$

0.07

0.23

0.62

o. 37
74

75 
Table 4. Stress estimates (bars)

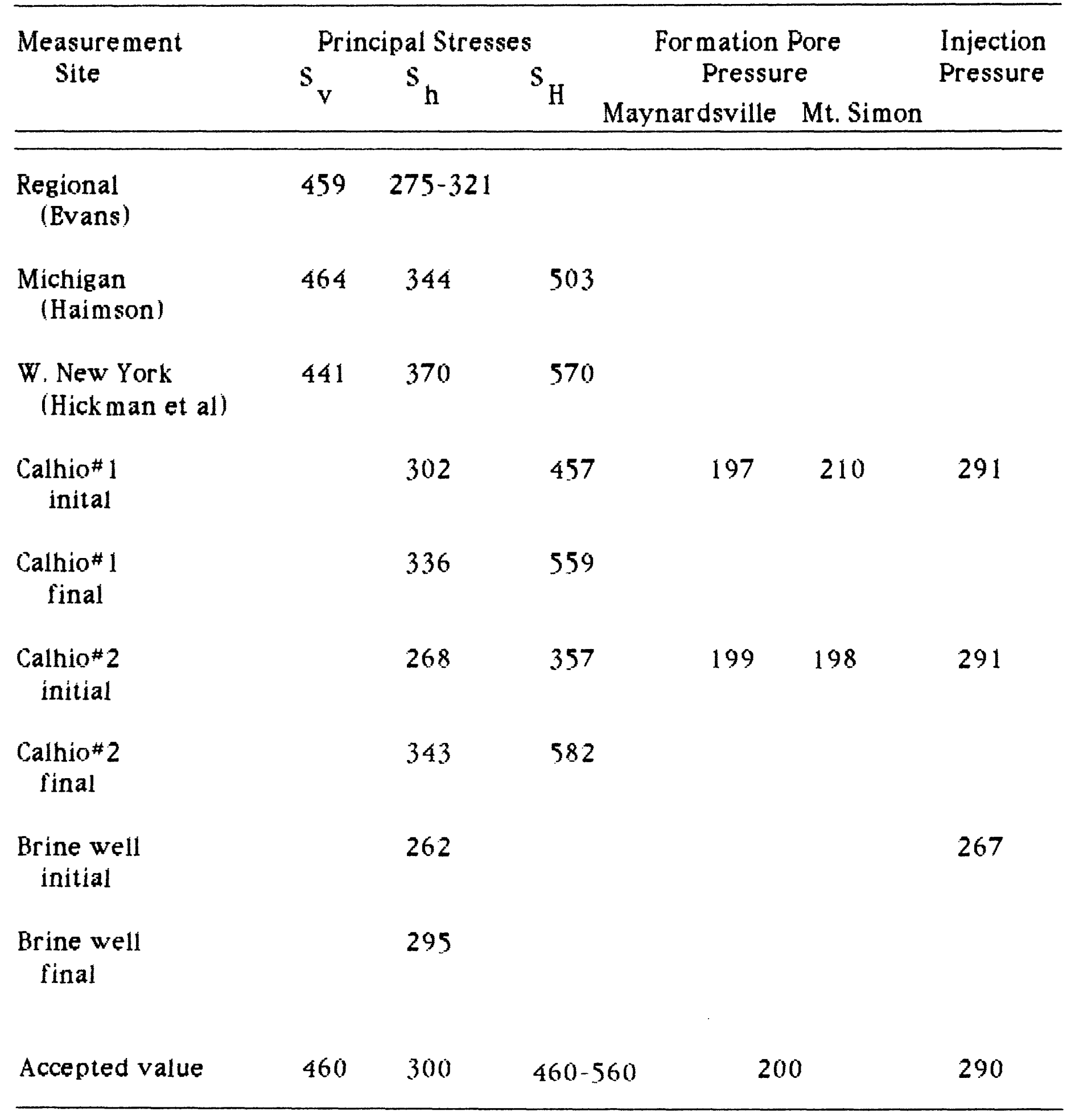


Table 5. Measured pore pressures from drill stem tests

\begin{tabular}{ccc} 
Formation & $\begin{array}{c}\text { Calhio \#1 } \\
\text { April 11, 1971 }\end{array}$ & $\begin{array}{c}\text { Calhio \#2 } \\
\text { August 20, 1979 }\end{array}$ \\
\hline \hline Maynardsville & 2821 psi & 2930 psi \\
Mt. Simon & 3096 psi & 2906 psi \\
\hline
\end{tabular}


Table 6. Physical properties of reservoir rocks into which waste is being injected

\begin{tabular}{lccc}
\hline & Maynardville & Rome & Mt. Simon \\
\hline $\begin{array}{l}\text { Permeability, } \\
\text { darcies }\end{array}$ & $4.2 \mathrm{E}-3$ & $?$ & $5.5 \mathrm{E}-3$ \\
$\begin{array}{l}\text { Hydraulic conductivity, } \\
\text { m/s }\end{array}$ & $4.2 \mathrm{E}-8$ & $?$ & $5.5 \mathrm{E}-8$ \\
$\begin{array}{c}\text { Thickness, } \\
\text { meters }\end{array}$ & 52.7 & 22.3 & 37.8 \\
$\begin{array}{c}\text { Transmissivity, } \\
\text { m }{ }^{2} / \mathrm{s}\end{array}$ & $2.2 \mathrm{E}-6$ & $?$ & $2.1 \mathrm{E}-6$ \\
$\begin{array}{l}\text { Porosity } \\
\text { Minimum storativity }\end{array}$ & $1.25 \mathrm{E}-5$ & $?$ & 0.085 \\
\hline
\end{tabular}

Other values assumed are fluid density $=1.2 \mathrm{~g} / \mathrm{cm}^{3}$, fluid compressibility $=3.03 \mathrm{E}-11$ $\mathrm{cm}^{2} /$ dyne 
Table 7. Origin time and locations for seismic events by GEOS for time period 2/1/86 through $2 / 10 / 86$

\section{Aftershocks}

Yr Mo Da Origin Lat. $N$ Lon. W Depth RMS ERH ERZ GAP

(Max. disf

\begin{tabular}{lllllllllllll}
\hline \hline 86 & 2 & 2 & 322 & 48.57 & 4138.76 & 819.50 & 5.12 & 0.01 & 1.16 & 0.78 & 150 & 1.1 \\
86 & 2 & 3 & 194719.65 & 4138.92 & 819.43 & 5.81 & 0.03 & 0.88 & 0.76 & 116 & 2.2 \\
86 & 2 & 5 & 634 & 2.40 & 4138.96 & 819.68 & 4.05 & 0.02 & 0.88 & 1.31 & 134 & 0.9 \\
86 & 2 & 6 & 183622.26 & 4138.68 & 819.33 & 6.06 & 0.03 & 0.82 & 0.80 & 121 & 2.5 \\
86 & 2 & 7 & 152020.19 & 4138.97 & 819.42 & 4.66 & 0.03 & 0.92 & 5.21 & 115 & 1.9 \\
86 & 2 & 10 & 20613.59 & 4139.07 & 819.31 & 3.38 & 0.04 & 0.81 & 6.31 & 115 & 1.5 \\
\hline
\end{tabular}


Table 8. Near-surface velocity measurements *

\begin{tabular}{cccl}
\hline $\begin{array}{c}\text { Elevation } \\
(\mathrm{feet})\end{array}$ & $\begin{array}{c}V_{p} \\
(\mathrm{ft} / \mathrm{s})\end{array}$ & $\begin{array}{c}V_{s} \\
(\mathrm{ft} / \mathrm{s})\end{array}$ & \multicolumn{1}{c}{ Description } \\
\hline 620 & & & Lacustrine Sediments: \\
612 & 1200 & 600 & (unsaturated) \\
605 & 5000 & 700 & (saturated) \\
595 & 5000 & 1200 & (saturated) \\
583 & 5900 & 1900 & Glacial till: (upper) \\
560 & 7800 & 2600 & (lower) \\
510 & 10400 & 4900 & Shale \\
410 & 9000 & 4000 & Shale \\
\hline * Safety Analysis Report, Perry & Nuclear Plant
\end{tabular}




\section{FIGURE CAPTIONS}

Figure 1. Seismicity map of Ohio.

Figure 2. Intensities resulting from the January 31, 1986 earthquake in northeastern Ohio as compiled by the U.S. Geological Survey.

Figure 3. Intensites compiled by Weston Geophysical.

Figure 4. Example smoked paper recordings of aftershocks

Figure 5. Seismograph stations deployed by all cooperating institutions to record aftershocks. Shaded areas on this and subsequent maps represent areas of dense population.

Figure 6. Smoked paper recordings of two local quarry blasts.

Figure 7. Composite Wadati diagram for four aftershocks as recorded by U.S. Geological Survey stations.

Figure 8. Map of U.S. Geological Survey seismograph stations.

Figure 9. Map showing mainshock epicenter (solid star), locations of six aftershocks (open circles) and two blasts (filled circles). Numbers correspond to relative position in time.

Figure 10. Map showing distribution of aftershock and blast epicenters with associated $94 \%$ confidence ellipses. Other symbols as in Figure 9.

Figure 11. Vertical cross sections of aftershock hypocenters with associated error estimates. Orientations of cross sections are shown on map at left.

Figure 12. Enlarged map showing all seismograph stations in immediate epicentral area.

Figure 13. Map and vertical cross sections of aftershock locations obtained using all available data as of April 15, 1986. Cross sections show projections onto planes parallel and perpendicular to $\mathrm{N} 20^{\circ} \mathrm{E}$.

Figure 14. Lower hemisphere, equal area, single event focal mechanisms for two largest aftershocks, February 6 18:36, and February 3 19:47. Solid circles are 
compressions; open triangles are dilatations. Legend indicates origin time, location and focal depth.

Figure 15. Focal mechanisms for aftershocks February 10 20:06 and February 5 06:34. Notice relatively large component of normal faulting for these two events.

Figure 16. Focal mechanisms for aftershocks February 2 03:22 and Febraury 7 15:20. Notice that these two events show nearly diametrically opposite solutions.

Figure 17. Focal mechanisms for aftershocks February 23 03:29 and February 1 18:54. Nodal planes are not well constrained.

Figure 18. Composite of first motions for all smaller aftershocks with nodal planes determined for largest aftershock, February 6 18:36.

Figure 19. Volume of fluid injected into Calhio wells through time.

Figure 20. Location of deep injection wells in Lake County and epicenters of earthquakes. Large uncertainties in location are associated with both the 1943 and 1983 earthquake epicenters.

Figure 21. Seismogram of small event near station GS02 within $3 \mathrm{~km}$ of the Calhio injection wells.

Figure 22. Mohr circle diagrams showing state of stress a) at bottom of injection well; b) at hypocenter.

Figure 23. Pressure produced by waste injection into infinite reservoir. Each curve is labeled with the elapsed number of years since the beginning of injection. Injection at steady rate of 6.7 million liters/month.

Figure 24. Pressure versus time at the wellhead for the three reservoir models. See text for explanation.

Figure 25. Pressure produced by waste injection into strip reservoir $7.5 \mathrm{~km}$ wide with same transmissivity as infinite reservoir.

Figure 26. Pressure produced by waste injection into strip reservoir $1 \mathrm{~km}$ wide. 
Figure 27. Spatial pressure distribution for the scenario of ceasing injection after injection at steady rate of 6.7 million liters/month for 15 years, a) infinite reservoir, b) infinite strip reservoir with width of $7.5 \mathrm{~km}, \mathrm{c}$ ) infinite strip reservoir with width of $1 \mathrm{~km}$.

Figure 28. Pressure at well head for the scenarios of ceasing injection after 15 years.

Figure 29. a) Distribution of Silurian salt [from Dunrud and Nevins, 1981] and b) major injection wells, solution mines and historical earthquakes in northeastern Ohio. Filled circles are major injection wells for disposal or solution mining.

Figure 30. Side and front panel view of the General Earthquake Observation System (GEOS) together with a WWVB antenna and two sets of three-component sensors commonly used to provide more than $180 \mathrm{~dB}$ of linear, dynamic range. Full capability to reconfigure system in the field is facilitated by simple operator response to English language prompts via keyboard.

Figure 31. Unit-impulse response of GEOS recorder, spectra for typical earth noise, and complete system response with two types of sensors (force-balance accelerometer and velocity transducer).

Figure 32. Locations of sites occupied by GEOS recorders and location of mainshock on January 31, 1986 (J. Dewey, pers. comm., 1986). Major highways, city and community boundaries, and lake boundaries also are shown.

Figure 33. Acceleration, velocity and displacement time histories obtained at foundation of reactor building for the mainshock for a) vertical b) north-south and c) eastwest components [Kinemetrics/Systems, 1986].

Figure 34. Acceleration, velocity and displacement time histories obtained on the annulus of the containment vessel for the main shock for a) vertical b) north-south and c) east-west components [Kinemetrics/Systems, 1986].

Figure 35. Relative velocity response and Fourier spectra for mainshock as recorded at foundation of reactor building a) vertical, b) north-south and c) east-west component [Kinemetrics/Systems, 1986]. 
Figure 36. Relative velocity response and Fourier spectra for mainshock as recorded on annulus of containment vessel a) vertical, b) north-south and c) east-west component [Kinemetrics/Systems, 1986].

Figure 37. Equiscaled plots of ground velocity aas recorded at station GS01 (traces 1, 2, 3 ) and at station GS02 (traces 4, 5, 6) for aftershock on February 3 at 19:47 (Magnitude 2.2). Comparison of amplitudes shows that vertical amplitudes of velocity are up to four times larger at station GS01, which is about $8 \mathrm{~km}$ more distant from the hypocenter.

Figure 38. Equiscaled plots of ground velocity as recorded at station GS01 (traces 1, 2, 3 ) and at station GS02 (traces 4, 5, 6) for aftershock on February 6 at 18:36.

Figure 39. Plot of peak acceleration amplitudes as a function distance observed for aftershock of February 3 19:47 a) with and b) without correction for geometric spreading.

Figure 40. Spectral ratios computed to characterize amplitude response at station GS01 relative to station GS02 $(a, b, c)$ and relative to station GS03 $(d, e, f)$. Spectral ratios shown cover the band from 0.1 to $130 \mathrm{~Hz}$, the frequency band for which the signal-to-noise ratio exceeds 2 . Note that the spectral ratios computed from broadband digital data allow recognition of site response characteristics at frequencies much higher than previously observed with conventional recording equipment!

Figure 41. Spectral ratios of vertical component computed to characterize amplitude response at station GS01 relative to station $\operatorname{GSO2}(a, b, c)$ and relative to station GS03 (d, e, f) as shown in Figure 40 for frequency band 0.1 to $50 \mathrm{~Hz}$. Amplitude response as computed for station GS01 with respect to station GS02 and station GSO3 and for both events (19:47 and 18:36) suggests exaggerated levels of ground motion between 5 and $10 \mathrm{~Hz}$ and near $20 \mathrm{~Hz}$. Smaller, but still significant levels of exaggerated shaking are also apparent for horizontal components. 
DEPARTMENT OF THE INTERIOR

UNITED STATES GEOLOGICAL SUR VEY

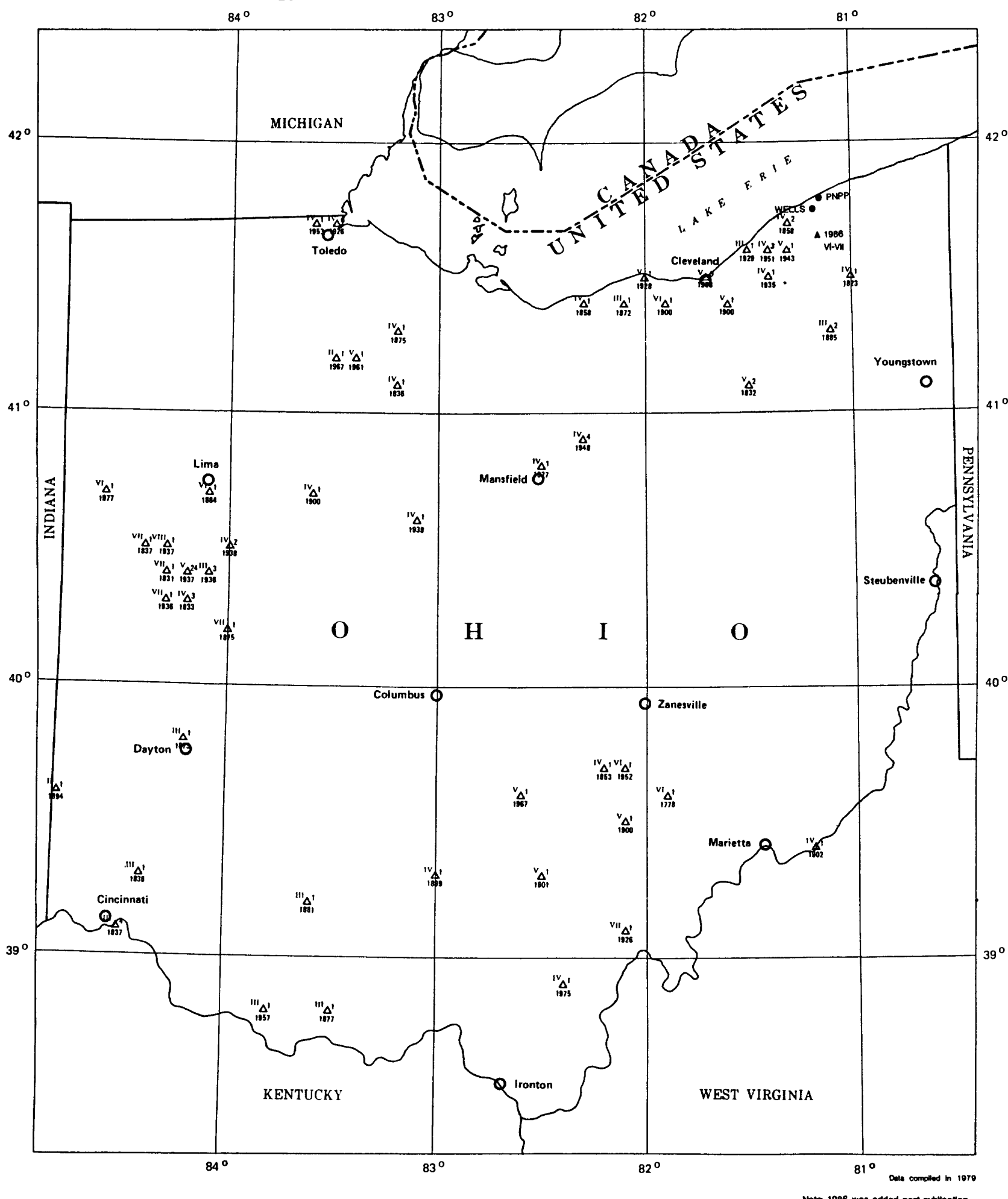

SCALE 11000000

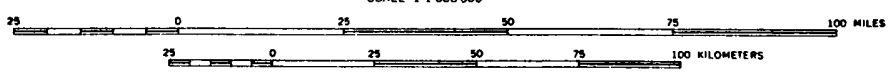

SEISMICITY MAP OF THE STATE OF OHIO

By

C. W. Stover, B. G. Reagor, and S. T. Algermissen

1979

Figure 1 


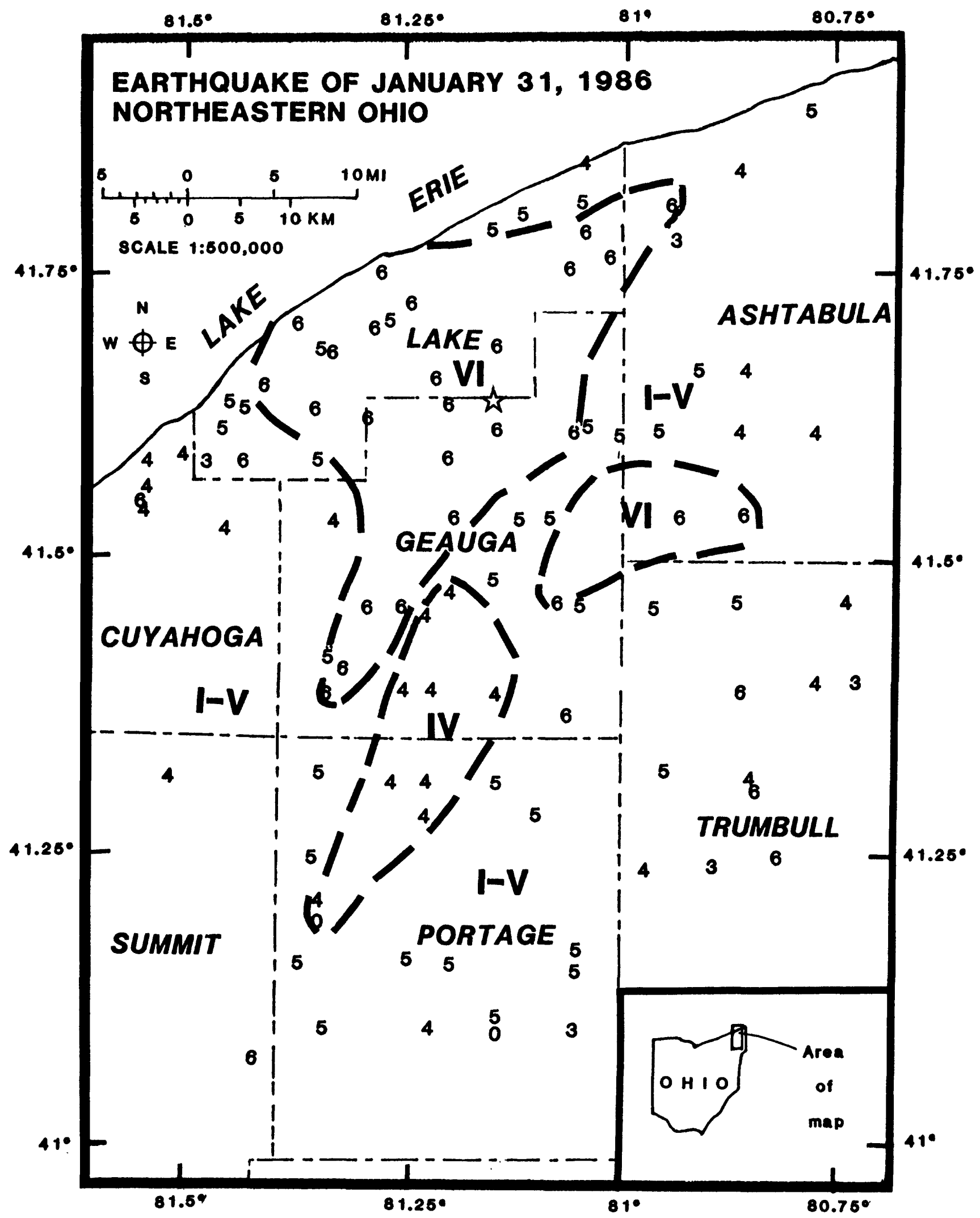

Preliminary interior MM isoseismals for the earthquake of January 31, 1986, northeastern Ohio. Site intensities are shown by Arabic numerals. Isoseismal intensities are denoted by Roman numerals. Star shows the location of the main shock epicenter. The isoseismal lines are shown as dashed because all the data are not yet in. When the data set is complete the lines will be finalized. 


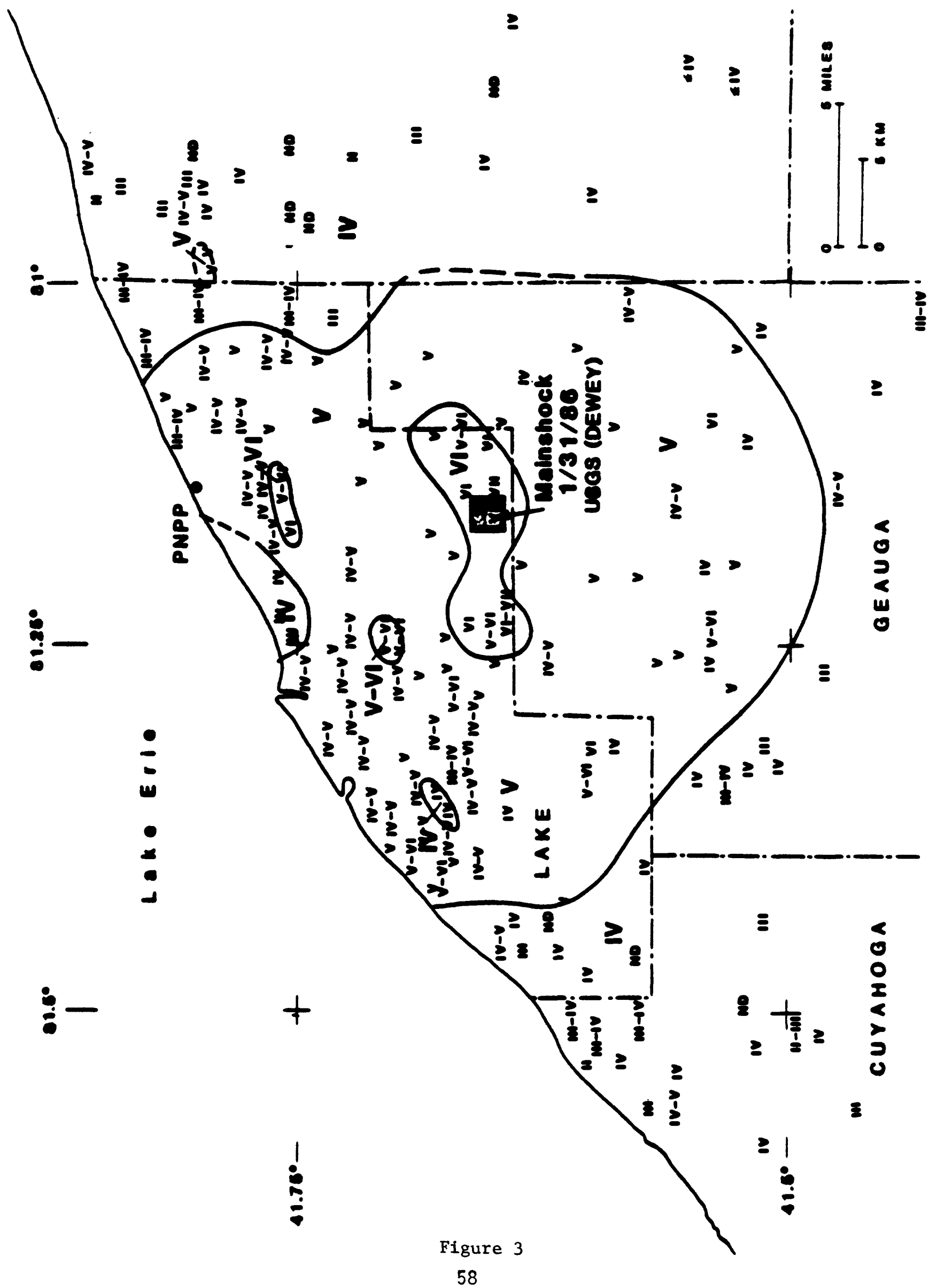




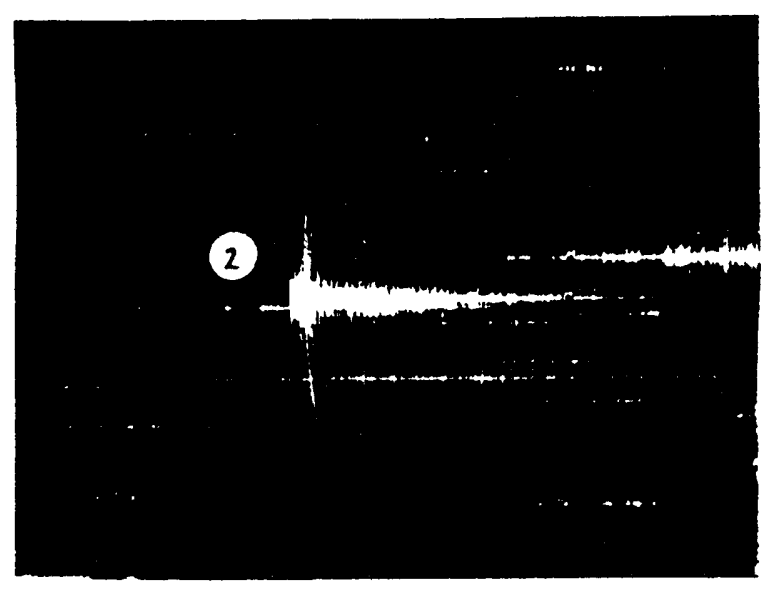

\section{2-3-86 19:47}

HAR

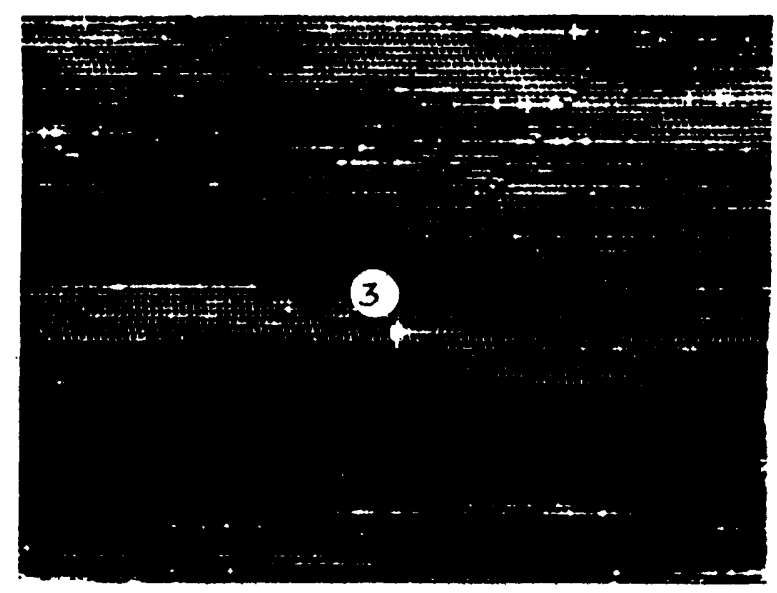

\section{2-5-86 6:34}

HAM
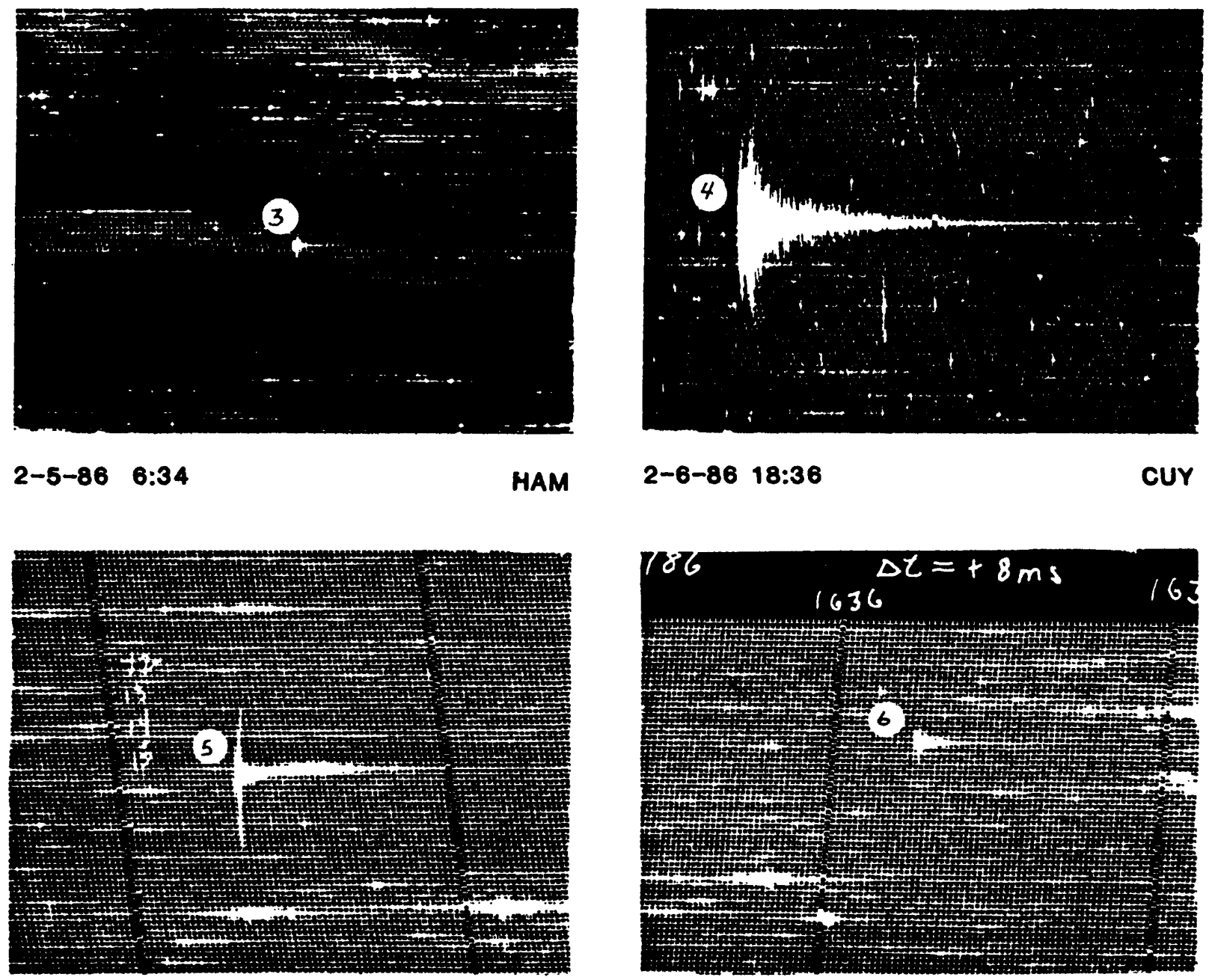

CAL 


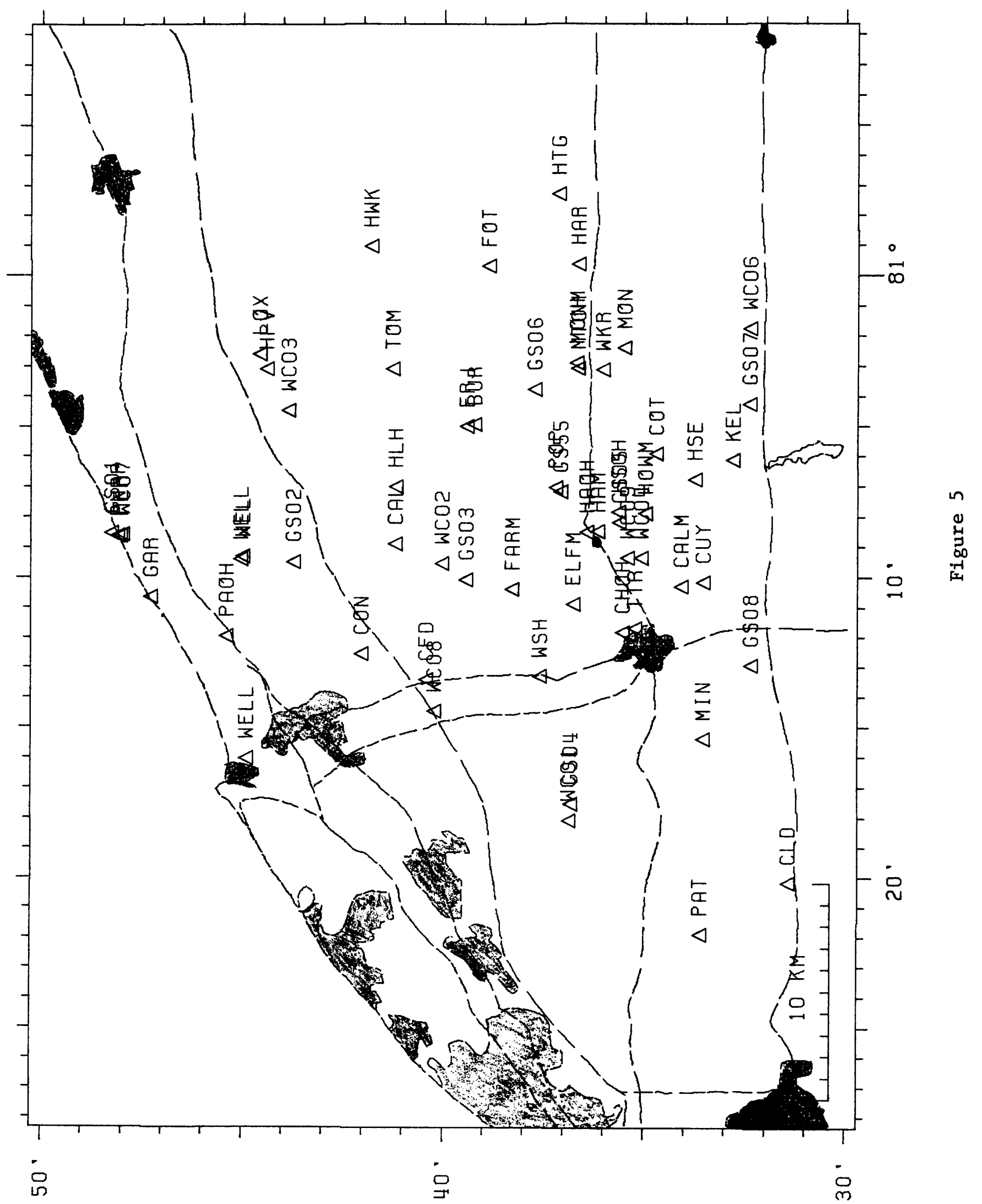




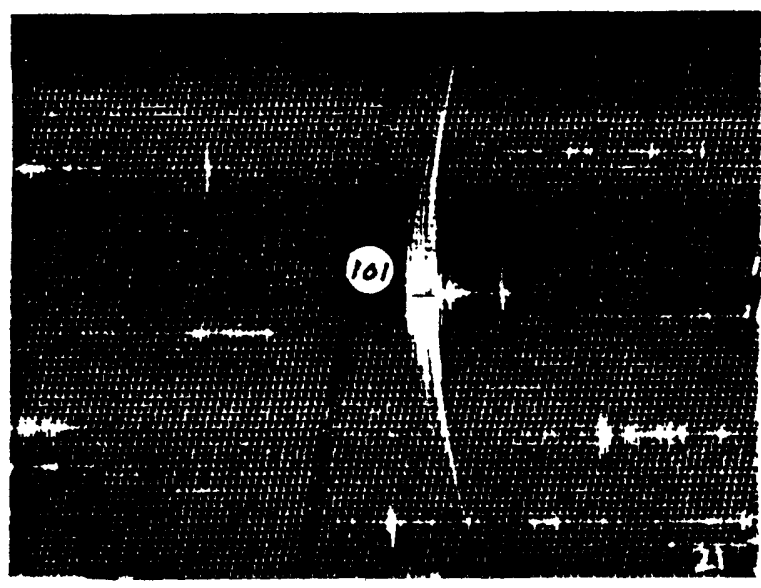

2-5-86 15:39

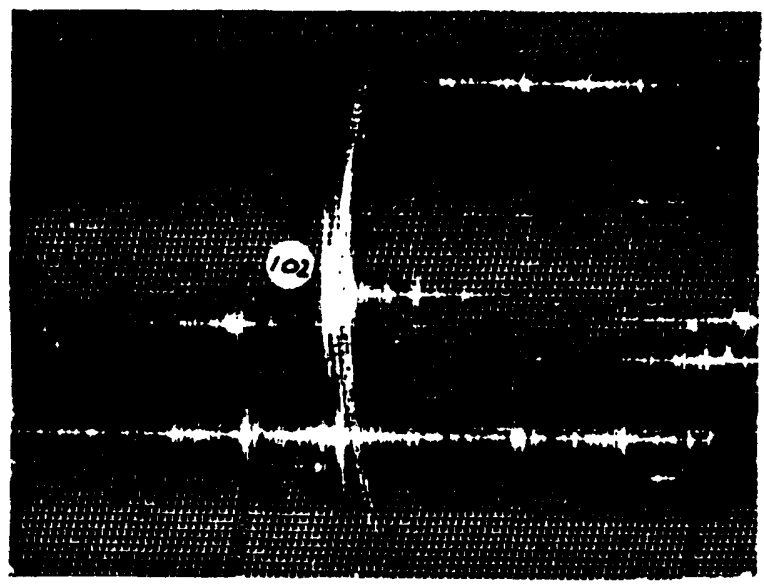

2-5-86 17:57

FOT

Figure 6 


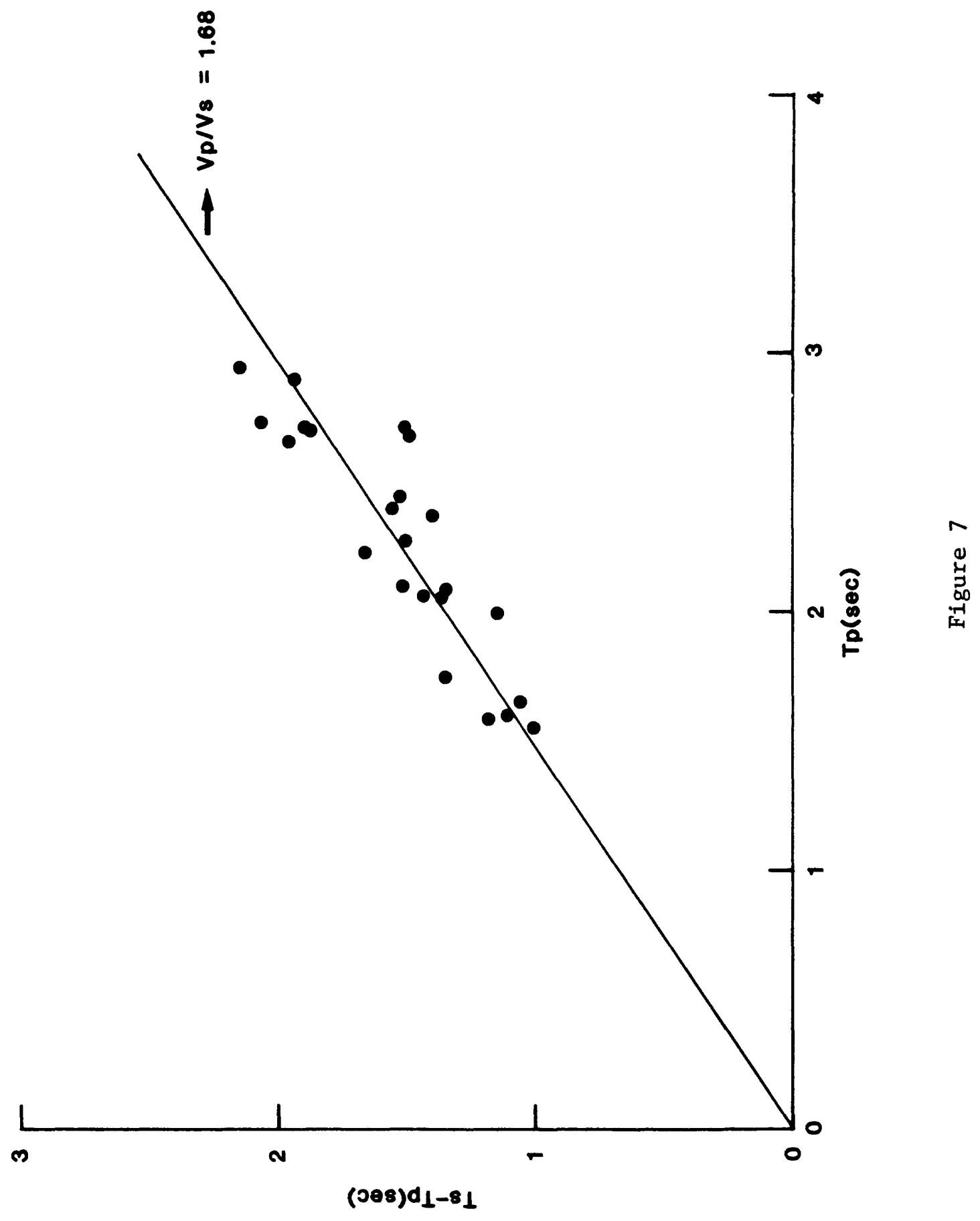




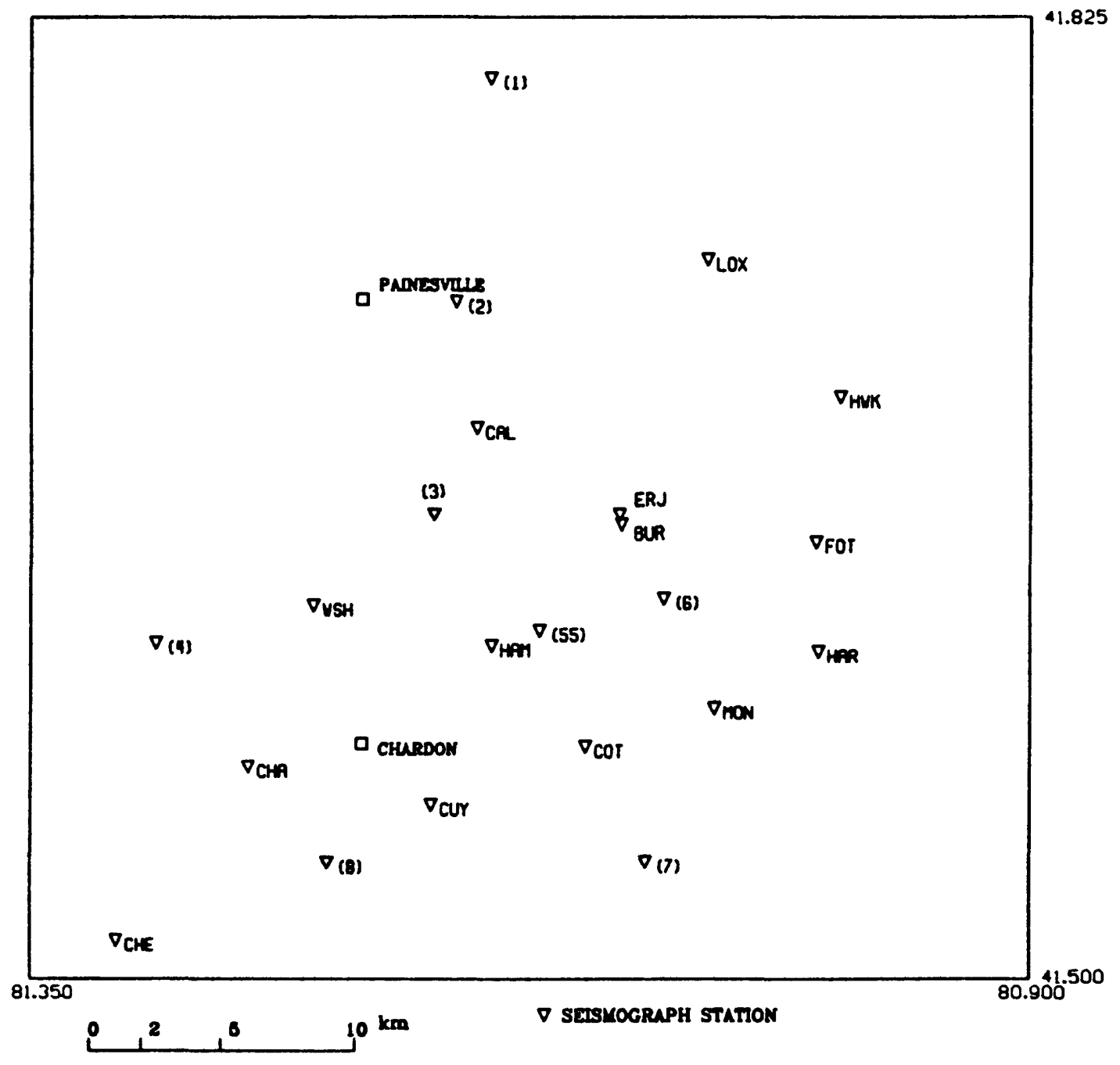

Figure 8 


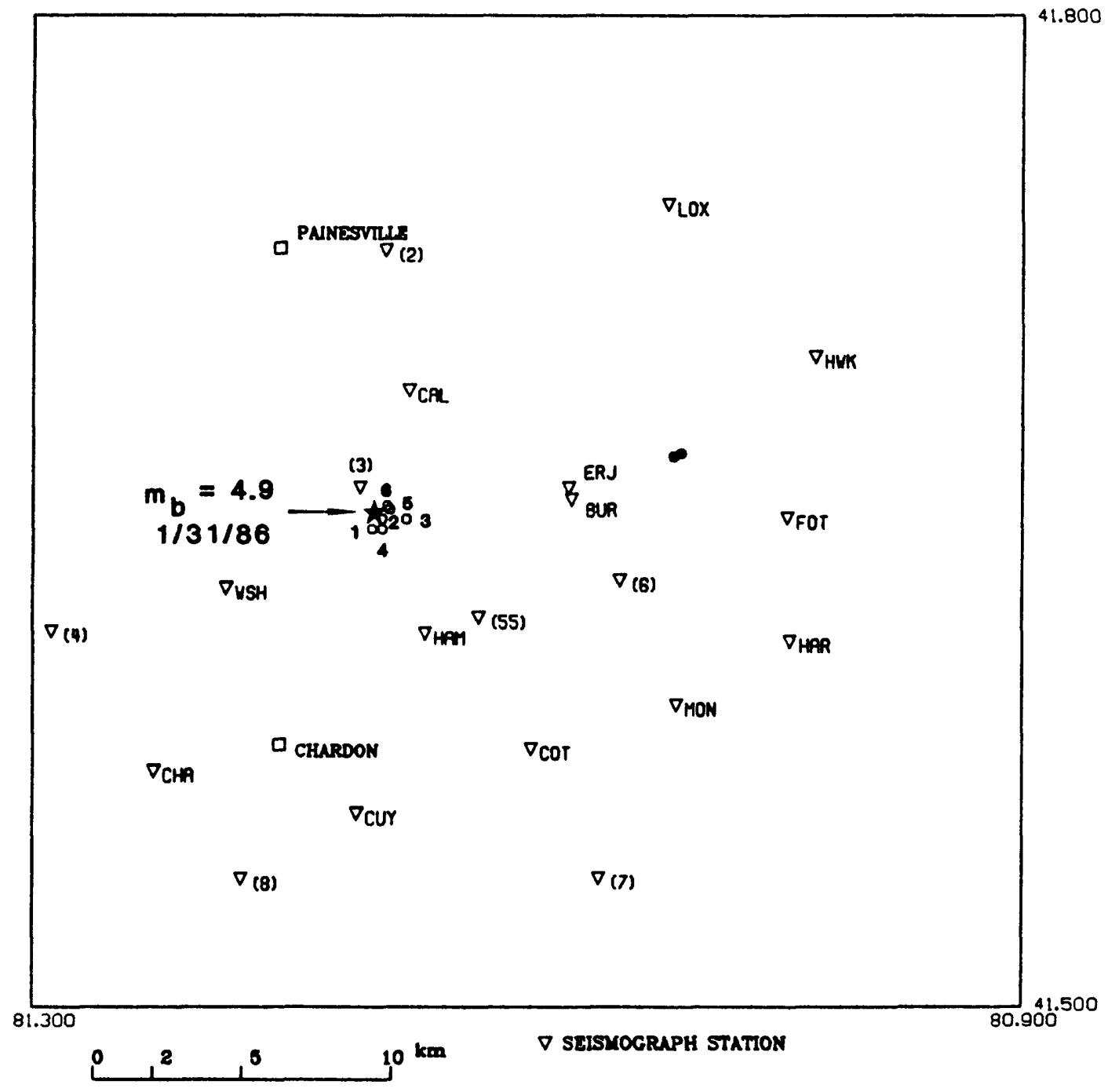

Figure 9 


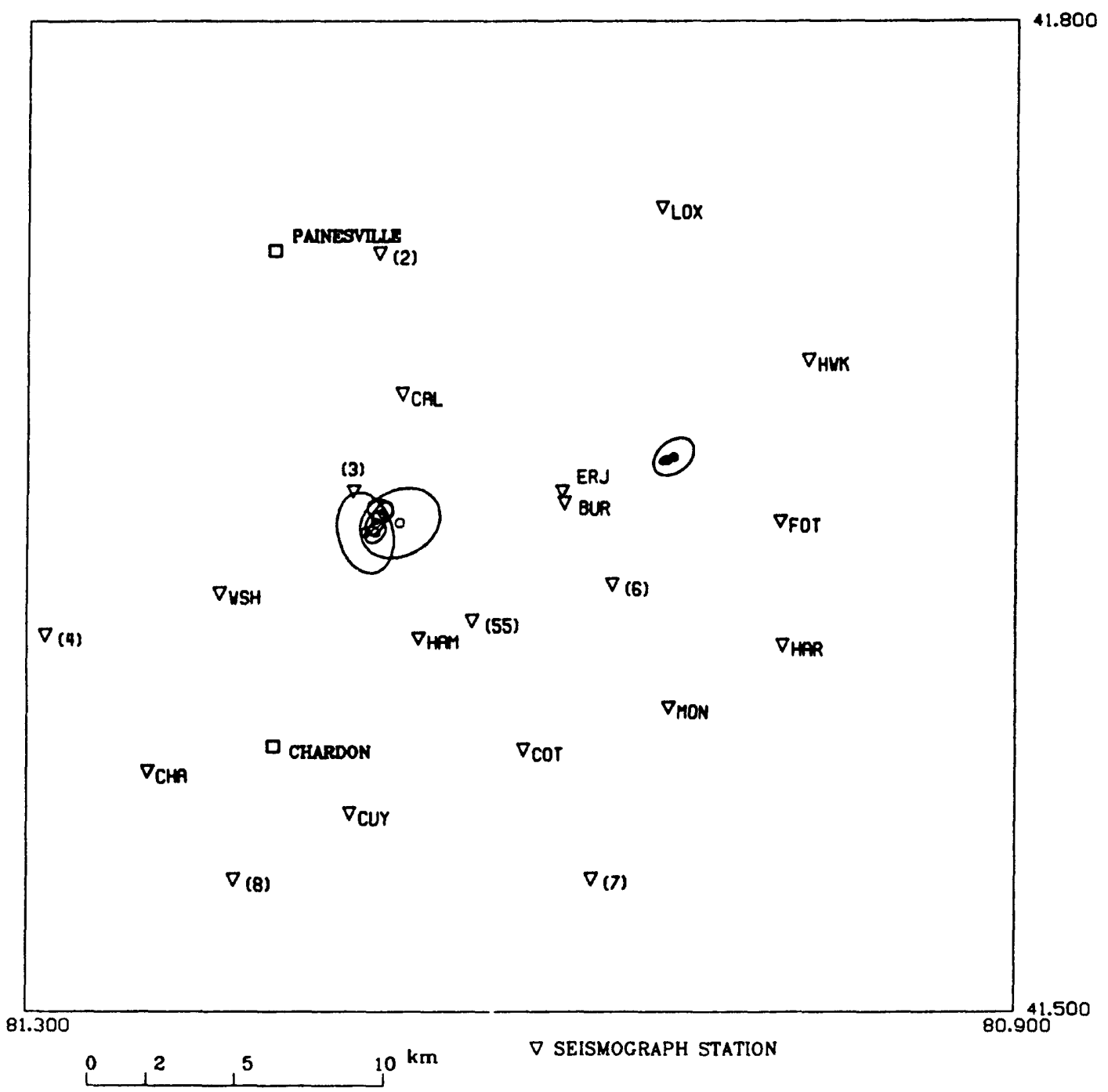

Figure 10 

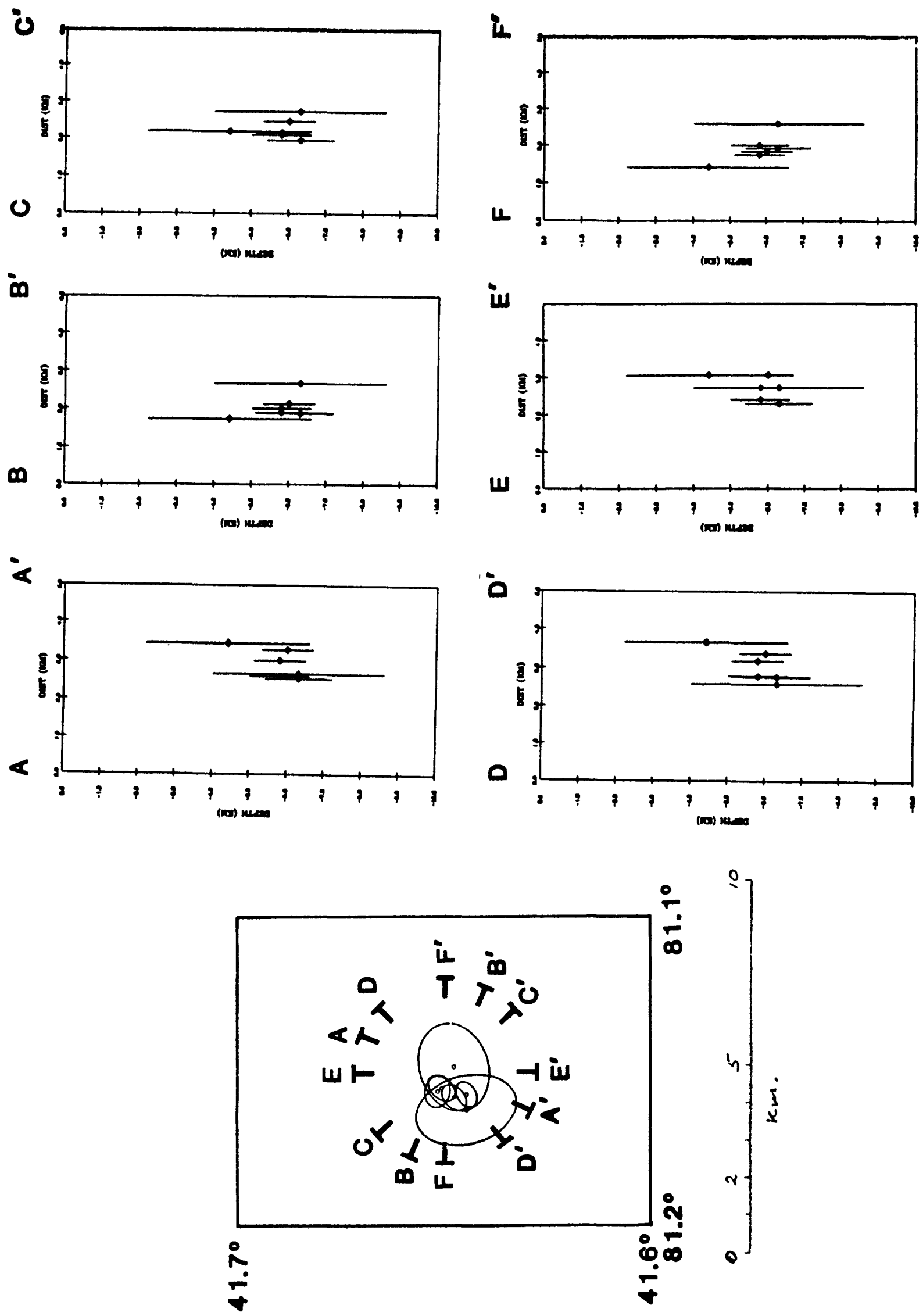

Figure 11 


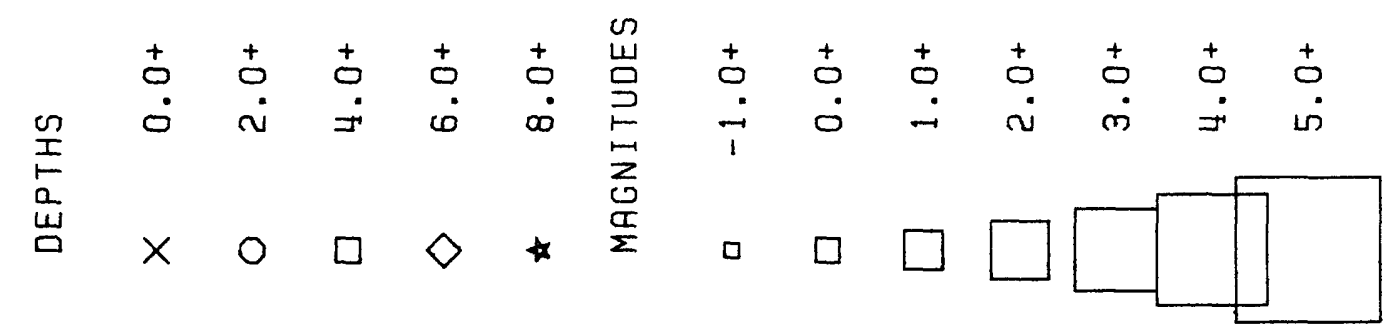

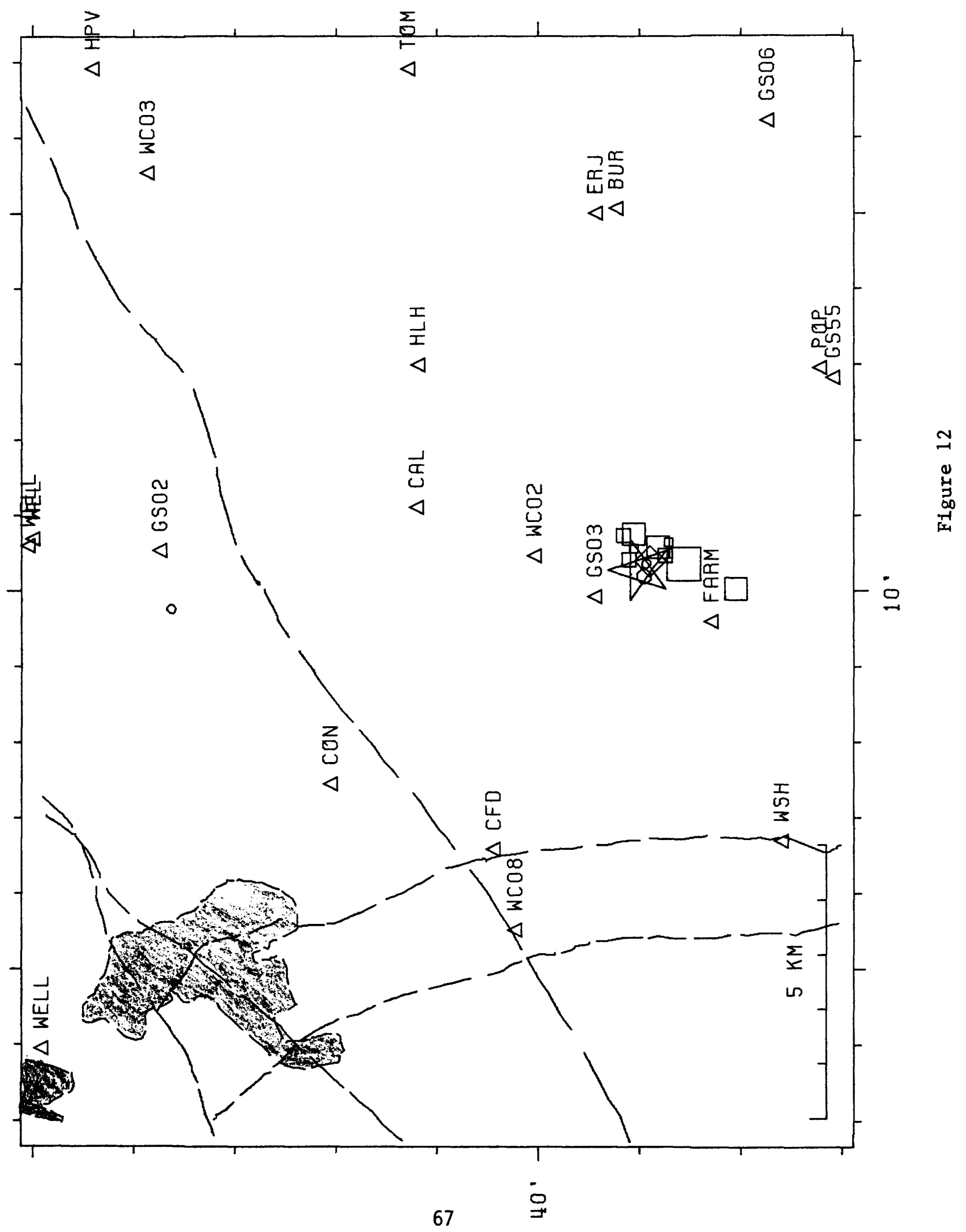


68
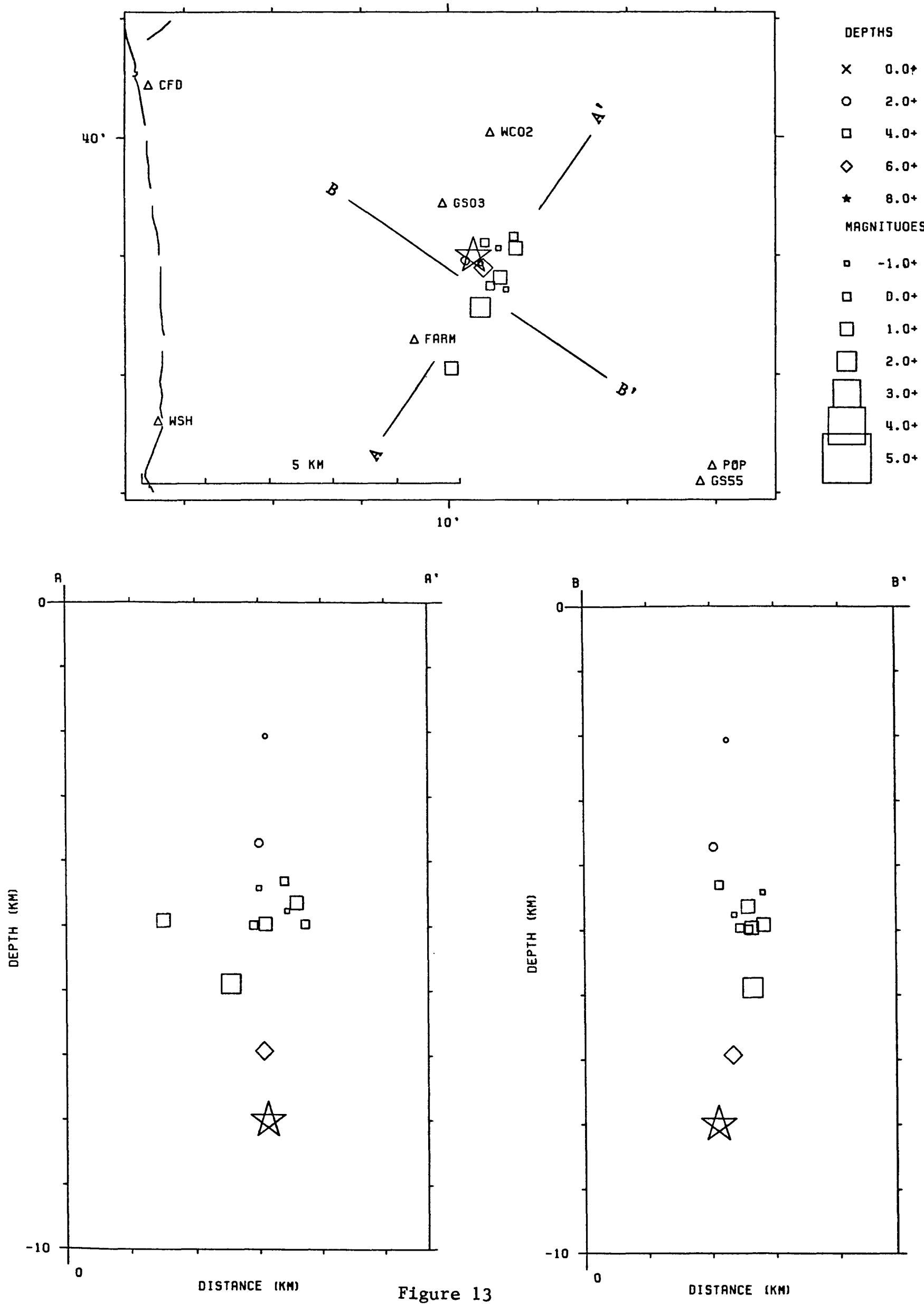

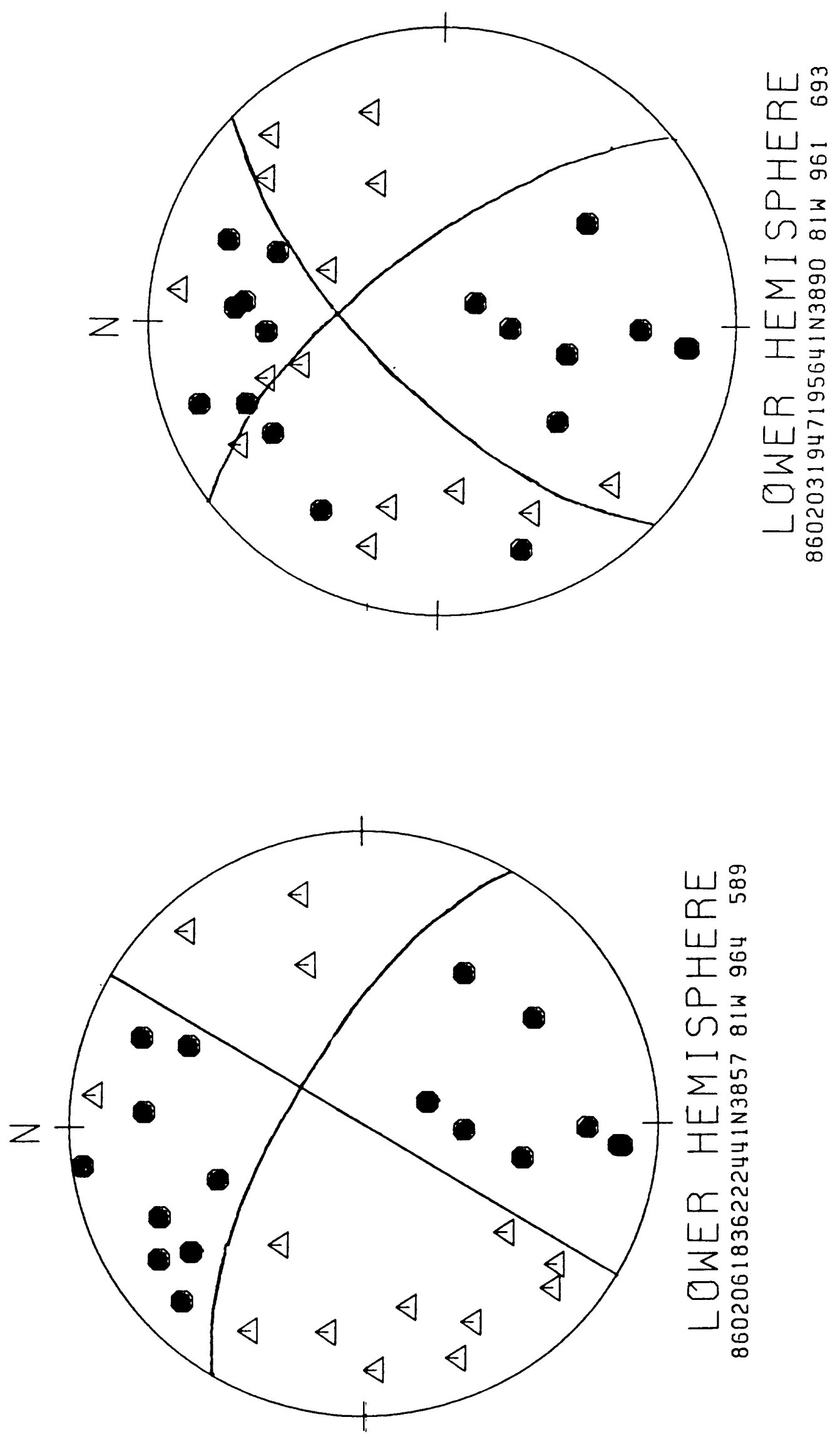

$\underset{-1}{ \pm}$ 

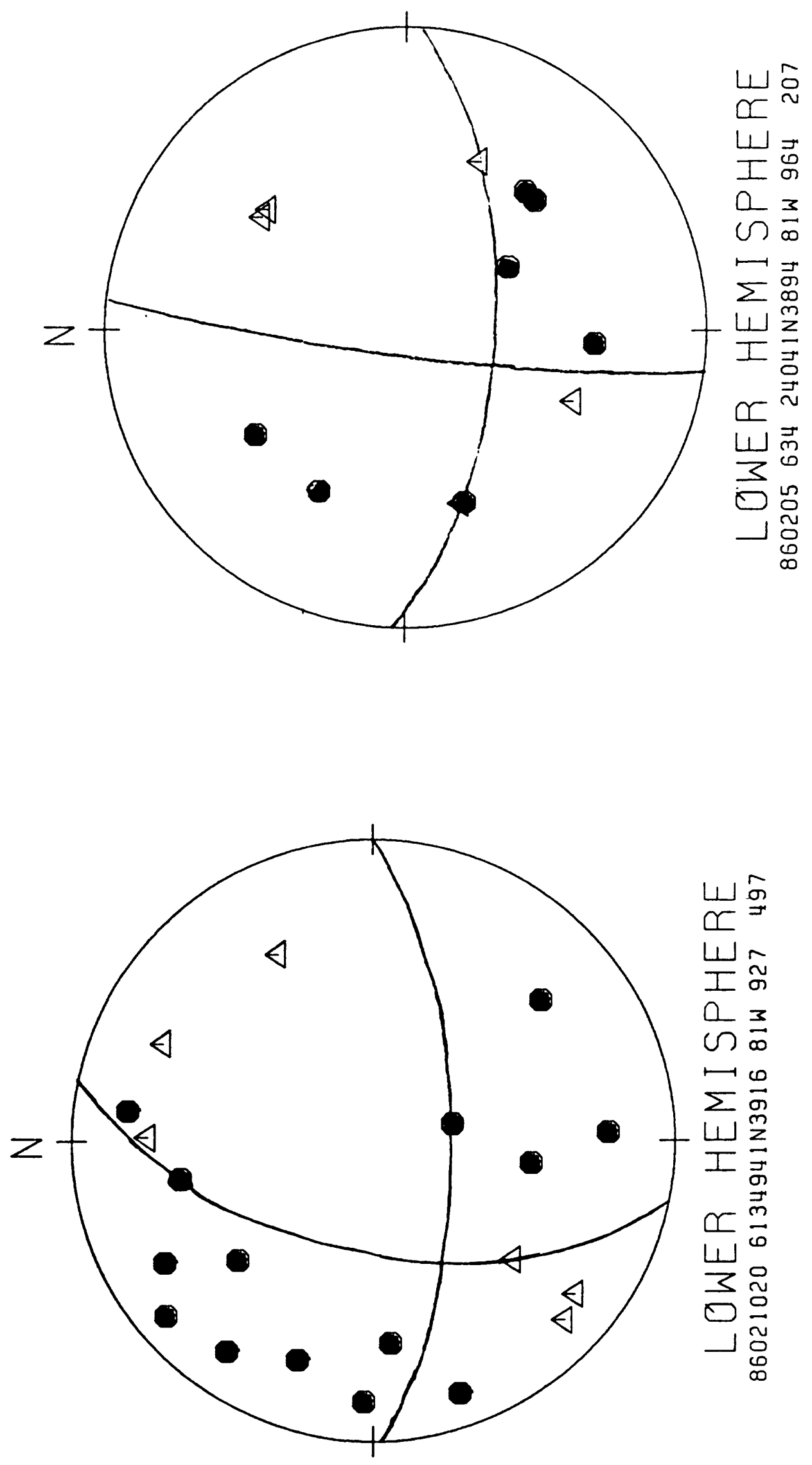

$\underset{7}{n}$ 


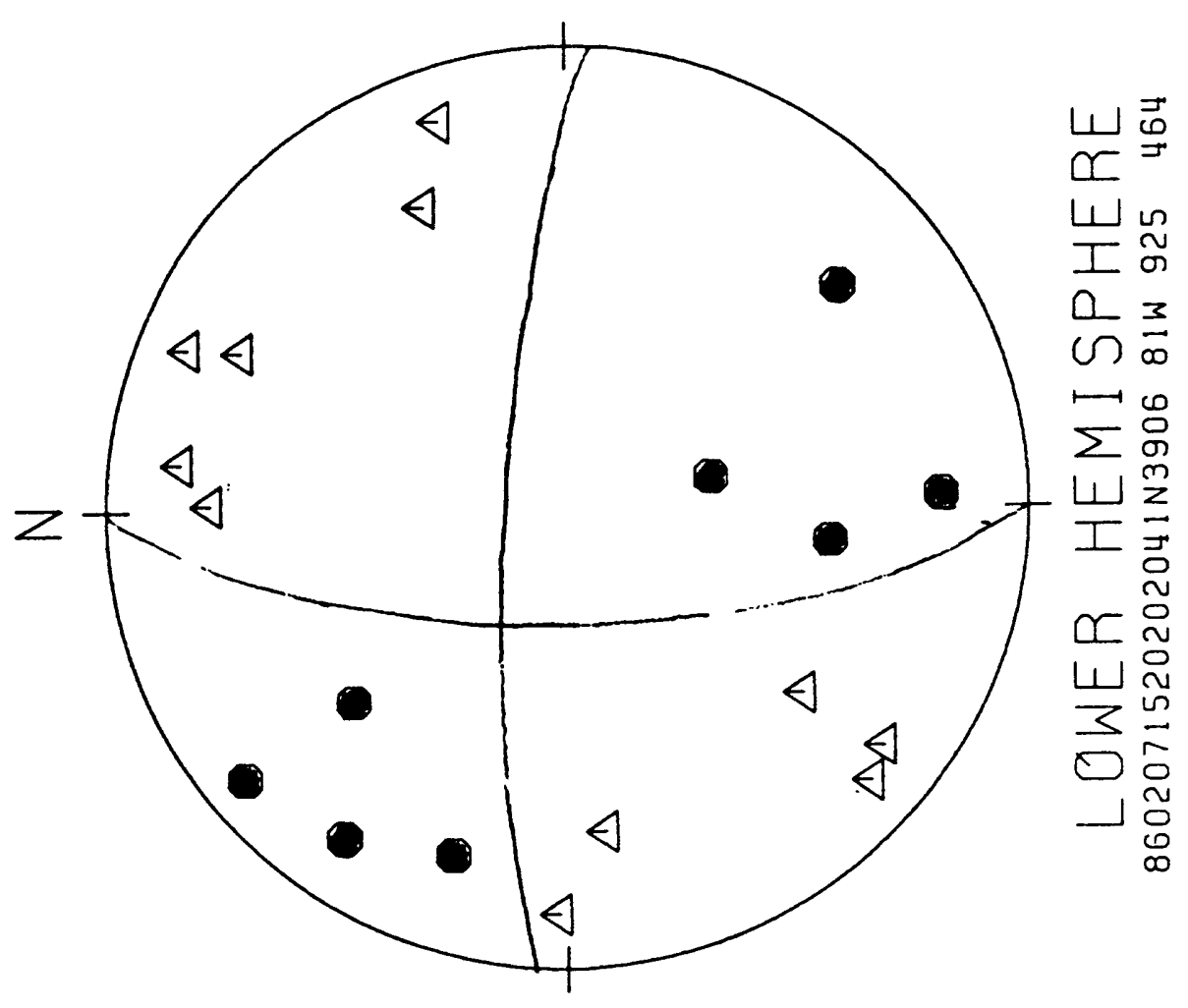

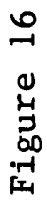

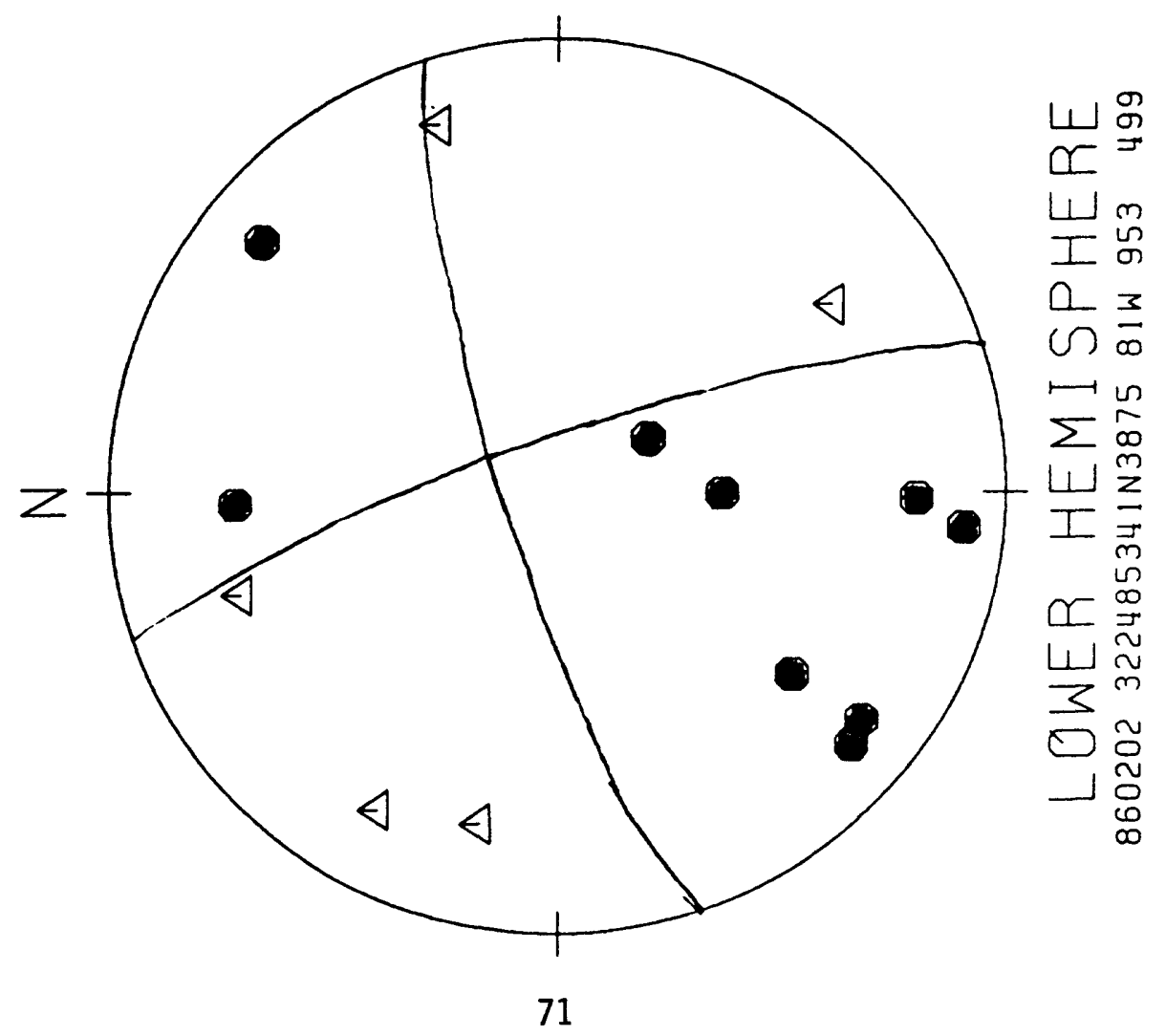




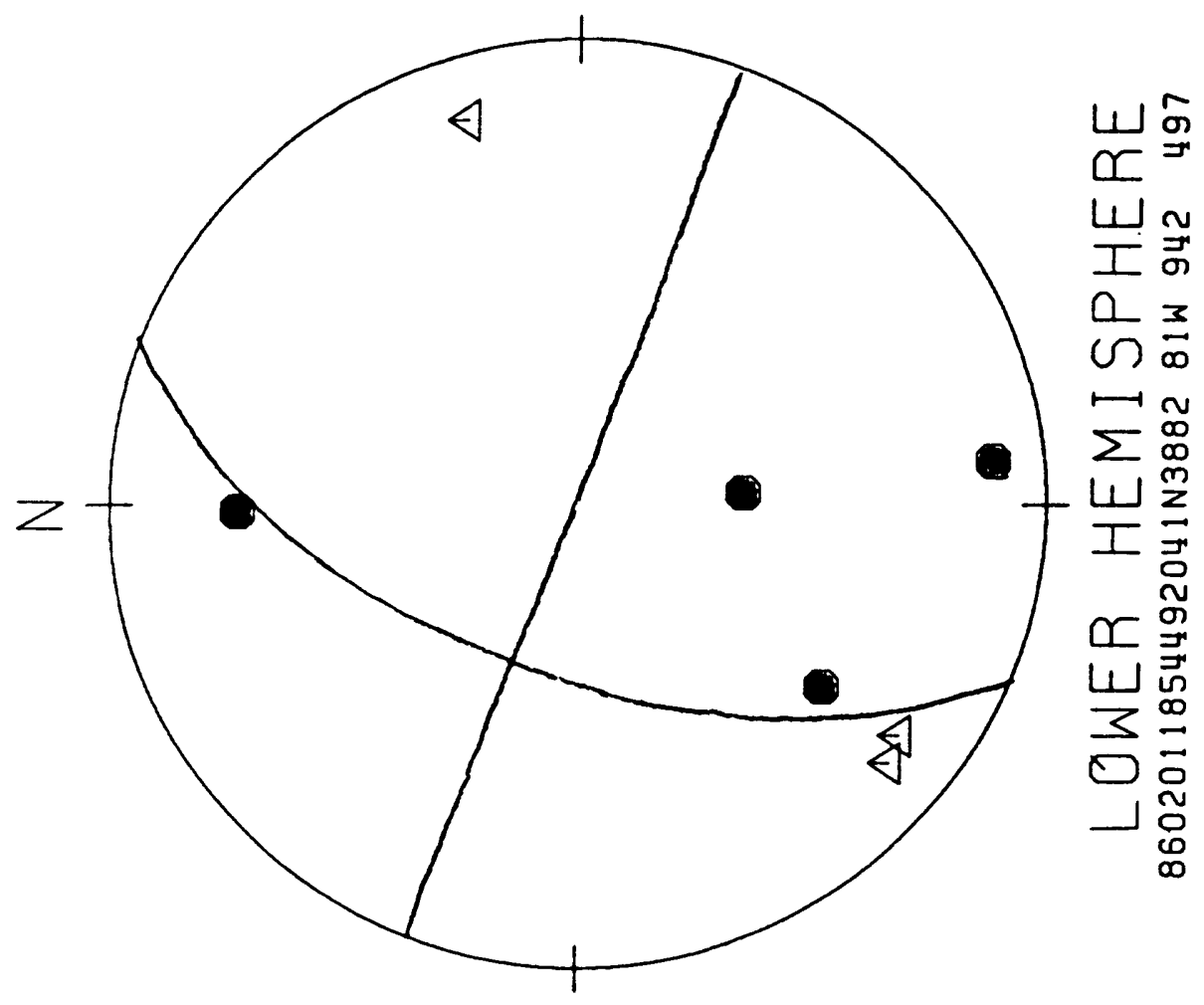

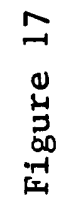

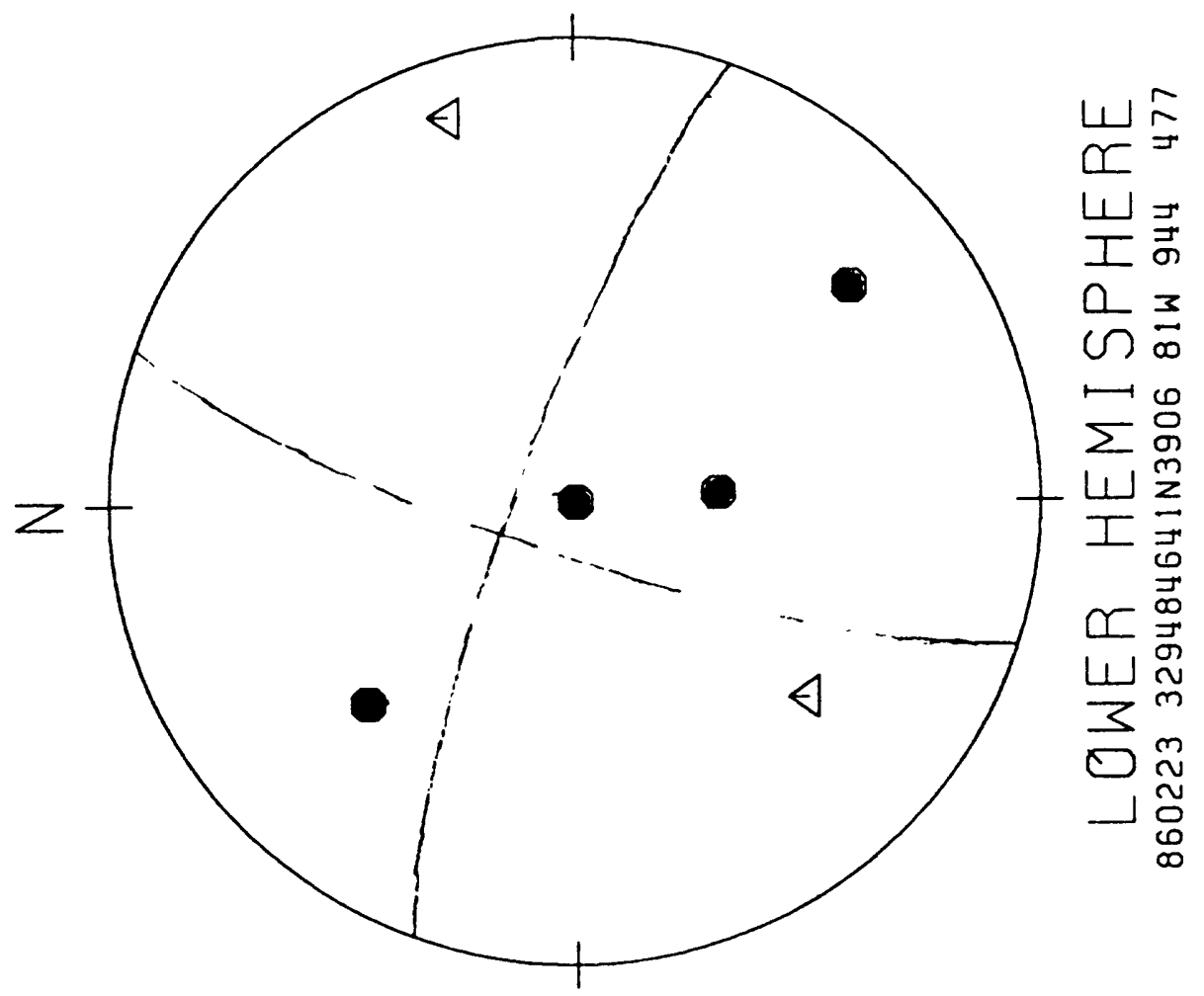




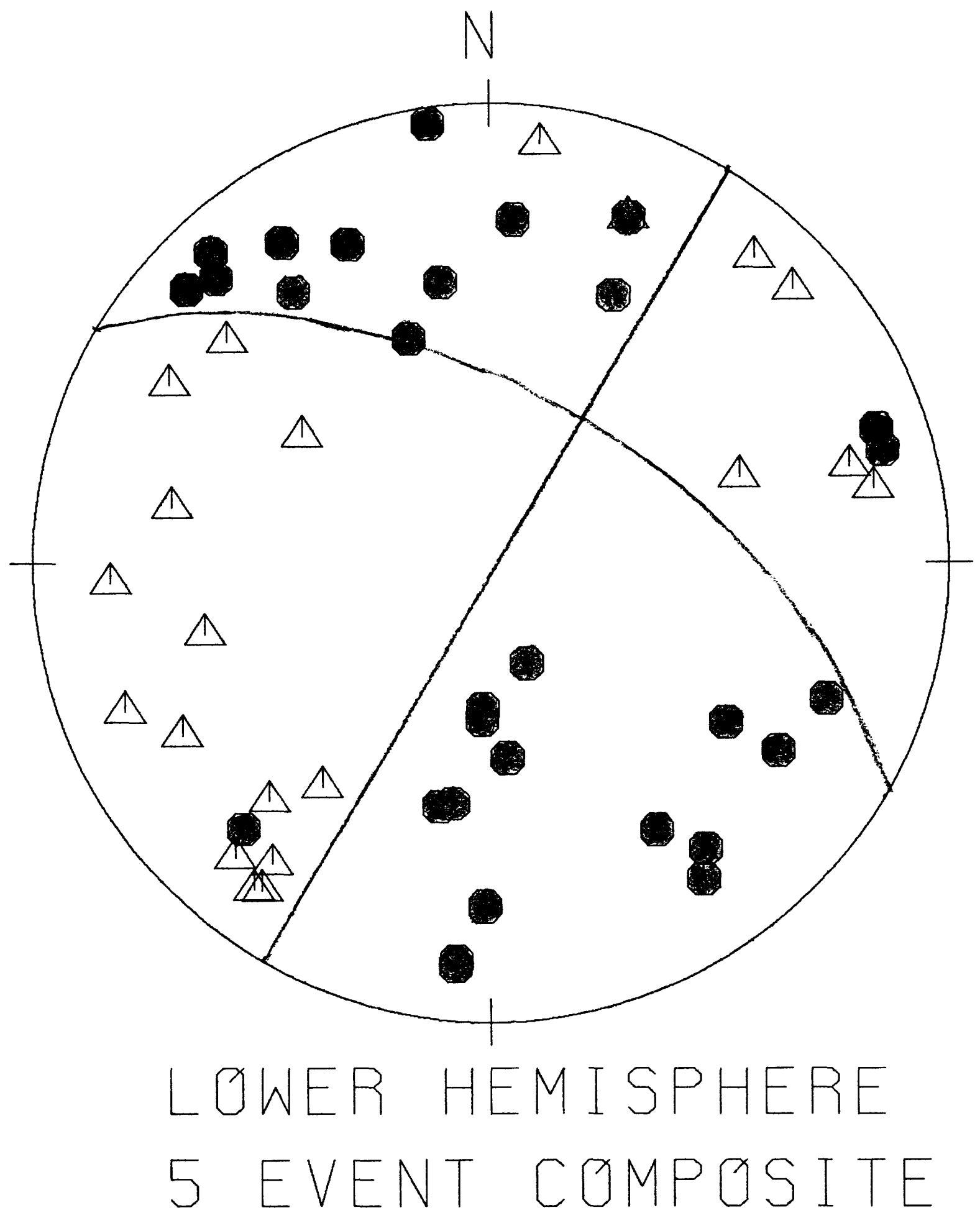

Figure 18 
CALHIO\# 1

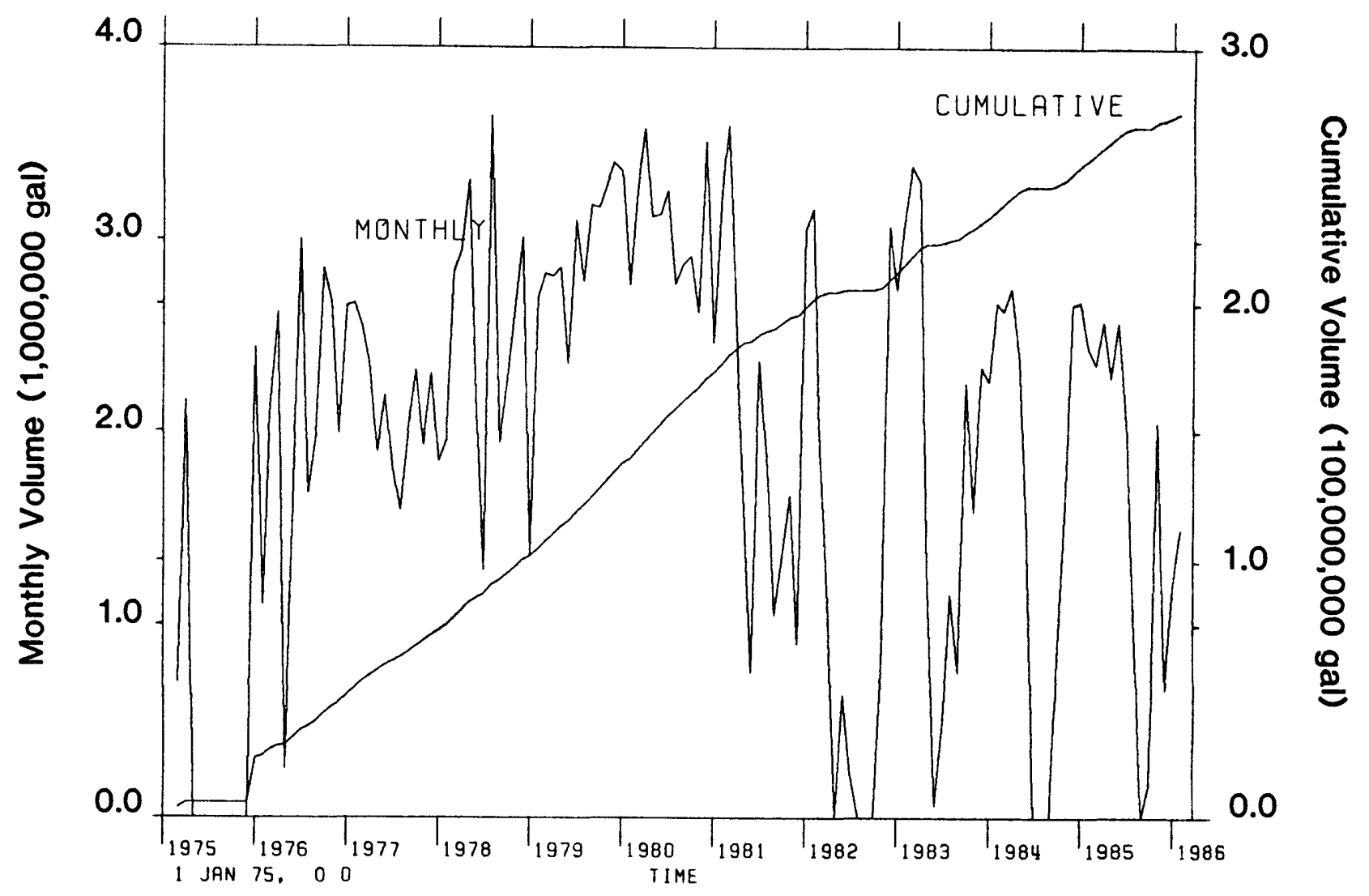

CALHIO\#2

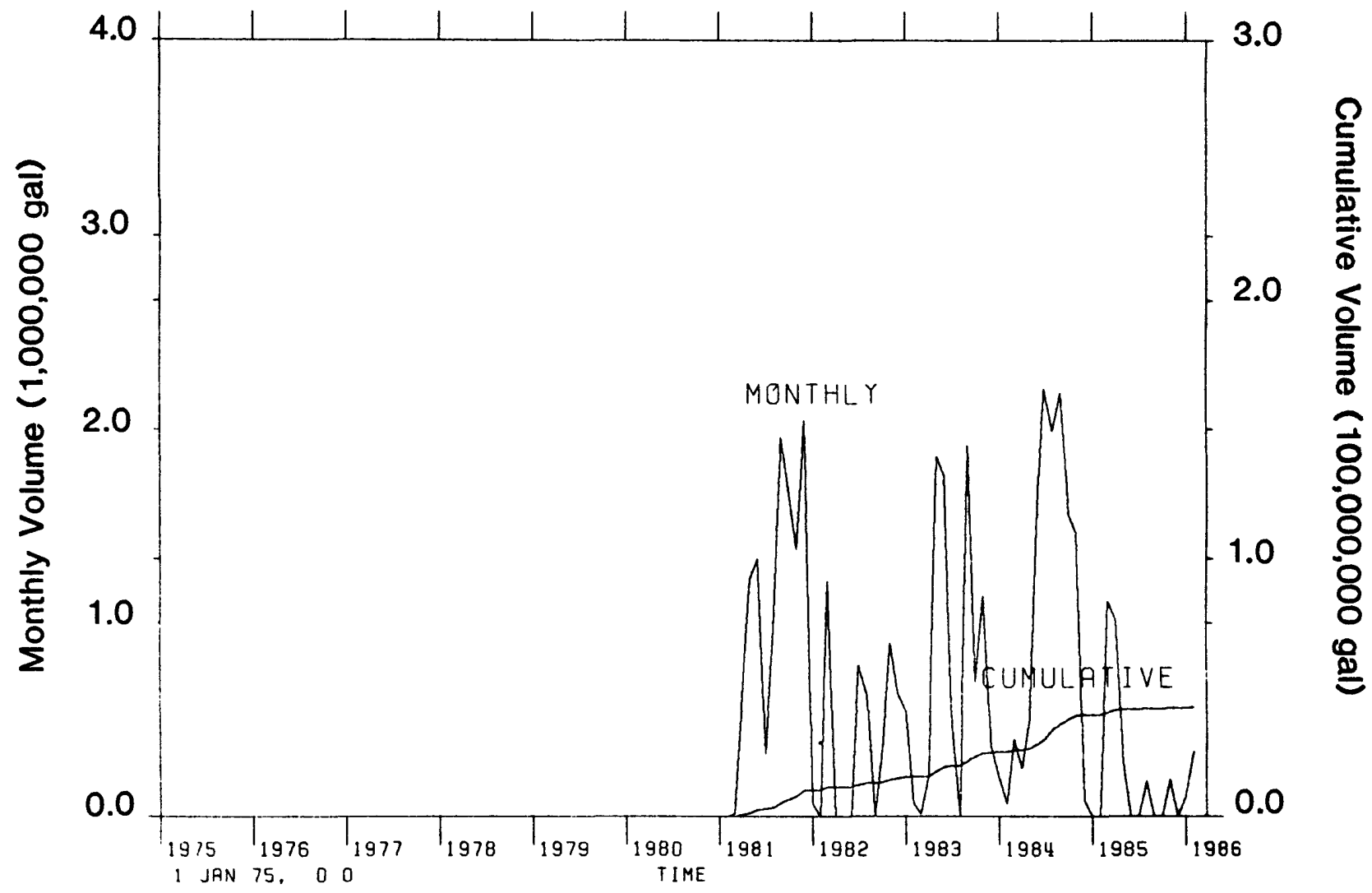




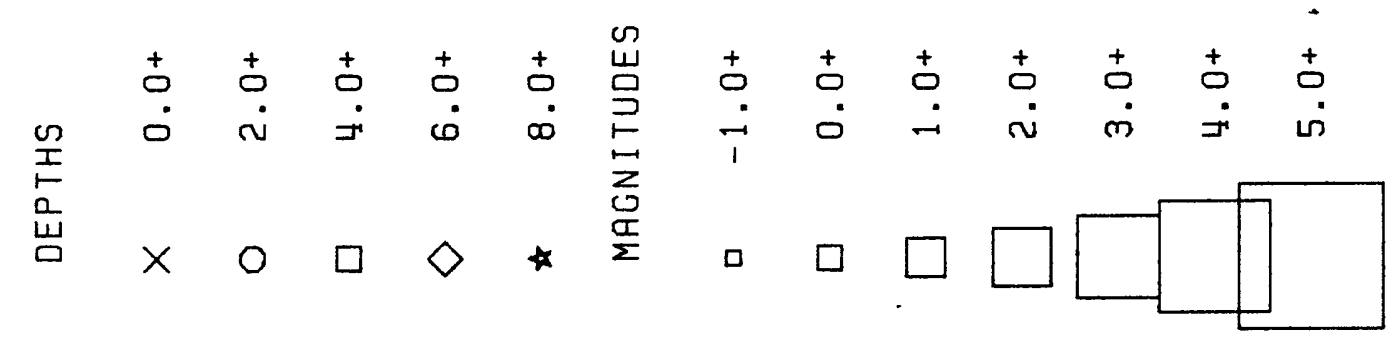

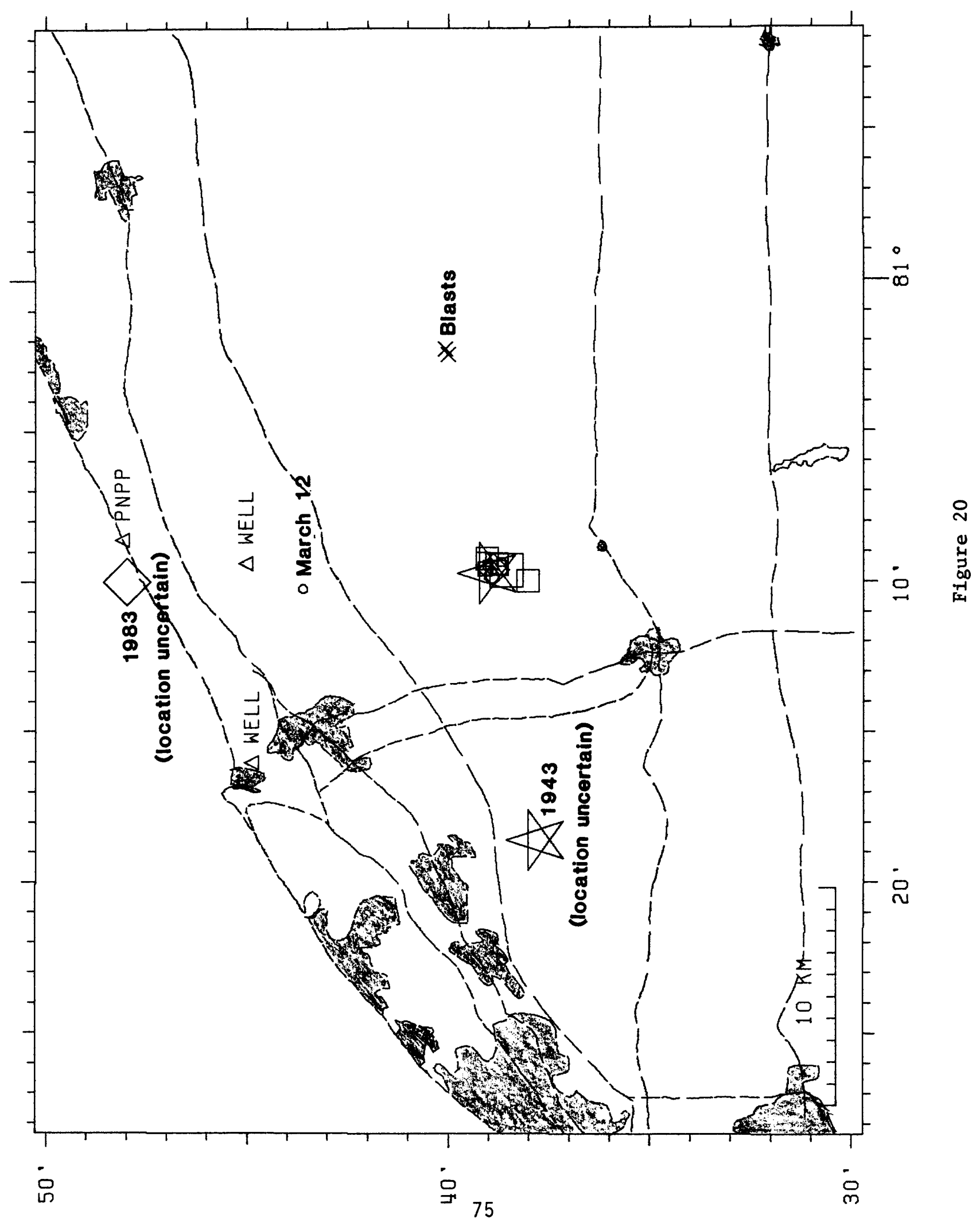




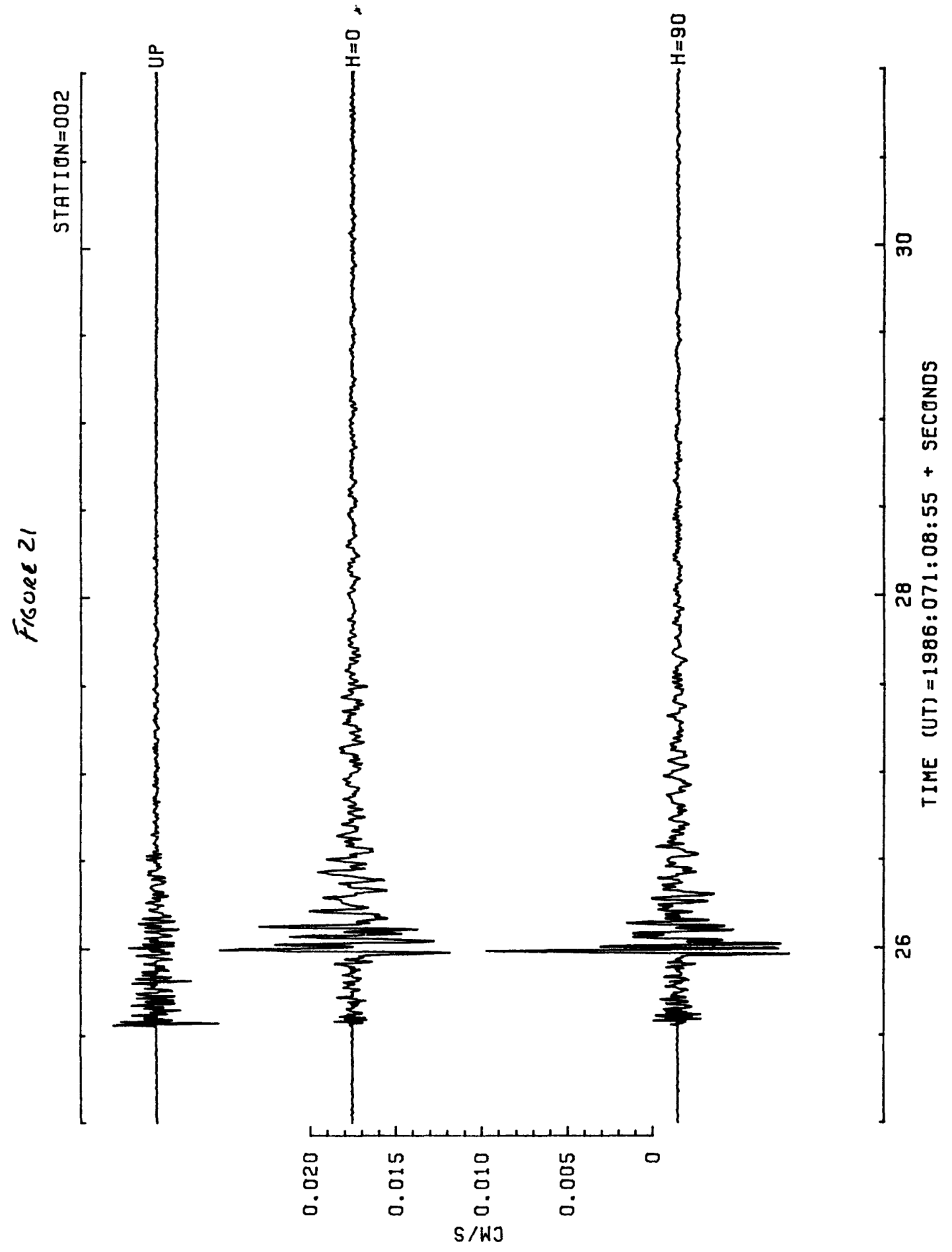

Figure 21 


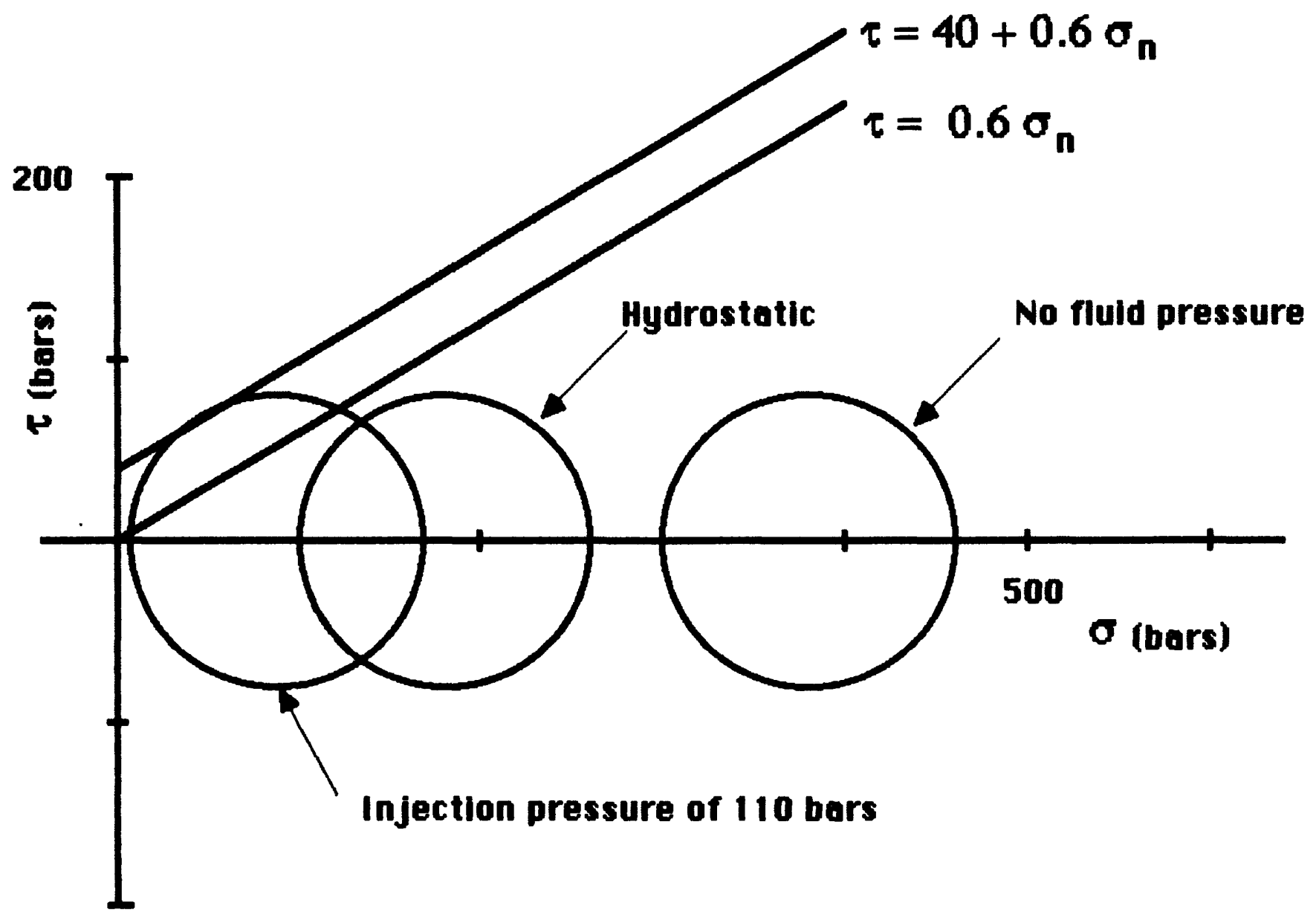

Figure $22 \mathrm{~A}$ 


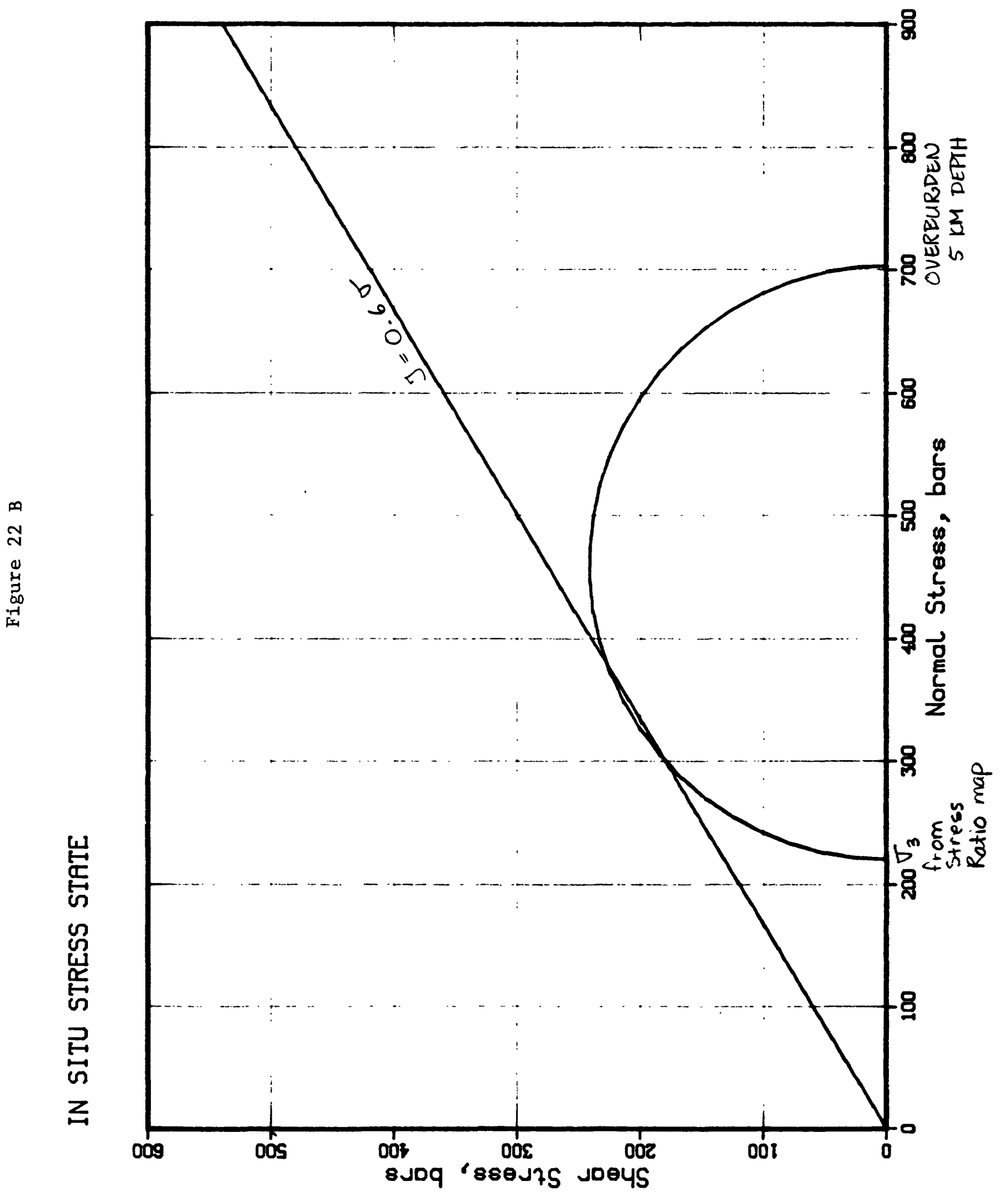




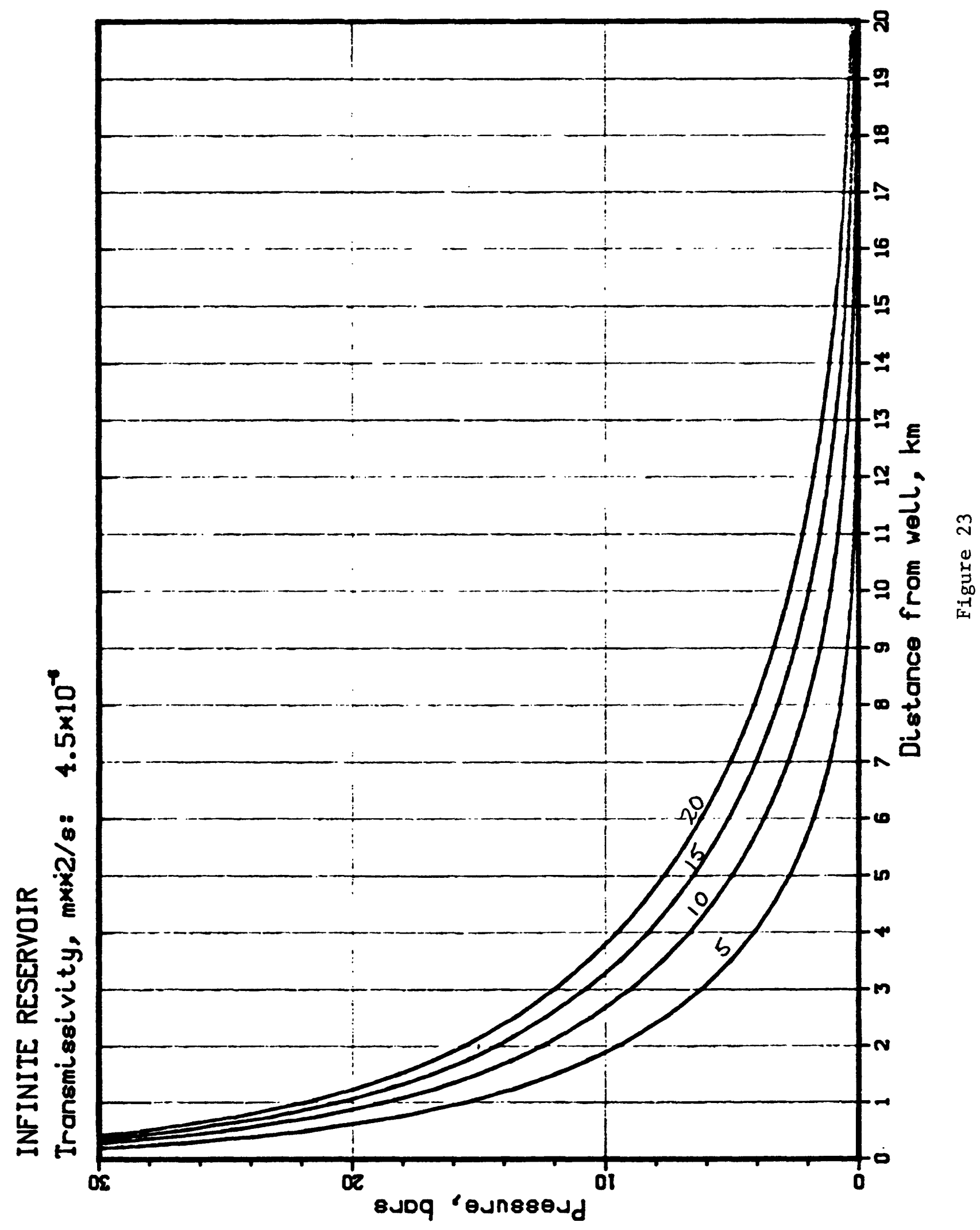




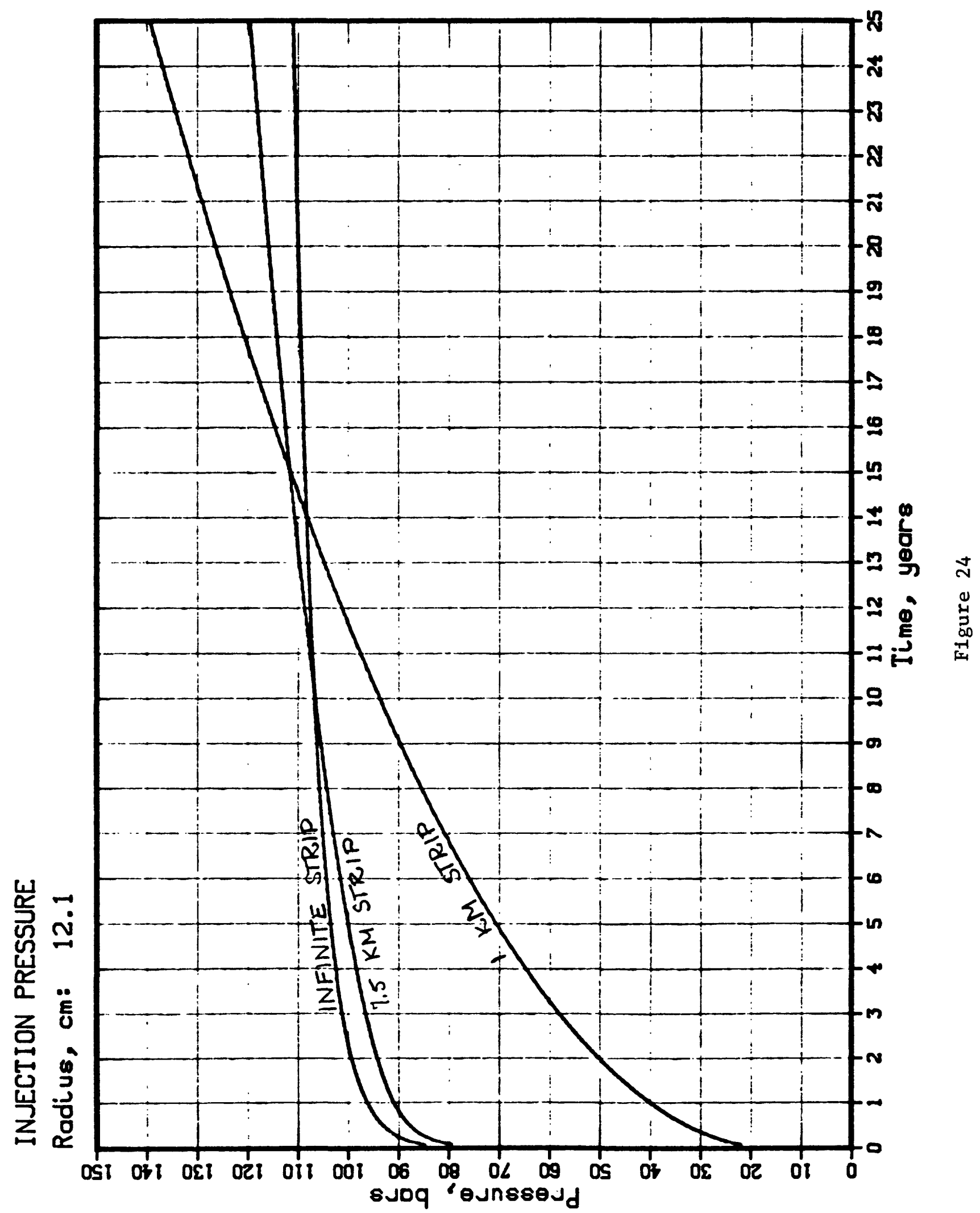




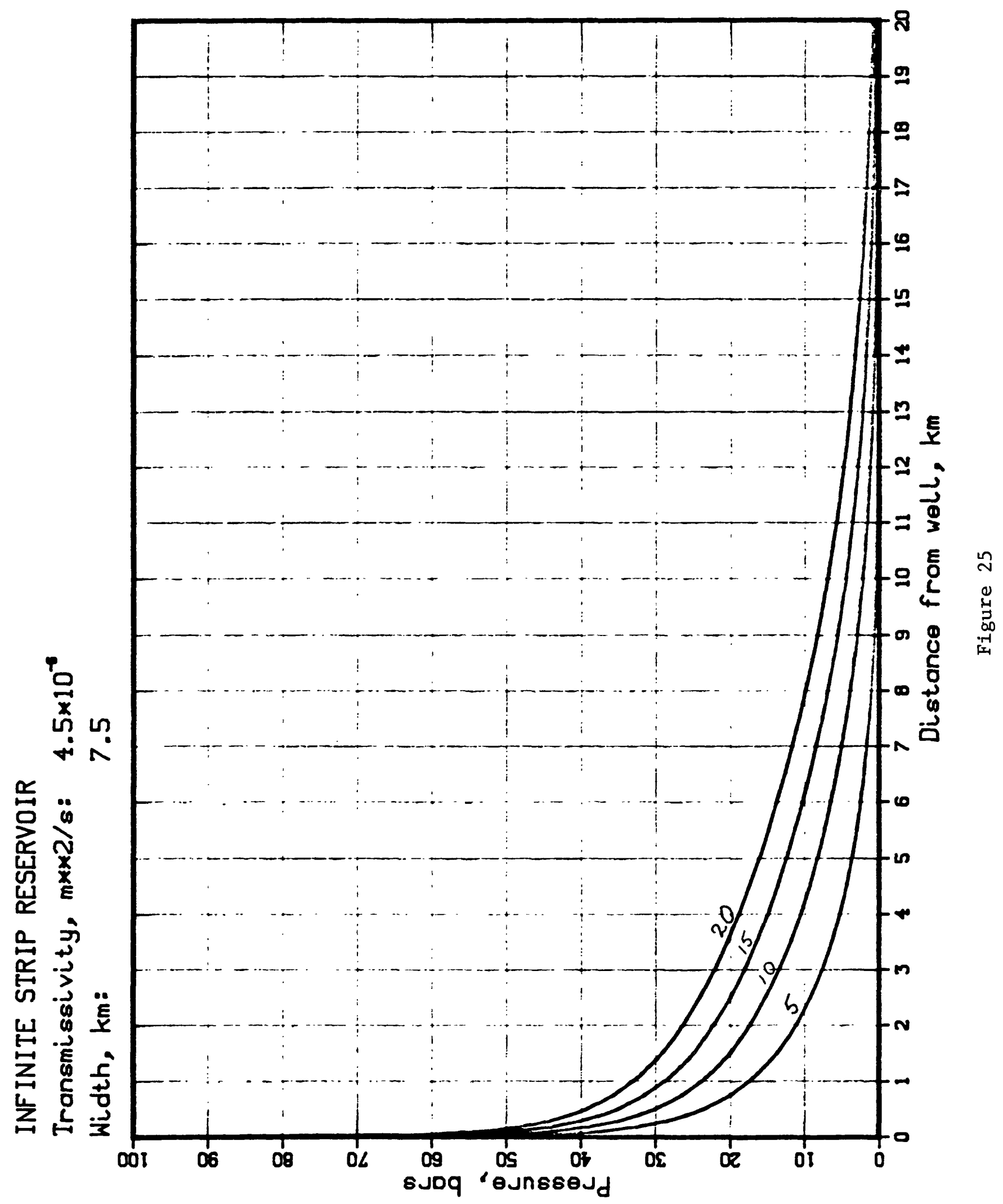




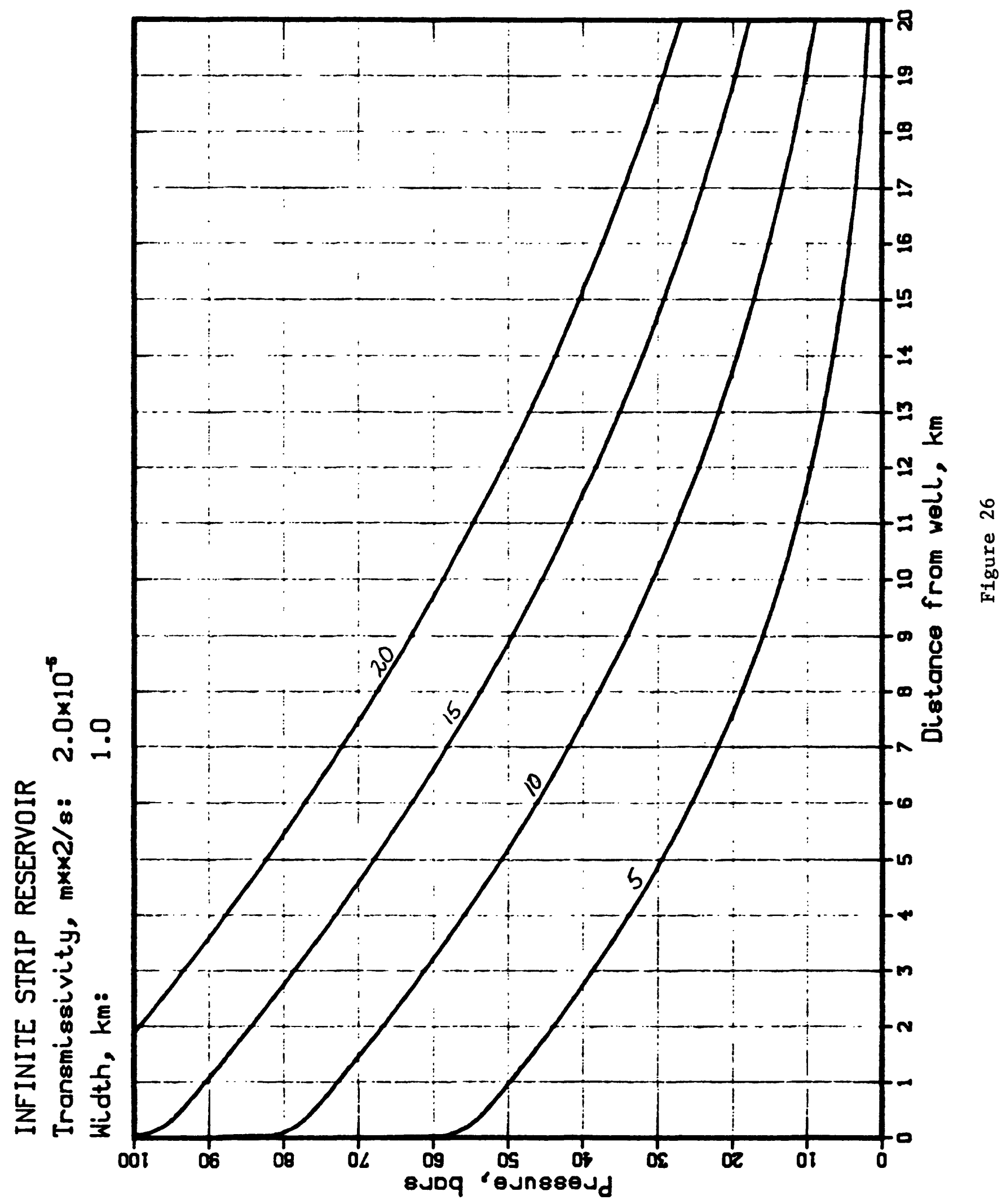




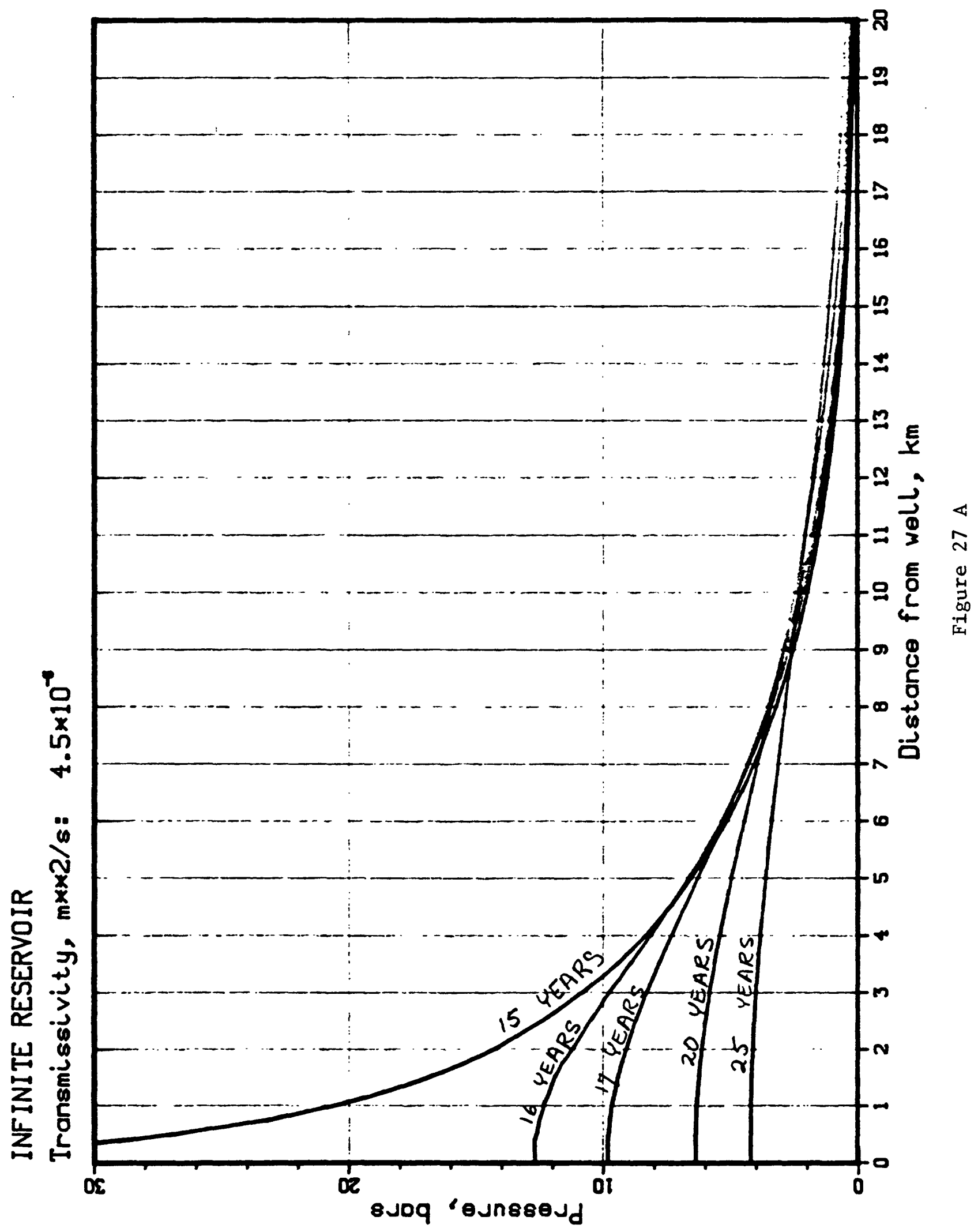




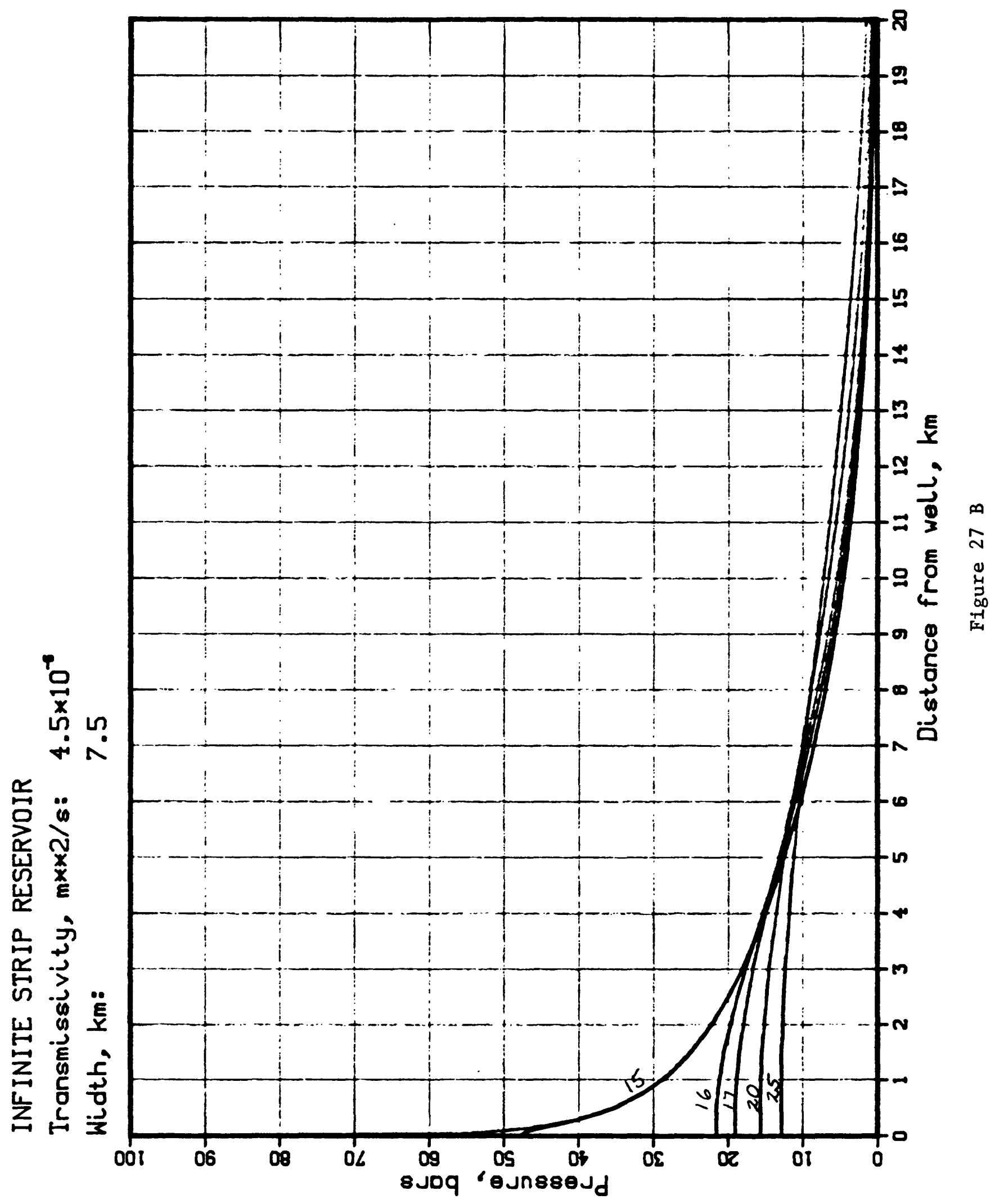




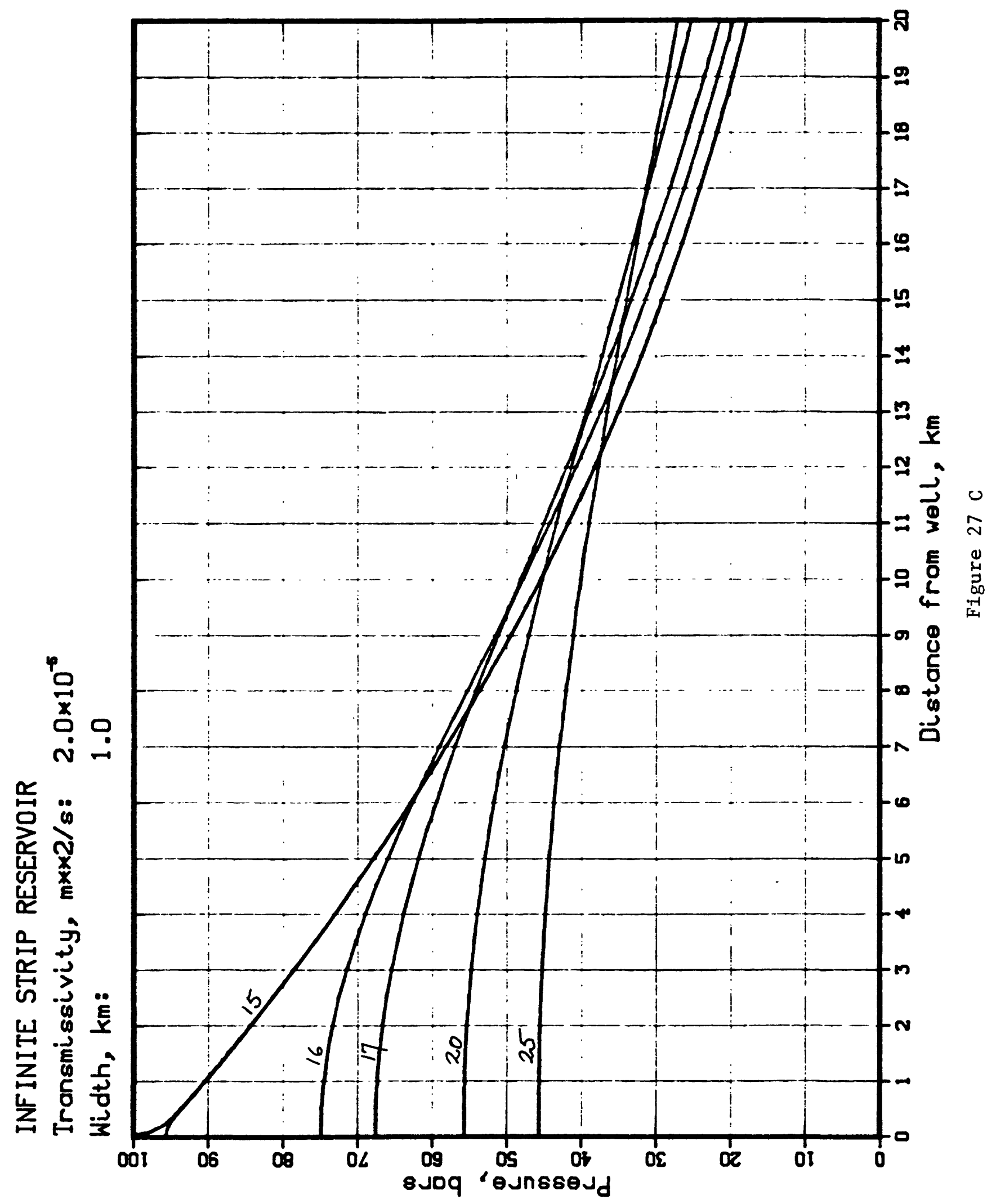




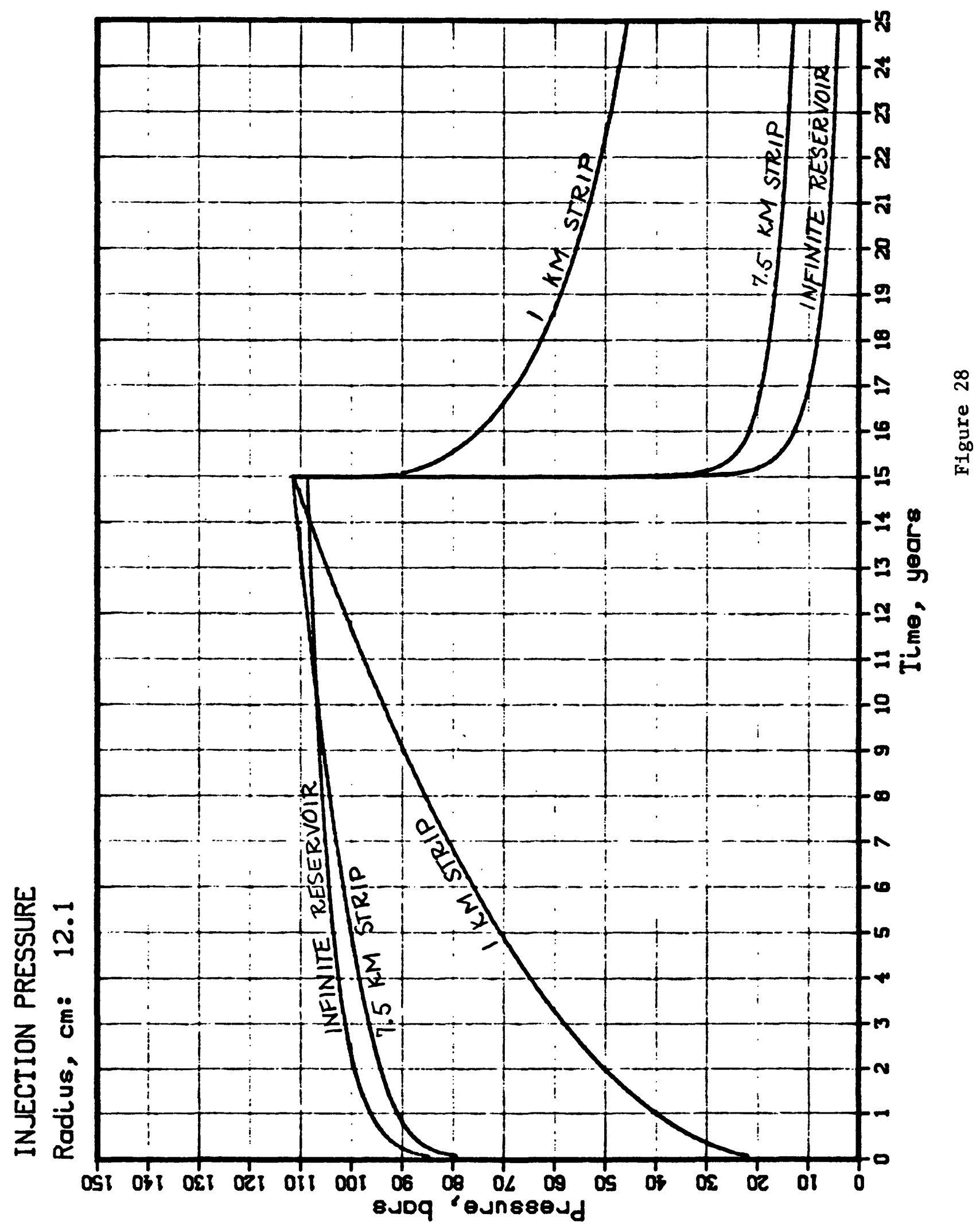




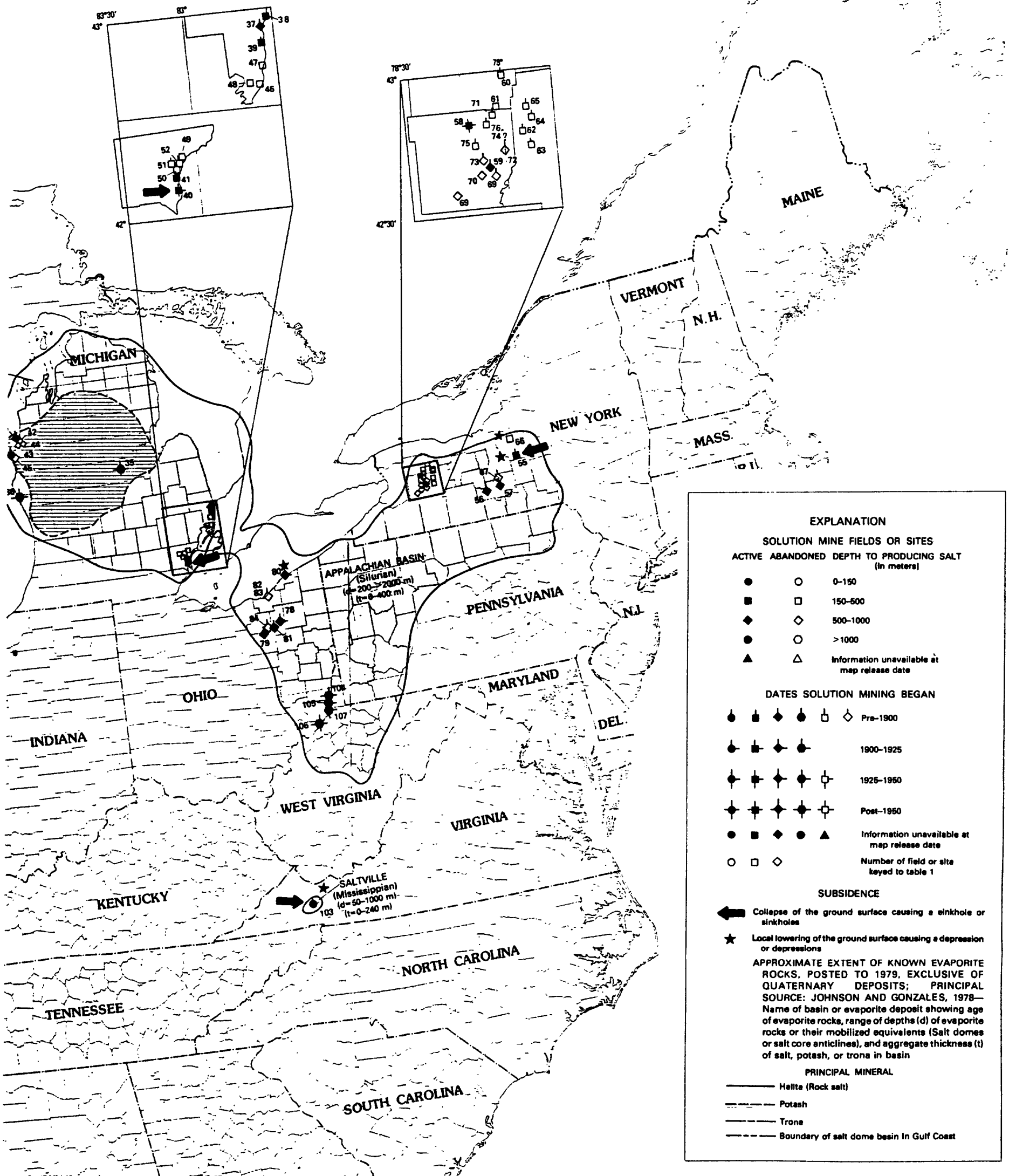


Figure 29 B

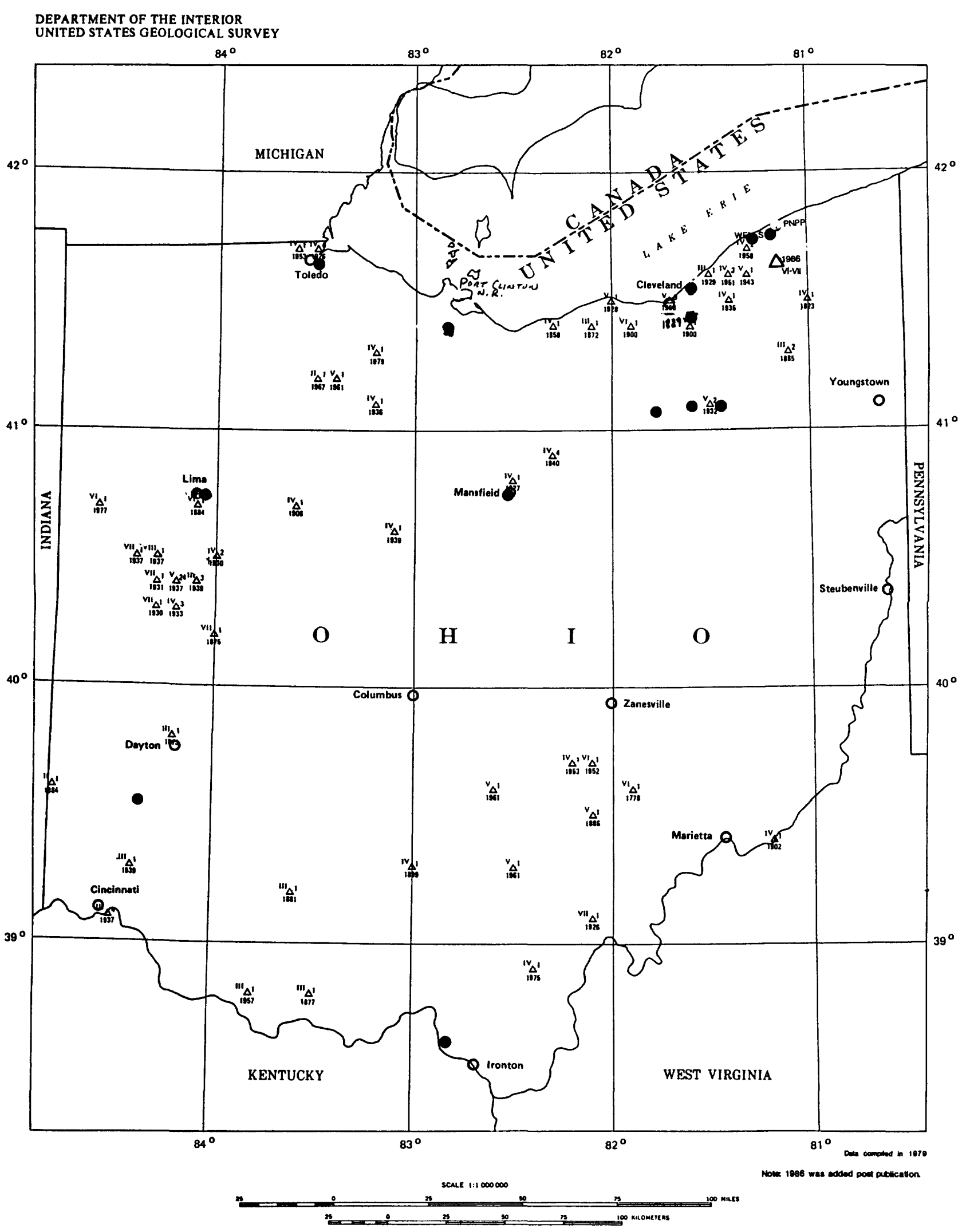

SEISMICITY MAP OF THE STATE OF OHIO

By

C. W. Stover, B. G. Reagor, and S. T. Algermissen 

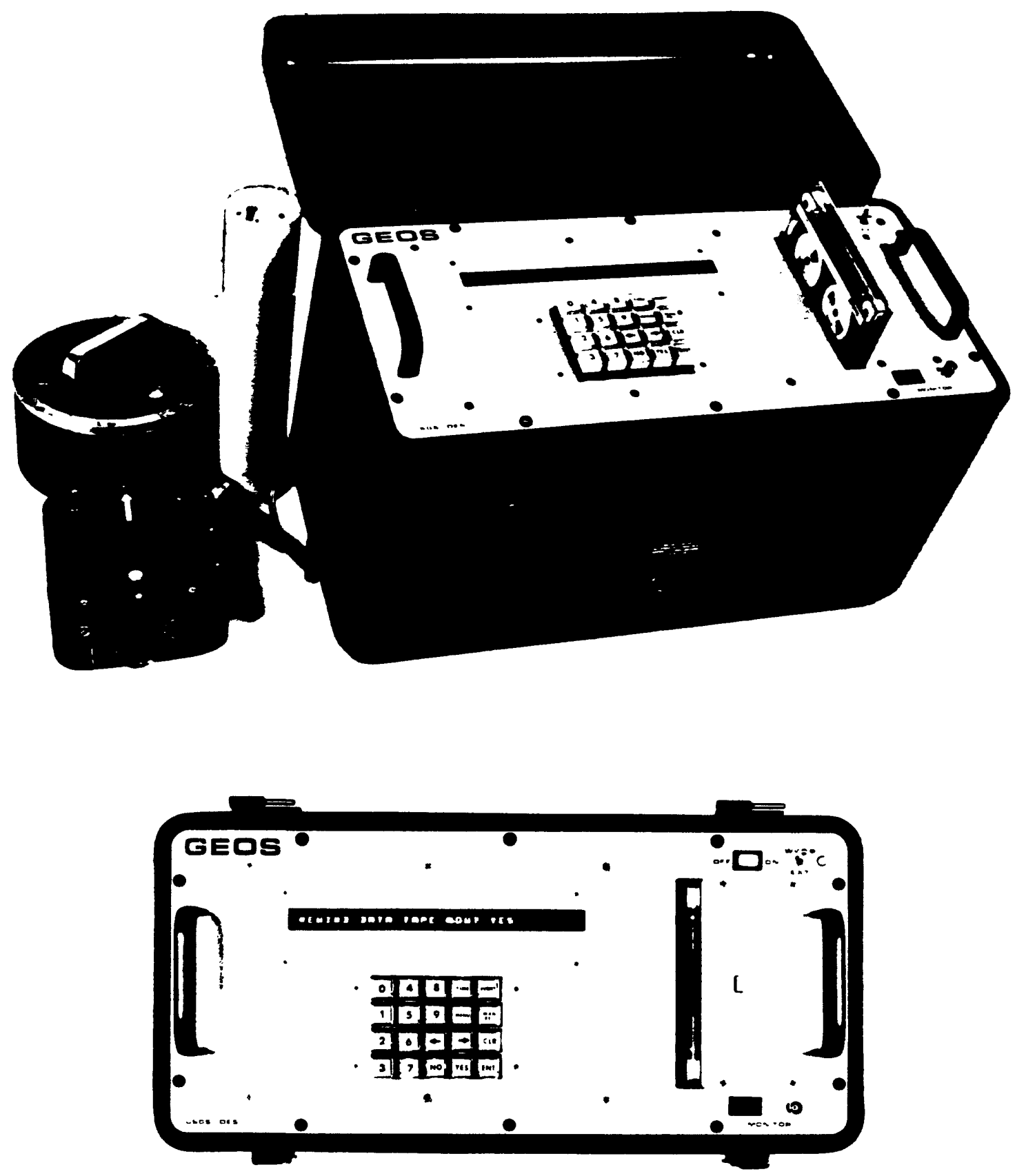

Figure 1. Side and front panel view of the General Earthquake Observation System (GEOS) together with a WWVB antenna and two sets of three-component sensors commonly used to provide more than $180 \mathrm{~dB}$ of linear, dynamic range. System operation for routine applications requires only initiation of power. Full capability to reconfigure system in the field is facilitated by simple operator response to english language prompts via keyboard. 


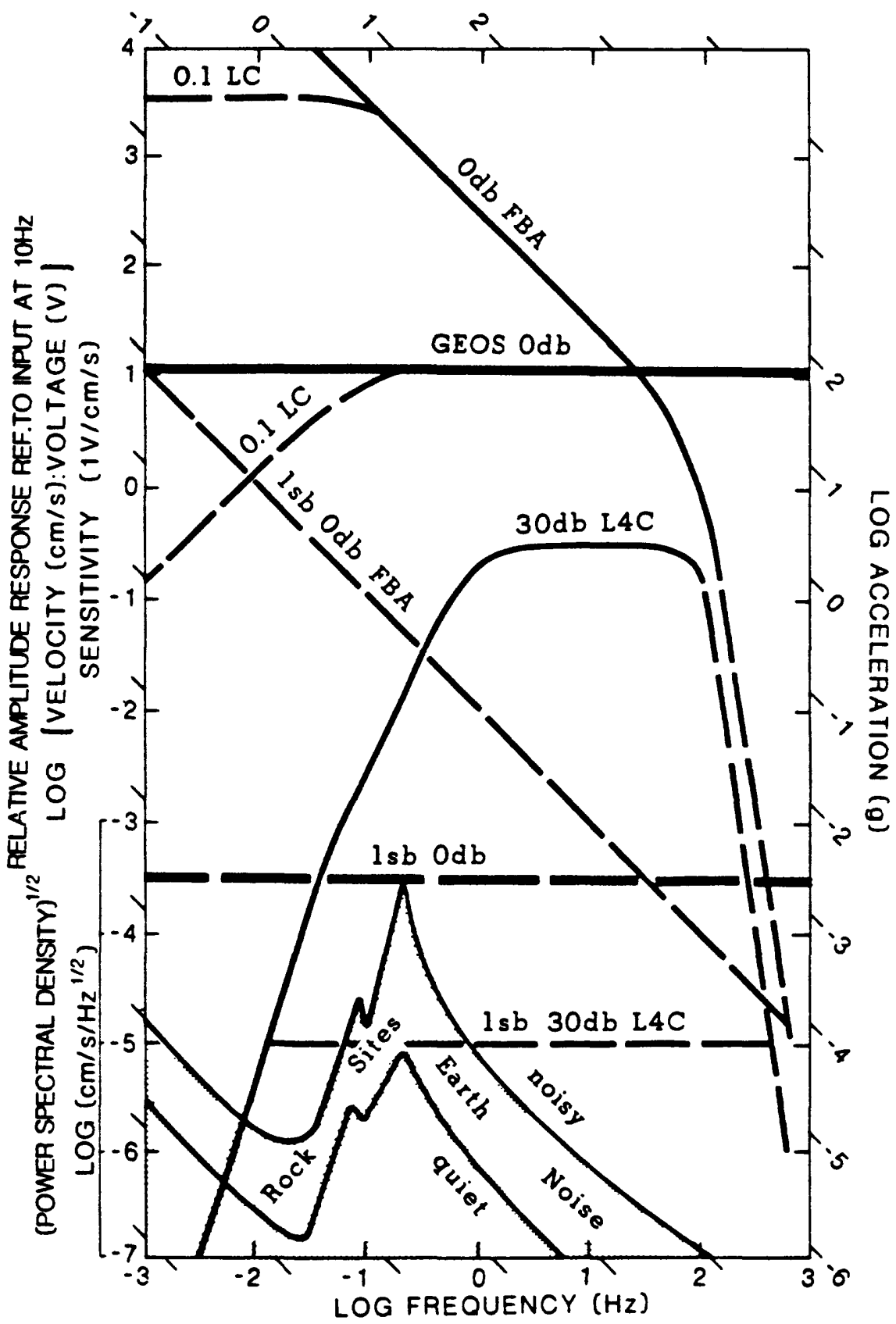

The unit-impulse response designed for the GEOS recorder, spectra for Earth noise (Aki and Richards, 1980), and complete system response with two types of sensors (force-balance accelerometer at $0 \mathrm{~dB}$ gain and L4-C velocity transducer at $30 \mathrm{~dB}$ gain). Two sets of sensors and linear dynamic range of $96 \mathrm{~dB}$ (16-bit) offers the capability to record without gain change $10 \mathrm{~Hz}$ signals on scale with amplitudes ranging from 20 angstroms in displacements to $2 \mathrm{~g}$ in acceleration. 


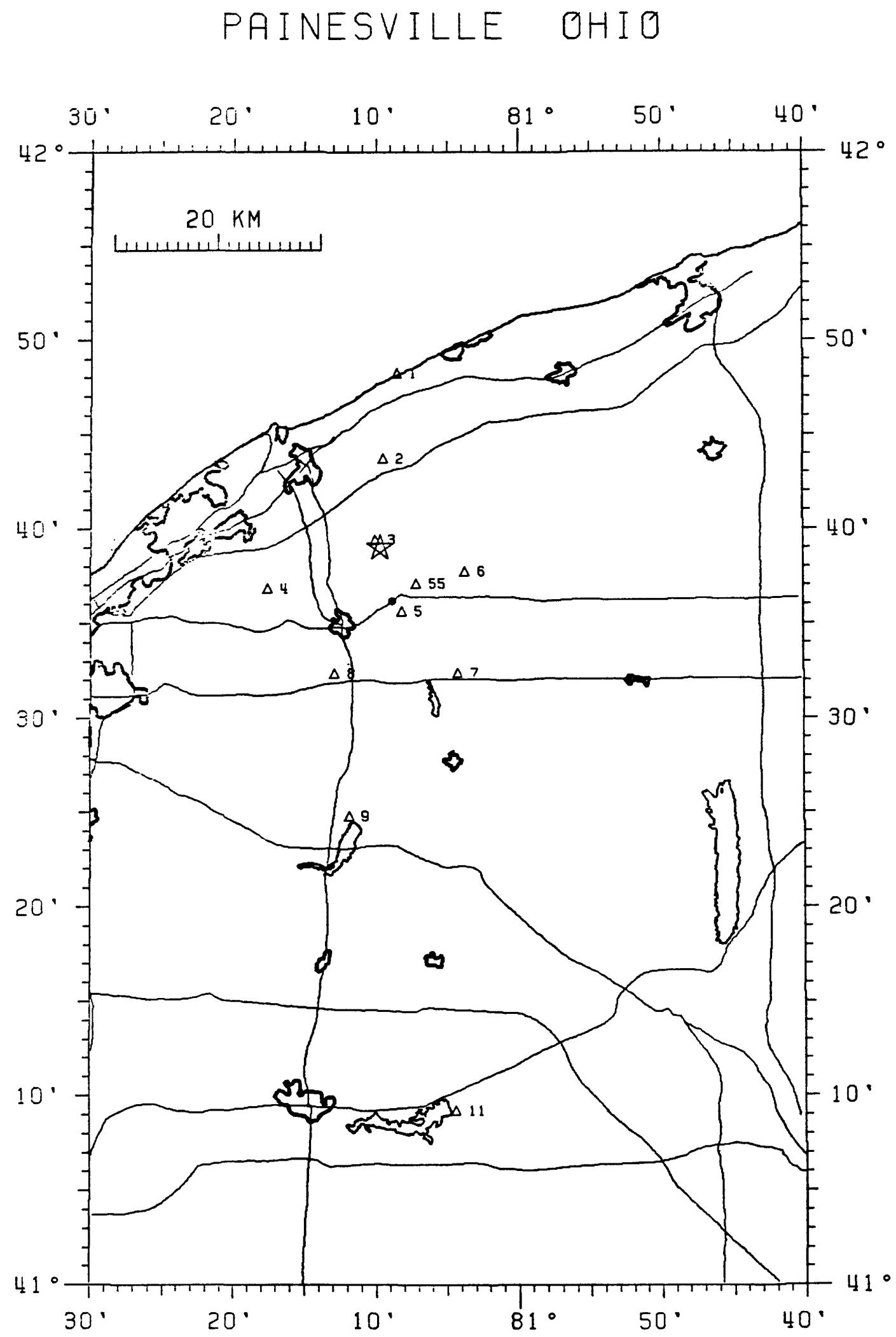

Locations of sites occupied by GEOS recorders and location of main shock on January 31, 1986 (J. Dewey, pers. comm., 1986). Major highways, city and community boundaries, and lake boundaries also are shown. 

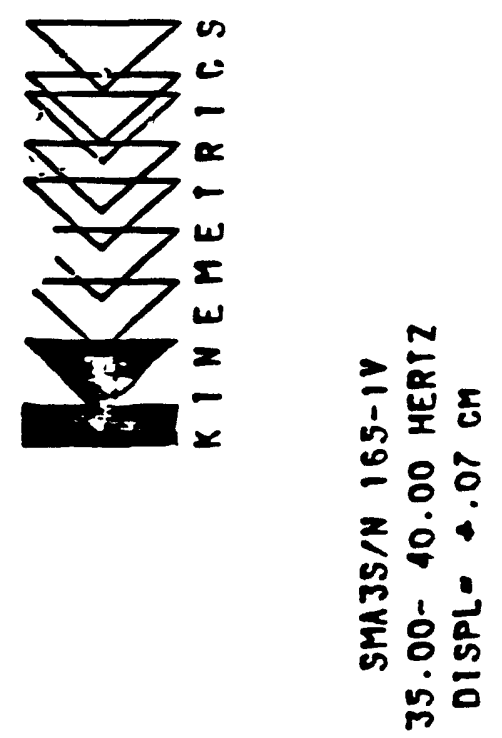

0
0
0
$-\frac{0}{2}$
0

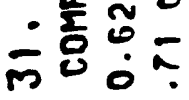
2
$\sum$
$\sum$ $>\sqrt{\mathrm{w}}$. 兹岕 $\omega \underline{y}$ 층형 웅원 오원

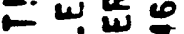
당 ن 0 舟 4 $0 \%$ is i $\frac{0}{4}$ is a ₹ $\sum_{0}^{0}$

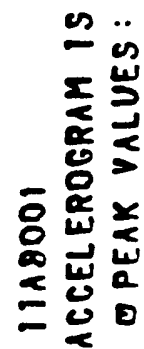

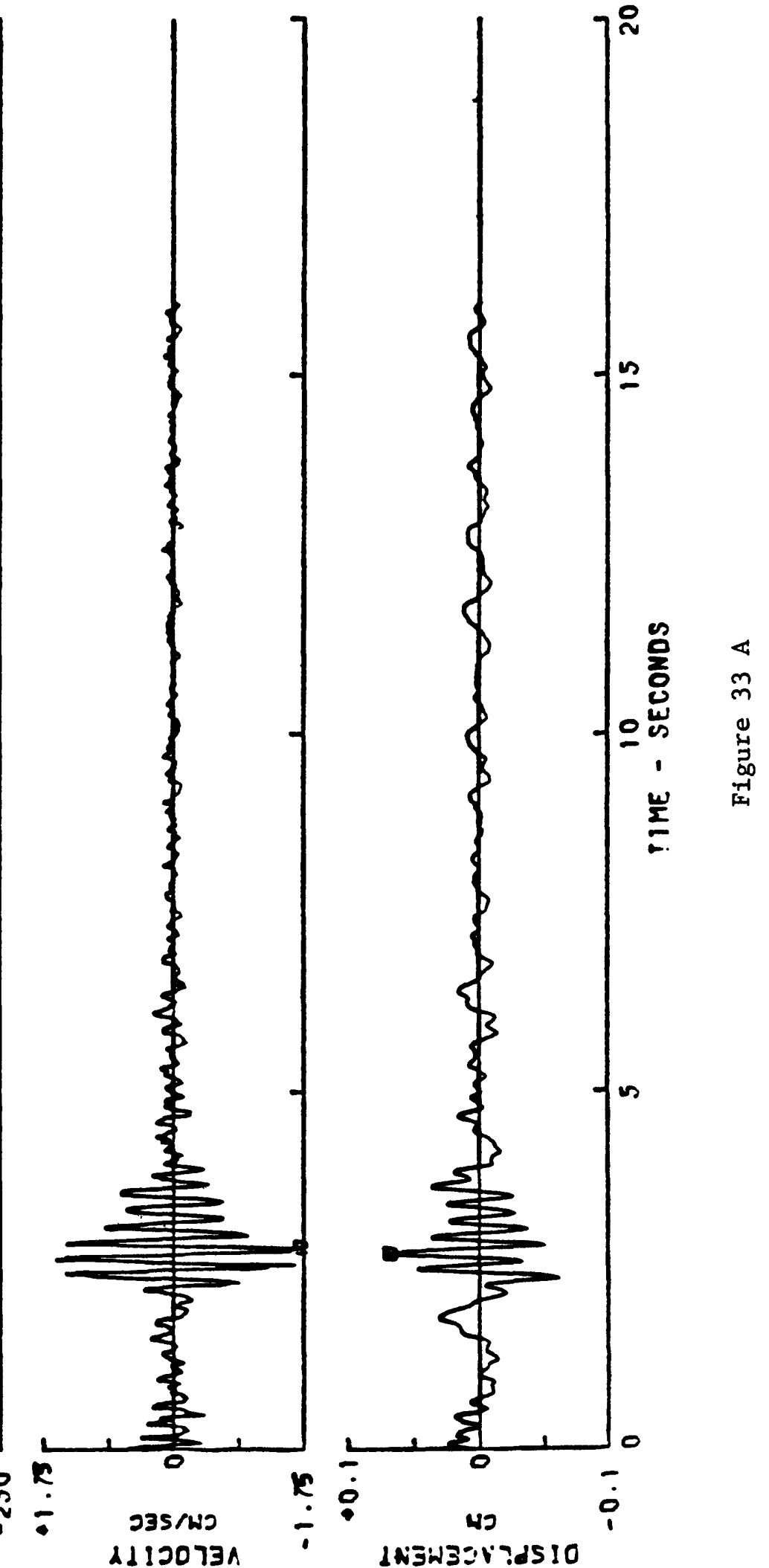



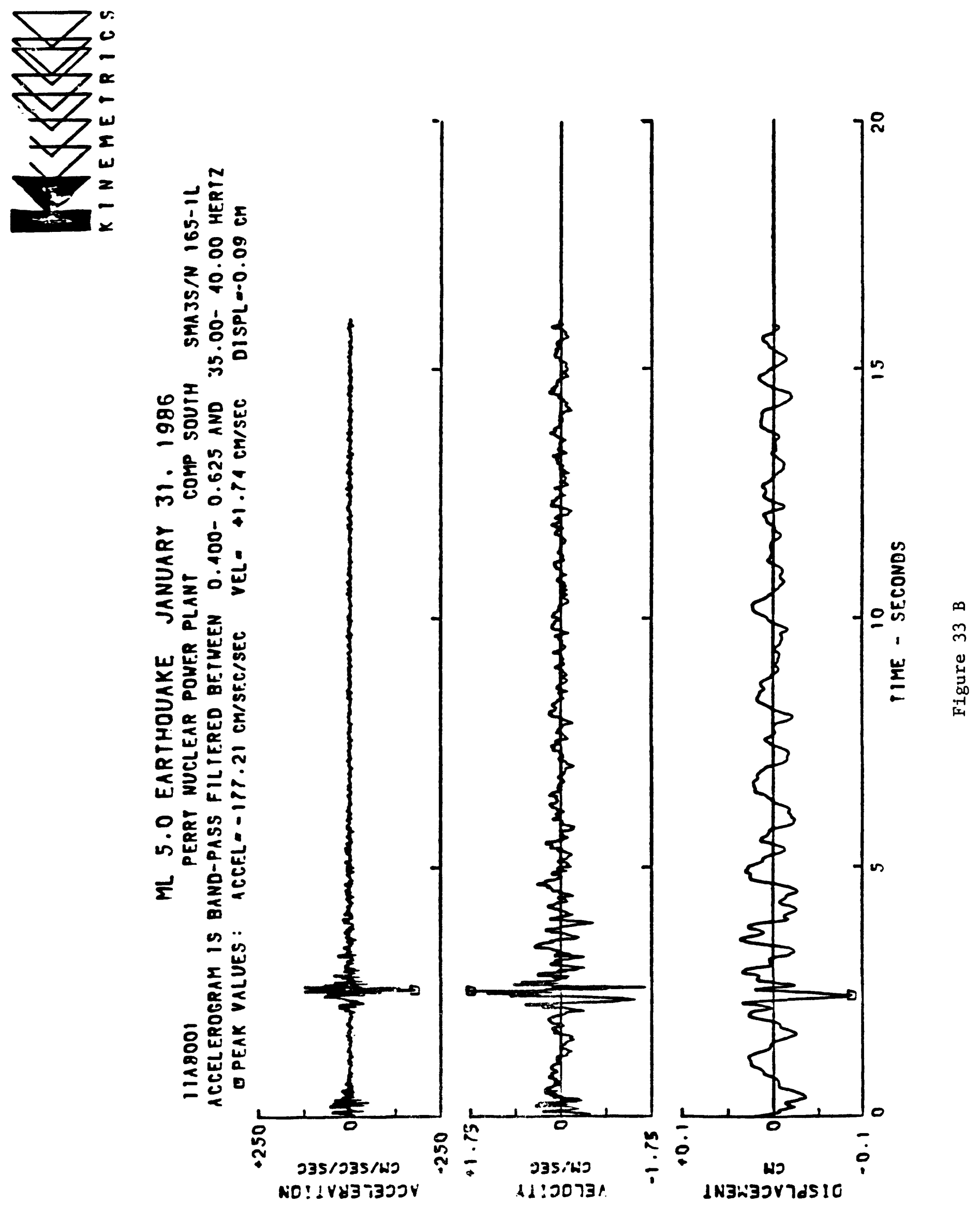

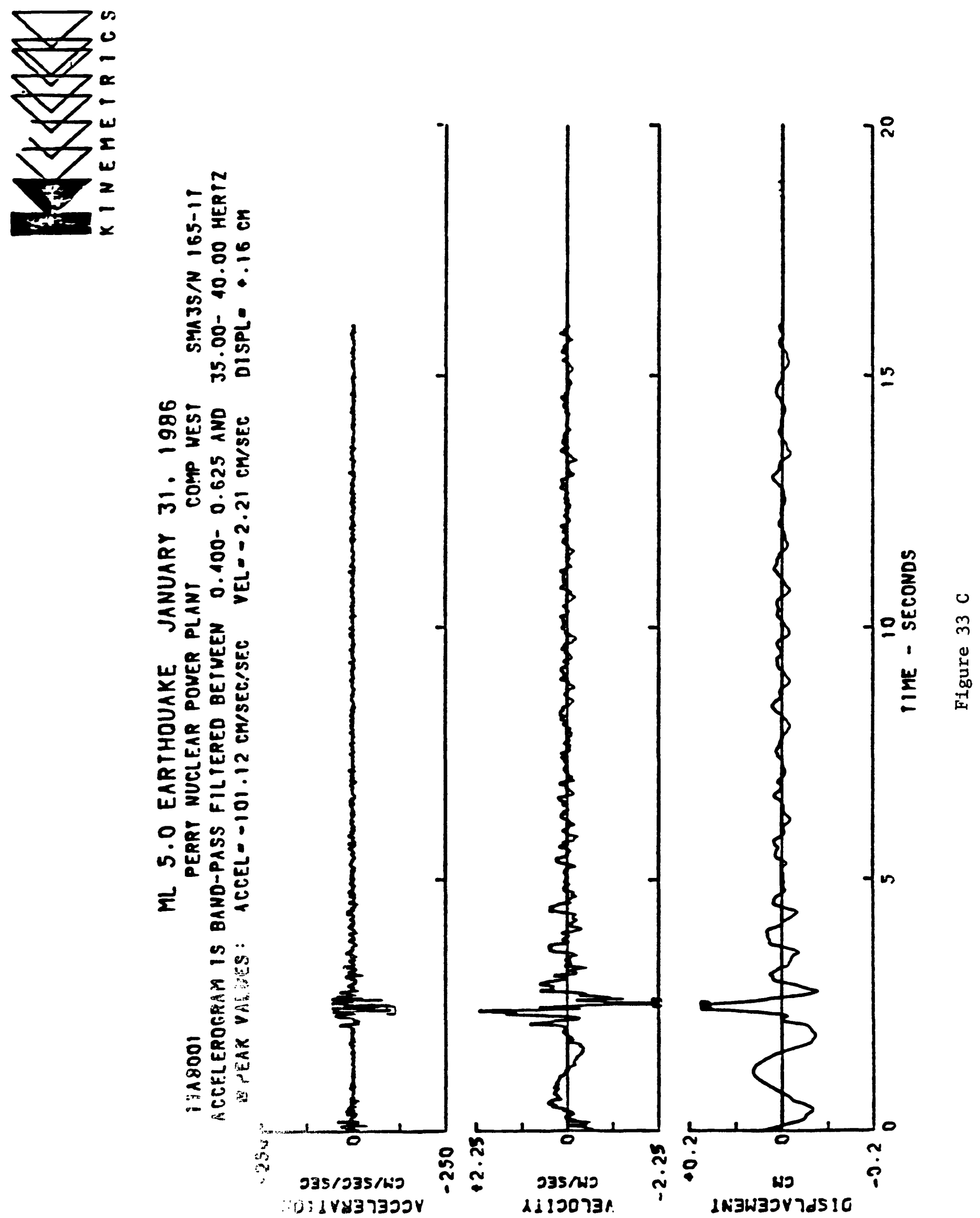

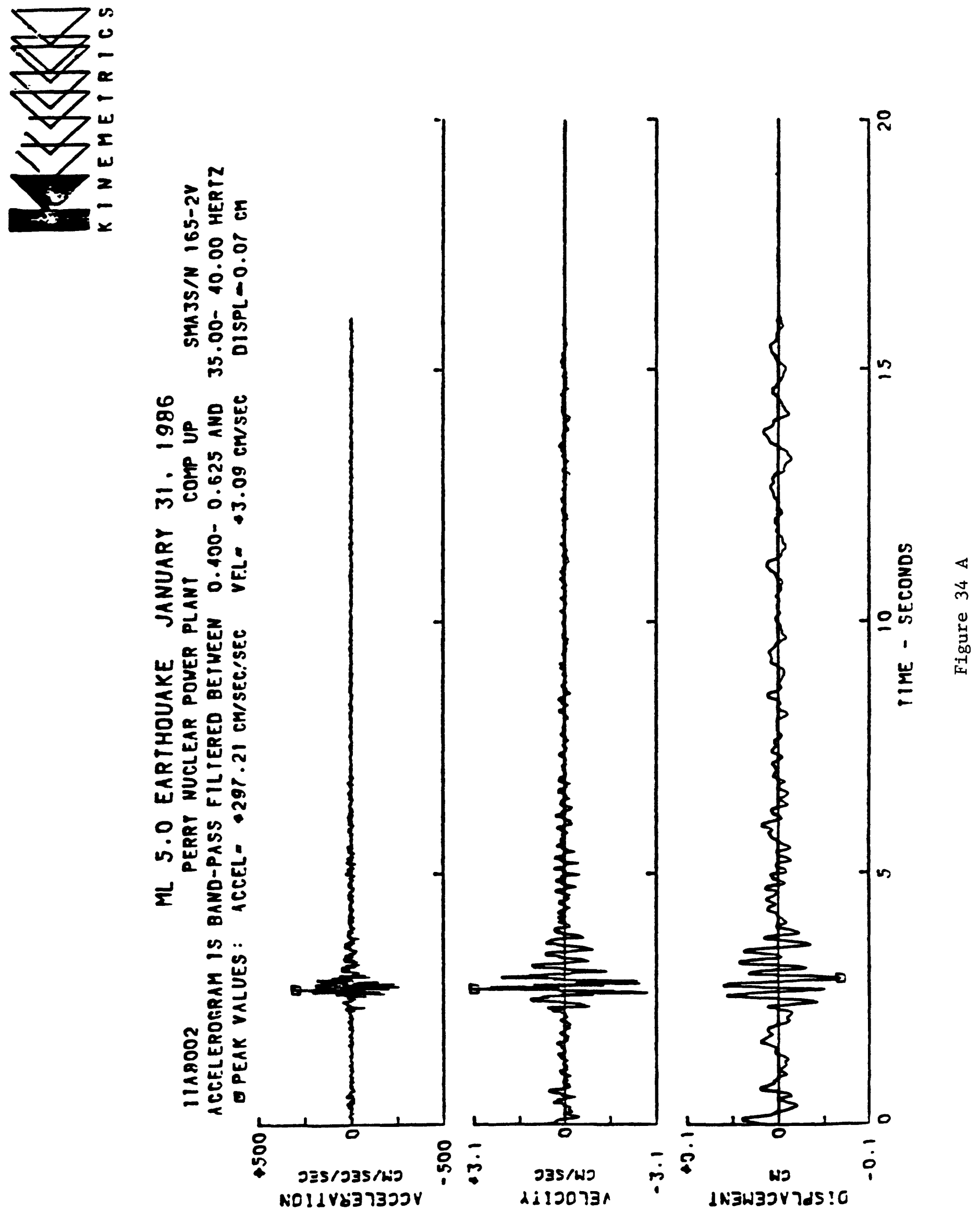

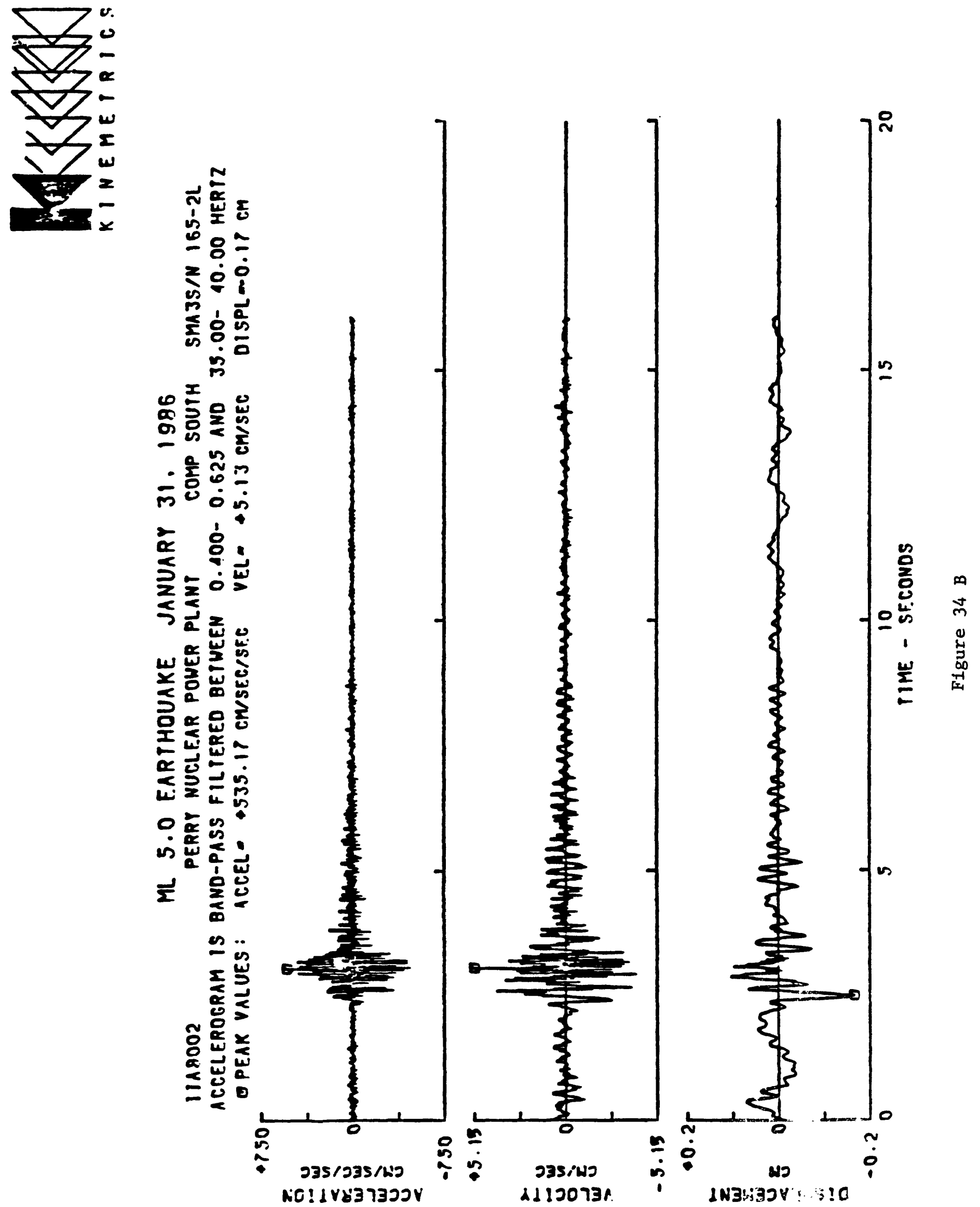

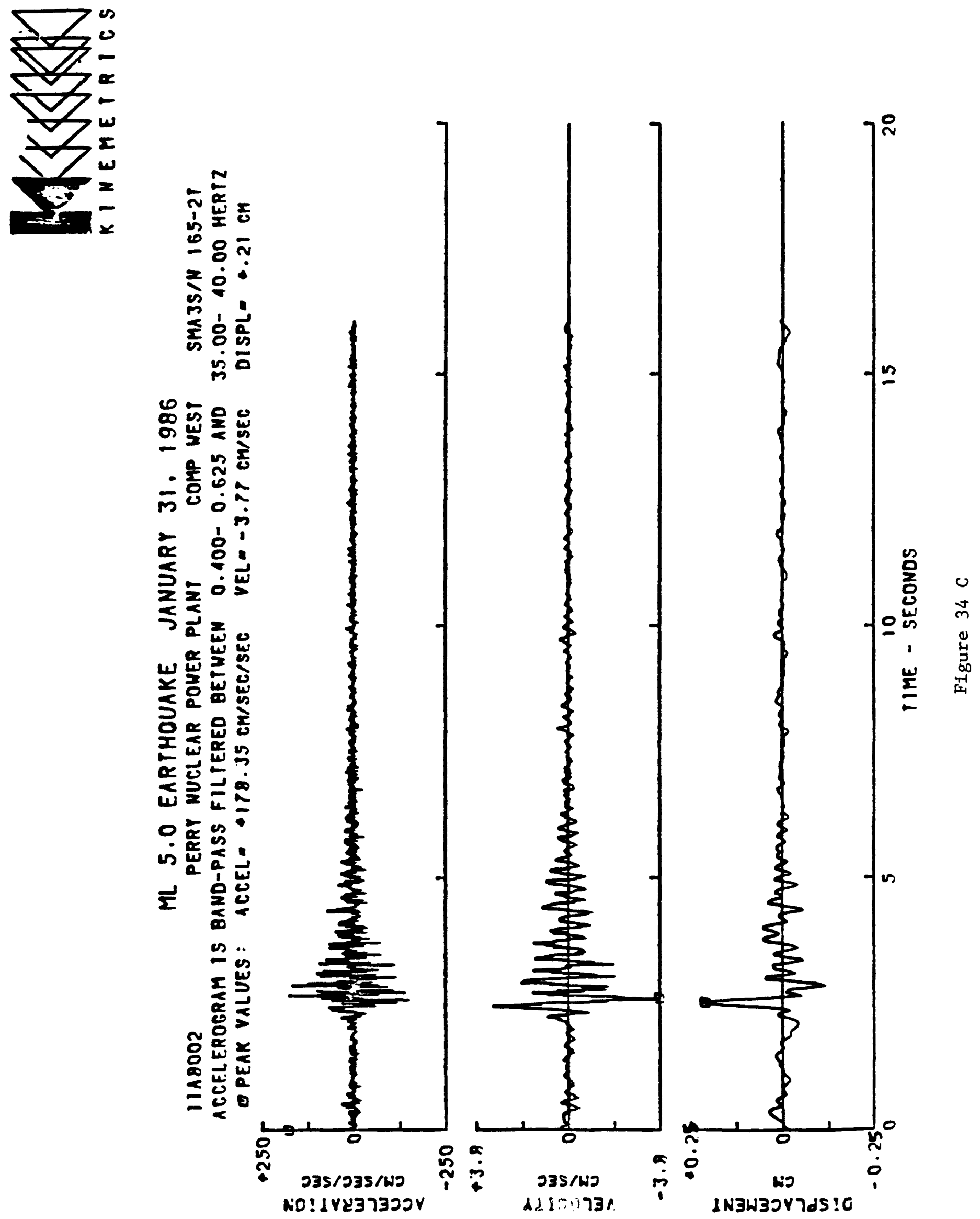


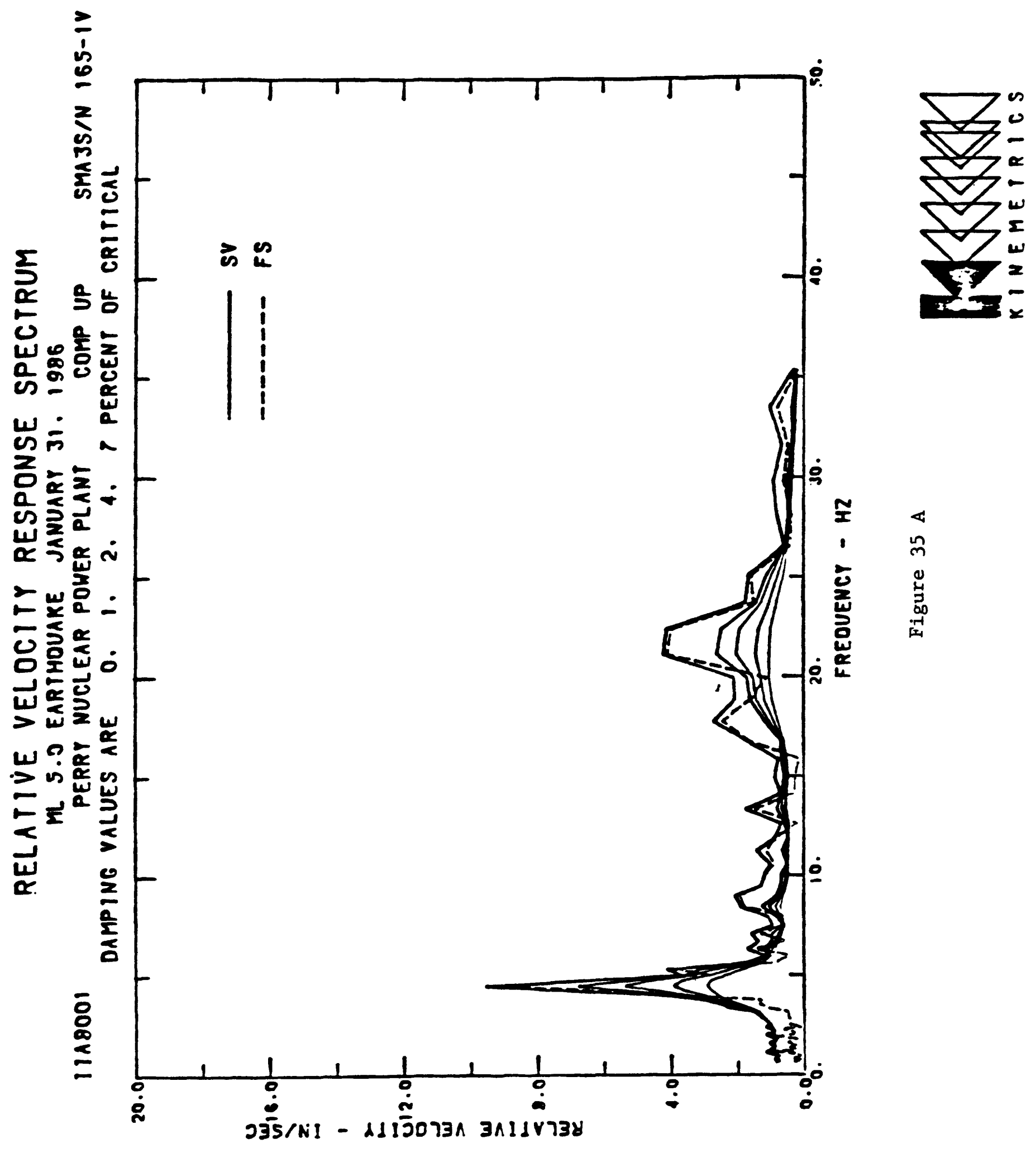




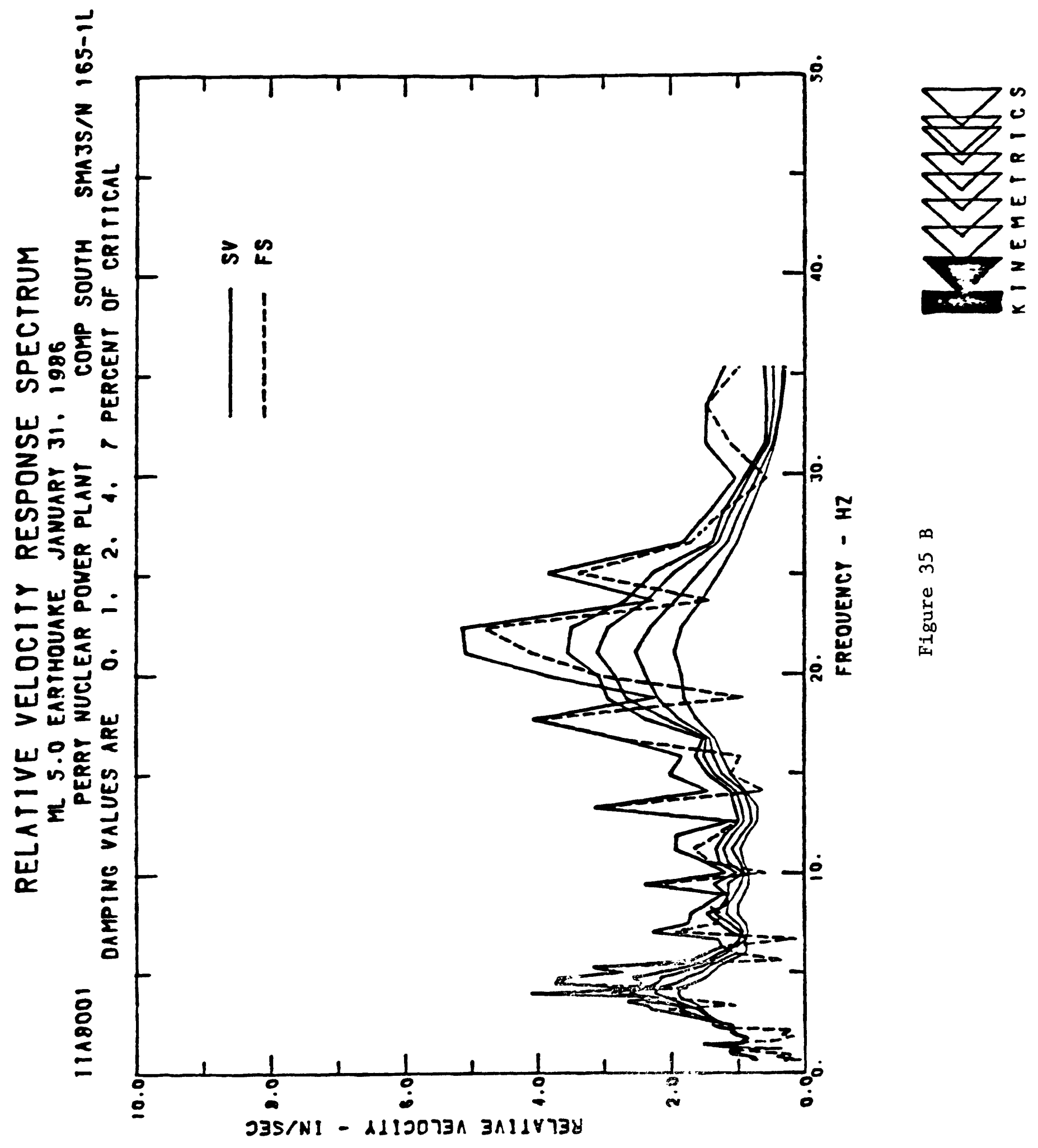




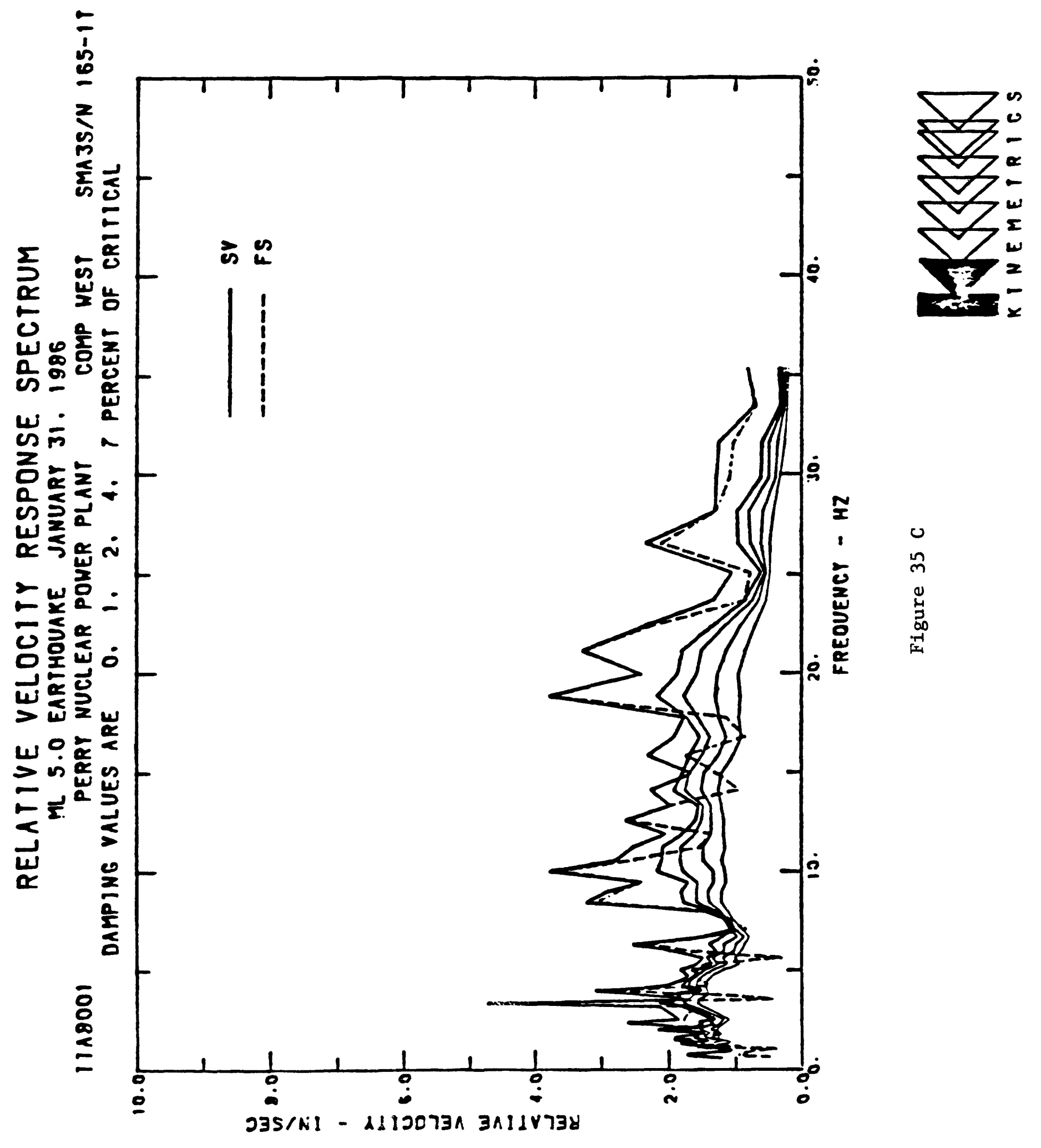




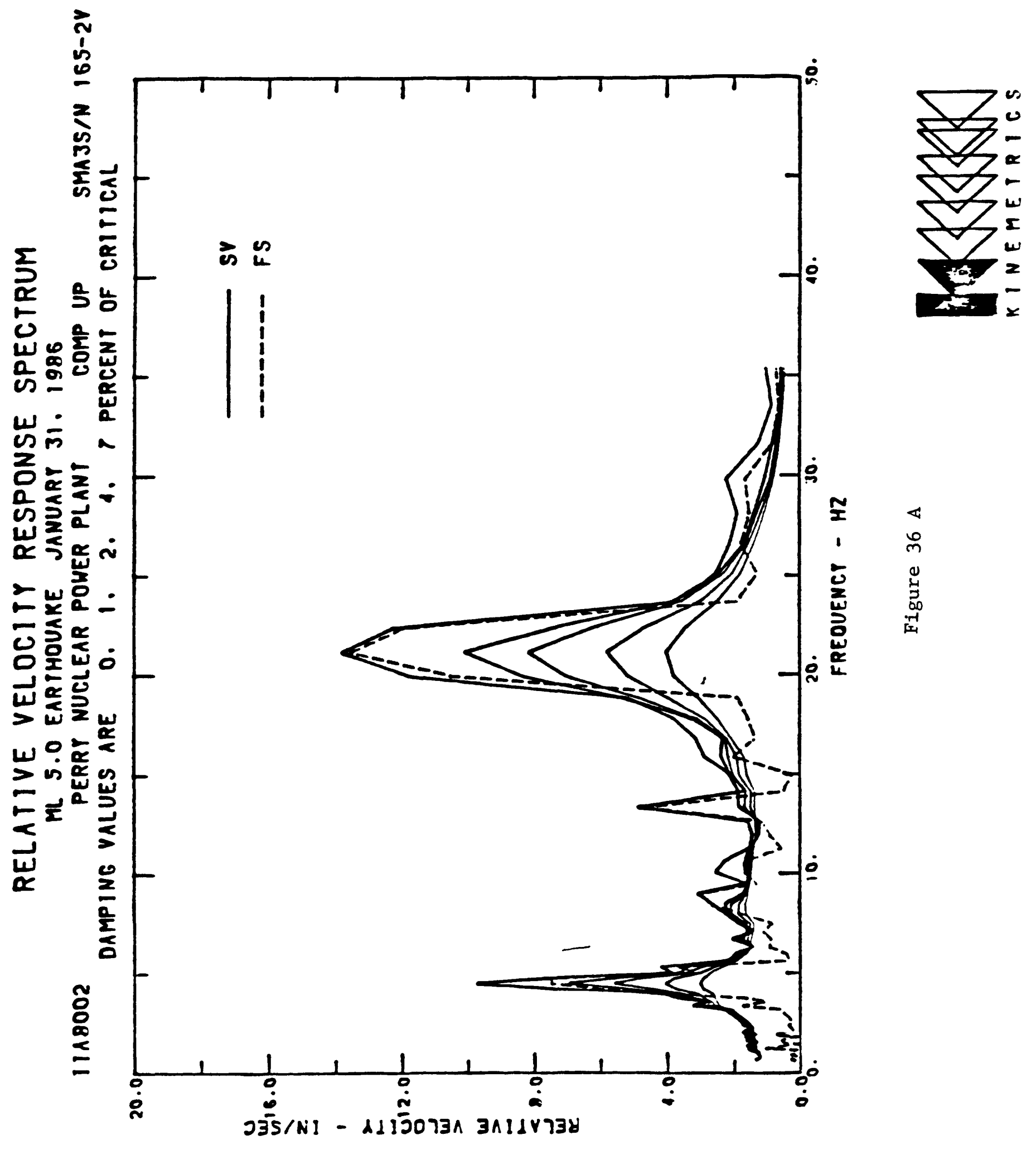




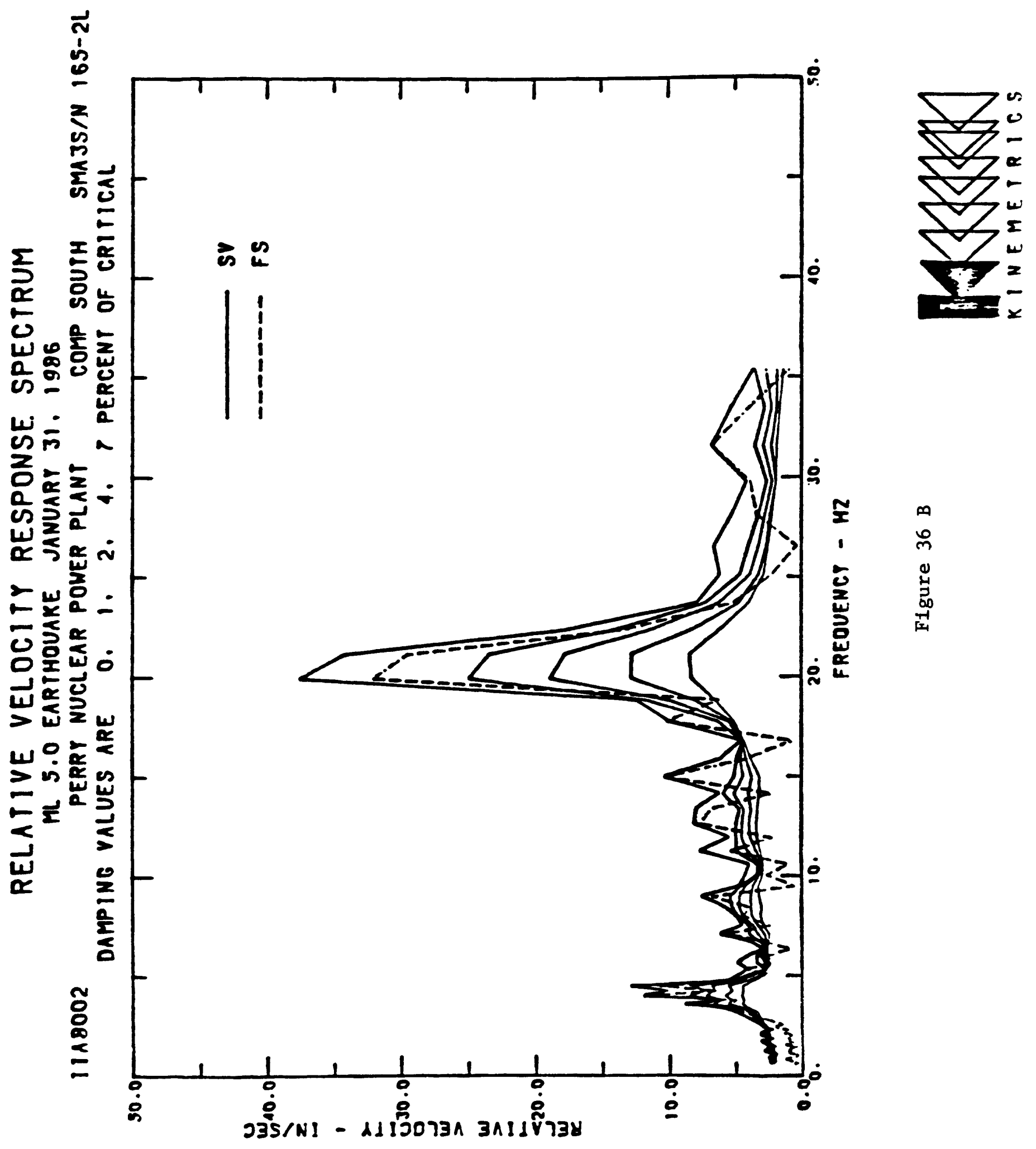




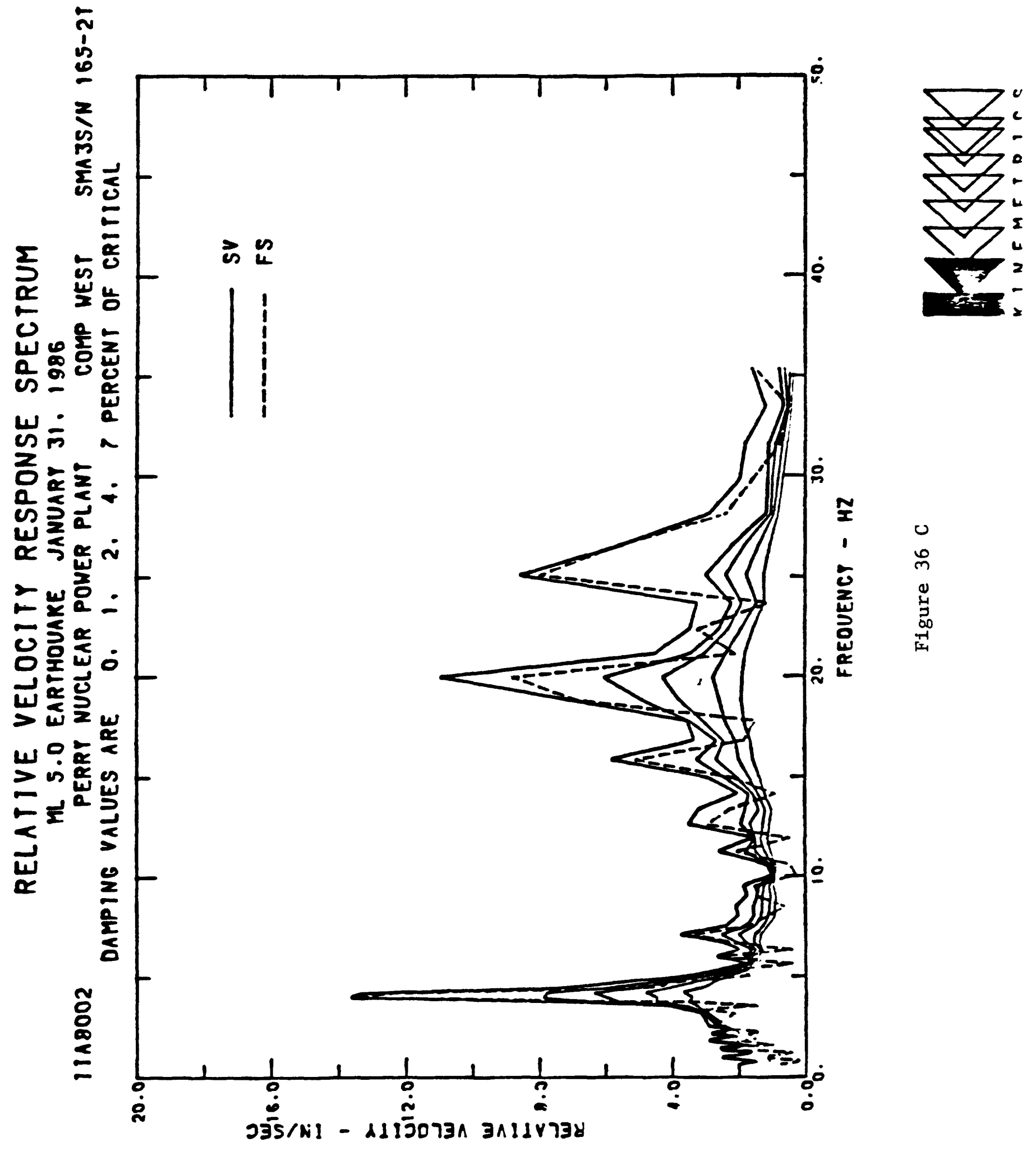




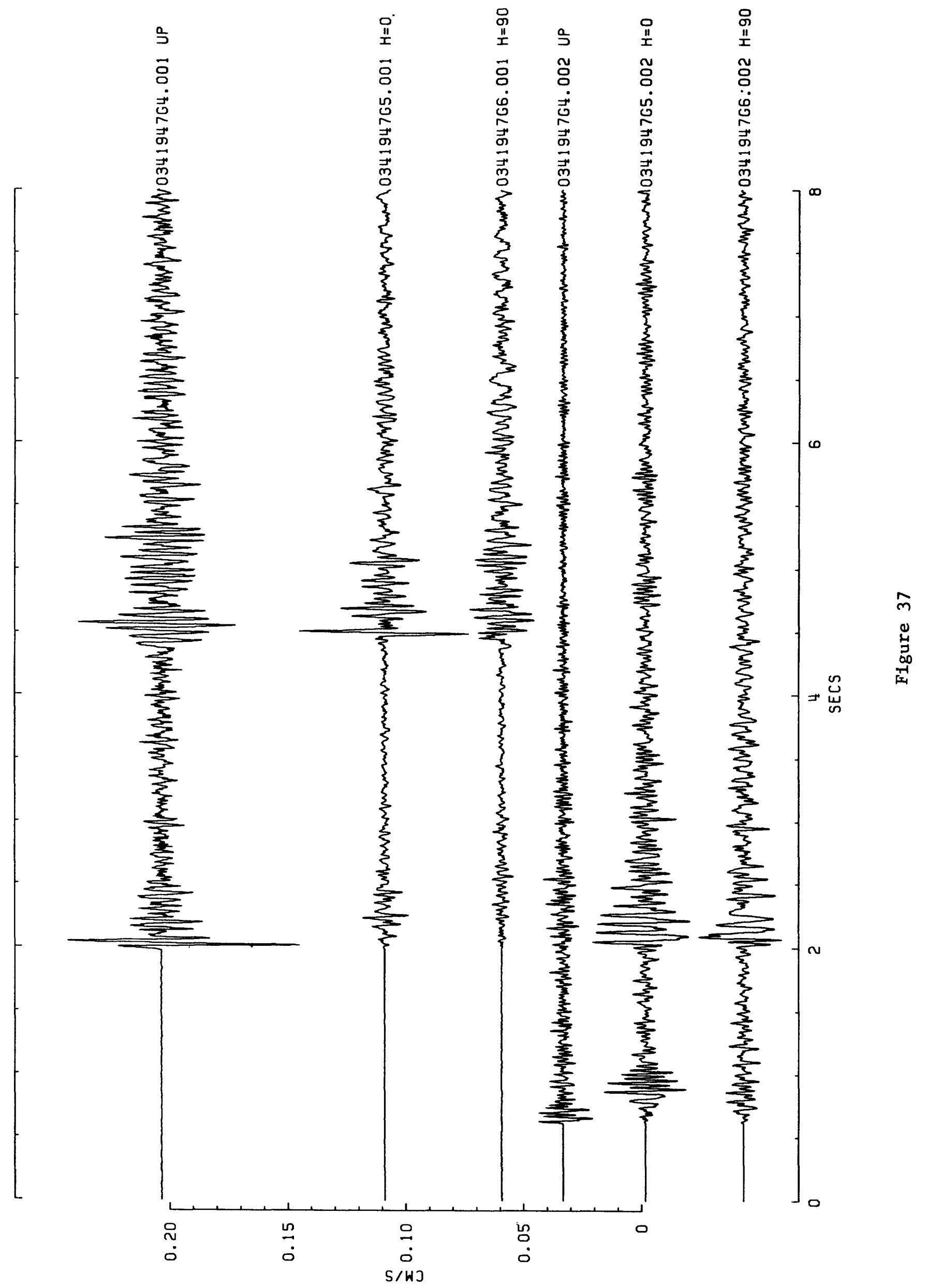




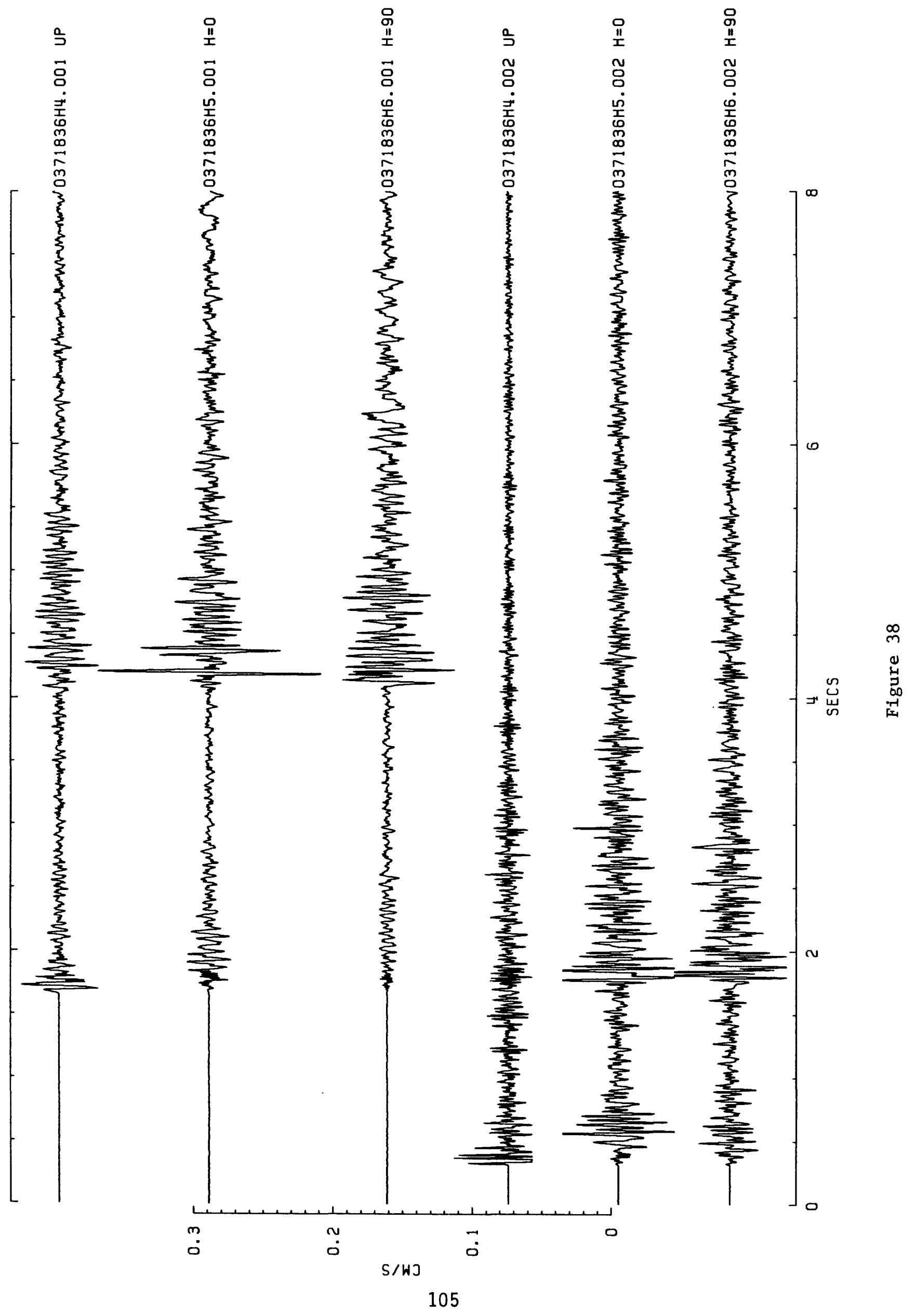



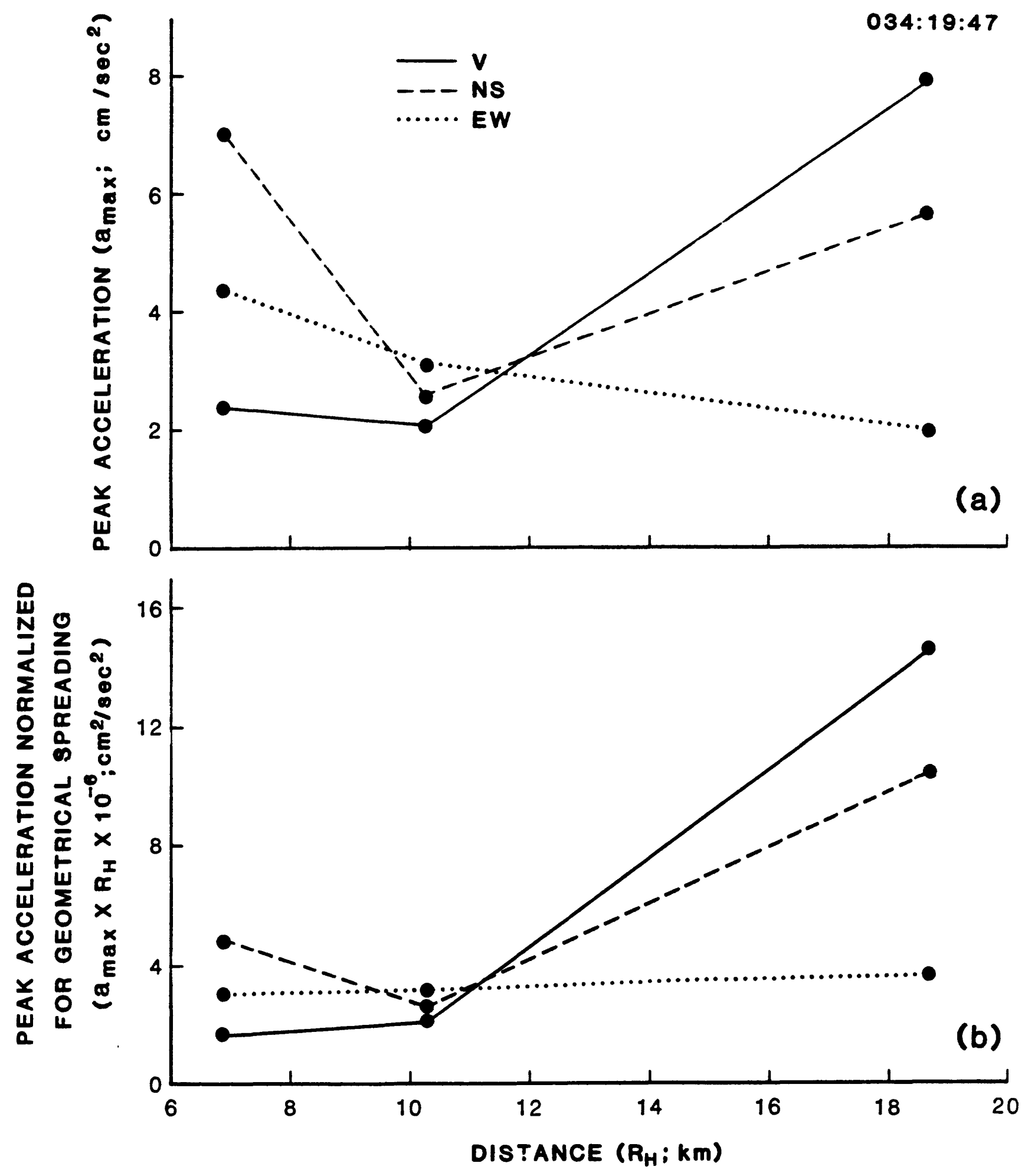

Figure 39 

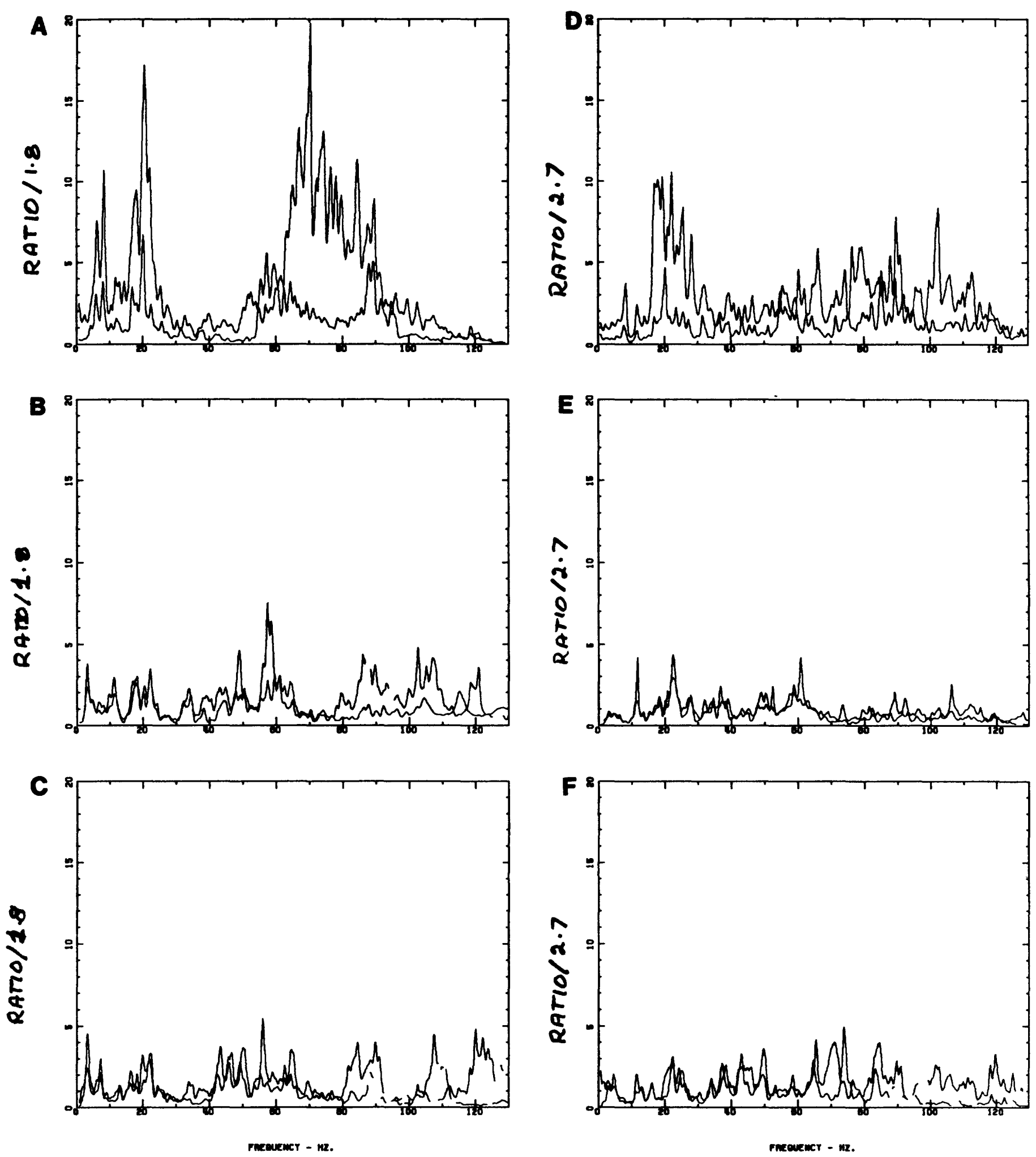

Figure 40 

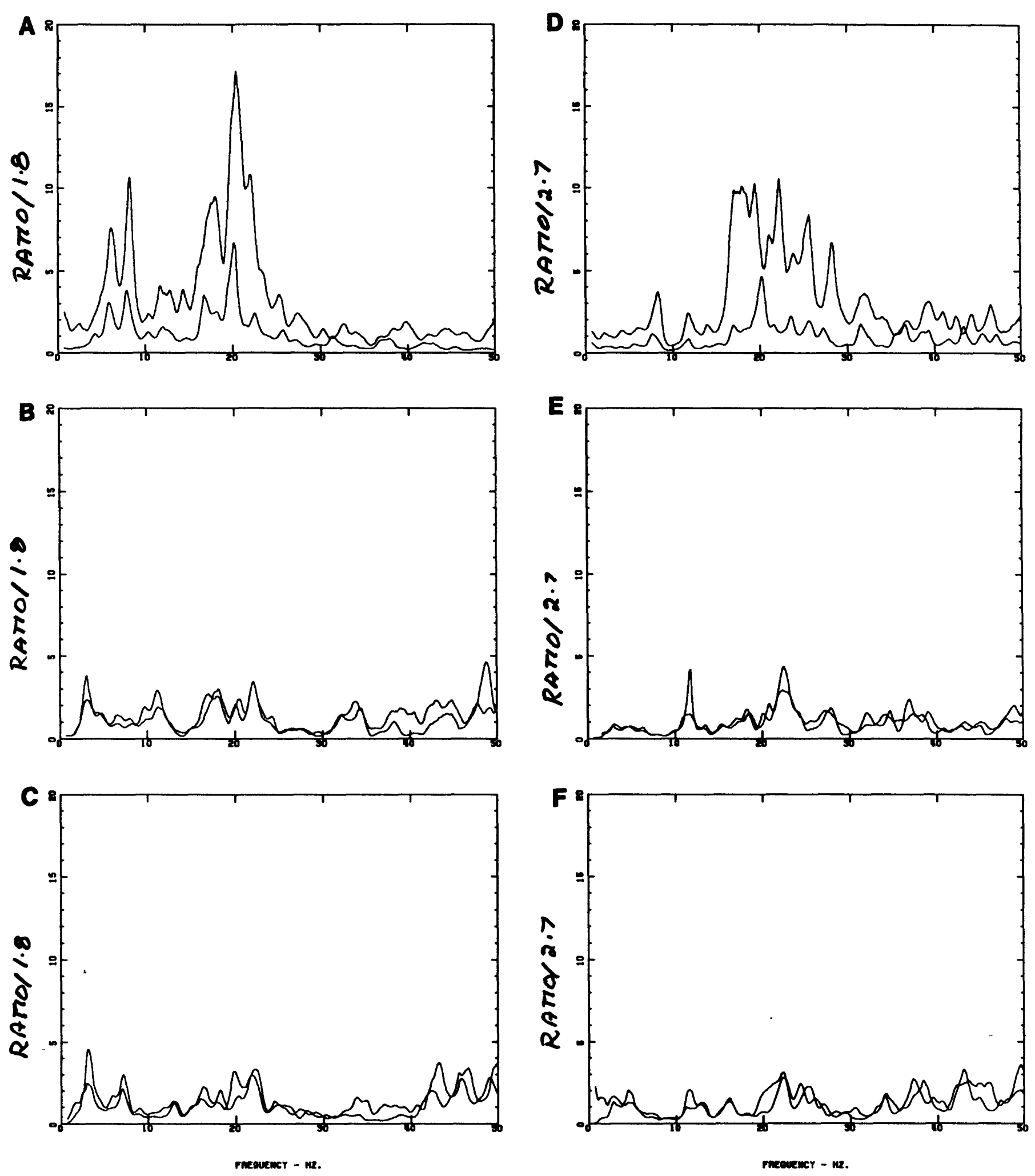

Figure 41 
APPENDIX A

HISTORICAL AND INSTRUMENTALLY RECORDED SEISMIC EVENTS WITHIN THE STATE OF OHIO

1776 THROUGH 1986 


\section{Explanation of Table 1(a) Flle Format}

The cata are listec chronologically by late and origin time in Coordinated Universal Time (UTC). Each earthauake entry contains the tollowing intorination: Geograpnic coordinates, clefth, hypoconter quality with reterence sources, magnitudis, and intensity with reference sources. The tile has some basic limitations in terms of size (magnitude or intensity) of the earthquakes listecl. All felt earthquakes or those with computea magnitucles greater than 2.5 are 12sted. It no nagnitude was computed and the earthauake was telt, it was inclucled in tha 1ist. The low-magnitude avents located since 1965 with data trom dense seismlc netuorks have not been includeci.

Listed bolow is an explanation of the syinbols and codes thet are used in the tile listing:

1. Leaciers (...) incicate informetion not avallable.

2. Latitude ancl longltude are listed to a thousaneten of a degree it they have iseen published with that precision. A "x" to the right of the longltude indicates that the entry is nontectonic: at "indicates the coordinates have bean assigned by the compiler; a "p" Indicates that publishad clascriptions of the event ara inconclusive anc it may or may not be an earthauake.

3. Depth or the hypocenter in kilometers.

4. Under the HYPOCENTER neading, the GUAL is iefinea is:

a. Deterniznations of instrumental nypocenters are estimeted to be accurete within the clegree range of latitucie and longitude listea below; each range is latter cocied as indicatad:

$$
\begin{aligned}
& A=0.0-0.1 \\
& B=0.1-0.2 \\
& C=0.2-0.5 \\
& D=0.5-1.0 \\
& E=1.0 \text { or lirger. }
\end{aligned}
$$

b. Detarminations ot noninstrumentai ejicenters tron telt data are estinated to be sicurate witn the clegree ranges ot latitude and longltude listad lelow; each renge is letter coded as Indicated:

$$
\begin{aligned}
& F=0.0-0.5 \\
& \dot{G}=0.5-1.0
\end{aligned}
$$




$$
\begin{aligned}
& H=1.0-2.0 \\
& I=2.0 \text { or larger. }
\end{aligned}
$$

5. The reterence latentificition numbers uncler the HYPOCENTER (REF) and INTENSLTY (REF) columns incicate the sources of the hypocenter end intensity. These sources are eivalizble on reauest.

o. Tha magnztucles e.ra composed of three sections:

a. Uncler the USGS neacing:

The mb values (Gutenberj and Richter, 195t) end the Ms values (jeth, $176 t$ or iutenbery, ly4j) were publashod in the Praliminary Determination of iplcenters (PDE) isy the Netzonal Earthauake Intormation Center, U. S. Geological jurvey and predecessor organizations.

b. Unciar the heacing of UTHEk, the essociated magnztudes are classitied by type and source. The sources are avallable on request. The magnitude types are iclentified as:

(1.) ML....(kichter, 1958)

(2.) Mn....(Nutt12, 1973)

(3.) Ms....(Bath, 1960 or Gutenberg, 1945)

(4.) mb....(Gutenberg and Richter, 1956)

(5.) Mnx...[Modified mbLG] (Jones and others, 1977)

(o.) MD.... Duration or Cocia Length

(7.) min...(Layson ancl otners, 1979)

(8.) Mifa...Magnitude based on felt area attenuatzon

(Y.) UKN... Unknown illagnitucie

c. Uncier the roment neading:

The Mu values ara computed tron the log of the moment in dynes/cm. The source of the contributed villue is coded at tha right. The tormuli used in tha conversion is trom ranks and Kanamor 1 (197y).

7. Intensity. Values are based on the Modified Mercallz Scalo of 1931 (wood anci Neumann, 1931). A letter "F" appears ir this column if the quake was telt; but the intormation was not sutticient or too ambigious to assign a numerical value. A "inl appears to the right of the intensity velua it the value ules assigned by the compllers.

3. Comnunts. The conmont lines rre genaraliy useat to list some of the stronger eftects causel by those earthauakes lith intensities 
listecl at vI or orezter. otnar types of commonta explains unique teature(s) that occurrad as a result of en esirthouske. It source reference tollows the comment, then the comnent was teken from that referenca; otherwise, the comment was taken trom the sourca reference following the intensity assignment. 


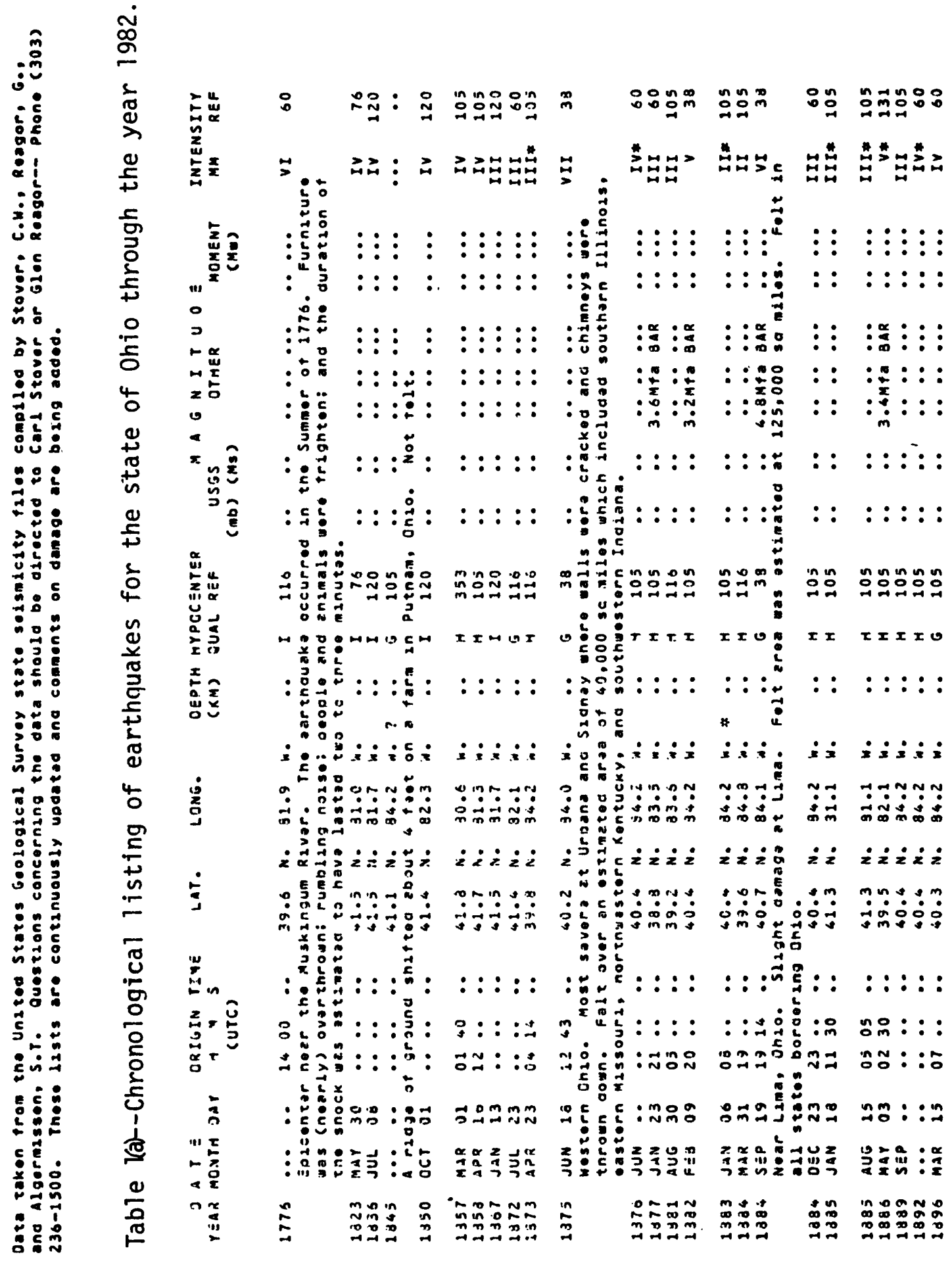




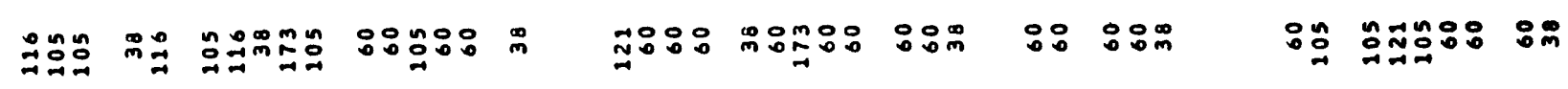

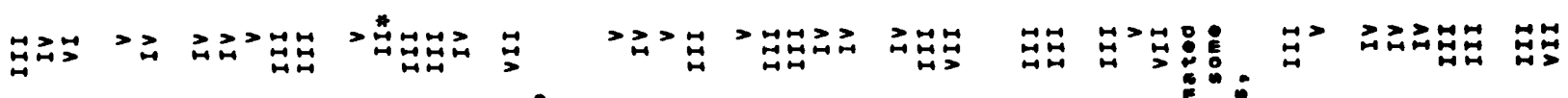

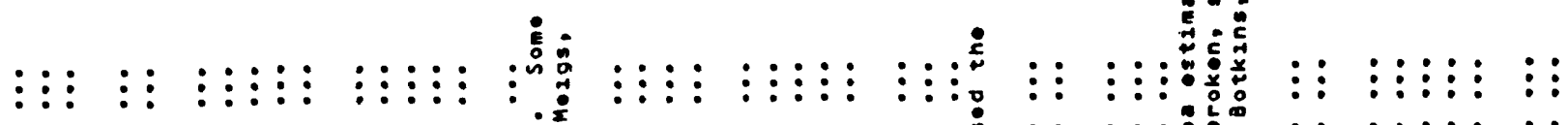

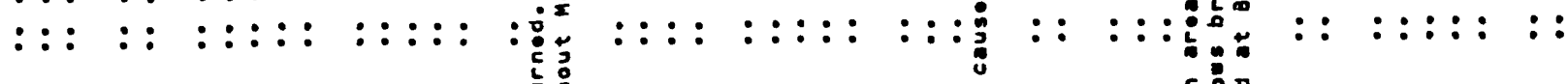

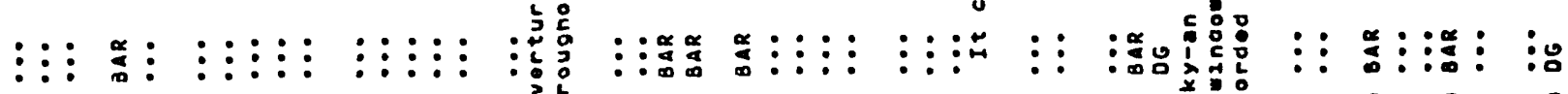

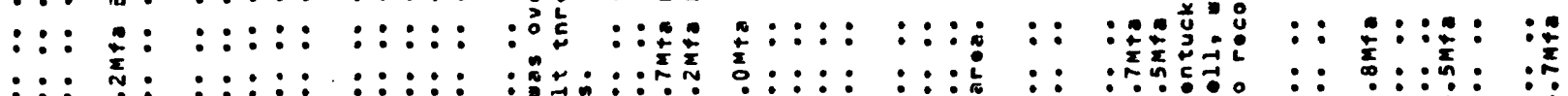

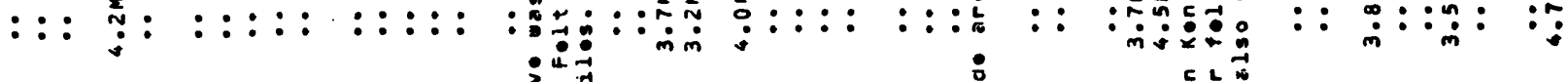

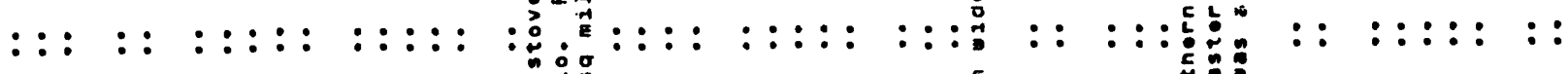

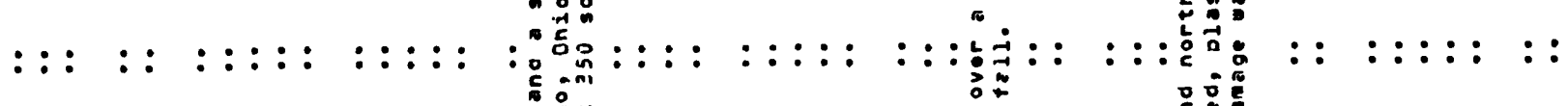

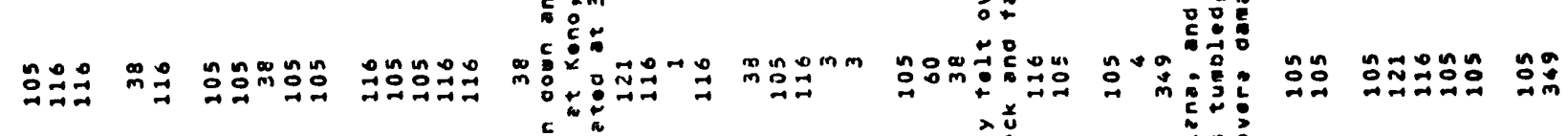

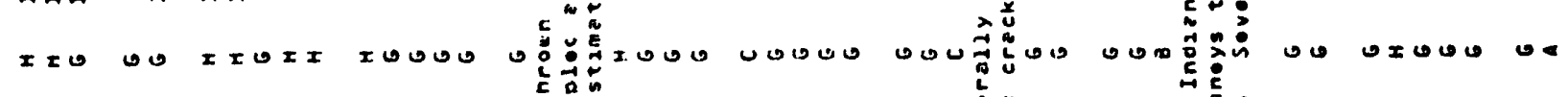

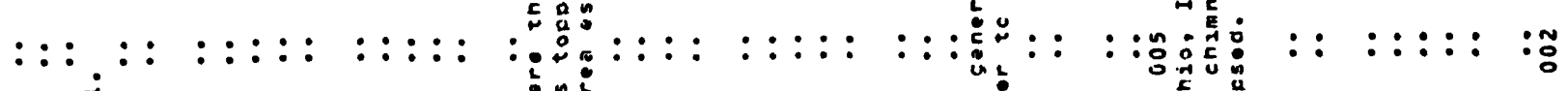
ii:

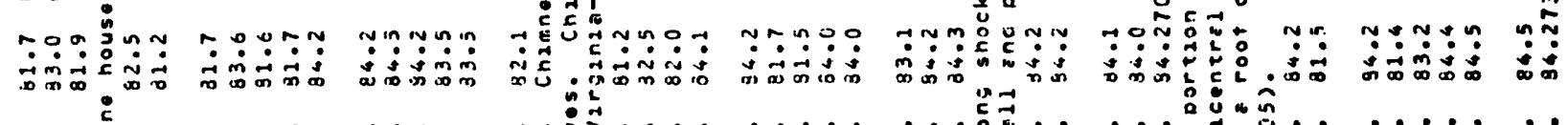

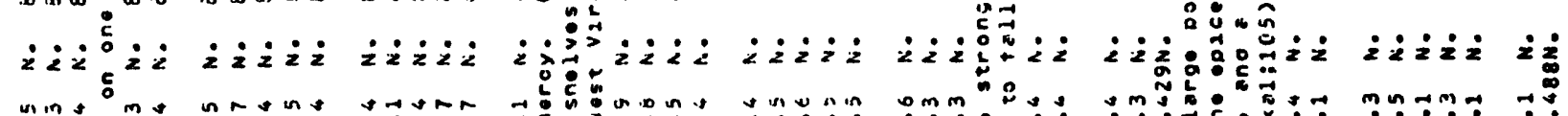

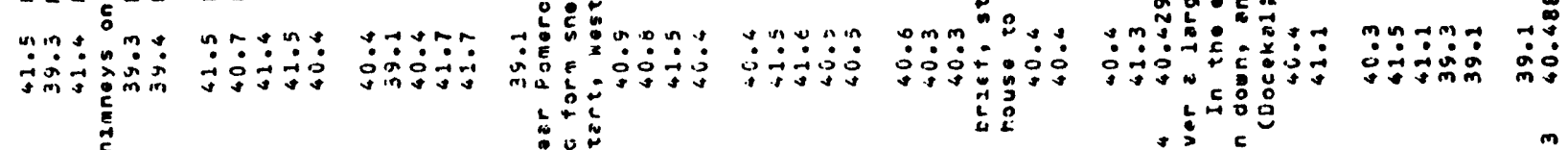

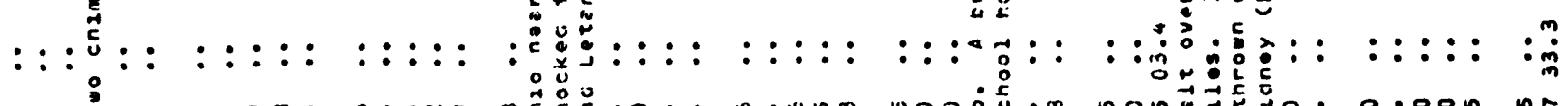

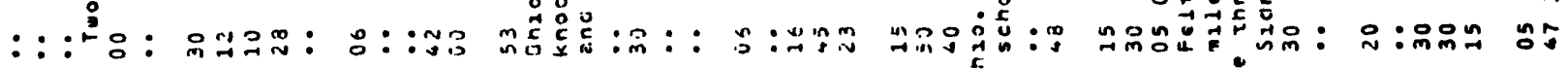
:

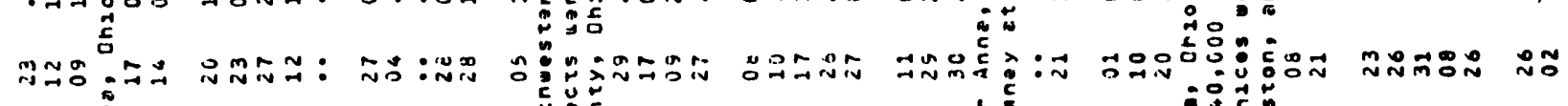

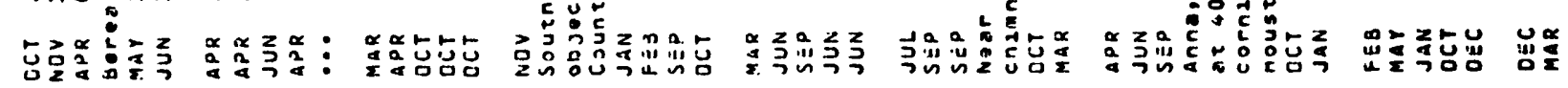

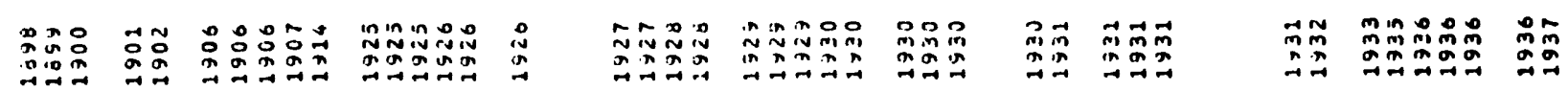


$:: 0 \%$

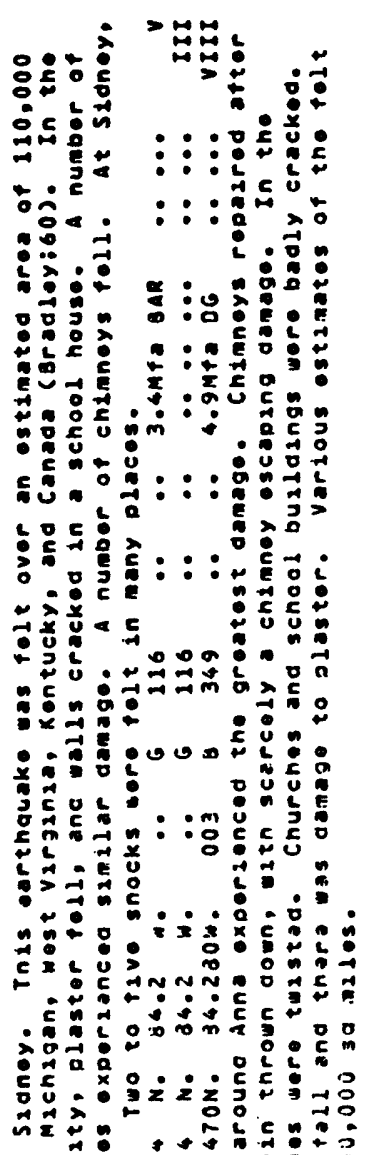

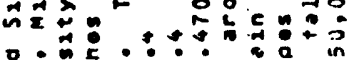

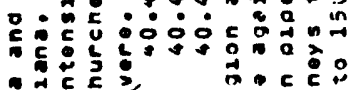

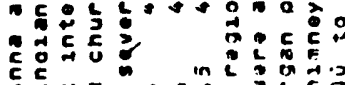

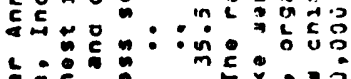

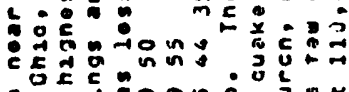

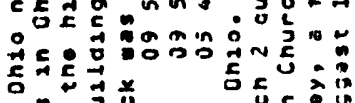

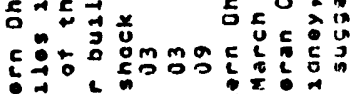

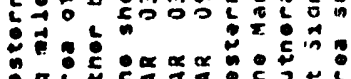

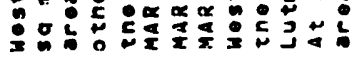

影

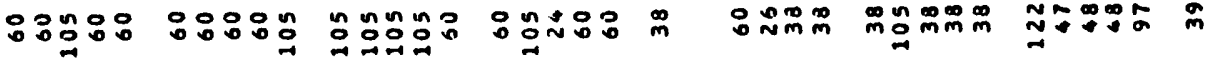

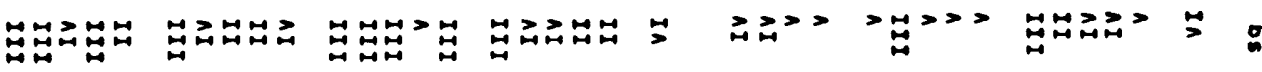

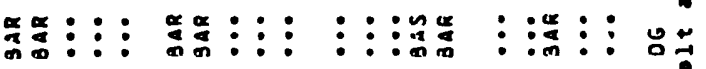

$:::::::::: \vdots::::: \vdots: \vdots:$

$::::::::::::::::_{:}^{a}$

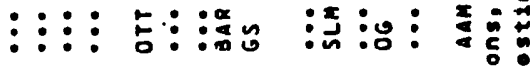

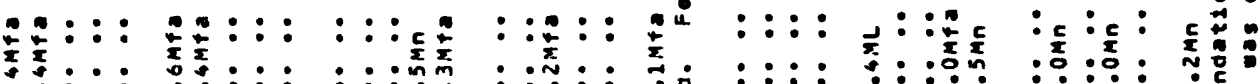

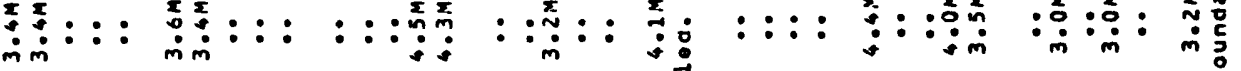

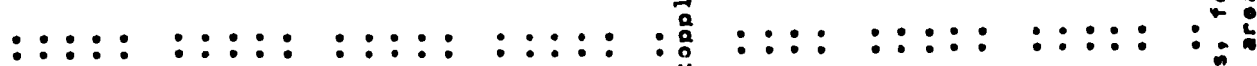

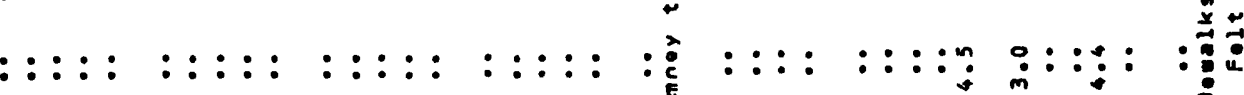

定

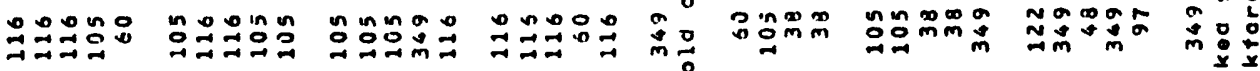

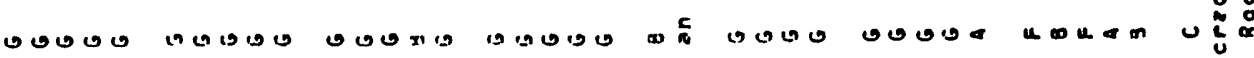

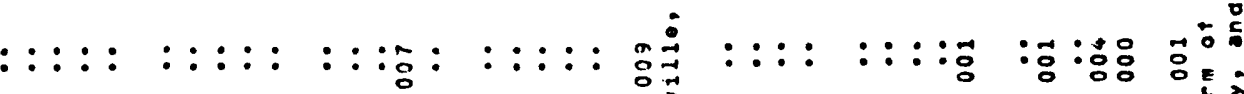

* $\times$ *

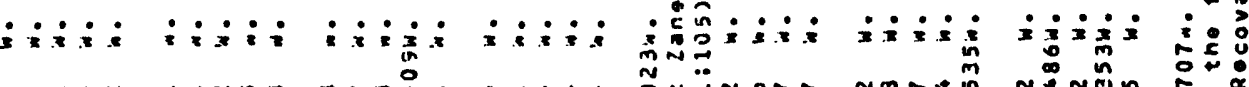

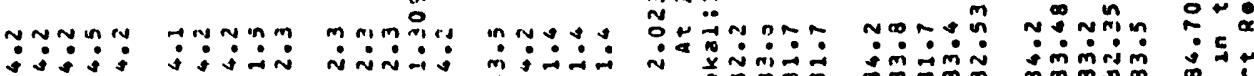

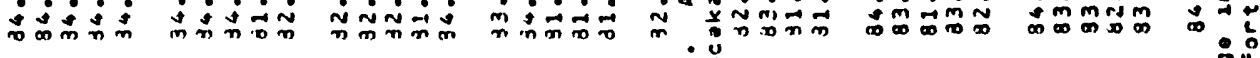

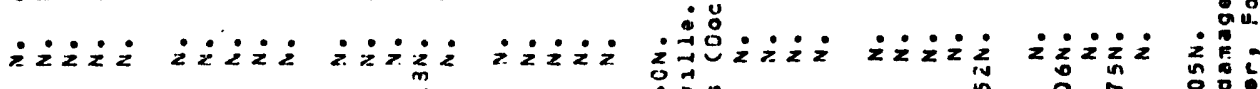

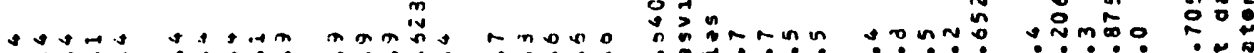

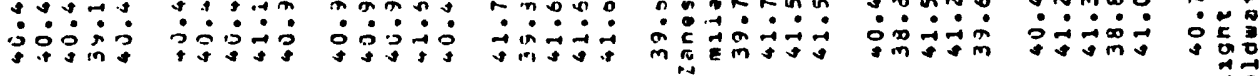

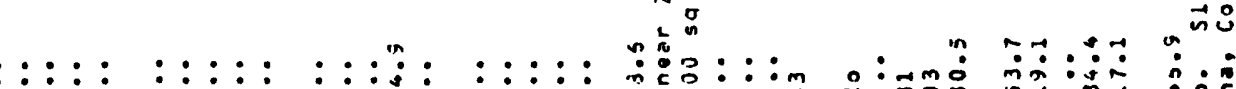

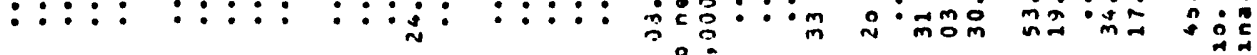

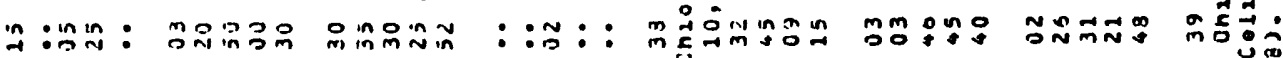

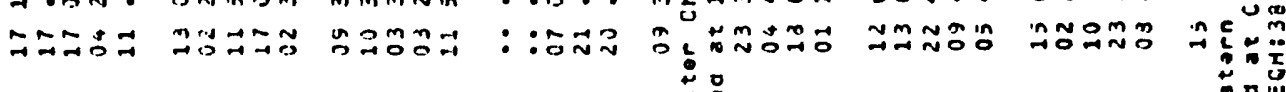

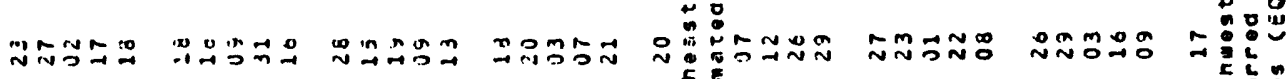

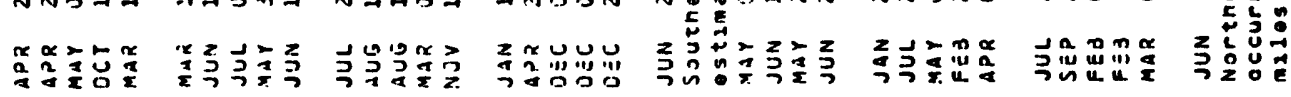

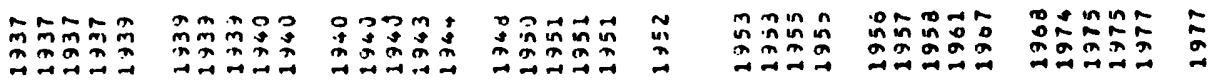




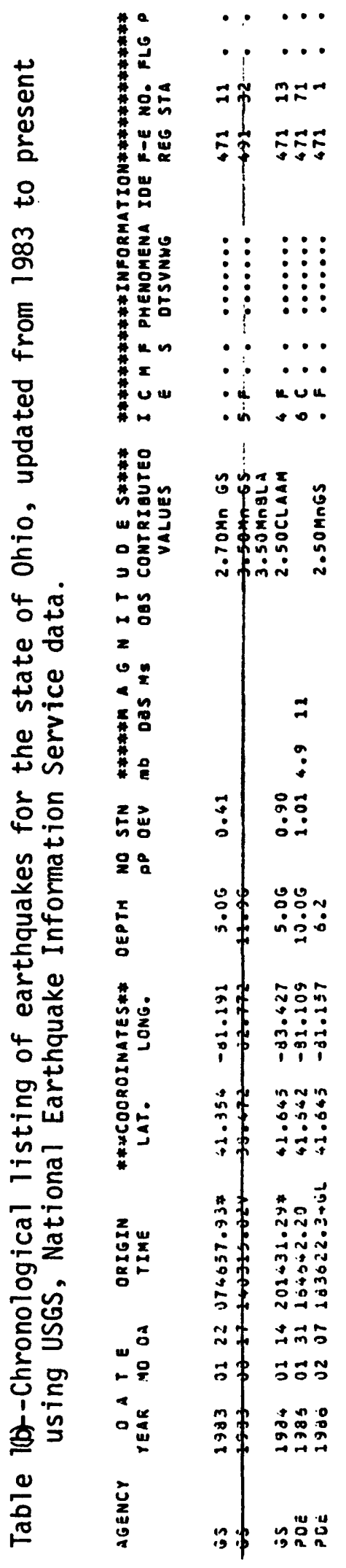




\begin{abstract}
APPENDIX B
PHASE DATA AND PREFERRED LOCATIONS FOR

EARTHQUAKES LOCATED NEAR PAINESVILLE, OHIO

FEBRUARY 6 THROUGH MARCH 24, 1986
\end{abstract}




\begin{tabular}{|c|c|c|c|c|}
\hline \multicolumn{2}{|c|}{ CRUSTAL MODEL } & $\begin{array}{l}1 \\
\text { IIEPTH }\end{array}$ & THICKNESS & UPUS \\
\hline & $\mathrm{KH} / \mathrm{SEC}$ & $K M$ & $K H$ & \\
\hline 1 & $1+800$ & 0.000 & 0.050 & 3.000 \\
\hline 2 & 3.000 & 0.050 & 0.450 & 1.700 \\
\hline 3 & 4.200 & 0.500 & 0.500 & 1.800 \\
\hline 4 & 4.500 & 1.000 & 0.750 & 1,780 \\
\hline 5 & 4.750 & 1.750 & 0.350 & 1.760 \\
\hline 6 & 6.150 & 2.100 & 17.900 & 1.740 \\
\hline 7 & 6.700 & 20.000 & 20.000 & 1.730 \\
\hline 8 & 8.100 & 40.000 & 1000.000 & 1.750 \\
\hline
\end{tabular}

THE NEXT NODEL IS FOR 5 ONLY:

CRUSTAL MODEL 2

$\begin{array}{rcccc}\text { LAYER } & \begin{array}{c}\text { VELOCITY } \\ \text { KM/SEC }\end{array} & \begin{array}{c}\text { IEFTH } \\ \text { KM }\end{array} & \begin{array}{c}\text { THICKNESS } \\ \text { KM }\end{array} & \text { UFUS } \\ 9 & 0.600 & 0.000 & 0.050 & 0.000 \\ 10 & 1.579 & 0.050 & 0.450 & 0.000 \\ 11 & 2.333 & 0.500 & 0.500 & 0.000 \\ 12 & 2.528 & 1.000 & 0.750 & 0.000 \\ 13 & 2.699 & 1.750 & 0.350 & 0.000 \\ 14 & 3.534 & 2.100 & 17.900 & 0.000 \\ 15 & 3.873 & 20.000 & 20.000 & 0.000 \\ 16 & 4.629 & 40.000 & 1000.000 & 0.000\end{array}$

$86 / 2 / 1 \quad 18 / 54$

TEST DATA

$86 / 2 / 1 \quad 18 / 54$

HORIZONTAL AND UERTICAL SINGLE VARIAELE STANDARI IEVIATIONS (68\% - ONE DEGREE OF FREEUOM) [VALUES TRUMCATED AT $25 \mathrm{KM}$ ]

$$
\begin{array}{lll}
\text { SEH }=0.25 & \text { SEH }=0.43 & \text { SEZ }=0.89 \quad \text { QUALITY }=A \\
A Z=25 . & A Z=-65 . &
\end{array}
$$

SE OF ORIG $=0.08$ TOTAL NUABER OF ITERATIONS $=5$ IMAX $=90.00$ SEQUENCE NUMEER $=$

AT THE CLOSEST STATION USED IN THE SOLUTION BOTH P AND S WERE USED. THE S NINUS P INTERVAL EQUALS 0,52

IATE ORIGIN LAT LONG DEPTH MAG NO DI GAP D RMS SEH SEZ Q SQD AIIJ IN NR AUR AAR NM AUXM SUXM NF AUFM SIFH

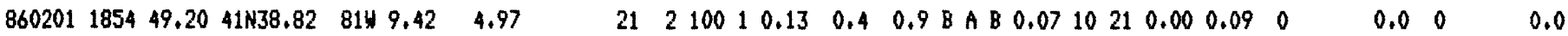

(- STATION DATA -) (----- P-WAVE TRAVEL-TIME JATA AND DELAYS -----) VARI (--- S-WAVE TRAVEL-TIME IATA --) (--- MAGNITUDE DATA --)

STN DIST AZM AIN PSEC PRMK+TCOR-D=TTOE-TTCAL C-DLAY-EDLY=P-RES P-WT THIC SSEC SRYK TTOB TTCAL S-RES S-WT AKX PR XYAG R FMP FMAG

WCO2 $2.3 \quad 356 \quad 15150.37 I P C O$

heoh 4.516413150 .60 IP 1

hlh $5.5 \quad 37 \quad 12550.771 \mathrm{PCO}$

hsoh $6.215912151 .05 I P 1$

WCO4 $6.917911850 .89 I P C O$

choh 6.920911850 .70 IP 1

toh $9.7114 \quad 11051.201 P 1$

wCO3 $11.6 \quad 36 \quad 106 \quad 51$.49IPDO

wC01 $12.5 \quad 254 \quad 105 \quad 51.72$ IPIO

hpv $13.6 \quad 40 \quad 104 \quad 51.851$ PDo

gor $15.8 \quad 354 \quad 102 \quad 52.22$ IPC1

$$
\begin{array}{ll}
1.17 & 1.101 \\
1.40 & 1.331 \\
1.57 & 1.451 \\
1.85 & 1.551 \\
1.69 & 1.641 \\
1.50 & 1.651 \\
2.00 & 2.051 \\
2.29 & 2.361 \\
2.52 & 2.511 \\
2.65 & 2.671 \\
3.02 & 3.021
\end{array}
$$

$\begin{array}{llllll}50.89 & \text { es3 } & 1.69 & 1.99 & -0.30 & 0.131\end{array}$

$\begin{array}{llllll}51.20 & \text { es3 } & 2.00 & 2.39 & -0.39 & 0.131\end{array}$

$\begin{array}{lllllll}51.61 & \text { is } 3 & 2.41 & 2.60 & -0.19 & 0.131\end{array}$ 4

$\begin{array}{llllll}51.81 & \text { es2 } & 2.61 & 2.94 & -0.33 & 0.525\end{array}$

$\begin{array}{llllll}52.05 & \text { es } 2 & 2.85 & 2.95 & -0.09 & 0.525\end{array}$

$\begin{array}{llllll}52.60 & \text { es3 } & 3.40 & 3.66 & -0.26 & 0.131\end{array}$

$\begin{array}{llllll}53.14 & \text { es2 } & 3.94 & 4.19 & -0.25 & 0.525\end{array}$

$\begin{array}{llllll}53.25 & \text { es3 } & 4.05 & 4.44 & -0.39 & 0.131\end{array}$

$\begin{array}{lllllll}53.75 & \text { is } 3 & 4.55 & 4.73 & -0.18 & 0.131\end{array}$

$\begin{array}{lllllll}54.57 & \text { is } 3 & 5.37 & 5.34 & 0.04 & 0.131\end{array}$

QUALITY EVALUATION

UIAGONALS IN ORDER OF STRENGTH AUE, OF END POINTS

$$
\begin{array}{rrrrrrr}
Z & \text { SE } & \text { NW } & \text { E } & \text { NE } & \text { SW } & N \\
0.24 & 0.47 & 0.60 & 0.70 & 0.84 & 0.85 & 0.89
\end{array}
$$

$\begin{array}{rrrrr}\text { NUMBEF } & \text { RHS } & \text { MIN DRMS } & \text { AUE DRMS } & \text { OUALITY } \\ 21 & 0.13 & 0.30 & 0.69 & \text { A }\end{array}$


$86 / 2 / 2 \quad 3 / 22$

TEST DATA

$86 / 2 / 2$

$3 / 22$

HORIZONTAL ANI UERTICAL SINGLE VARIABLE STANUARD DEUIATIONS (68\% - ONE DEGREE OF FFEEUON) [UALUES TRUNCATED AT $25 \mathrm{KM}$ ]

$\begin{array}{lll}\text { SEH }=0.12 & \text { SEH }=0.13 & \text { SEZ }=0.30 \quad \text { QUALITY }=A \\ A Z=-132 . & A Z=-42 . & \end{array}$

SE OF ORIG $=0.03$ TOTAL NUMBER OF ITERATIONS $=3$ IMAX $=90.00$ SEQUENCE NUMBER $=$

AT THE CLOSEST STATION USED IN THE SOLUTION BOTH P AND $S$ WERE USED. THE $S$ MINUS $P$ INTERVAL EQUALS 0,83

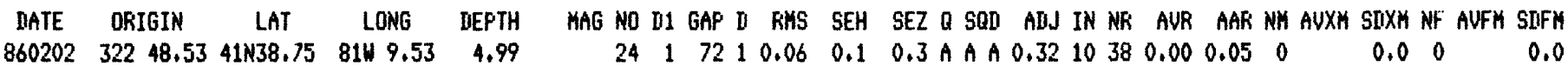

(- STATION UATA -) (------ P-WAUE TRAUEL-TIKE BATA AND IELAYS ------) UAKI (---- S-WAUE TRAUEL-TIME DATA --)(--- MAGNITUDE DATA --)

STN DIST AZM AIN PSEC PRMK+TCOR-0=TTOB-TTCAL C-DLAY-EILY=P-RES P-UT THIC SSEC SRMK ITOB TTCAL S-RES S-WT AKX PR XYAG R FYP FMAG

$\begin{array}{lllll}W C 02 & 2.4 & 0 & 150 & 49.69 I P C O\end{array}$

$1.161 .111 \quad 0.051 .455$

$\begin{array}{lll}1.92 & 1.90 \quad 0.020 .818\end{array}$

heoh 4.516113249 .90 IF 1

$1.37 \quad 1.331$

0.050 .818

$1.58 \quad 1.481$

0.100 .818

$1.47 \quad 1.621$

$-0.150 .818$

$1.63 \quad 1.631$

0.001 .455

$1.72 \quad 1.711$

0.010 .091

$1.81 \quad 1.721$

0.090 .818

$1.88 \quad 1.841$

0.041 .455

$2.01 \quad 1.991$

$\begin{array}{lllllllll}50.32 & 54 & 1.79 & 2.01 & -0.22 & 0.000\end{array}$

how 7.316211750 .251 PI3

0.021 .455

$2.14 \quad 2.131$

0.010 .818

$2.42 \quad 2.37 \quad 1$

0.051 .455

$2.34 \quad 2.391$

$-0.051 .455$

$2.51 \quad 2.481$

0.030 .818

$2.47 \quad 2.521$

$-0.050 .364$

$\begin{array}{lllllllllllll}50.40 & \text { es4 } & 1.87 & 2.38 & -0.51 & 0.000\end{array}$

$\begin{array}{llllll}51.00 & \text { is } 4 & 2.47 & 2.67 & -0.19 & 0.000\end{array}$

$\begin{array}{llllll}51.33 \text { es4 } & 2.80 & 2.90 & -0.10 & 0.000\end{array}$

$\begin{array}{lllllll}51.19 & 54 & 2.66 & 2.92 & -0.25 & 0.000\end{array}$

$\begin{array}{lllllll}51.45 & \text { es4 } & 2.92 & 3.05 & -0.13 & 0.000\end{array}$

$\begin{array}{llllll}51.31 & \text { is4 } & 2.78 & 3.08 & -0.30 & 0.000\end{array}$

$\begin{array}{llllll}51.75 & \text { is } & 3.22 & 3.28 & -0.06 & 1.455\end{array}$

$\begin{array}{llllll}51.95 & \text { iso } & 3.42 & 3.56 & -0.14 & 1.455\end{array}$

$2.57 \quad 2.541$

0.030 .818

2.672 .701

$-0.030 .818$

0.080 .091

0.031 .455

$3.35 \quad 3.321$

$-0.030 .091$

$\begin{array}{llllll}52.66 & \text { is0 } & 4.13 & 4.21 & -0.08 & 1.455\end{array}$

$\begin{array}{lllllll}52.54 & \text { is4 } & 4.01 & 4.24 & -0.23 & 0.000\end{array}$

$\begin{array}{lllllll}52.64 & 54 & 4.11 & 4.39 & -0.28 & 0.000\end{array}$

$\begin{array}{llllll}52.92 & \text { es4 } & 4.39 & 4.46 & -0.07 & 0.000\end{array}$

$\begin{array}{lllllllll}52.80 & \text { es4 } & 4.27 & 4.51 & -0.23 & 0.000\end{array}$

$\begin{array}{lllllll}53.17 & \text { is4 } & 4.64 & 4.78 & -0.14 & 0.000\end{array}$

$\begin{array}{llllll}53.73 & \text { is } & 5.20 & 5.39 & -0.19 & 0.000\end{array}$

$3.67 \quad 3.701$

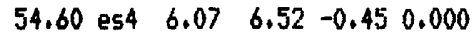

QUALITY EVALUATION

DIAGONALS IN ORDER OF STRENGTH AUE. OF ENU POINTS

$\begin{array}{rrrrrrr}Z & \text { SE } & \text { NW } & \text { SH } & \text { NE } & N & E \\ 0.37 & 0.72 & 0.80 & 0.87 & 0.90 & 0.94 & 0.99\end{array}$

$\begin{array}{rrrrr}\text { NUMBER } & \text { RMS } & \text { WIN DRMS AUE DFMS } & \text { QUALITY } \\ 24 & 0.06 & 0.41 & 0.84 & \text { A }\end{array}$


HORIZONTAL AND VERTICAL SINGLE VARIABLE STANDARD DEVIATIONS (68\% - ONE DEGREE OF FREEDOK) [UALUES TRUNCATED AT $25 \mathrm{KM}]$

$$
\begin{array}{lll}
\text { SEH }=0.12 & \text { SEH }=0.18 & \text { SEZ }=0.36 \quad \text { QUALITY }=A \\
A Z=16 . & A Z=-74 . &
\end{array}
$$

SE OF ORIG $=0.03$ TOTAL NUMBER OF ITERATIONS $=3$ DMAX $=90.00$ SEQUENCE NUMBER $=$

AT THE CLOSEST STATION USED IN THE SOLUTION BOTH P AND S WERE USED. THE S MINUS P INTERUAL EQUALS 0.85

IATE ORIGIN LAT LONG DEPTH MAG NO III GAP D RKS SEH SEZ Q SQD AIIJ IN NR AUR AAR MM AUXM SDXK NF AVFM SDFH

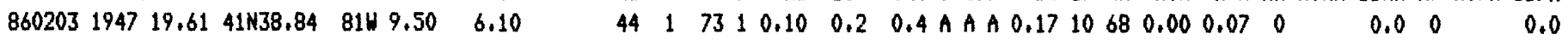

(- STATION IATA -) (----- P-WAVE TRAVEL-TIME DATA AND DELAYS ------) VARI (---- S-WAUE TRAVEL-TIME DATA --)(--- MAGNITUDE DATA --)

\begin{tabular}{|c|c|c|c|c|c|c|c|c|c|}
\hline$x 03$ & $1.432516620 .83 \mathrm{IPCO}$ & 1.22 & 1.221 & 0.001 .470 & 21.68 & is1 & 2.07 & 2,19 & $\begin{array}{lll}-0.12 & 0.827\end{array}$ \\
\hline wCO2 & $2.2359 \quad 157 \quad 20.91 \mathrm{IPCO}$ & 1.30 & 1.261 & 0.041 .470 & & 4 & & & \\
\hline elfi & $4.3207 \quad 14121.20 \mathrm{IPH}$ & 1.59 & 1.431 & 0.160 .092 & 22.30 & es4 & 2.69 & 2.57 & 0.120 .000 \\
\hline cal & $\begin{array}{llll}4.5 & 11 & 139 & 21.24 I P C I\end{array}$ & 1.63 & 1.451 & 0.180 .827 & 22.54 & is4 & 2.93 & 2,61 & 0.320 .000 \\
\hline ham & $5.1 \quad 164 \quad 135 \quad 21.16$ IPD1 & 1.55 & 1.531 & 0.020 .827 & 21.66 & is 4 & 2.05 & 2.74 & -0.690 .000 \\
\hline hlh & $\begin{array}{lllll}5.6 & 38 & 132 & 21.26 I P C 1\end{array}$ & 1.65 & 1.581 & 0.070 .827 & & 4 & & & \\
\hline wsh & $\begin{array}{llll}5.8 & 247 & 131 & 21.321 P 11\end{array}$ & 1.71 & 1.601 & 0.110 .827 & 22,30 & is4 & 2.69 & 2.86 & -0.170 .000 \\
\hline $\begin{array}{l}\text { bur } \\
\text { wCO4 }\end{array}$ & $\begin{array}{rrrr}6.4 & 83 & 128 & 21.40 I P I 1 \\
6.9 & 178 & 126 & 21.35 I P C 0\end{array}$ & $\begin{array}{l}1.79 \\
1.74\end{array}$ & $\begin{array}{l}1.671 \\
1.741\end{array}$ & $\begin{array}{ll}0.12 & 0.827 \\
0.00 & 1.470\end{array}$ & $\begin{array}{l}22,75 \\
22,38\end{array}$ & $\begin{array}{r}\text { is4 } \\
54\end{array}$ & $\begin{array}{l}3.14 \\
2.77\end{array}$ & $\begin{array}{l}2,99 \\
3,11\end{array}$ & $\begin{array}{rr}0.15 & 0.000 \\
-0.34 & 0.000\end{array}$ \\
\hline con & $\begin{array}{llll}7.3 & 325 & 124 & 21.47 I P C 1\end{array}$ & 1.86 & 1.791 & 0.070 .827 & & 4 & & & \\
\hline$t t r$ & $7.3 \quad 205 \quad 12421.52$ IPC1 & 1.91 & 1.791 & 0.120 .827 & 22.92 & is4 & 3.31 & 3.21 & $0.10 \quad 0.000$ \\
\hline how & $7.516312421 .50 \mathrm{IP}^{-3}$ & 1.89 & 1.811 & $0.08 \quad 0.092$ & 22.70 & es 4 & 3.09 & 3.25 & -0.160 .000 \\
\hline$x 06$ & $8.2 \quad 104 \quad 121 \quad 21.55 I P I 0$ & 1.94 & 1.921 & 0.021 .470 & 22.89 & is1 & 3.28 & 3.43 & -0.150 .827 \\
\hline cali & $8.818711921 .61 \mathrm{IP}+3$ & 2.00 & 2.011 & -0.010 .092 & 23.00 & es4 & 3.39 & 3.58 & -0.190 .000 \\
\hline $\cot$ & $9.1147 \quad 11821.72 \mathrm{IPCl}$ & 2.11 & 2.051 & 0.060 .827 & 23.16 & is4 & 3.55 & 3.64 & -0.090 .000 \\
\hline$x 02$ & $9.10118 \quad 21.60 \mathrm{IPCO}$ & 1.99 & 2.051 & -0.061 .470 & 22.98 & is2 & 3.37 & 3,64 & $\begin{array}{lll}-0.27 & 0.367\end{array}$ \\
\hline cuy & $9.8185116 \quad 21.76 \mathrm{IPC1}$ & 2.15 & 2.151 & 0.000 .827 & 23.28 & is4 & 3.67 & 3.83 & -0.160 .000 \\
\hline tom & $10.0 \quad 63 \quad 116 \quad 21.82 \mathrm{IPDO}$ & 2.21 & 2.171 & 0.041 .470 & & 4 & & & \\
\hline hse & $10.115811521 .81 \mathrm{IP}+1$ & 2.20 & 2.201 & 0.000 .827 & 23.31 & is4 & 3.70 & 3.90 & $-0.20 \quad 0.000$ \\
\hline cha & $11.4 \quad 223 \quad 11322.05 I P D O$ & 2,44 & 2.381 & 0.061 .470 & 23.76 & es4 & 4.15 & 4.22 & -0.070 .000 \\
\hline mon & $11.6 \quad 122 \quad 112 \quad 22.06 I P C 1$ & 2,45 & 2,421 & 0.030 .827 & 23.62 & is 4 & 4.01 & 4.29 & $-0.28 \quad 0.000$ \\
\hline wCO3 & $11.6 \quad 37 \quad 112 \quad 21.98 \mathrm{IP} 1$ & 2.37 & 2.421 & -0.050 .827 & 23.78 & 54 & 4.17 & 4.29 & -0.120 .000 \\
\hline$x 04$ & $11.8 \quad 252 \quad 112 \quad 22.19 \mathrm{IPDO}$ & 2.58 & 2.441 & 0.141 .470 & & 4 & & & \\
\hline min & $12.8 \quad 22011022.06$ IPDO & 2.45 & 2.591 & -0.141 .470 & 23.97 & es4 & 4.36 & 4.60 & -0.240 .000 \\
\hline$x 08$ & $12.9202 \quad 11022.25 \mathrm{IPCO}$ & 2.64 & 2.601 & 0.041 .470 & 24.19 & ist & 4.58 & 4.63 & $-0.05 \quad 0.827$ \\
\hline$x 07$ & $14.0149 \quad 108 \quad 22.46 \mathrm{EP}-1$ & 2.85 & 2.771 & $0.08 \quad 0.827$ & 24,42 & is1 & 4.81 & 4.92 & $\begin{array}{lll}-0.11 & 0.827\end{array}$ \\
\hline har & $14.3 \quad 106 \quad 108 \quad 22.45 I P D 1$ & 2.84 & 2.821 & 0.020 .827 & 24.39 & is4 & 4.78 & 5.01 & -0.230 .000 \\
\hline $10 x$ & $14.3 \quad 42 \quad 108 \quad 22.50$ IPU1 & 2.89 & 2.821 & 0.070 .827 & 24.55 & is4 & 4.94 & 5.01 & -0.010 .000 \\
\hline hwk & $15.5 \quad 69 \quad 106 \quad 22.89$ IPC1 & 3.28 & 3.031 & 0.250 .827 & 25.19 & is4 & 5.58 & 5.35 & 0.230 .000 \\
\hline wCO7 & $17.0 \quad 4 \quad 10522.751 F C O$ & 3.14 & 3.251 & -0.111 .470 & 25.03 & is4 & 5.42 & 5.74 & -0.320 .000 \\
\hline per & $17.144105 \quad 22.62$ IFCI & 3.01 & 3.271 & $-0.26 \quad 0.827$ & 24.60 & 4 & 4,99 & 5.77 & $-0.780,000$ \\
\hline htg & $17.3 \quad 100 \quad 105 \quad 22.82 I P \quad 0$ & 3.21 & 3.291 & -0.081 .470 & 25.52 & es4 & 5.91 & 5.82 & 0.100 .000 \\
\hline$x 01$ & $17.5410422 .98 \mathrm{IPCO}$ & 3.37 & 3.331 & 0.041 .470 & 25,45 & is1 & 5,84 & 5.88 & -0.040 .827 \\
\hline che & $\begin{array}{llll}19.6 & 221 & 103 & 23.24 I P D O\end{array}$ & 3.63 & 3.661 & -0.031 .470 & 25.93 & es4 & 6.32 & 6.45 & -0.130 .000 \\
\hline cld & $\begin{array}{llll}20.2 & 227 & 102 & 23.32 \mathrm{IPDO}\end{array}$ & 3.71 & 3.761 & -0.051 .470 & & 4 & & & \\
\hline ifd & $21.7 \quad 161 \quad 101 \quad 23.62 \mathrm{IPCO}$ & 4.01 & 3.991 & 0.021 .470 & 26.52 & es4 & 6.91 & 7.03 & $-0,120,000$ \\
\hline$\times 09$ & $\begin{array}{llll}26.2 & 187 & 99 & 24.32 E P^{-}-1\end{array}$ & 4.71 & 4.711 & $0.00 \quad 0.827$ & 27.70 & isi & 8.09 & 8.28 & $\begin{array}{lll}-0.19 & 0.827\end{array}$ \\
\hline
\end{tabular}

STN DIST AZM AIN PSEC PRMK+TCOR-0=TTOB-TTCAL C-DLAY-EDLY=P-RES P-HT THIC SSEC SRMK TTOB TTCAL S-RES S-WT AMX PR XWAG R FKP FMAG

QUALITY EUALUATION

IIIAGONALS IN ORDER OF STRENGTH AUE. OF END POINTS
$\begin{array}{rrrrrrr}Z & \text { SE } & \text { NW } & \text { E } & \text { NE } & \text { SW } & N \\ 0.29 & 0.67 & 0.70 & 0.75 & 0.85 & 0.85 & 1.07\end{array}$

RMS MIN IIRMS AUE DRMS QUALITY
0.10
0.78

\section{A}




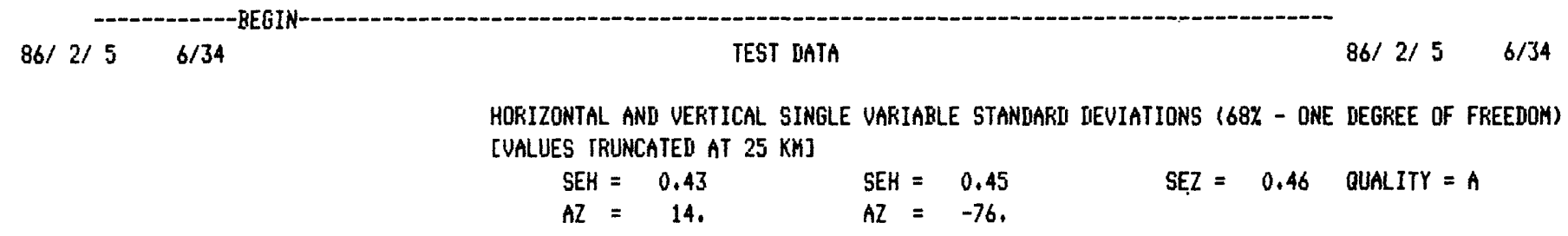

SE OF ORIG $=0.07$ TOTAL NUMBER OF ITERATIONS $=5$ IMAAX $=90.00$ SEQUENCE NUIABER $=$

AT THE CLOSEST STATION USED IN THE SOLUTION BOTH P AND S HERE USED. THE S MINUS P INTERVAL EQUALS 1,74

DATE ORIGIN LAT LONG IIEPTH MAG NO DI GAF D RMS SEH SEZ Q SQD AIJ IN NR AUR AAR NM AUXM SUXM NF AUFM SUFM

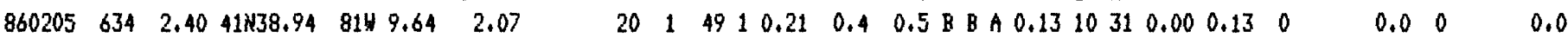

(- STATION IATA -) (----- P-WAVE TRAUEL-TIME IATA AND IELLAYS ------) VARI (---- 5- WAUE TRAVEL-TIME DATA --)(--- MAGNITUDE DATA --) STN IIIST AZM AIN FSEC PRMK+TCOR-D=TTOB-TTCAL C-DLAY-EDLY=P-RES P-HT THIC SSEC SRMK TTOB ITCAL S-RES 5-UT AMX PK XHAG R FMP FMAG

\begin{tabular}{|c|c|c|c|c|c|c|c|c|c|c|}
\hline$x 03$ & 1.1328 & 147 & $2,27 \mathrm{IFCl}$ & -0.13 & 0.601 & $-0.74 \quad 1.047$ & 4.01 is2 & 1.61 & 1.12 & 0.480 .465 \\
\hline form & 1.6222 & 136 & $3.10 \mathrm{IP} 3$ & 0.70 & 0.661 & 0.030 .116 & 3.80 es4 & 1.40 & 1.24 & 0.160 .000 \\
\hline wCO2 & $2.1 \quad 4$ & 127 & $3.391 \mathrm{PCO}$ & 0.99 & 0.731 & 0.251 .860 & 3.92 is & 1.52 & 1.36 & 0.150 .000 \\
\hline pop & 4.8131 & 51 & $3.62 \mathrm{IPC} 1$ & 1.22 & 1.191 & 0.031 .047 & 4,24 ist & 1,84 & 2.15 & -0.320 .000 \\
\hline$x 55$ & 4.8135 & 51 & $3.691 \mathrm{ICl} 1$ & 1.29 & 1.191 & 0.091 .047 & $4.60 \mathrm{is} 1$ & 2.20 & 2.16 & 0.031 .047 \\
\hline hlh & 5.641 & 51 & 3.77 IPDI & 1.37 & 1.311 & 0.051 .047 & 4.82 is4 & 2.42 & 2.37 & 0.050 .000 \\
\hline cfd & 5.9298 & 51 & $3.90 \mathrm{IPCO}$ & 1.50 & 1.371 & 0.121 .860 & 4 & & & \\
\hline con & 7.0325 & 51 & $4.03 \mathrm{IFC} 1$ & 1.63 & 1.551 & 0.071 .047 & 4.98 is4 & 2.58 & 2.79 & $-0.21 \quad 0.000$ \\
\hline wCO4 & 7.1177 & 51 & $3.97 \times 1$ & 1.57 & 1.571 & 0.001 .047 & 4.84 es4 & 2.44 & 2.81 & -0.370 .000 \\
\hline ttr & 7.4203 & 51 & 4.06 IPD1 & 1.66 & 1.611 & 0.041 .047 & 5.34 is4 & 2.94 & 2.89 & 0.050 .000 \\
\hline$x 02$ & 8.92 & 51 & 0.004 & $-2,40$ & 1.861 & -4.260 .000 & 5.62 is1 & 3.22 & 3.32 & $\begin{array}{lll}-0.10 & 1.047\end{array}$ \\
\hline ton & $10+1$ & 51 & 4.25 IP 2 & 1.85 & 2.051 & -0.200 .465 & 4 & & & \\
\hline mon: & 10.2114 & 51 & $4.30 \mathrm{IPJ} 3$ & 1.90 & 2.071 & -0.180 .116 & 5.75 es4 & 3.35 & 3.69 & -0.350 .000 \\
\hline wC03 & $11.6 \quad 38$ & 51 & $4.60 \mathrm{IPD} 0$ & 2.20 & 2.301 & $-0.10 \quad 1.860$ & $6.00 \mathrm{es4}$ & 3.60 & 4.08 & -0.490 .000 \\
\hline$x 04$ & 11.6251 & 51 & 4.79 IPC2 & 2.39 & 2.301 & 0.080 .465 & $6.41 \mathrm{is} 1$ & 4.01 & 4.09 & -0.091 .047 \\
\hline wCO1 & 12.3252 & 51 & 4.81 IPDO & 2.41 & 2.411 & -0.011 .860 & 6.63 ist & 4.23 & 4.28 & -0.050 .000 \\
\hline $\min$ & 12,8219 & 51 & 4.85 IP 2 & 2.45 & 2.491 & $-0.04 \quad 0.465$ & 4 & & & \\
\hline
\end{tabular}

QUALITY EVALUATION

IIAGONALS IN ORIER OF STRENGTH AVE. OF END POINTS

\begin{abstract}
2 SE NW NE N SW E $\begin{array}{lllllll}0.18 & 0.58 & 0.60 & 0.76 & 0.79 & 0.19 & 0.81\end{array}$
\end{abstract}

$\begin{array}{rrrrr}\text { NUMBER } & \text { RMS } & \text { MIN IIKMS } & \text { AUE IRKS } & \text { QUALITY } \\ 20 & 0.21 & 0.24 & 0.69 & 8\end{array}$ 
HORIZONTAL ANO UERTICAL SINGLE VARIABLE STANDARD DEVIATIONS (68\% - ONE IEGREE OF FREEDON) [UALUES TRUNCATED AT $25 \mathrm{KM}$ ]

$$
\begin{array}{lll}
\text { SEH }=0.15 & \text { SEH }=0.21 & \text { SEZ }=0.44 \quad \text { QUALITY }=A \\
A Z=5 . & A Z=-85 . &
\end{array}
$$

SE OF ORIG $=0.04$ TOTAL MUMBER OF ITERATIONS $=4$ DMAX $=90.00$ SEQUENCE . MUMBER $=$

AT THE CLOSEST STATION LSED IN THE SOLUTION BOTH P AND S WERE USED. THE S MINUS P INTERVAL EQUALS O

DATE ORIGIN LAT LONG DEPTH MAG NO DI GAP D RHS SEH SEZ Q SQD ADJ IN NR AUR AAR NM AUXK SDXY NF AUFH SDFK

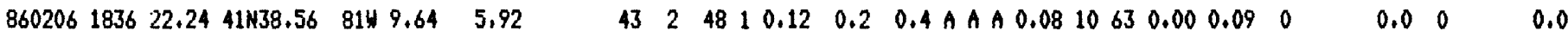

(- STATION DATA -) (---- P-WAVE TRAVEL-TIME IATA AND DELAYS -----) VARI (--- S-WAVE TRAVEL-TIME DATA --)(--- KAGNITUDE DATA --)

STN DIST AZM AIN PSEC PRYKTTCOR-O=TTOB-TTCAL C-ILLAY-EDLY=P-RES P-WT THIC SSEC SRIKK TTOB ITCAL S-RES S-WT AMX PR XYMG R FHP FHAG

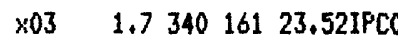

$\begin{array}{llllll}\text { wCO2 } & 2.8 & 3 & 152 & 23.56 \text { IPCO }\end{array}$

pop $\quad 4.4 \quad 124 \quad 139 \quad 23.75 I P D 1$

how $\quad 4.716013723 .70$ IPC1

$\begin{array}{llllll}\text { col } & 5.0 & 12 & 135 & 23.81 \text { IPCI }\end{array}$

wsh $5.4251 \quad 132 \quad 23.91$ IFD1

hin $6.1 \quad 37 \quad 12923.91$ IFII

ifd $6.3304128 \quad 23.95 I P C 0$

wC04 $6.4 \quad 177 \quad 12723.96 I P 1$

erj $\quad 6.6 \quad 76 \quad 126 \quad 23.95 I P D 1$

ttr 6.820512624 .111 PC1

con $7.6328122 \quad 24.08$ IPC1

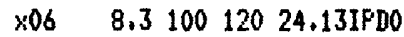

cot $8.814411824 .34 I F C 1$

cuy $9.3184116 \quad 24.42 I P C 1$

$\begin{array}{lllll}x 02 & 9.6 \quad 1116 & 24.31 \text { IFCO }\end{array}$

hse $9.715611524,44 E \mathrm{EP}+1$

tol $10,4 \quad 6111424,40$ IPDI

mon $11.5 \quad 119 \quad 11124.71$ IPD1

wC01 $12.1255 \quad 110 \quad 24,781$ PDO

$\begin{array}{llllll}\text { wCO3 } & 12.2 & 36 & 110 & 24.711 \text { F DO }\end{array}$

min $12.3221 \quad 11024.70$ EF 3

$x 08 \quad 12.3202 \quad 110 \quad 24,43 E P+1$

$x 07 \quad 13.6 \quad 147 \quad 10824.91 E P C 1$

fot $13.8 \quad 87 \quad 108 \quad 25.02$ IPD1

lox $\quad 14.8 \quad 41 \quad 106 \quad 25.07$ IF'D1

wCO6 $15.8 \quad 136 \quad 105 \quad 25.40 I P C O$

hwk $15.9 \quad 68 \quad 105 \quad 25.53$ IPD1

htg $17.49810425,40 \mathrm{EP} 3$

wC07 17.5 510425.49 IPCO

$\begin{array}{llll}x 01 \quad 18.0 \quad 5 & 103 & 25.66 I P C O\end{array}$

che $19.0221 \quad 10325.80$ IPDO

cld $19.7 \quad 228 \quad 102 \quad 26.00$ IPII 2

afd $21.3 \quad 16010126.30$ IP 2

$\begin{array}{lllll}x 09 & 25.7 \quad 187 \quad 99 & 26.89 E P I I\end{array}$

x11 $54.8 \quad 172 \quad 9431.62$ IPU1

$\begin{array}{lll}1.28 & 1.20 & 1 \\ 1.32 & 1.27 & 1 \\ 1.51 & 1.42 & 1 \\ 1.46 & 1.46 & 1 \\ 1.57 & 1.49 & 1 \\ 1.67 & 1.54 & 1 \\ 1.67 & 1.62 & 1 \\ 1.71 & 1.65 & 1 \\ 1.72 & 1.66 & 1 \\ 1.71 & 1.69 & 1 \\ 1.87 & 1.70 & 1 \\ 1.84 & 1.81 & 1 \\ 1.89 & 1.92 & 1 \\ 2.10 & 1.99 & 1 \\ 2.18 & 2.06 & 1 \\ 2.07 & 2.11 & 1 \\ 2.20 & 2.13 & 1 \\ 2.16 & 2.22 & 1 \\ 2.47 & 2.39 & 1 \\ 2.54 & 2.48 & 1 \\ 2.47 & 2.49 & 1 \\ 2.46 & 2.501 \\ 2.19 & 2.51 & 1 \\ 2.67 & 2.71 & 1 \\ 2.79 & 2.74 & 1 \\ 2.83 & 2.901 \\ 3.16 & 3.061 \\ 3.29 & 3.08 & 1 \\ 3.16 & 3.301 \\ 3.25 & 3.331 \\ 3.42 & 3.41 & 1 \\ 3.56 & 3.57 & 1 \\ 3.76 & 3.68 & 1 \\ 4.06 & 3.92 & 1 \\ 4.65 & 4.62 & 1 \\ 9.38 & 9.34 & 1\end{array}$

0.081 .592

0.051 .592

0.090 .896

0.000 .896

0.080 .896

0.130 .896

0.050 .896

0.061 .592

0.060 .896

0.020 .896

0.170 .896

0.030 .896

$-0.031 .592$

0.110 .896

0.120 .896

$-0.041 .592$

0.070 .896

$-0.060 .896$

0.080 .896

0.061 .592

$-0.021 .592$

$-0.040 .100$

$-0.320 .896$

$-0.040 .896$

0.040 .896

$-0.070 .896$

0.101 .592

0.210 .896

$-0.140 .100$

$-0.081 .592$

0.011 .592

$-0.011 .592$

0.080 .398

0.140 .398

0.030 .896

0.040 .308 $\begin{array}{lllllll}24.39 & \text { is } 1 & 2.15 & 2.17 & -0.02 & 0.896\end{array}$

$$
4
$$

$\begin{array}{lllllllll}24.33 & \text { is } 4 & 2.09 & 2.62 & -0.53 & 0.000\end{array}$

$\begin{array}{llllll}25.06 & \text { is } & 2.82 & 2.68 & 0.14 & 0.000\end{array}$

$\begin{array}{lllllllll}24,93 & \text { is } 4 & 2,69 & 2,75 & -0.06 & 0.000\end{array}$ 4

25.00 es4 $2.76 \quad 2.94 \quad-0.18 \quad 0.000$

$\begin{array}{llllll}25.07 & \text { is } & 2.83 & 3.02 & -0.19 & 0.000\end{array}$

$\begin{array}{llllll}25.52 & \text { is } & 3.28 & 3.04 & 0.24 & 0.000\end{array}$ 4

$\begin{array}{llllll}25.49 & \text { is } & 3.25 & 3.42 & -0.17 & 0.896\end{array}$

25.49 is $3.25 \quad 3.54-0.290 .000$

$\begin{array}{lllllll}25.78 & \text { is } & 3.54 & 3.67 & -0.13 & 0.000\end{array}$

25.73 is $\quad 3.49 \quad 3.75 \quad-0.26 \quad 0.896$

$\begin{array}{llllll}25.99 & \text { is } 4 & 3.75 & 3.78 & -0.03 & 0.000\end{array}$

4

$\begin{array}{llllll}26.11 & \text { is4 } & 3.87 & 4.24 & -0.37 & 0.000\end{array}$

$\begin{array}{llllll}26.46 & \text { es } 4 & 4.22 & 4.41 & -0.19 & 0.000\end{array}$

$\begin{array}{llllll}26.66 & \text { es4 } & 4.42 & 4.42 & 0.00 & 0.000\end{array}$

$\begin{array}{llllll}26.50 & \text { es4 } & 4.26 & 4.45 & -0.19 & 0.000\end{array}$

26.31 ist $4.07 \quad 4.47 \quad-0.40 \quad 0.896$

$\begin{array}{llllll}26.91 & \text { ist } & 4.67 & 4.82 & -0.15 & 0.896\end{array}$

$\begin{array}{llllll}27.02 & \text { is } 4 & 4.78 & 4.87 & -0.09 & 0.000\end{array}$

27.09 is $4 \quad 4.85 \quad 5.13 \quad-0.28 \quad 0.000$

27.48 is $\quad 5.24 \quad 5.41 \quad-0.17 \quad 0.000$

$\begin{array}{llllll}27.93 & \text { is } 4 & 5.69 & 5.44 & 0.25 & 0.000\end{array}$ 4

$\begin{array}{llllll}27.82 & \text { es4 } & 5.58 & 5.88 & -0.30 & 0.000\end{array}$

$\begin{array}{lllllll}28.12 & \text { is } & 5.88 & 6.01 & -0.13 & 0.896\end{array}$

$\begin{array}{llllll}28.47 & \text { es4 } & 6.23 & 6.29 & -0.06 & 0.000\end{array}$ 4

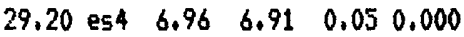

$\begin{array}{lllllll}30.25 & \text { ist } & 8.01 & 8.13 & -0.12 & 0.896\end{array}$

QUALITY EUALUATION

DIAGONALS IN ORDER OF STRENGTH AUE, OF ENI FOINTS

$$
\begin{array}{rrrrrrr}
Z & E & \text { SE } & \text { NH } & \text { NE } & \text { SH } & \text { N } \\
0.29 & 0.70 & 0.73 & 0.75 & 0.78 & 0.81 & 1.09
\end{array}
$$

$\begin{array}{rrrrr}\text { NUMBER } & \text { RHS } \\ 43 & 0.12 & 0.34 & 0.78\end{array}$ 
$86 / 2 / 7 \quad 15 / 20$

HORIZONTAL ANI VERTICAL SINGLE VARIABLE STANUARD IEUIATIONS (68\% - ONE IEGREE OF FREEDOK) [UALUES TRUNCATED AT $25 \mathrm{KM}$ ]

$$
\begin{array}{ll}
\text { SEH }=0.13 & \text { SEH }=0.16
\end{array} \quad \text { SEZ }=0.56 \quad \text { QUALITY }=A
$$

SE OF URIG $=0.04$ TOTAL NUMBER OF ITERATIONS $=4$ IMAXX $=90.00$ SEQUENCE NUMBER $=$ $S$ AND P ARE NOT BOTH USEO AT CLOSEST STATION

DATE ORIGIN LAT LONG DEPTH MAG NO DI GAP II RMS SEH SEZ Q SQII AIJ IN NR AUR AAR NM AUXM SIIXY NF AUFM SIIFH $\begin{array}{llllllllllllllllllllllllll}860207 & 1520 & 20.20 & 41 N 39.06 & 81 \mathrm{~W} & 9.24 & 4.59 & 27 & 2 & 42 & 1 & 0.08 & 0.2 & 0.6 \text { A A A } 0.07 & 10 & 46 & 0.00 & 0.06 & 0 & 0.0 & 0\end{array}$

(- STATION DATA -) (----- P-WAVE TRAVEL-TIME IATA GND DELAYS ------) VARI (---- S-WAVE TRAVEL-TIME IIATh --)(--- MAGNITUDE IIATA --) STN DIST AZM AIN PSEC PRYK+TCOR-0=TTOB-TTCAL C-ULAY-EILY=P-RES P-WT THIC SSEC SRYK TTOB TTCAL S-RES S-WT AMX PR XYAG R FMF FḦAG

WC02 $1.934815421 .29 \mathrm{PC1}$

cal $4.0713221 .511 P C 1$

pop $4.6 \quad 138 \quad 128 \quad 21.51$ IPC1

hlh $5.0 \quad 38 \quad 125 \quad 21.59$ IPDI

hat $5.416912321 .56 \mathrm{ip} 1$

$\begin{array}{lllll}\text { er.j } & 5.9 & 83 & 120 & 21.77 \text { IPDI }\end{array}$

wsh 6.224511821 .76 IPU1

cfd 6.329411821 .70 IP 1

con 7.232011421 .91 IPC1

wC04 7.318111421 .91 IPDI

ttr 7.820611222 .04 IPII

x06 8.010811222 .01 IPC1

$\begin{array}{lllll}x 02 & 8.7 & 358 & 110 & 22.12 I P C 2\end{array}$

$\begin{array}{llllll}\text { cuy } \quad 10.3 \quad 187 & 106 \quad 22.391 P D 1\end{array}$

wC03 $11.1 \quad 37 \quad 10522.45$ IPDO

mon $11.6 \quad 124 \quad 104 \quad 22.56$ IFC1

wC01 $12.9 \quad 252 \quad 103 \quad 22.80$ IFDO

fot $13.3 \quad 91 \quad 102 \quad 22.83$ EPD1

$\begin{array}{lllll}\text { min } 13.3 \quad 220102 & 22.70 \text { IP } 1\end{array}$

$\begin{array}{lllll}x 08 \quad 13.4203 \quad 102 & 22.78 E F[1\end{array}$

$\begin{array}{llllll}\text { lox } & 13.8 \quad 42 & 102 & 22.85 I P 01\end{array}$

wC06 $16.1 \quad 140 \quad 100 \quad 23.30$ IFCO

$\begin{array}{llllll}x 01 & 17.1 & 3 & 99 & 0.00 & 4\end{array}$

ufd $21.9162 \quad 9724.20 \mathrm{IF} 1$
$1.09 \quad 1.01$

1.311 .231

1.311 .291

$1.39 \quad 1.351$

$1.36 \quad 1.401$

$1.57 \quad 1.481$

$1.56 \quad 1.521$

$1.50 \quad 1.541$

1.711 .661

1.711 .681

$1.84 \quad 1.751$

$1.81 \quad 1.771$

$1.92 \quad 1.881$

$2.19 \quad 2.131$

$2.25 \quad 2.261$

$2.36 \quad 2.331$

$2.60 \quad 2.551$

$2.63 \quad 2.601$

$2.50 \quad 2.611$

$2.58 \quad 2.621$

$2.65 \quad 2.681$

$3.10 \quad 3.061$

$-20.20 \quad 3.211$

$4.00 \quad 3.991$
$0.08 \quad 0.938$

0.080 .938

$0.02 \quad 0.938$

0.040 .938

$\begin{array}{lll}-0.04 & 0.938\end{array}$

0.090 .938

0.040 .938

$-0.040 .938$

0.050 .938

0.030 .938

0.090 .938

0.040 .938

0.040 .417

$0.06 \quad 0.938$

$-0.011 .668$

0.030 .938

0.051 .668

0.030 .938

$\begin{array}{lll}-0.11 & 0.938\end{array}$

$-0.040 .738$

$-0.030 .938$

0.041 .668

$-23.410 .000$

0.010 .938
21.64 es4 $1.44 \quad 1.84-0.40 \quad 0.000$

22.38 is $\quad 2.18 \quad 2.21 \quad-0.03 \quad 0.000$

$\begin{array}{llllll}22.17 & \text { is } & 1.97 & 2.32 & -0.35 & 0.000\end{array}$

$\begin{array}{llllll}22.34 & \text { is } & 2.14 & 2.43 & -0.27 & 0.000\end{array}$

22.46 is $\quad 2.26 \quad 2.53 \quad-0.27 \quad 0.000$

22.71 is4 $2.51 \quad 2.65 \quad-0.140 .000$

$\begin{array}{llllll}22.82 & \text { is } & 2.62 & 2.73 & -0.11 & 0.000\end{array}$

22.60 es $4 \quad 2.40 \quad 2.75 \quad-0.350 .000$

$\begin{array}{lllllll}22.86 & \text { is } & 2.66 & 2.97 & -0.31 & 0.000\end{array}$

23.16 es4 $2.96 \quad 3.00 \quad-0.04 \quad 0.000$

$\begin{array}{llllll}23.45 & \text { is } & 3.25 & 3.13 & 0.12 & 0.000\end{array}$

23.22 is $3.02 \quad 3.18 \quad-0.16 \quad 0.938$

$\begin{array}{llllll}23.39 & \text { is } 1 & 3.19 & 3.37 & -0.18 & 0.938\end{array}$

23.89 is $\quad 3.69 \quad 3.79-0.10 \quad 0.000$

$\begin{array}{llllll}24.05 & \text { es4 } & 3.85 & 4.02 & -0.17 & 0.000\end{array}$

24.09 is4 $3.89 \quad 4.14 \quad-0.250 .000$

24.57 est $4.37 \quad 4.51 \quad-0.150 .000$

24,71 is $4.51 \quad 4,61 \quad-0,10 \quad 0.000$

$\begin{array}{llllll}24.66 & \text { is } & 4.46 & 4.64 & -0.17 & 0.438\end{array}$

24.92 is4 $4.72 \quad 4.75 \quad-0.03 \quad 0.000$

25.43 es4 $5.23 \quad 5.40 \quad-0.18 \quad 0.000$

25.84 is $\quad 5.64 \quad 5.67 \quad-0.03 \quad 0.938$

QUALITY EUALUATION

DIAGONALS IN ORUER OF STRENGTH

AUE, OF ENI POINTS

\section{NH SE E SH NE N $\begin{array}{lllllll}0.24 & 0.74 & 0.75 & 0.81 & 0.85 & 0.85 & 1.08\end{array}$}

$\begin{array}{rrrrr}\text { MUMBER } & \text { RHS } & \text { MIN DRKS } & \text { AUE IRKS } & \text { QUALITY } \\ 27 & 0.08 & 0.29 & 0.80 & \end{array}$ 
SE OF ORIG $=0.05$ TOTAL NUMBER OF ITERATIONS $=4$ IIMAX $=90.00$ SEQUENCE NUMBER $=$

$S$ AND P ARE NOT BOTH USED AT CLOSEST STATION

IATE ORIGIN LAT LONG DEPTH HAG NO III GAF II RMS SEH SEZ Q SQD AIIJ IN NR AUR AAR NM AUXM SIXY NF AUFH SDFM

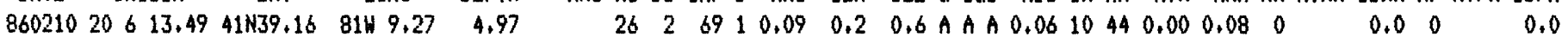

(- STATION DATA -) (---.- P-WAVE TKAVEL-TIME DATA AND DELAYS ------) VARI (--- S-WAVE TRAVEL-TIME DATA --)(--- MAGNITUDE DATA --) STN DIST AZM AIN PSEC FRMK+TCOR-0=TTOB-TTCAL C-DLAY-EDLY=F-RES P-HT THIC SSEC SRKK TTOB TTCAL S-RES S-WT AHX PR XMAG R FHP FHAG

WCO2 $1.7348 \quad 158 \quad 14.54 I F C O$

cal $\quad 3.8 \quad 8 \quad 136 \quad 14.89 \mathrm{IPCl}$

pop $4.7 \quad 139 \quad 130 \quad 14.87$ IFC1

hlh $\quad 4.9 \quad 40 \quad 129 \quad 14.931 P D 1$

han $5.6 \quad 169 \quad 125 \quad 14.86 \mathrm{IPCl}$

er.j $\quad 6.0 \quad 85 \quad 123 \quad 15.06$ IPC1

wsh $\quad 6.3243 \quad 121 \quad 15.16$ IFD1

con $7.0320118 \quad 15.21$ IFC1

WCO4 7.5 $181 \quad 116 \quad 15.15 I F U O$

ttr $8.0205114 \quad 15.35 I P D 1$

x06 $8.110911415 .361 \mathrm{ICl}$

$x 02 \quad 8.5358113 \quad 15.421 \mathrm{IPCl}$

$\begin{array}{llllll}x 02 & 8.5 & 358 & 113 & 15.48 \quad 2\end{array}$

cot $9.4150111 \quad 15.54$ IFC1

cuy $10.4187 \quad 109 \quad 15.72 E P C 2$

$\begin{array}{lllll}\text { wCO3 } & 11.0 & 37 & 107 & 15.67 I P D O\end{array}$

won $11.7 \quad 125 \quad 106 \quad 15.91$ IPCI

wC01 $12.925110515 .95 P 1$

fot $13.39210416 .19 E P C 2$

lox $\quad 13.7 \quad 43 \quad 104 \quad 16.09$ IPDI

huk $15.171 \quad 102 \quad 16.62$ IPC1

WCOS 16.314010116 .50 IFCO

$\begin{array}{llllll}x 01 \quad 16.9 \quad 4101 \quad 0.00 \quad 4 & 4\end{array}$

$\begin{array}{rll}1.05 & 1.06 & 1 \\ 1.40 & 1.25 & 1 \\ 1.38 & 1.35 & 1 \\ 1.44 & 1.38 & 1 \\ 1.37 & 1.46 & 1 \\ 1.57 & 1.50 & 1 \\ 1.67 & 1.56 & 1 \\ 1.72 & 1.67 & 1 \\ 1.66 & 1.73 & 1 \\ 1.86 & 1.80 & 1 \\ 1.87 & 1.81 & 1 \\ 1.93 & 1.88 & 1 \\ 1.99 & 1.88 & 1 \\ 2.05 & 2.01 & 1 \\ 2.23 & 2.16 & 1 \\ 2.18 & 2.26 & 1 \\ 2.42 & 2.37 & 1 \\ 2.46 & 2.56 & 1 \\ 2.70 & 2.63 & 1 \\ 2.60 & 2.68 & 1 \\ 3.13 & 2.901 \\ 3.01 & 3.101 \\ 13.49 & 3.191 & 1\end{array}$

\section{$-0.011 .719$}

0.150 .967

0.030 .967

0.060 .967

$\begin{array}{lll}-0.09 & 0.967\end{array}$

0.070 .967

0.110 .967

0.050 .967

$-0.071 .719$

0.060 .967

0.050 .967

0.050 .967

0.110 .430

0.040 .967

0.070 .430

$-0.081 .719$

0.050 .967

$-0.11 \quad 0.967$

0.070 .430

$\begin{array}{lll}-0.08 & 0.967\end{array}$

0.230 .967

$-0.091 .719$

$-16.680 .000$ $\begin{array}{lllllll}14.89 & \text { es4 } & 1.40 & 1.91 & -0.51 & 0.000\end{array}$

$\begin{array}{llllll}15.76 & \text { is } 4 & 2.27 & 2.25 & 0.02 & 0.000\end{array}$

$\begin{array}{llllll}15.54 & \text { is } & 2.05 & 2.43 & -0.38 & 0.000\end{array}$

$\begin{array}{llllll}15.97 & \text { is } & 2.48 & 2.47 & 0.01 & 0.000\end{array}$

$\begin{array}{llllll}15.06 & \text { is } 4 & 1.57 & 2.64 & -1.07 & 0.000\end{array}$

$\begin{array}{llllll}16.24 & \text { is } & 2.75 & 2.72 & 0.03 & 0.000\end{array}$

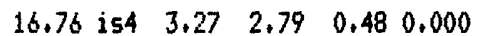

$\begin{array}{llllll}22.86 & \text { is4 } & 9.37 & 2.98 & 6.39 & 0.000\end{array}$

$\begin{array}{llllll}15.93 & \text { es4 } & 2.44 & 3.10 & -0.66 & 0.000\end{array}$

$\begin{array}{llllllll}16.68 & \text { is } & 3.19 & 3.21 & -0.02 & 0.000\end{array}$

$\begin{array}{llllll}16.62 & \text { is } & 3.13 & 3.24 & -0.11 & 0.967\end{array}$

$\begin{array}{llllll}16.72 & \text { is } 1 & 3.23 & 3.35 & -0.12 & 0.967\end{array}$

$\begin{array}{llllll}16.74 & \text { is } 2 & 3.25 & 3.35 & -0.10 & 0.430\end{array}$

16.91 is $3.42 \quad 3.60-0.18 \quad 0.000$

$\begin{array}{llllll}17.39 & \text { is } & 3.90 & 3.87 & 0.03 & 0.000\end{array}$

$\begin{array}{llllll}17.35 & \text { es } 4 & 3.86 & 4.02 & -0.16 & 0.000\end{array}$

$\begin{array}{rrrrr}17,78 \text { es4 } & 4,29 & 4,55 & -0.26 & 0.000\end{array}$

$\begin{array}{llllll}18.21 & \text { is4 } & 4.72 & 4.65 & 0.07 & 0.000\end{array}$

$\begin{array}{llllll}18.34 & \text { is } 4 & 4.85 & 4.75 & 0.10 & 0.000\end{array}$

18.98 is $\quad 5.49 \quad 5.13 \quad 0.36 \quad 0.000$

4

$\begin{array}{lllll}19.07 & \text { is } 1 \quad 5.58 \quad 5.64 & -0.06 & 0.967\end{array}$

QUALITY EVALUATION

IIIAGONALS IN ORDER OF STRENGTH

AVE, OF END POINTS

\section{Z E SH NE SE NH N $\begin{array}{lllllll}0.23 & 0.68 & 0.69 & 0.71 & 0.73 & 0.76 & 0.99\end{array}$}

$\begin{array}{rrrrr}\text { NUMEER } & \text { RMS } & \text { HIN IRIMS } & \text { AUE IIMS } & \text { QUALITY } \\ 26 & 0.09 & 0.27 & 0.72 & B\end{array}$ 
HORIZONTAL AND UERTICAL SINGLE VARIABLE STANIARI IEVIATIONS (68\% - ONE IEGREE OF FREEIOM) [UALUES TRUNCATEII AT $25 \mathrm{KK}$ ]

$$
\begin{aligned}
& \text { SEH }=0.24 \quad \text { SEH }=0.28 \quad \text { SEZ }=0.73 \text { QULALITY }=\text { A } \\
& A Z=-19 . \quad A Z=-109 \text {. }
\end{aligned}
$$

SE OF URIG $=0.07$ TOTAL NUMBER OF ITERATIONS $=4$ IMHAX $=90.00$ SEQUENCE NUMBER $=$

AT THE CLOSEST STATION USEI IN THE SOLUTION BOTH P ANI S WERE USED. THE S MINUS P INTERUAL EQUALS

DATE ORIGIN LAT LONG DEPTH HAG NO III GAF I RMS SEH SEZ Q SQII ADJ IN NR AUR AAR NM AUXK SIXXM NF AUFM SIFM $860223 \quad 329 \quad 48,46 \quad 41 N 39.06 \quad 8149,44 \quad 4,77$ $\begin{array}{llllllllllllllllll}16 & 2 & 95 & 1 & 0.08 & 0.3 & 0.7 \text { B A B } & 0.071016 & 0.00 & 0.06 & 0 & 0.0 & 0\end{array}$ 0.0

(- STATION DATA -) (----- P-WAVE TRAVEL-TIME DATA ANI IELAYS -----) VARI (---- S-WAVE TRAVEL-TIME IATAA --)(--- MAGNITUDE IAATA --) STN DIST AZM AIN PSEC PRZKKTTCOR-0=TTOB-TTCAL C-ILAY-EDLY=P-RES P-WT THIC SSEC SRMK TTOB TTCAL S-RES S-WT AMX FR XHAG R FHF FMAG

wCO2 $1.8356 \quad 15549.551$ FCO

pop $4.7 \quad 136 \quad 12849.82$ IFCO

hith $5.2 \quad 40 \quad 125 \quad 49.86$ EFIO

con 7.032211650 .141 PCO

ttr $\quad 7.720411450 .29 E \mathrm{EP} 1$

wC $03 \quad 11.3 \quad 38 \quad 106 \quad 50.66 E F 3$

WCO1 $12.6 \quad 252 \quad 104 \quad 50,911$ PDO

WCO6 16.313910151 .48EF 3
0.062 .586

0.032 .586

0.012 .586

0.032 .586

0.081 .455

$-0.100 .162$

$-0.062 .586$

$-0.070 .162$ $\begin{array}{llllll}50.10 & 53 & 1.64 & 1.88 & -0.24 & 0.162\end{array}$

$\begin{array}{llllll}50.47 & \text { is } 3 & 2.01 & 2.40 & -0.39 & 0.162\end{array}$

50.81 is $32.35 \quad 2.50-0.150 .162$

$\begin{array}{llllll}51.14 & \text { is3 } & 2.68 & 2.95 & -0.27 & 0.162\end{array}$

$\begin{array}{llllll}51.54 & \text { is3 } & 3.08 & 3.12 & -0.04 & 0.162\end{array}$

$\begin{array}{lllllll}52.28 & 53 & 3.82 & 4.08 & -0.25 & 0.162\end{array}$

52.79 is $\quad 4.33 \quad 4.45 \quad-0.12 \quad 0.162$

$\begin{array}{llllll}53.71 & 053 & 5.25 & 5.47 & -0.22 & 0.162\end{array}$

QUALITY EVALUATION

IIAGONALS IN ORUER OF STRENGTH AUE, OF END POINTS

$\begin{array}{rrrrrrr}Z & \text { NH } & \text { NE } & N & \text { SE } & \text { SH } & E \\ 0.26 & 0.61 & 0.66 & 0.66 & 0.68 & 0.71 & 0.72\end{array}$

$\begin{array}{rrrrr}\text { NUMBER } & \text { RMS } & \text { WIN IRMS } & \text { AUE IRMS } & \text { RUALITY } \\ 16 & 0.08 & 0.28 & 0.64 & \text { B }\end{array}$ 
HORIZONTAL ANU UERTICAL SINGLE VARIABLE STANDARD DEVIATIONS (68\% - ONE DEGREE OF FREEDON) [VALUES TRUNCATEII AT $25 \mathrm{KH}$ ]

$$
\begin{array}{lll}
\text { SEH }=0.33 & \text { SEH }=0.46 & \text { SEZ }=3.54 \quad \text { QUALITY }=\mathrm{C} \\
A Z=1 . & \text { AZ }=-89 . &
\end{array}
$$

SE UF URIG $=0.22$ TOTAL NUMBER OF ITERATIONS $=5$ IMAX $=90.00$ SEQUENCE NUMBER $=$

AT THE CLOSEST STATION USED IN THE SOLUTION BOTH P AND S WERE USED, THE S MINUS P INTERUAL EQUALS 0,64

JATE ORIGIN LAT LONG IIEPTH MAG NO II GAF D RHS SEH SEZ Q SQI ADJ IN NR AUR AAR NM AUXH SDXM NF AUFM SDFH $860224 \quad 1655 \quad 6.37 \quad 41 N 38.96 \quad 81 \mathrm{~W} 9.81 \quad 3.72$

$\begin{array}{lllllllllllllll}10 & 5 & 126 & 1 & 0.09 & 0.5 & 3.5 C C & 0.32 & 10 & 12 & 0.00 & 0.05 & 0 & 0.0 & 0\end{array}$

(- STATION DATA -) ( ----- P-WAUE TRAUEL-TIME DATA AKD LIELAYS -----) VARI (--- S- WAVE TRAVEL-TIME DATA --)(--- MAGNITUDE IATA --) STN DIST AZK AIN PSEC PRHKTTCOR-0=TTOB-TTCAL C-ILLAY-EDLY=P-RES P-HT THIC SSEC SRMK TTOB TTCAL S-RES S-UT AMX PR XIAG R FKP FMAG

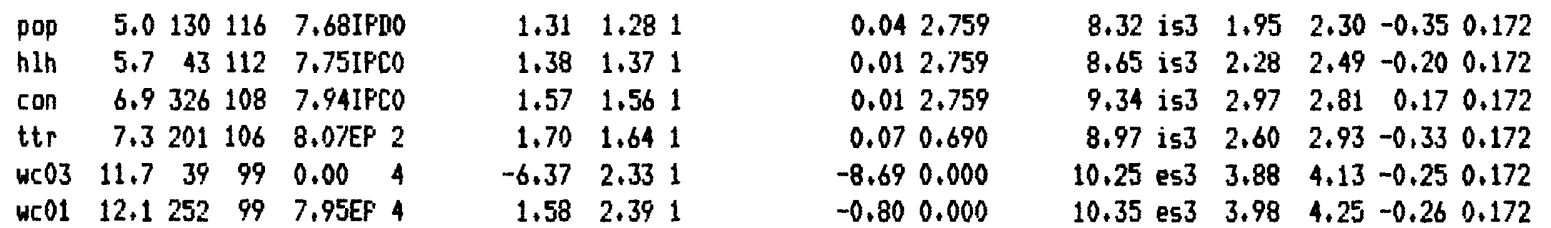

QUALITY EVALUATION

IIIAGONALS IN ORDER OF STRENGTH $Z$ NE $E$ SW NW N $\quad$ SE AUE. OF ENI POINTS

$\begin{array}{lllllll}0.16 & 0.58 & 0.60 & 0.66 & 0.66 & 0.70 & 0.73\end{array}$

$\begin{array}{rrrrr}\text { NUMEER } & \text { RHS } & \text { HIN DRISS } & \text { AUE DRHS } & \text { QUALITY } \\ 10 & 0.09 & 0.21 & 0.62 & \mathrm{~B}\end{array}$ 
HORIZONTAL AND UERTICAL SINGLE VARIABLE STANDARD UEVIATIONS (68\% - ONE DEGREE OF FREEION) [UALUES TRUNCATED AT $25 \mathrm{KM}$ ]

$$
\begin{array}{lll}
\text { SEH }=0.28 & \text { SEH }=0.39 & \text { SEZ }=0.87 \quad \text { QUALITY }=A \\
A Z=6 . & A Z=-84 . &
\end{array}
$$

SE OF ORIG $=0.08$ TOTAL NUMBER OF ITERATIONS $=5$ IMAAX $=90.00$ SEQUENCE NUMBER $=$

AT IHE CLOSEST STATION USED IN THE SOLUTION BOTH P AND S WERE USED, THE S MINUS P INTERVAL EQUALS 0.60

$$
\begin{aligned}
& \text { IIATE ORIGIN LAT LONG IIEPTH MAG NO III GAP II RMS SEH SEZ Q SQII AIIJ IN NR AUR AAR WH AUXM SIXXH WF AUFH SIFH } \\
& 860228 \quad 139 \quad 34.07 \quad 41 N 39.11 \quad 81 \% 9.59 \quad 4,31 \\
& 0.00
\end{aligned}
$$

\begin{tabular}{|c|c|c|c|}
\hline $\mathrm{wCO}$ & $1.7315435 .10 \mathrm{IPCO}$ & 1.03 & 0.961 \\
\hline pop & 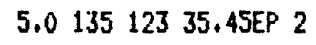 & 1.38 & 1.311 \\
\hline hlh & $\begin{array}{llll}5.3 & 43 & 120 & 35.43 I P T 10\end{array}$ & 1.36 & 1.36 \\
\hline wc09 & $6.817711435 .70 \mathrm{IP}_{4}$ & 1.63 & 1.58 \\
\hline con & $6.8323 \quad 113 \quad 35.65 I P C 0$ & 1.58 & 1.58 \\
\hline ttr & $7.7202 \quad 110 \quad 35.781 P D O$ & 1.71 & 1.7 \\
\hline wCO1 & $\begin{array}{llll}12.5 & 251 & 102 & 36.60 \mathrm{EP}+3\end{array}$ & 2.53 & 2.47 \\
\hline
\end{tabular}$$
\begin{array}{llllllllllllllll}
12 & 2 & 92 & 0.08 & 0.4 & 0.9 & \text { B A B } & 0.05 & 10 & 13 & 0.00 & 0.04 & 0
\end{array}
$$

(- STATION DATA -) (---- P-WAUE TRAVEL-TIME DATA AND IIELAYS SIN DIST AZM AIN FSEC PRMK+TCOR-0=TTOB-TTCAL C-DLAY-EDLY=P-RES P-HT THIC SSEC SRMK TTOB ITCAL S-RES S-HT AMX PR XMAG $R$ FMP FHAG

\begin{abstract}
0.072 .560
\end{abstract}
0.070 .640

0.002 .560

0.050 .000

0.002 .560

0.002 .560

0.060 .160

QUALITY EUALUATION

UIAGONALS IN ORIEER OF STRENGTH AVE, OF END POINTS

$$
\begin{array}{rrrrrrr}
2 & N W & E & S E & \text { SW } & \text { NE } & N \\
0.26 & 0.51 & 0.53 & 0.65 & 0.67 & 0.57 & 0.71
\end{array}
$$

$\begin{array}{rrrrr}\text { NUMBER } & \text { RMS } & \text { MIN IRRS } & \text { AUE IRMS } & \text { QUUALITY } \\ 12 & 0.08 & 0.27 & 0.59 & \end{array}$ 
HORIZONTAL AND VERTICAL SINGLE VARIABLE STANWARD DEUIATIONS (68\% - ONE DEGREE OF FREEDOM) [UALUES TRUNCATED AT $25 \mathrm{KM]}$

$$
\begin{array}{ll}
\text { SEH }=0.34 & \text { SEH }=0.35 \\
A Z=-56 . & A Z=34 .
\end{array} \quad \text { SEZ }=0.98 \quad \text { QUALITY }=A
$$

SE OF ORIG $=0.07$ TOTAL NUMBEF OF ITERATIONS $=4$ IMAX $=90.00$ SEQUENCE NUMBER $=$

AT THE CLOSEST STATION USEI IN THE SOLUTION BOTH P ANI S WERE USEI. THE S MINUS $P$ INTERVAL EQUALS

IATE ORIGIN LAT LONG DEFTH MAG NO DI GAF D RMS SEH SEZ Q SQII AIN IN NR AUR AAR NIT AUXM SIXXM NF AUFM SUFH

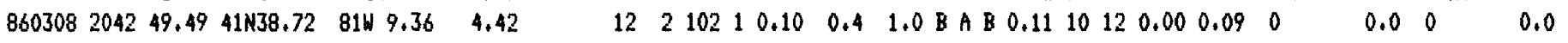

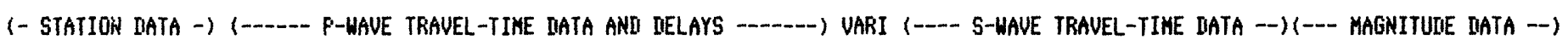
SIN DIST AZM AIN PSEC PRKK+TCOR-0=ITOB-TTCAL C-ILAY-EILY=P-RES P-WT THIC SSEC SRHK TTOB TICAL S-RES S-HT AMX PR XHAG R FMF FHAG WCO2 $2.535514550 .601 P C O$ $\begin{array}{lll}1.11 & 1.04 & 1 \\ 1.41 & 1.48 & 1 \\ 1.81 & 1.71 & 1 \\ 2.26 & 2.35 & 1 \\ 2.41 & 2.49 & 1 \\ 3.11 & 3.00 & 1\end{array}$

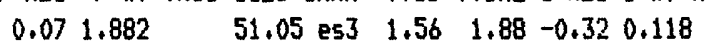
$\begin{array}{llllllll}\text { WCO } & 6.118011750 .90 \text { IF } 0 & 1.41 & 1.481 & -0.071 .882\end{array}$ $\begin{array}{lllllll}\text { WC08 } & 7.629211251 .30 I F C O & 1.81 & 1.711 & 0.101 .882\end{array}$ $\begin{array}{lllllllll}\text { we03 } & 11.7 & 36 & 103 & 51.75 I P D O & 2.26 & 2.351 & -0.09 & 1.882\end{array}$ $\begin{array}{llllllll}\text { WCO1 } & 12.6 & 254 & 102 & 51.90 I F C O & 2.41 & 2.491 & -0.071 .882\end{array}$ wCO6 $15.8 \quad 138100 \quad 52.60$ IFCO

$$
3.113 .001 \quad 0.121 .882
$$$$
\begin{array}{llllll}
51.90 \text { es } 3 & 2.41 & 2.66 & -0.25 & 0.118
\end{array}
$$$$
\begin{array}{llllll}
52.60 \text { es3 } & 3.11 & 3.07 & 0.04 & 0.118
\end{array}
$$$$
\begin{array}{llllll}
53.50 & \text { is } 3 & 4.01 & 4.17 & -0.16 & 0.118
\end{array}
$$$$
\begin{array}{llllll}
53.80 \text { es3 } & 4.31 & 4.41 & -0.10 & 0.118
\end{array}
$$$$
\begin{array}{llllll}
54.75 & \text { es } 3 & 5.26 & 5.30 & -0.04 & 0.118
\end{array}
$$

QUALITY EUALUATION

IIIAGONALS IN ORIER OF STRENGTH AUE, OF ENII POINTS

$$
\begin{array}{rrrrrrr}
z & \text { NE } & \text { NW } & \text { SW } & \text { SE } & N & \text { E } \\
0.22 & 0.66 & 0.69 & 0.73 & 0.77 & 0.77 & 0.89
\end{array}
$$


$86 / 3 / 12 \quad 8 / 55$

HORIZONTAL ANI VERTICAL SINGLE VARIABLE STANDARII DEVIATIONS (68\% - ONE DEGREE OF FREEIIUM) [UALUES TRUNCATED AT $25 \mathrm{KM}$ ]

$$
\begin{aligned}
& \text { SEH }=0.30 \quad \text { SEH }=0.71 \quad \text { SEZ }=0.38 \text { QUALITY }=A \\
& A Z=-115 \text {. } \\
& A Z=-25 \text {. }
\end{aligned}
$$

SE OF ORIG $=0.13$ TOTAL NUMBER OF ITERATIONS $=9$ IMAX $=90.00$ SEQUENCE NUMBER $=$ $S$ ANI P ARE NOT BOTH USEII AT CLOSEST STATION

IATE ORIGIN LAT LONG DEPTH MAG NO II GAP I RMS SEH SEZ Q SQN AIJ IN NR AUR AAR NM AUXM SIIXM NF AUFM SDFM

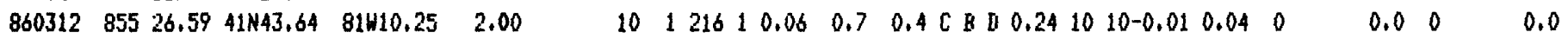

(- STATION DATA -) (-...- P-WAUE TRAUEL-TIME DATA ANI DELAYS

-) VARI (---- S-WAVE TRAUEL-TIME DATA --)(--- MAGNITUDE IATA --) STN IIST AZK AIN PSEC PRMK+TCOR-O=TTOB-TTCAL C-DLAY-EILY=P-KES P-UT THIC SSEC SRMK TTOB TTCAL S-RES S-WT AMX PR XMAG R FMF FHAG

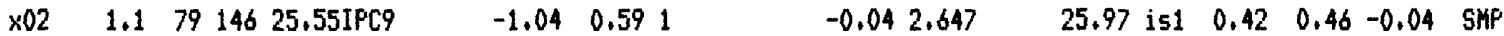
$\begin{array}{lllllll}\text { WCO2 } & 6.7171 \quad 5128.16 \text { IF } 1 & 1.57 & 1.511\end{array}$ 0.062 .647

1.76 1.73

0.062 .647

29.23 is $\quad 2.64 \quad 2.71 \quad-0.07 \quad 0.294$

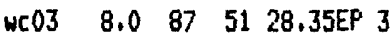

$1.81 \quad 1.821$

0.030 .294

$\begin{array}{llllll}29.56 & \text { es3 } & 2.97 & 3.09 & -0.12 & 0.294\end{array}$

WC08 $8.6223 \quad 5128,40 E P 3$

$2.88 \quad 2.891$

$-0.010 .294$

$\begin{array}{llllll}29.65 & \text { es3 } & 3.06 & 3.25 & -0.19 & 0.294\end{array}$

UC09 $15.2175 \quad 5129.47 \mathrm{EP} 1$

3.113 .111

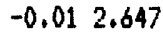

$0.00 \quad 0.294$

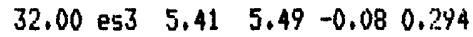

QUALITY EUALUATION

IIIAGONALS IN URIIER OF STRENGTH AUE. OF END POINTS

$\begin{array}{rrrrrrr}Z & N H & S E & N & S H & E & \text { NE } \\ 0.39 & 0.69 & 0.69 & 0.75 & 0.82 & 0.85 & 0.87\end{array}$

$\begin{array}{rrrrr}\text { NLMBER } & \text { RMS } & \text { MIN IRMS } & \text { AUE IURS } & \text { QUALITY } \\ 10 & 0.06 & 0.64 & 0.77 & \text { A }\end{array}$


HORIZONTAL ANI VERTICAL SINGLE VARIABLE STANDARD IEUIATIONS ( $68 \%$ - ONE IEGREE OF FREEDOM) [VALUES TRUNCATEII AT $25 \mathrm{KH}$ ]

$$
\begin{array}{ll}
\text { SEH }=0.22 & \text { SEH }=0.24 \\
A Z=-42 . & A Z=-132 .
\end{array} \quad \text { SEZ }=0.69 \quad \text { QUALITY }=A
$$

SE OF URIG $=0.05$ TOTAL NUMBER OF ITERATIONS $=4$ IMAX $=90.00$ SEQUENCE NUMBER $=$

AT THE CLOSEST STATION USEI IN THE SOLUTION BOTH P ANI S MERE USED. THE S MINUS P INIERVAL EQUALS 0,70

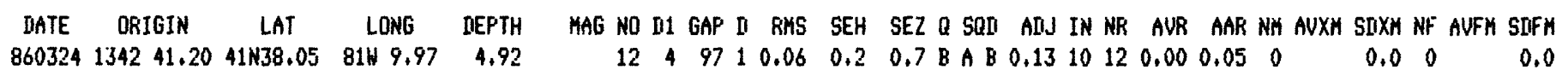

(- STATION IATA -) (--.-- P-WAUE TRAUEL-TIME IATA AND IELLAYS

) VARI (--- S-WAVE TRAUEL-TIHE IATA - ) (-- MAGNITUIE DATA - )

STN DIST AZM AIN PSEC PRMKTTCOR-Q=TTOB-TTCAL C-DLAY-EULY=P-RES P-UT THIC SSEC SRYK TTOB TTCAL S-RES S-UTT AMX PR XYAG R FHP FHAG

wCO2 $3.8 \quad 9 \quad 136 \quad 42,45 I P C O$

WCO9 $4,9170 \quad 128 \quad 42,65 I P C O$

$$
1.251 .231
$$

$1.45 \quad 1.371$

$1.70 \quad 1.721$

$2.35 \quad 2.331$

$2.65 \quad 2.611$

$2.90 \quad 2.971$
0.011 .882

0.081 .882

$-0.021 .882$

0.011 .882

0.041 .882

$-0.071 .882$ $\begin{array}{lllllll}43.15 & \text { es } 3 & 1.95 & 2.23 & -0.28 & 0.118\end{array}$

$\begin{array}{llllll}43,45 & e \leq 3 & 2.25 & 2,45 & -0,21 & 0.118\end{array}$

$\begin{array}{lllllll}44.07 & \text { es3 } & 2.87 & 3.08 & -0.21 & 0.118\end{array}$

$\begin{array}{llllll}45+25 & \text { es } 3 & 4.05 & 4.14 & -0.10 & 0.118\end{array}$

$\begin{array}{lllllll}45,80 & \text { es } 3 & 4.60 & 4.62 & -0.02 & 0.118\end{array}$

$\begin{array}{llllll}46.33 & \text { es3 } & 5.13 & 5.25 & -0.12 & 0.118\end{array}$

QUALITY EVALUATION

UIAGONALS IN ORIER OF STRENGTH AUE, OF ENI POINTS

$\begin{array}{rrrrrrr}Z & \text { NE } & \text { SW } & \text { NW } & N & S E & E \\ 0.22 & 0.68 & 0.71 & 0.72 & 0.77 & 0.83 & 0.90\end{array}$

NUMBER RMS MIN IRISS AUE IRNS QUALITY

0.06

0.29

0,73

\section{B}




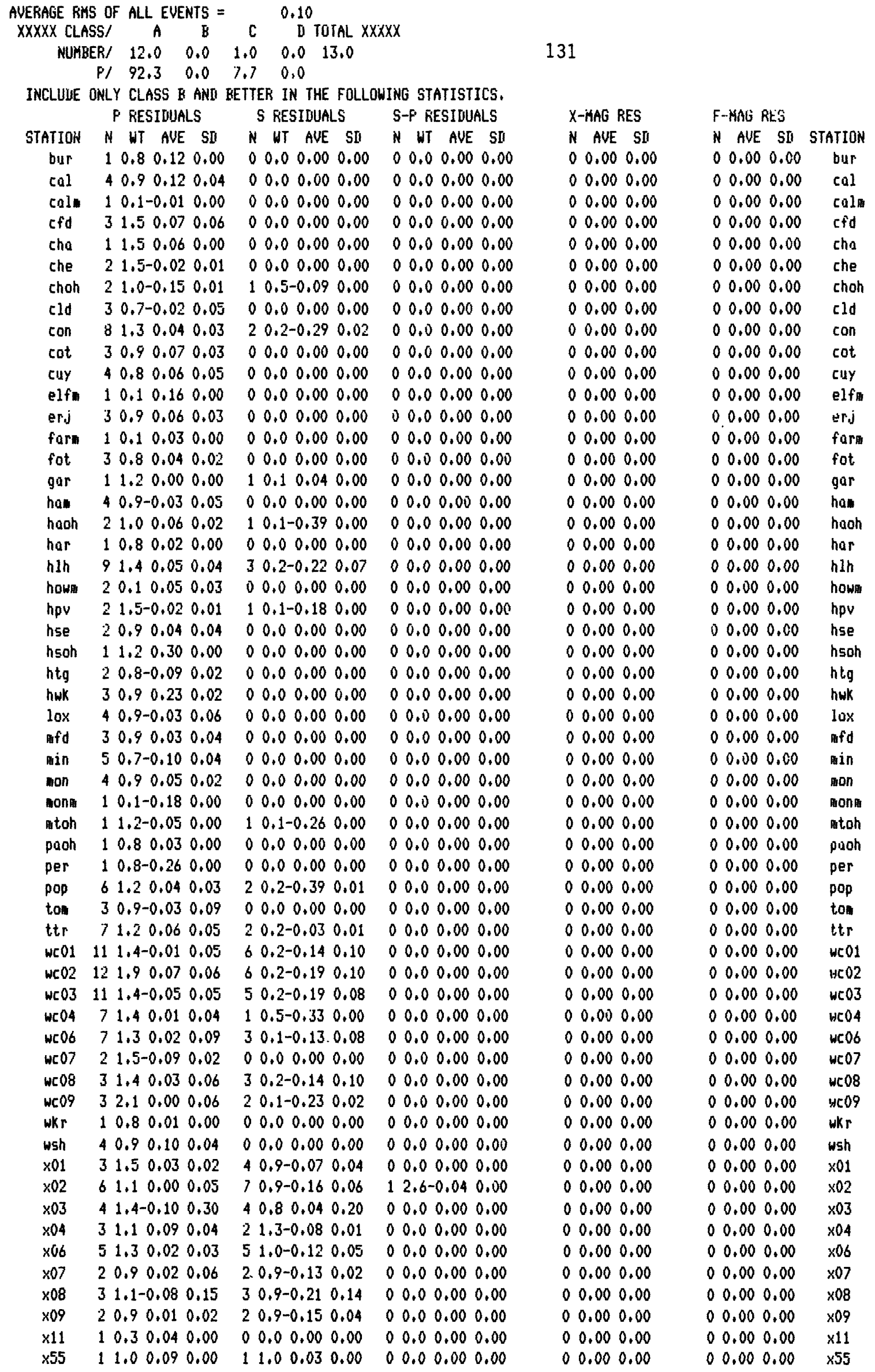

